\title{
DESIGN OF AN INTEGRATED SYSTEM TO RECYCLE ZIRCALOY CLADDING USING A HYDRIDE-MILLING- DEHYDRIDE PROCESS
}

\author{
A Dissertation \\ by \\ RANDY DEAN KELLEY \\ Submitted to the Office of Graduate Studies of \\ Texas A\&M University \\ in partial fulfillment of the requirements for the degree of \\ DOCTOR OF PHILOSOPHY
}

August 2010

Major Subject: Interdisciplinary Engineering 


\title{
DESIGN OF AN INTEGRATED SYSTEM TO RECYCLE ZIRCALOY CLADDING USING A HYDRIDE-MILLING- DEHYDRIDE PROCESS
}

\author{
A Dissertation \\ by \\ RANDY DEAN KELLEY \\ Submitted to the Office of Graduate Studies of \\ Texas A\&M University \\ in partial fulfillment of the requirements for the degree of \\ DOCTOR OF PHILOSOPHY
}

\begin{abstract}
Approved by:
Co-Chairs of Committee, Sean McDeavitt Thomas Lalk

Committee Members, John Poston Warren Heffington

Head of Department, Robin Autenrieth
\end{abstract}

August 2010

Major Subject: Interdisciplinary Engineering 


\begin{abstract}
Design of an Integrated System to Recycle Zircaloy Cladding Using a Hydride-MillingDehydride Process. (August 2010)

Randy Dean Kelley, B.S., Texas A\&M University; M.S., Kansas State University;

M.B.A., West Texas A\&M University; M.E. Texas A\&M University. Co-Chairs of Advisory Committee: Dr. Sean M. McDeavitt

Dr. Thomas Lalk
\end{abstract}

A process for recycling spent nuclear fuel cladding, a zirconium alloy (Zircaloy), into a metal powder that may be used for advanced nuclear fuel applications, was investigated to determine if it is a viable strategy. The process begins with hydriding the Zircaloy cladding hulls after the spent nuclear fuel has been dissolved from the cladding. The addition of hydrogen atoms to the zirconium matrix stresses the lattice and forms brittle zirconium hydride, which is easily pulverized into a powder. The dehydriding process removes hydrogen by heating the powder in a vacuum, resulting in a zirconium metal powder.

The two main objectives of this research are to investigate the dehydriding process and to design, build and demonstrate a specialized piece of equipment to process the zirconium from cladding hulls to metal powder without intermediate handling.

The hydriding process (known from literature) took place in a $95 \%$ argon - $5 \%$ hydrogen atmosphere at $500^{\circ} \mathrm{C}$ while the dehydriding process conditions were researched with a Thermogavimetric Analyzer (TGA). Data from the TGA showed the dehydriding 
process requires vacuum conditions ( $\sim 0.001$ bar) and $800^{\circ} \mathrm{C}$ environment to decompose the zirconium hydride.

Zirconium metal powder was created in two separate experiments with different milling times, 45 minutes (coarse powder) and 12 hours (fine powder). Both powders were analyzed by three separate analytical methods, X-Ray Diffraction (XRD), size characterization and digital micrographs. XRD analysis proved that the process produced a zirconium metal. Additionally, visual observations of the samples silvery color confirmed the presence of zirconium metal.

The presence on zirconium metal in the two samples confirmed the operation of the hydriding / milling / hydriding machine. Further refining of the hydride / milling / dehydride machine could make this process commercially favorable when compared to the high cost of storing nuclear waste and its components. An additional important point is that this process can easily be used on other metals that are subject to hydrogen embrittlement, knowing the relevant temperatures and pressures associated with the hydriding / dehydriding of that particular metal. 


\section{ACKNOWLEDGEMENTS}

I would like to give a special thanks to Dr. Sean McDeavitt who not only rescued me from a bad situation, but gave me guidance and lots of help in the past few years. The rest of my committee, Dr. John Poston, Dr. Warren Heffington and a last minute substitution, Dr. Thomas Lalk were enormously helpful with ideas and encouragement through this long tough journey. I received lots of help and ideas by my lab mates, Jeffery Hauseman, Michael Naramore, Zane Adams, Adam Parkison and Aaron Totemeier. We didn't always get along, but we helped each other when it counted. Outside the Fuel Cycle and Materials Laboratory, I received a great amount of help from the smartest person I know, Brandon Dooley. Regardless of how frustrating the day was, my children could always put things into perspective and brighten my day when I got

home. Therefore, I would very much like to thank Amber, Sara and Tabitha for being themselves. The final two people I would like to thank are the two women who have had faith in me, my mother, Violet Kelley and my wife, Carla. Carla has put up with a lot on this journey and didn't complain as much as she should. Thank you all. 


\section{TABLE OF CONTENTS}

Page

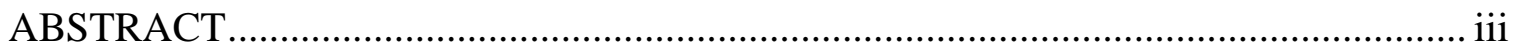

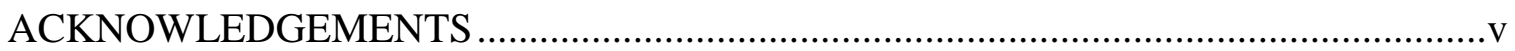

TABLE OF CONTENTS ..................................................................................... vi

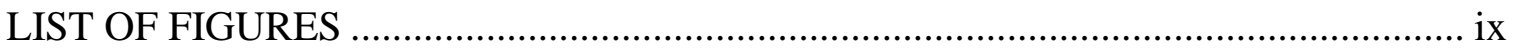

LIST OF TABLES .................................................................................... xvi

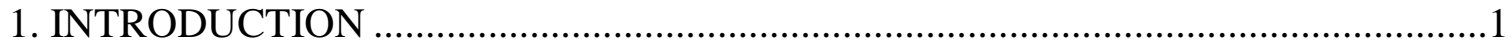

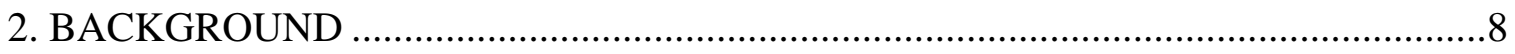

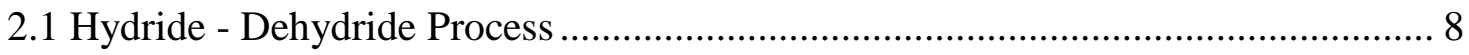

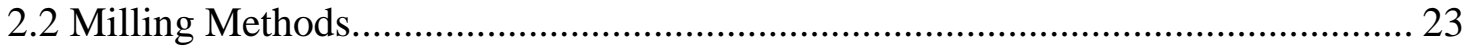

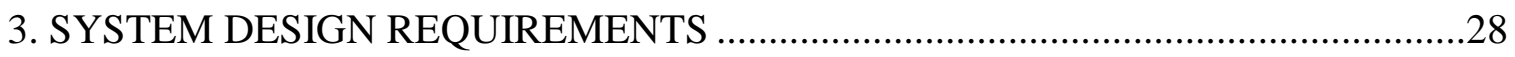

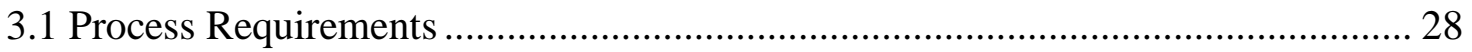

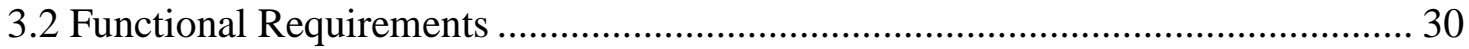

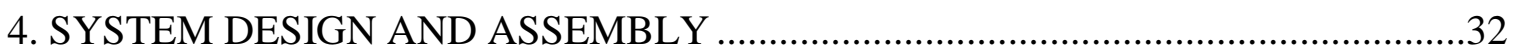

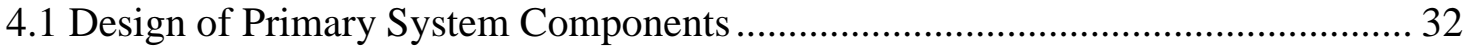

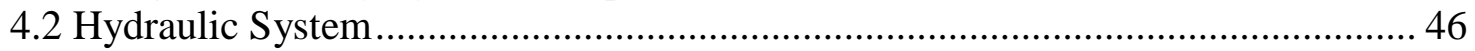

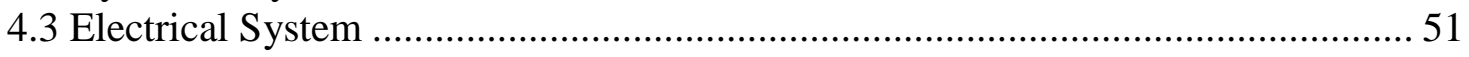

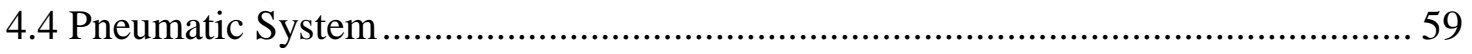

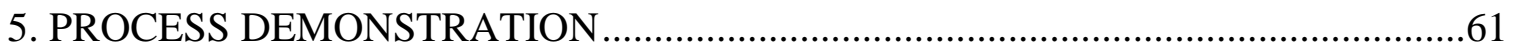

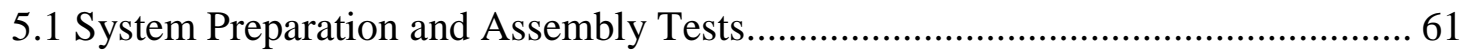

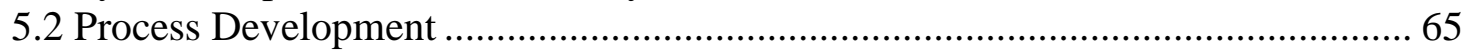

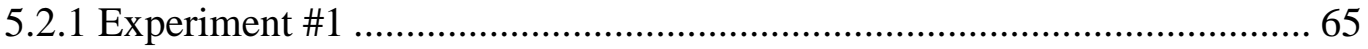

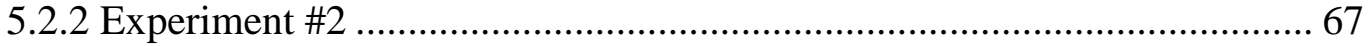

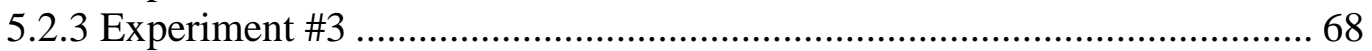

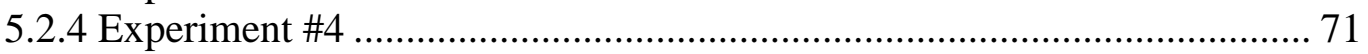

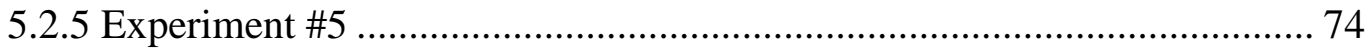

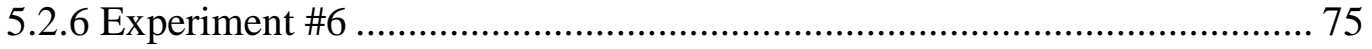




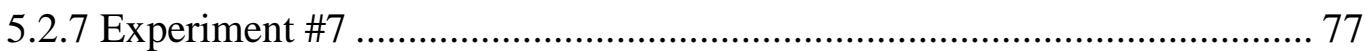

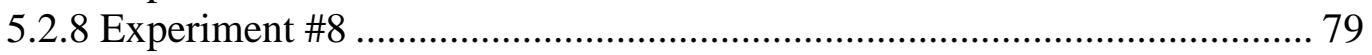

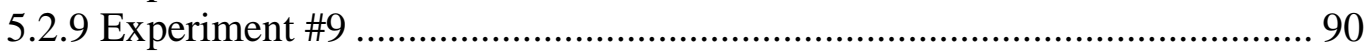

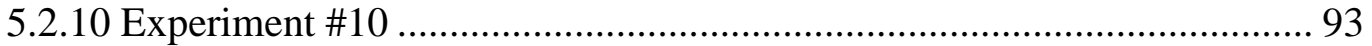

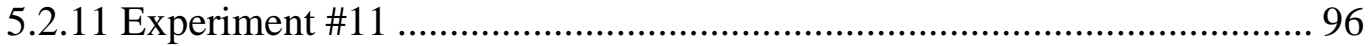

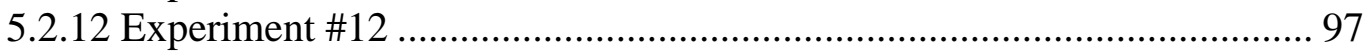

5.2.13 Experiment \#13 .................................................................................. 101

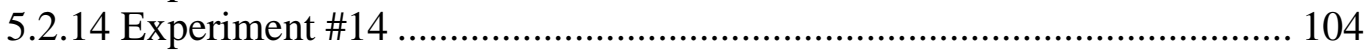

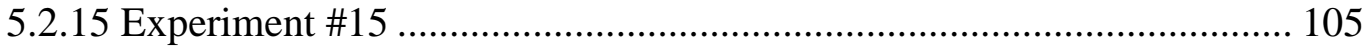

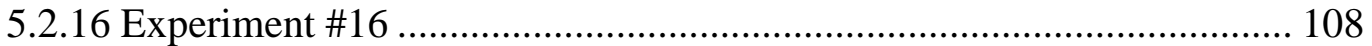

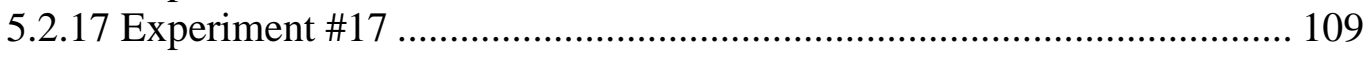

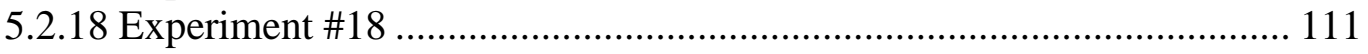

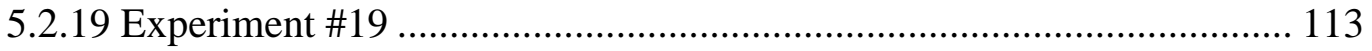

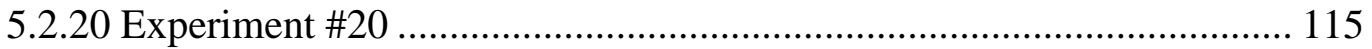

5.2.21 Experiment \#21 ............................................................................. 117

5.2.22 Experiment \#22 ......................................................................... 117

5.3 Characterization of The Powder. ............................................................... 119

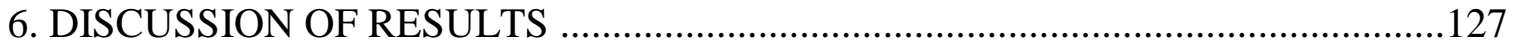

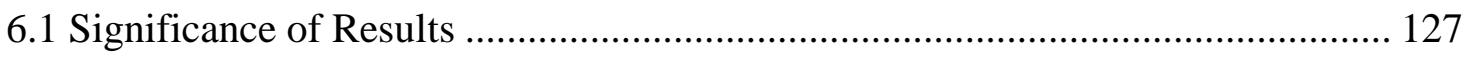

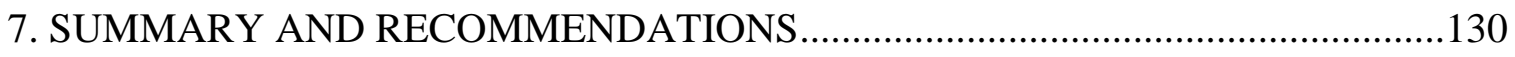

7.1 Recommendations for Future Work ......................................................... 130

7.2 Recommended Design Improvements ...................................................... 131

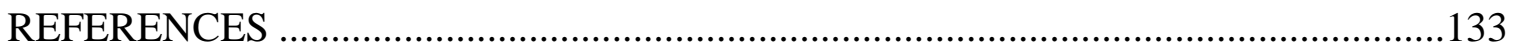

APPENDIX A HYDRAULIC SYSTEM SCHEMATIC ..........................................138

APPENDIX B ELECTRICAL SYSTEM SCHEMATIC FOR THE HYDRAULIC

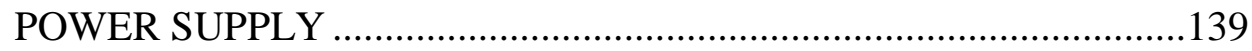

APPENDIX C ELECTRICAL SYSTEM SCHEMATIC FOR THE VACUUM

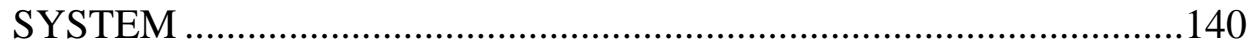

APPENDIX D ELECTRICAL SYSTEM SCHEMATIC FOR THE HEATER

SYSTEM 
APPENDIX E ELECTRICAL SYSTEM SCHEMATIC FOR THE HEATER SYSTEM AFTER REBUILD ...........................................................142 APPENDIX F PNEUMATICS SYSTEM SCHEMATIC ..............................................143

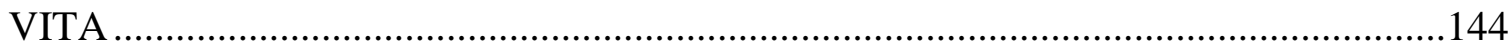




\section{LIST OF FIGURES}

Page

Figure 1: A schematic of the UREX process showing the separation of various constituents [14] 5

Figure 2: Photographs of a typical Zircaloy-4 sample (insert) and a sample that was processed below $545 \mathrm{deg} \mathrm{C}$ as removed from the reaction vessel [19].

Figure 3: Measured completion of hydride formation in Zircaloy-4 samples, Percent

Hydrogen (lines are curve-fitted to the data)

Figure 4: Zirconium-zirconium hydride phase diagram.

Figure 5: A schematic of a hexagonal close-packed structure and a body-centered cubic structure [27].

Figure 6: The crystalline structure of the alpha phase from zirconium [28]. 14

Figure 7: Equilibrium calculation for an absolute pressure of 0.5 bar 20

Figure 8: Equilibrium calculation for an absolute pressure of 0.1 bar...... 21

Figure 9: Equilibrium calculation for an absolute pressure of $0.01 \mathrm{bar}$ 22

Figure 10: Equilibrium calculation for an absolute pressure of 0.001 bar. 22

Figure 11: A graphical representation of a ball mill. 24

Figure 12: A representation of a hammer mill [47]. 25

Figure 13: A roller mill showing the grooved cylinders to grind the material that falls between them [47]. .27

Figure 14: Overall system design. 34

Figure 15: A nitrogen getter assembly to remove nitrogen from the process gas. 35 
Figure 16: Photograph of the front panel of the control rack. 36

Figure 17: The backside of the control panel.

Figure 18: The backside of the control panel showing the electronics, hydraulics and pneumatics.

Figure 19: Preliminary design of the tumbler for zirconium powder formation. 38

Figure 20: The moveable end cap showing the sparge tube, heating element, thermocouple and unloading tray. 39

Figure 21: Partial assembly showing the hydraulic motor, couplings and end cap. 40

Figure 22: The revised tumbler design with the simpler sample collection technique.... 41

Figure 23: Sample collection cup and the system designed to apply the lid. 42

Figure 24: Main assembly with the rocker support system.

Figure 25: Wheel assembly installed in the inside edge of the vessel along with its Solid Works model.

Figure 26: The end plate showing the heating element, thermocouple (and shield) and gas feed tube.

Figure 27: The pneumatic cylinder and the two slides shown from the top and end views. .46

Figure 28: The hydraulic power supply which consists of a gear pump and an electric motor .47

Figure 29: Tumbler speed control valve attached to the front of the control panel. 47 
Figure 30: Hydraulic lines attached via quick disconnects to the seal welded

couplings.

Figure 31: Hydraulic lines enter the access plate and connect to the hydraulic motor.... 49

Figure 32: Insulation covering the hydraulic motor and the feed lines.

Figure 33: Heat exchanger to cool the hydraulic fluid once it has left the motor. 50

Figure 34: Oil filter and mounting bracket inside the control panel.

Figure 35: Wiring diagram for the hydraulic power supply motor. 52

Figure 36: Electrical box mounted on the inside of the control panel. 53

Figure 37: Electrical distribution panels showing the ground wires (left) and the two 120 bolt power lines, L1 and L2 (right).

Figure 38: The push button controls for the hydraulic power supply and the vacuum pump. 54

Figure 39: Motor starter for the hydraulic power supply. The vacuum pump has the identical configuration.

Figure 40: The front side of the control panel showing the heater controls. 56

Figure 41: A transformer used to step down the voltage from 120 volts (max) to 40 volts. 57

Figure 42: Conax-Buffalo fittings allowing current flow to penetrate the vacuum chamber. 58

Figure 43: The end plate attached to the sliding plate prior to full assembly. 58

Figure 44: The molybdenum disilicide heating element attached to the end plate. 59 
Figure 45: Pneumatic control valves to actuate the end plate and the sample

collection lid.

Figure 46: Zircaloy tubes being cut to size with a diamond bladed saw.

Figure 47: Vibrating cleaning system to prep the samples prior to testing.

Figure 48: Weighing the samples prior to testing. 64

Figure 49: Samples prior to processing. 64

Figure 50: Insulation on the tumbler to inhibit heat loss from the chamber. 66

Figure 51: AeroRod heating elements shaped to enhance the heat flux on the sample... 68

Figure 52: Insulation adhesion failure. 70

Figure 53: The end plate with the silicon carbide heating elements installed. 71

Figure 54: Samples from experiment \#4 shows slight embrittlement. 73

Figure 55: Insulating the unheated length of the heating elements. 74

Figure 56: Samples from experiment \#6 show a gold tint which is indicative of zirconium nitride. 76

Figure 57: The screen holding the titanium powder after nitrogen contamination. 77

Figure 58: Samples from experiment \#7 showing partial hydriding. 78

Figure 59: The tumbler broken due to a thermal shock during experiment \#8. 81

Figure 60: Results of dehydriding $\mathrm{ZrH}_{2}$ using a Thermogravometric Analyzer.

Figure 61: The new tumbling chamber made from a stainless steel pipe. 83

Figure 62: The stainless steel sleeve to protect the tumbling chamber from contamination. 
Figure 63: Insulation around the 1-1/2" stainless steel bolt welded to the hub that is attached to the hydraulic motor.

Figure 64: The WATLOW heater installed and surrounded by insulation. 86

Figure 65: The controller for the WATLOW heating element.

Figure 66: The blind flange with the roto-coupling installed with a ceramic spacer. .... 87

Figure 67: Seal type used to seal between the two mating flanges.............................. 88

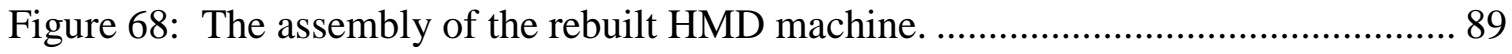

Figure 69: An oxygen trap mounted to the side of the control panel to filter oxygen from the specialty gas stream.

Figure 70: Samples from experiment \#9 shows partial hydriding. 92

Figure 71: An assembly drawing of the roto-coupling.

Figure 72: Ceramic putty applied to seal the inside from contamination caused by the roto-coupling.

Figure 73: A variac-type controller temporarily used to control the WATLOW heating element. .95

Figure 74: Samples from experiment \#10 showing slight hydriding and a dark "soot" coating. . .95

Figure 75: Ceramic paste applied to prevent oil residue from contaminating samples... 96

Figure 76: Samples from experiment \#11. 97

Figure 77: Installation of a small stainless steel plate to retard the flow of contaminants into the sample chamber. 
Figure 78: Sample from experiment \#12.......

Figure 79: Graphite residue remaining on the blind flange following experiment \# 12 . 100

Figure 80: Flexitallic gasket mounted on the tumbler flange. 101

Figure 81: Samples from experiment \#13.

Figure 82: The offset structure installed on the blind flange. 103

Figure 83: The thermocouple bent to lightly touch the sample cup edge. 104

Figure 84: Samples from experiment \#14. 105

Figure 85: The sample from experiment \#15. 106

Figure 86: A black residue coating the interior of the sample chamber. 107

Figure 87: The sample from experiment \#16.....

Figure 88: The samples from experiment \#17. 110

Figure 89: The sample powder from experiment \#18.

Figure 90: The argon filled glove box installed in the Fuel Cycle and Materials

Laboratory. 114

Figure 91: The sample from experiment \#19 incased in an argon filled vial.

Figure 92: Samples from experiment \#20 showing clearly the formation of zirconium nitride.

Figure 93: Samples from experiment \#22 showing the fine silver powder in an argon filled vial.

Figure 94: XRD analysis on the powder sample from experiment \#19....... 120 
Page

Figure 95: XRD analysis from the sample generated in experiment \#22 .................... 122

Figure 96: Sieves and shaker used to classify the two powder samples...................... 123

Figure 97: Size characterization of both powder samples. ...................................... 124

Figure 98: Microscopic photographs of the powder from experiment \#19................. 125

Figure 99: Microscopic photographs of the powder from experiment \#22 .................. 126 


\section{LIST OF TABLES}

Page

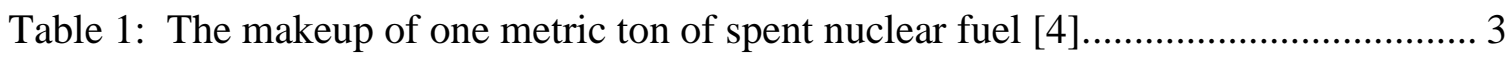

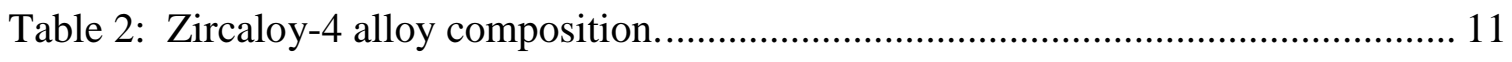

Table 3: Gibbs free energy relationship for zirconium hydride.................................... 19

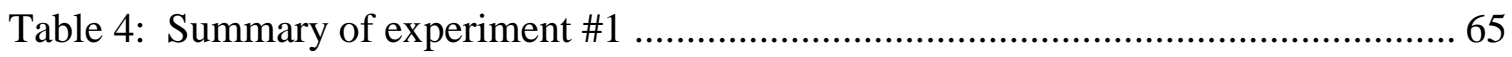

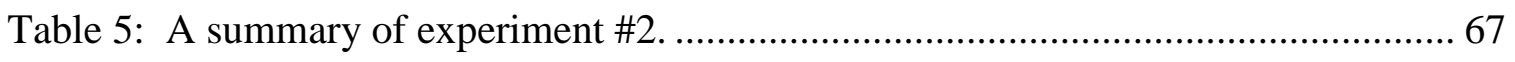

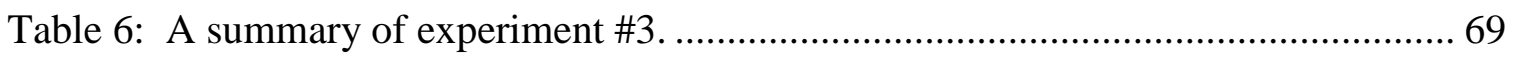

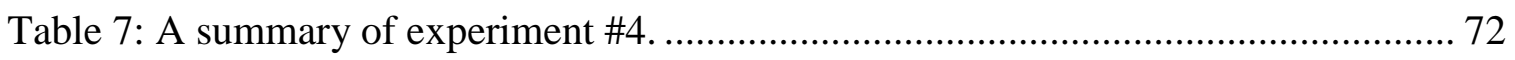

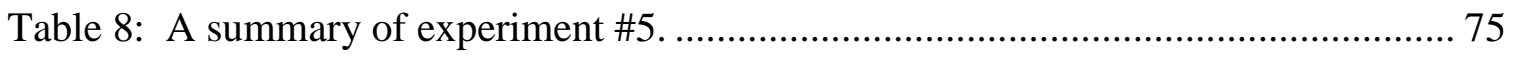

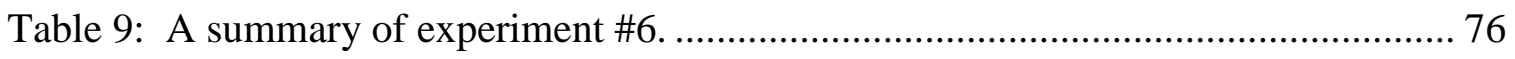

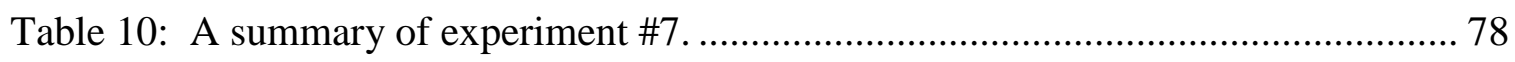

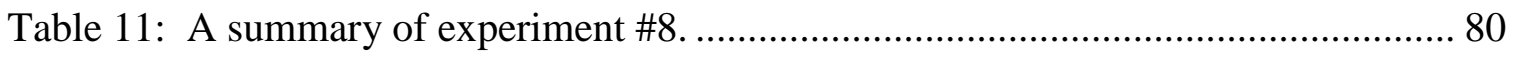

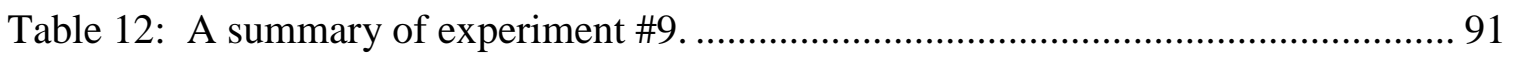

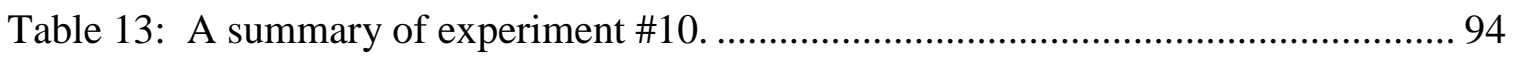

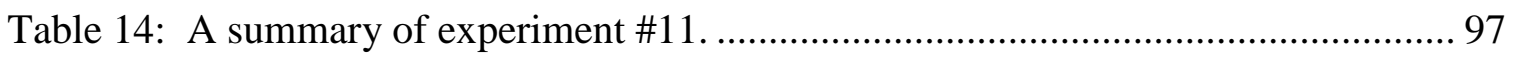

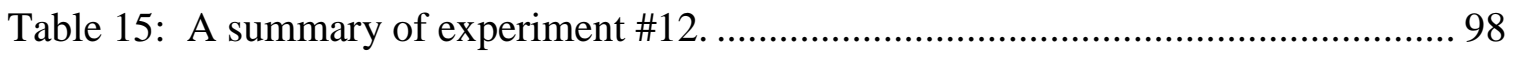

Table 16: A summary of experiment \#13. ......................................................... 102

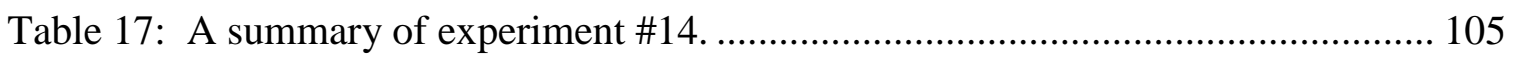

Table 18: A summary of experiment \#15............................................................ 106

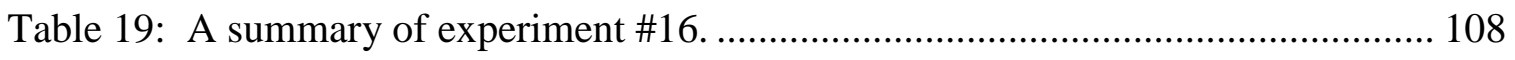

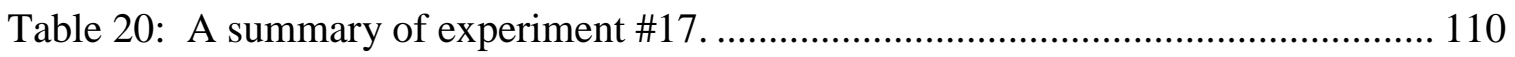


Table 21: A summary of experiment \#18........................................................... 111

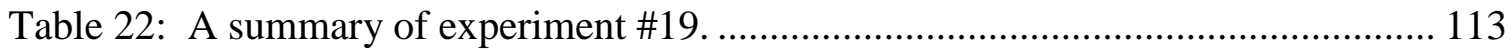

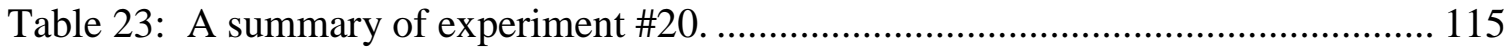

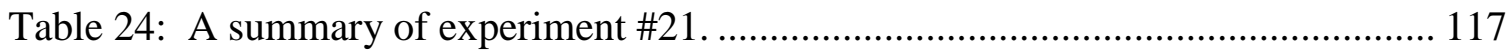

Table 25: A summary of experiment \#22. .................................................................. 118 


\section{INTRODUCTION}

The research described in this thesis describes the development and demonstration of a processing method that could be used to recycle Zircaloy cladding material from spent nuclear fuel (SNF). The research was part of a larger project funded by the United States Department of Energy under the Nuclear Energy Research Initiative (NERI). The NERI project sought to develop methods to recover transuranic (TRU) nuclides and embed them in a Zirconium matrix cermet pin [1]. The context for this project is that the United States Department of Energy (DOE) is developing waste management solutions associated with the generation of spent fuel from nuclear power plants [2]. Spent nuclear fuel is comprised of the used oxide fuel material, the Zircaloy cladding hulls and associated fuel assembly hardware that have been removed from a reactor core. The fuel assemblies for a typical light water reactor (LWR) initially contain uranium oxide pellets (small cylinders) encased in a Zircaloy cladding tube. Once burned, the spent fuel is transformed by the destruction of uranium, the buildup of fission products and activation products, and the neutron activation of certain nuclides within the assembly hardware. The spent fuel is highly radioactive and contains several toxic substances. Therefore, if nuclear power is to remain a safe, clean and reliable form of electrical generation, the SNF waste disposal must be managed in a safe and reliable manner.

This dissertation follows the style of the Journal of Nuclear Materials. 
Table 1 presents the nominal composition of spent fuel in terms of 1000 kilograms of initial uranium, one metric ton of initial heavy metal (1 MTIHM). This fuel has been burned to $\sim 35 \mathrm{GWd} / \mathrm{MT}$ (giga-watt-days/metric ton) and the table lists the distribution of activation products (e.g., $\mathrm{Pu}, \mathrm{Np}$, and $\mathrm{Am}$ ) as well as a breakdown of the primary fission products present in the fuel (e.g., I-129, Cs-137, Tc-99 and many more).

The radiotoxicity of SNF largely arises from the long-lived fission products and the minor actinides. For the first 30 years, the radiotoxicity is dominated by fission products but the toxicity of these materials decreases to a point where, after about 120 years, their toxicity decrease below that of natural uranium ore. For the transuranics (TRUs), several short-lived nuclides dominate the radiotoxicity for the first 30 years, but then plutonium dominates the SNF to the point where the SNF radiotoxicity drops below natural uranium ore after 100,000 years [3].

Up until 2010, the US DOE was investigating the viability of two SNF management strategies: direct disposal and reprocessing. The direct disposal option was focused on burying the SNF in a deep underground repository proposed at Yucca Mountain Nevada. The reprocessing option would chemically separate SNF and recycle fissionable materials into advanced energy systems and dispose a smaller volume of waste with a lower level of radiotoxicity. Both methods have advantages and disadvantages. One of the major advantages of direct disposal is the security is enhanced. Materials that could be used by terrorists are out of their reach in a secure, guarded repository. The major disadvantage is the cost. Not just the cost of the repository, which is significant, but the lost value of the SNF constituents that could be recovered; i.e., 
unburned fuel, valuable nuclides and fuel rod cladding [5]. It is notable that the Yucca Mountain Project has been terminated by the U.S. government at this time [6]. As that repository option is closing, a high-level panel of scientists and engineers is currently considering alternatives for SNF handling in the United States [7]. The outcome of this review is still to be determined, but it could involve recommendations for a different repository strategy, a continued above-ground waste storage strategy, or, perhaps, a move to reprocessing and recycling.

Table 1: The makeup of one metric ton of spent nuclear fuel [4].

\begin{tabular}{|c|c|}
\hline Constituent & kg \\
\hline Uranium & 955.4 \\
\hline Plutonium & 8.5 \\
\hline \multicolumn{2}{|c|}{ Minor Actinides } \\
\hline Neptunium & 0.5 \\
\hline Americium & 0.6 \\
\hline Curium & 0.02 \\
\hline Long-Lived Fission Products \\
\hline${ }^{129}$ lodine & 0.2 \\
\hline${ }^{99}$ Technecium & 0.8 \\
\hline${ }^{93}$ Zirconium & 0.7 \\
\hline${ }^{135}$ Cesium & 0.3 \\
\hline Short-Lived Fission Products \\
\hline${ }^{137}$ Cesium & 1.0 \\
\hline${ }^{90}$ Strontium & 0.7 \\
\hline \multicolumn{2}{|c|}{ Stable Nuclides } \\
\hline Lanthanides & 10.1 \\
\hline Other stable elements & 21.8 \\
\hline
\end{tabular}

Reprocessing also has advantages and disadvantages. The primary advantages include the recovery and recycle of valuable nuclear fuel materials and the potential 
minimization of high-level waste volumes. Uranium, plutonium and other transuranic elements may be separated and re-installed in a reactor so they can continue to fission. Other elements such as zirconium from the spent cladding may also be recycled and reused to decrease the mining of zirconium ore required. The disadvantages of reprocessing include the relatively high costs associated with building a new nuclear facility, developing and installing safeguards and security, and the development of fuel conversion and remanufacturing methods [8][9].

As noted above, the research described here contributes to the technology base required to implement the reprocessing option. The zirconium in the cladding tubes has value since it has already been chemically isolated from the hafnium found in natural zirconium ore. Raw zirconium ore has a significant amount of hafnium, which has to be removed due to the high neutron absorption cross section [10]. The primary mission of the process developed here was to recover "some" of the cladding for the cermet design.

One of the recycle methods that has been studied is the UREX (uranium extraction method) [11]. Figure 1 shows a schematic of this process. This method removes the uranium before disposal in waste repositories. This dramatically decreases the amount of material that requires disposal, as seen in Table 1. The UREX process also removes some of the more active fission products, but leaves the plutonium and TRU as a waste stream. Using this method, scientists at the Argonne National Laboratory were able to remove $99.999 \%$ of uranium from irradiated fuel from the Cooper Nuclear Station in Nebraska [12]. This reprocessing method starts with the mechanical chopping of the spent fuel rods into smaller pieces. The SNF is dissolved out of the Zircaloy cylinders 
with a nitric acid solution. Uranium is extracted along with technetium [ $\left.{ }^{99} \mathrm{Tc}\right]$ using the UREX process. Additional processes are used to isolate cesium $\left[{ }^{137} \mathrm{Cs}\right]$, strontium $\left[{ }^{90} \mathrm{Sr}\right]$, the TRU's and fission products [13].

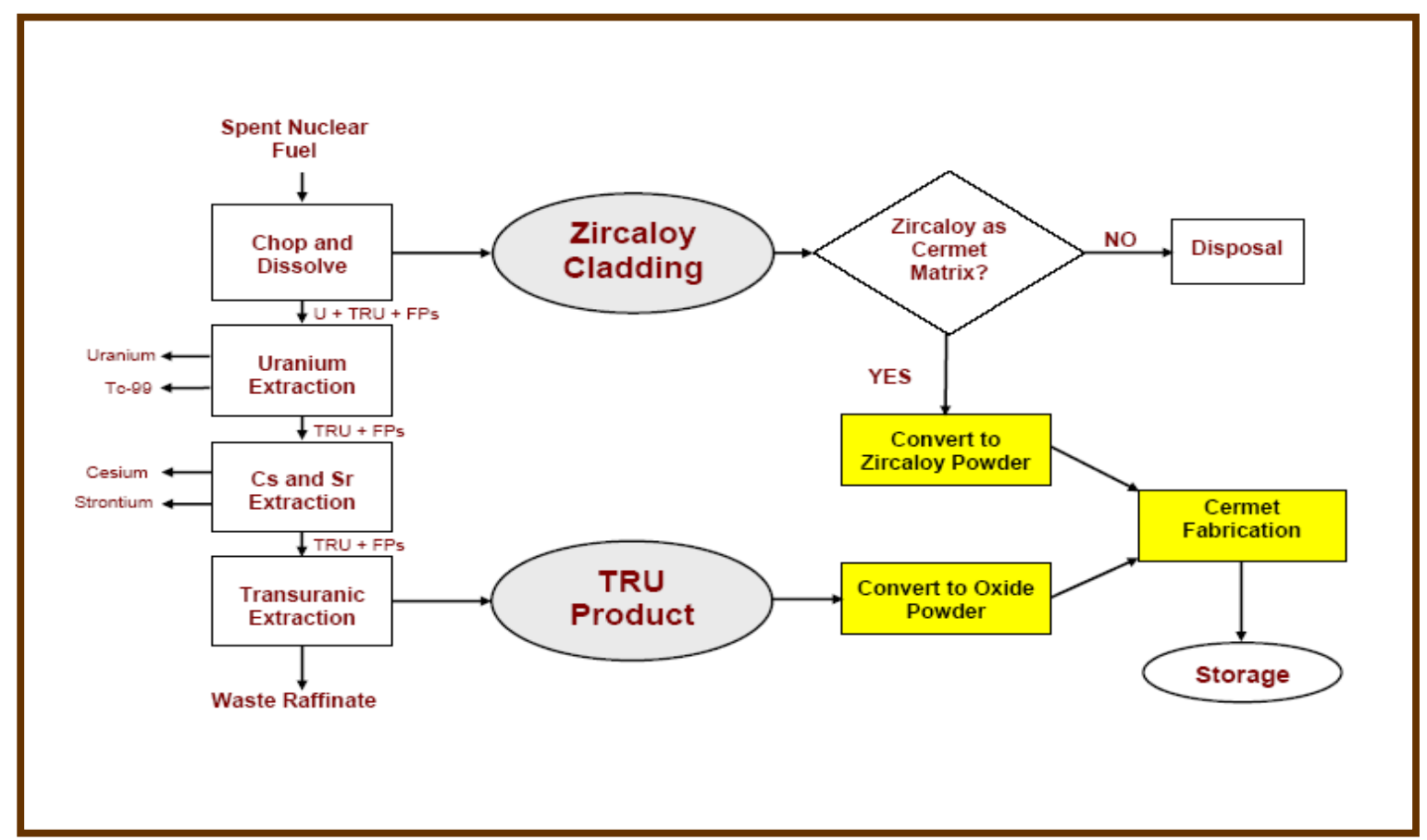

Figure 1: A schematic of the UREX process showing the separation of various constituents [14].

The NERI project that provided the context for this research was supported by the DOE's Advanced Fuel Cycle Initiative (AFCI), which had the objective to develop fuel cycle management strategies that provide for safe, proliferation resistant material management methods. The ultimate goal of AFCI was to formulate the transuranic nuclides into a form that can be burned up in a thermal reactor or a future advanced fast reactor, thus reducing or eliminating the need for long-term storage of these nuclides 
[15]. This particular NERI project had three parts; the recycle of spent fuel cladding, the generation of mixed oxide microspheres and the zirconium matrix cermet fuel [16].

This research reported here investigated the development of a zirconium hydridemilling-dehydride process to produce a zirconium metal powder from Zircaloy metal. Zircaloy-4 cladding subjected to a hydrogen rich environment ( $5 \%$ hydrogen $-95 \%$ argon) at elevated temperatures produces zirconium hydride, an extremely brittle material that is easily pulverized into a powder. Once in powder form, the temperature is raised and a vacuum pulled on the powder. This releases the hydrogen leaving a pure zirconium metal powder.

This dissertation describes the design, fabrication and operation of a specialized piece of equipment to perform the hydride, powder milling and dehydride processes on the Zircaloy-4 cylinders. Previous work, described in detail in Section 2, laid the foundation for the hydride process as well as the conditions required for efficient milling. The dehydriding process was briefly investigated, but more development was required to adequately define the dehydriding parameters. The goal was to design and demonstrate a prototype machine that demonstrated the entire process from tubes to powder. This consisted of; loading Zircaloy cylinders into the machine, heating to the hydriding temperature, flowing a 5\% hydrogen $-95 \%$ argon gas to hydride the zirconium, milling the zirconium hydride into a fine powder, raising the temperature under a vacuum to dehydride the material, and unloading the powder from the machine.

The following sections describe in detail the previous research in this area. Specifically, zirconium hydriding conditions will be researched and reported in Section 2. 
Section 2 will summarize common milling methods to analyze which type will be best for the specialized hydride-mill-dehydride machine. Section 3 provides details of the system design requirements. Section 4 describes the system design and procedure. SolidWorks [17] drawings, schematics (hydraulic, pneumatic and electrical) as well as photographs will give details of the machine and design process. Section 5 will present the results of the demonstration and discussion of these results will be presented in Section 6. Finally, Section 7 will give the conclusions as well as recommendations for future work and design modifications. Schematics (electrical, pneumatic and hydraulic) were generated prior to fabrication.

Once the equipment was fully assembled and tested, the verification of operation consisted of starting with Zircaloy-4 cylinders and ending up with a zirconium metal powder. The powder was characterized using x-ray diffraction (XRD) analysis, electron microscopy, and size classification to verify the successful demonstration of the hydridedehydride process, and thus the operation of the equipment. 


\section{BACKGROUND}

\subsection{HYDRIDE - DEHYDRIDE PROCESS}

The zirconium hydride process that was the foundation for the system designed for this research was developed by McDeavitt, et al. [18] D.T. Kraemer designed the initial testing apparatus at Purdue University and performed 14 "proof of concept" experiments on Zircaloy-4 hydriding [15]. A brief unsuccessful attempt was performed to demonstrate the dehydriding of zirconium, but the original setup failed due to heating problems. A.J. Parkison completed a thorough assessment of the hydride formation reaction and characterized the time and temperature relationship of the hydriding process [19]. It was also observed that pressure did affect the hydriding rate such that high pressures increased the rate of zirconium hydride formation. The test setup could only measure pressure as high at 25 inches of water, or about 1 psig. This however, was enough to show that a positive pressure strongly sped up the hydriding process [19].

Figure 2 and Figure 3 show some highlights from the previous work by Parkison and McDeavitt [19]. Figure 2 shows a crumbled Zircaloy-4 tube that was processed under flowing $\mathrm{Ar}-5 \% \mathrm{H}_{2}$ at a temperature between $520^{\circ} \mathrm{C}$ and $545^{\circ} \mathrm{C}$. The sample was completely embrittled [20] and crumbled into large shards of zirconium hydride without mechanical force. Samples of this type were readily ground to fine powder after treatment. Figure 3 shows a compilation of the hydride formation rate experiments expressed in terms of "percent hydride" formation, connoted by the variable $P_{H}$, which represents the completion percentage of the $\mathrm{Zr}$ to $\mathrm{ZrH}_{2}$ conversion. The dotted lines in Figure 3 represent the correlation developed for hydriding $\alpha-\mathrm{Zr}$ and $\beta-\mathrm{Zr}$. 


$$
\begin{aligned}
& P_{H}=(0.028 T-6.39) t^{(1.74)}, \quad \text { for } \alpha-\operatorname{Zr}\left(440^{\circ} \mathrm{C} \text { to } 545^{\circ} \mathrm{C}\right) \\
& P_{H}=(0.085 T-20.5) t^{(1.1)}, \quad \text { for } \beta-\operatorname{Zr}\left(545^{\circ} \mathrm{C} \text { to } 640^{\circ} \mathrm{C}\right) .
\end{aligned}
$$

These correlations are empirical fits to a limited data set. Two important observations from this previous research include the fact that the hydride formation reaction was rather rapid (complete in under 4 hours) and that hydriding at $545^{\circ} \mathrm{C}$ typically produced crumbled shards of zirconium hydride whereas hydriding above $545^{\circ} \mathrm{C}$ typically produced tough, hard tubes of zirconium hydride. This was attributed to differences in the reaction pathway and the relative solubility of hydrogen in $\alpha-\operatorname{Zr}$ and $\beta-\operatorname{Zr}[21]$.

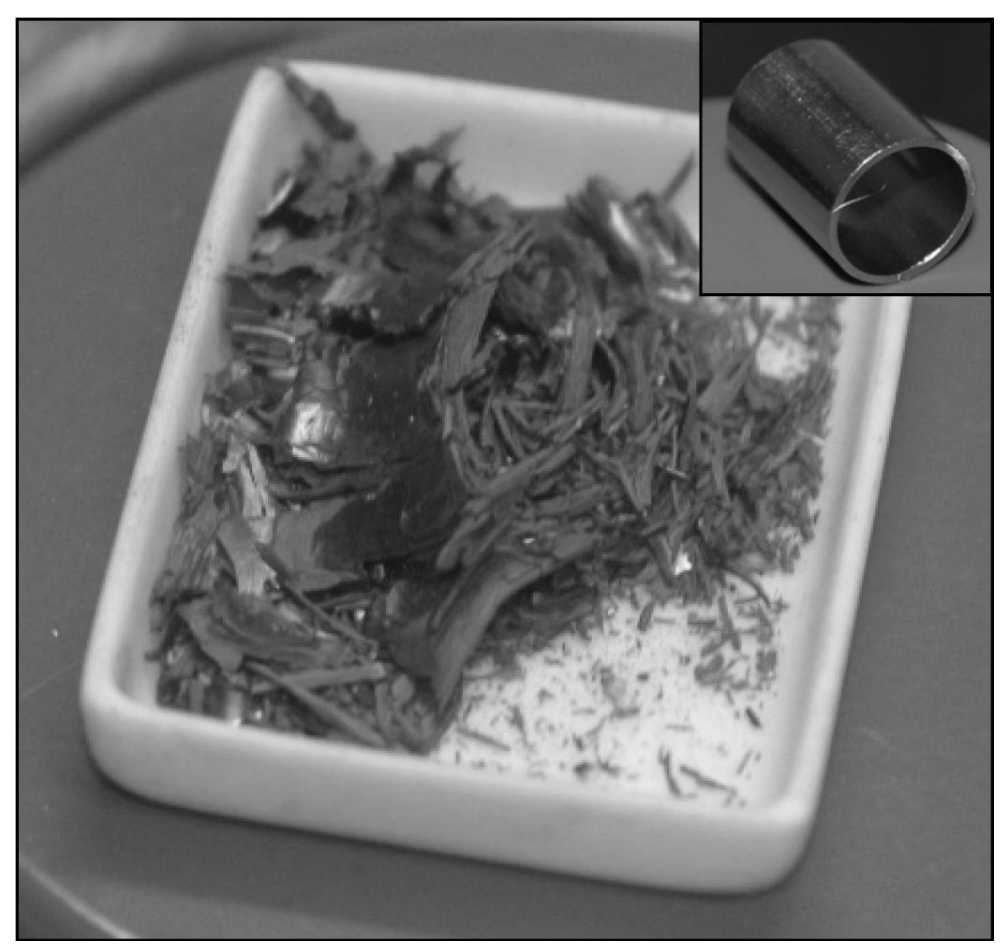

Figure 2: Photographs of a typical Zircaloy-4 sample (insert) and a sample that was processed below $545 \mathrm{deg} C$ as removed from the reaction vessel [19]. 


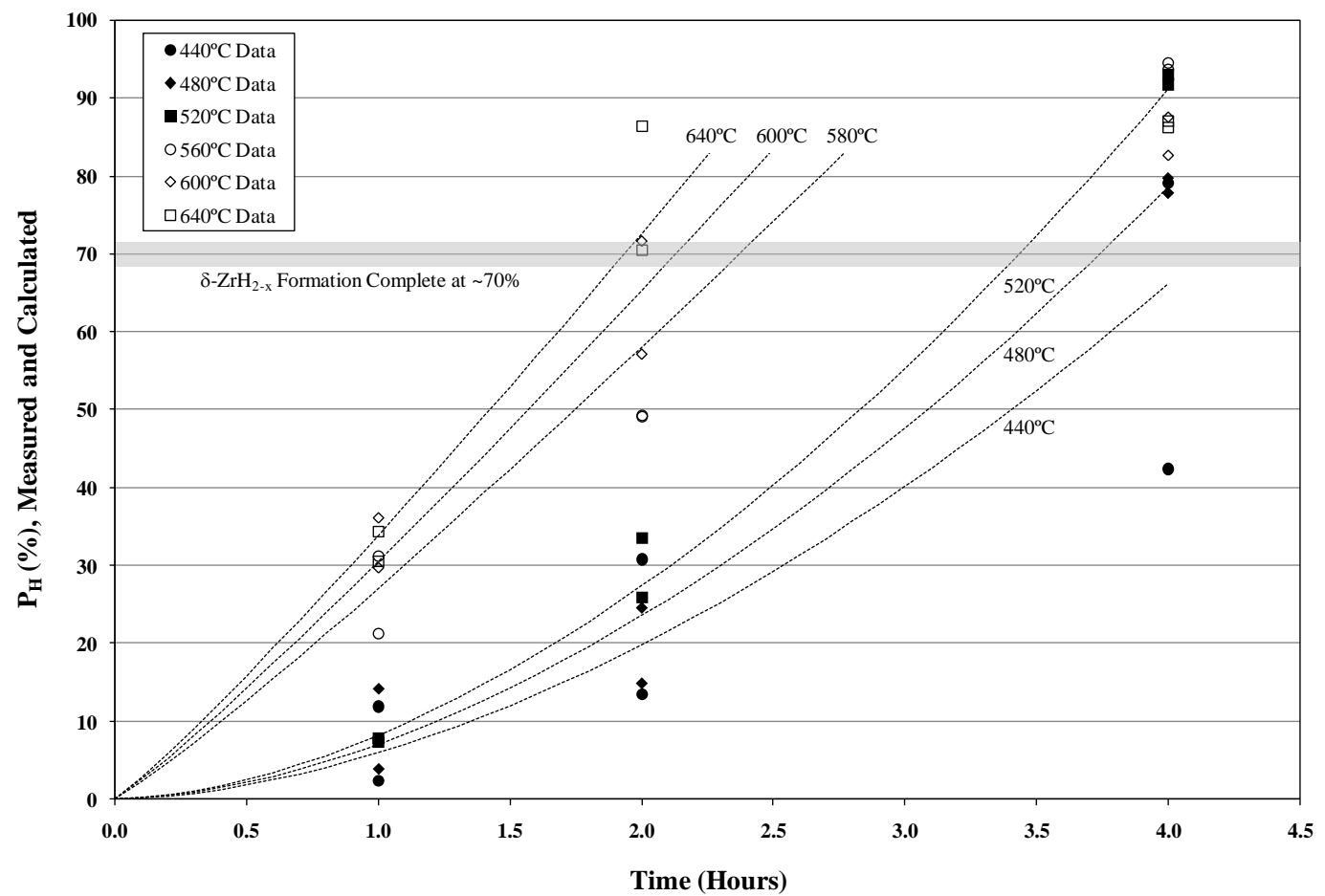

Figure 3: Measured completion of hydride formation in Zircaloy-4 samples, Percent Hydrogen (lines are curve-fitted to the data).

With the foundation laid by McDeavitt, Kraemer, and Parkison, the next step was to build a demonstration system to process Zircaloy-4 tubes directly into powder. Table 2 shows the weight percent of constituents that make up the alloy Zircaloy-4. As noted above, Zircaloy-4 cladding is a nuclear grade material, meaning that hafnium has been removed. The chemical properties of zirconium and hafnium are very similar, but they have vastly different nuclear properties. Hafnium is a strong neutron absorber and would poison the reactor if left in the cladding. On the other hand, hafnium hydride is being considered for use in control rods in fast reactors being developed by the Japanese Atomic Energy Agency (JAEA) [22]. 
Table 2: Zircaloy-4 alloy composition.

\begin{tabular}{c|c}
\hline Element & Weight Percent \\
\hline Tin & 1.2 to 1.7 \\
Iron & 0.18 to 0.24 \\
Chromium & 0.07 to 0.13 \\
Oxygen & 0.12 \\
Zirconium & Balance \\
\hline
\end{tabular}

A more subtle, albeit very important reason to recycle the cladding is the problem of imbedded fission fragments and other radionuclides on the inner surface of the spent fuel cladding. This contamination requires the cladding to be classified as a high-level nuclear waste. Therefore, reprocessing the cladding could ultimately decrease the amount of high-level waste to be stored in an underground repository (if such a facility is available in the future).

To illustrate the hydride formation process, Figure 4 shows a sketch of the binary $\mathrm{Zr}-\mathrm{ZrH}_{2}$ phase diagram for temperatures from $200^{\circ} \mathrm{C}$ to $1100^{\circ} \mathrm{C}$ [19]. It can be seen from the phase diagram that, at temperatures below the $\alpha-\beta-\delta$ eutectoid temperature the $\delta$ phase may begin precipitating at very low hydrogen concentrations. This is in contrast to temperatures above the eutectoid temperature, where the $\delta$-phase does not begin to form until a $\mathrm{P}_{\mathrm{H}}$ of $\sim 28 \%$ has been achieved. As noted above, the key observation from the 
Parkison experiments is that it is much easier to produce a millable form of zirconium hydride within the $\alpha$-zirconium structure as opposed to the $\beta$-zirconium structure. This transformation induces volumetric strains due to density changes associated with brittle $\delta$-phase formation.

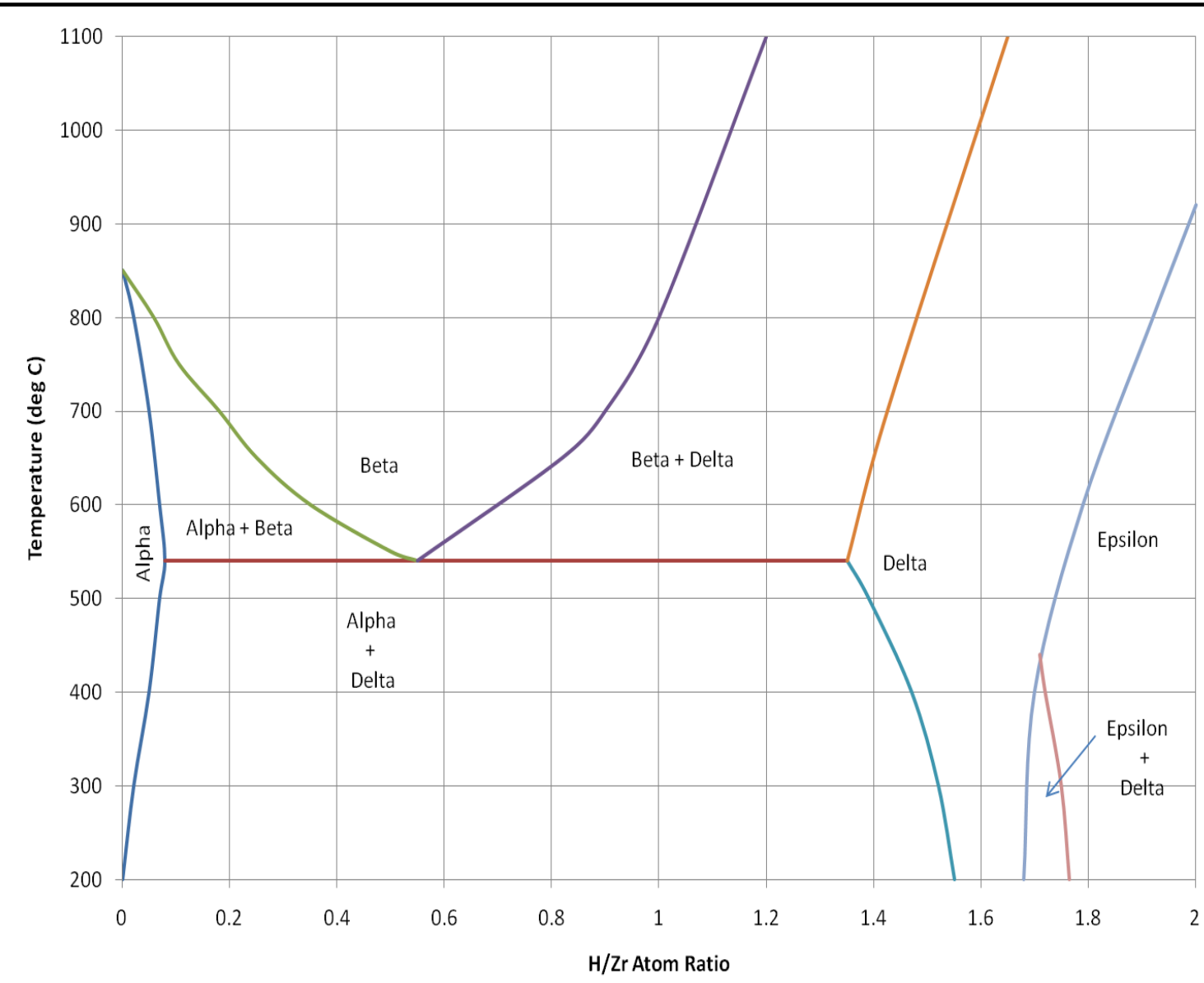

Figure 4: Zirconium-zirconium hydride phase diagram. 
Zirconium metal has a hexagonal close-packed structure in the $\alpha$-phase $\left(<862^{\circ} \mathrm{C}\right)$ and a body-centered cubic structure in the $\beta$-phase $\left(862^{\circ} \mathrm{C}\right.$ to $\left.1852^{\circ} \mathrm{C}\right)$. Figure 5 shows these two crystalline structures in schematic form. The alpha phase is composed of alternating planes of zirconium atoms in a hexagonal pattern (see Figure 6).

In the presence of hydrogen, hydrogen atoms begin to diffuse through the material at a rate depending on the temperature and the concentration gradient. The hydrogen atoms create a pressure inside the zirconium lattice that swells the material and drastically decreases the density $(8.2 \%$ to $15.4 \%)$. This volume change is responsible for making the lattice extremely brittle as these forces push the lattice apart [23]. This is sometimes referred to as hydrogen induced cracking (HIC).

The hydrogen atoms create platelets in the material. As the zirconium hydride platelets form, they force the alternating planes apart, making the matrix structure brittle and subject to fracturing [24]. Yamanaka, et. al. reported the addition of hydrogen to the zirconium structure elevated the elastic moduii over that of zirconium metal. Also, the presence of hydrogen in the lattice increased the microhardness of the material compared to pure zirconium [25]. The density of Zircaloy undergoes a transition during the absorption of the hydrogen from $\sim 6.5 \mathrm{~g} / \mathrm{cm}^{3}\left(\rho_{\mathrm{Zr}}=6.49\right)$ to $\sim 5.6 \mathrm{~g} / \mathrm{cm}^{3}$, which contributes to the brittleness of the material [26]. Utilizing the brittleness of this matrix, zirconium hydride can be shattered and ground into a fine powder. 

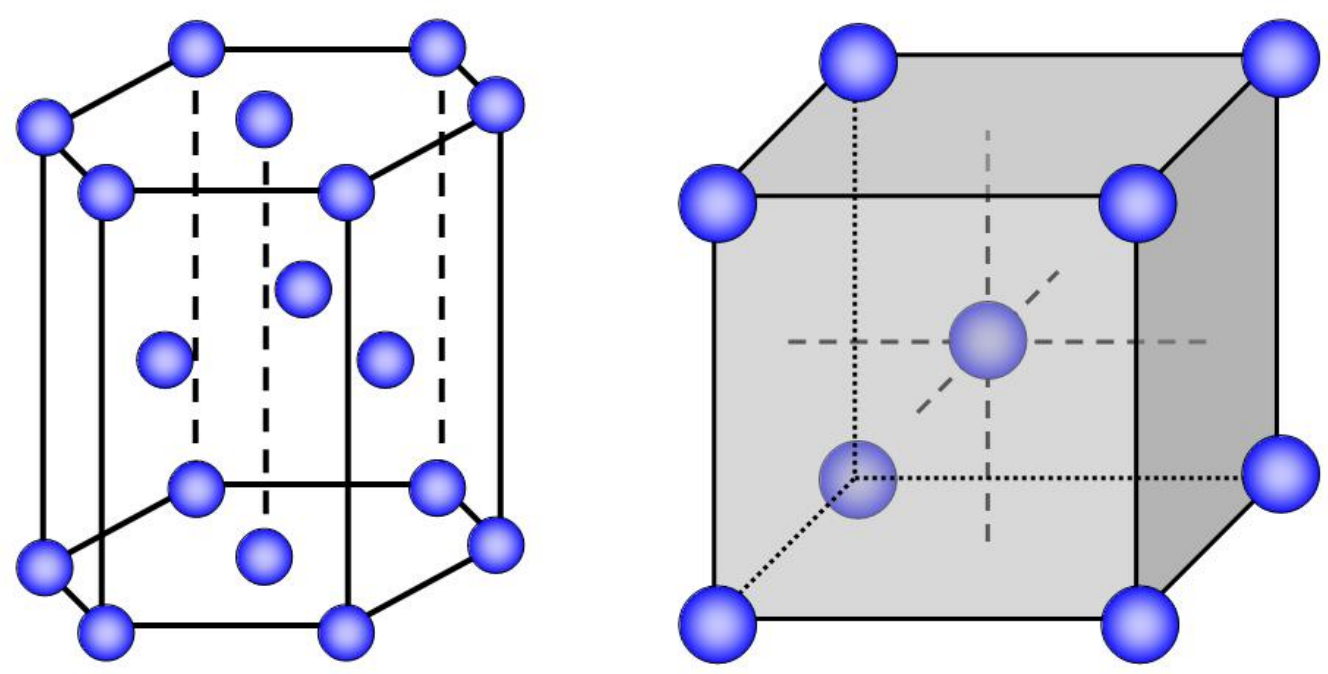

Figure 5: A schematic of a hexagonal close-packed structure and a body-centered cubic structure [27].

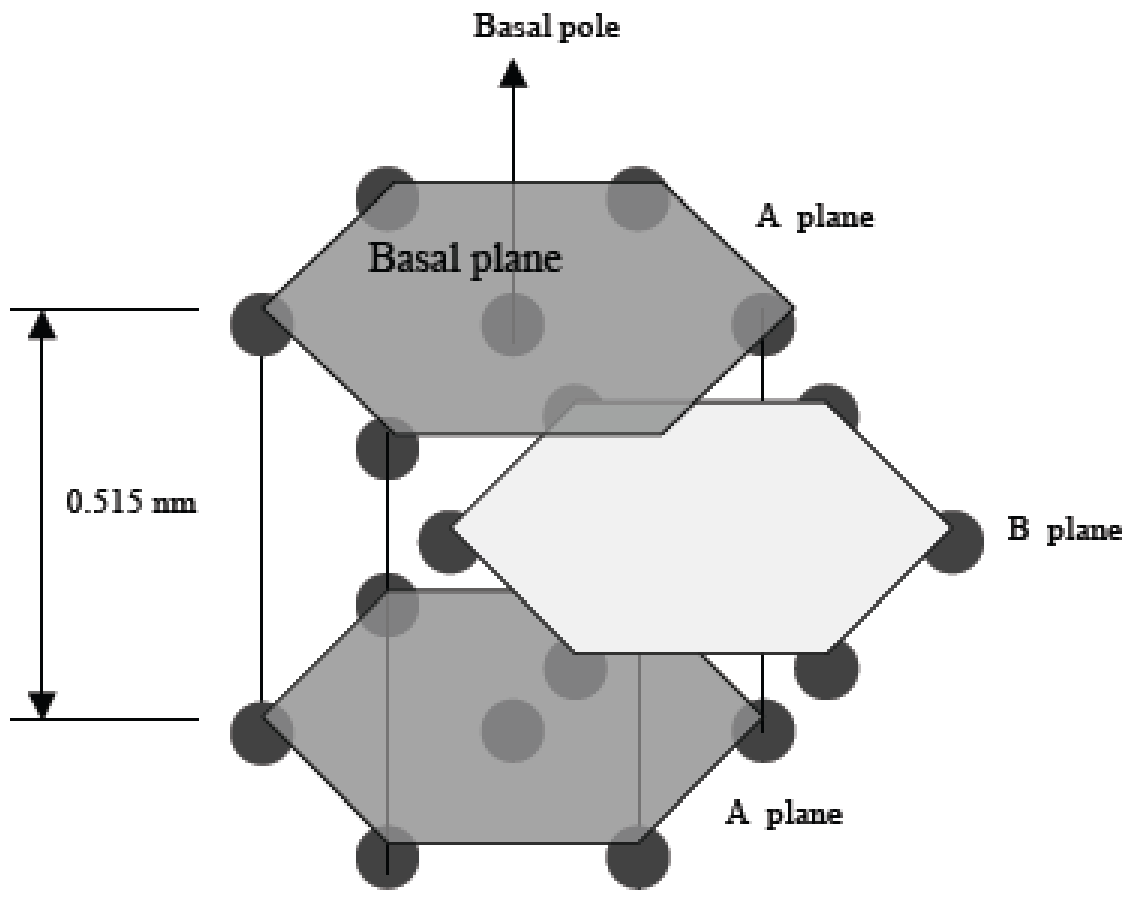

Figure 6: The crystalline structure of the alpha phase from zirconium [28]. 
Metal hydrides are not confined to zirconium. As previously mentioned, the Japanese Atomic Energy Agency is investigating the possibility of using hafnium hydride in control rods in a fast breeder reactor. Also, due to the rising cost of energy, nickel hydride battery research has been brought to the forefront. Ovshinksky, et. al. pointed out that nickel hydride batteries have a high energy density, high power, long life, tolerance to abuse, a wide range of operating temperature, quick-change capabilities and totally-sealed, maintenance-free operation [29].

Other metal hydrides have been proposed for use as electrodes. Chen, et. al. studied powder sintering methods for different metals (lanthanum, calcium, magnesium, nickel, titanium, aluminum and manganese) in various combinations [30]. These low cost materials could be combined in such a manner that they could absorb and off gas hydrogen at low temperature $\left(20^{\circ} \mathrm{C}\right)$ and at a pressure of $3.3 \mathrm{MPa}$. Their hydride ability, their electrochemical performance and their low cost make these compounds very attractive for solid state electronics.

Reilly and Wiswall looked at FeTi alloy to use as a potential hydrogen storage material [31]. It was found that this inter-metallic compound will easily react with Hydrogen to form a metal hydride and also readily dehydride, making it very useful as a hydrogen storage medium.

Robert Oppenheimer suggested a uranium hydride bomb to Edward Teller back in 1940's [32]. The reasoning was that the hydrogen atoms in the uranium hydride would moderate the neutrons into the thermal range to more effectively fission the $\mathrm{U}-235$, thus 
using a smaller critical mass. The moderation of the neutrons took too long and the bomb only partially exploded.

Once the Zircaloy-4 has been hydrided and milled to a powder, the material will be primed for the dehydriding process to transform the powder into a pure zirconium metal powder. A significant amount of research on dehydriding metal hydrides has been pursued recently due to the emergence of hydrogen fuel research. Much of the recent research deals with finding a metal hydride that is not thermodynamically stable; allowing easy decomposition. Schuth, et. al. studied the current state (2004) of hydrogen storage in metal and complex hydrides and concluded that the dehydriding process limited the hydrogen storage capabilities of these metals for fuel systems [33]. Alapati, et. al. developed a multistage approach using first principle calculations to assess the suitability of new metal hydrides prior to experimental studies [34]. Further study of the hydride-dehydride process by Flanagan and Oates showed the material developed a chemical hysteresis in addition to the plastic hysteresis. They mainly studied titaniumcopper-hydrogen systems [35]. The study of this elastic and plastic hysteresis was continued by Qian and Northwood who showed that for intermetallic compoundshydrogen systems, elastic strain energy is the major cause of hysteresis [36].

Balasubramaniam continued the study of chemical hysteresis in metal hydride formation and destruction with an elastic and elasto-plastic finite element analysis (FEA) [37].

Simonovic, et. al. studied the hydriding and dehydriding process of a particular zirconium alloy, $\mathrm{Zr}_{1.02} \mathrm{Ni}_{0.98}$ alloy. They investigated the capacity of the powder to hydride and dehydride at relatively cooler temperatures compared to Parkison, namely 
$150-250^{\circ} \mathrm{C}[38]$. Other investigations into dehydriding with zirconium (Chang, et. al.) involved zirconium-cobalt systems [39]. This reaction has been shown to play a very important role in delivering hydrogen isotopes to fusion energies. A numerical simulation performed by these researchers with their acquired parameters showed a more rapid dehydriding with increasing temperature and decreasing pressure. Therefore, the optimum conditions for the dehydriding of the zirconium hydride powder is not a well known phenomenon but will be investigated further in this research.

The $\mathrm{ZrH}_{2}$ dehydride reaction may be understood by analyzing the thermochemical parameters related to the reaction between zirconium and hydrogen:

$$
\mathrm{Zr}+\mathrm{H}_{2} \rightarrow \mathrm{ZrH}_{2} \text {. }
$$

The Gibbs free energy, $\Delta G$, for this reaction is a temperature dependent parameter that provides a relative measure of the reactivity of this system [40]. The following equation relates the standard-state free energy of reaction, $\Delta G_{o}$, with the free energy of reaction at any moment in time during a reaction:

$$
\Delta G=\Delta G^{o}+R T \ln K
$$

where,

$$
\begin{aligned}
& \Delta G o=\Delta H o+T \Delta S o \\
& \mathrm{R}=\text { universal gas constant }\left(8.314 \mathrm{~J} / \mathrm{mol}^{-}{ }^{\circ} \mathrm{K}\right) \\
& \mathrm{T}=\text { temperature in Kelvin } \\
& \mathrm{K}=\text { equilibrium constant } \\
& \mathrm{H}^{\mathrm{o}}=\text { enthalpy at standard conditions }
\end{aligned}
$$




$$
\mathrm{S}^{\mathrm{o}}=\text { entropy at standard condition }
$$

For chemical equilibrium, $\Delta G=0$ and $\Delta G^{o}=R T \ln K$. A negative value for $\Delta G^{o}$ implies energy has to be supplied for the reaction to proceed as written (i.e., endothermic). A positive value for $\Delta G^{o}$ means the reaction is exothermic or releases energy as it is proceeding. Therefore, the temperature dependent values of $\Delta G^{o}$ for the reaction in Eq. 2.3 may be examined to develop a reaction plan for dehydriding $\mathrm{ZrH}_{2}$.

An equilibrium thermo-chemistry software package called HSC Chemistry (version 6.0) [41] was used to evaluate this reaction. Table 3 shows an example from the HSC database presenting $\Delta G^{o}$ values calculated for one atmosphere pressure (inert gas) and temperatures from $0^{\circ} \mathrm{C}$ to $1000^{\circ} \mathrm{C}$. The $\Delta G^{o}$ values approach zero and turn positive between $950^{\circ} \mathrm{C}$ and $1000^{\circ} \mathrm{C}$. This implies at standard pressure (one bar) in an inert atmosphere, $\mathrm{ZrH}_{2}$ will spontaneously dehydride above $950^{\circ} \mathrm{C}$ to $1000^{\circ} \mathrm{C}$. (Note that Eqn. 3 is the hydride "formation" reaction, so dehydriding would be the reverse of that reaction, which would occur when the $\Delta G^{o}$ values are positive). 
Table 3: Gibbs free energy relationship for zirconium hydride.

\begin{tabular}{|c|c||c|c|}
\hline Temperature & Gibbs Free Energy & Temperature & Gibbs Free Energy \\
\hline${ }^{\circ} \mathrm{C}$ & $\mathrm{Kcal} / \mathrm{mol}$ & ${ }^{\circ} \mathrm{C}$ & $\mathrm{Kcal} / \mathrm{mol}$ \\
\hline 0 & -31.97 & 650 & -10.41 \\
\hline 50 & -30.41 & 700 & -8.73 \\
\hline 100 & -28.80 & 750 & -7.06 \\
\hline 150 & -27.17 & 800 & -5.38 \\
\hline 200 & -25.52 & 850 & -3.72 \\
\hline 250 & -23.86 & 900 & -2.03 \\
\hline 300 & -22.19 & 950 & -0.33 \\
\hline 350 & -20.51 & 1000 & 1.35 \\
\hline 400 & -18.83 & 1050 & 3.03 \\
\hline 450 & -17.14 & 1100 & 4.70 \\
\hline 500 & -15.46 & 1150 & 6.35 \\
\hline 550 & -13.77 & 1200 & 8.00 \\
\hline 600 & -12.09 & 1250 & 9.65 \\
\hline
\end{tabular}

The implication from the data in Table 3 is that heating $\mathrm{ZrH}_{2}$ to $\sim 1000^{\circ} \mathrm{C}$ would induce spontaneous decomposition. However, reducing the ambient pressure enables the reduction of this temperature. By heating zirconium hydrided under rough vacuum conditions ( 0.001 bar), lower process temperatures are possible. The HSC database is again useful to illustrate this point. Figure 7 to Figure 10 present the results of temperature dependent equilibrium concentration calculations at various ambient pressures and assuming one mole of $\mathrm{ZrH}_{2}$ is present. At low temperatures, the equilibrium condition is that one mole of $\mathrm{ZrH}_{2}$ is present without $\mathrm{Zr}$ or $\mathrm{H}_{2}$, whereas no $\mathrm{ZrH}_{2}$ is present at high temperatures. (While not shown, the profiles for $\mathrm{Zr}$ and $\mathrm{H}_{2}$ are the inverse to the $\mathrm{ZrH}_{2}$ profiles). Figure 7 shows the equilibrium calculation for an absolute pressure of 0.5 bar. The destabilization of $\mathrm{ZrH}_{2}$ begins to be noticeable at $\sim 600^{\circ} \mathrm{C}$ and becomes complete at $\sim 1100^{\circ} \mathrm{C}$. In between $600^{\circ} \mathrm{C}$ and $1100^{\circ} \mathrm{C}$, equilibrium would allow 
a stable mixture of $\mathrm{Zr}, \mathrm{H}_{2}$ and $\mathrm{ZrH}_{2}$ to coexist. However, if the $\mathrm{H}_{2}$ is removed (e.g., by a vacuum system), the reaction could possibly be driven to complete dehydration over time.

Kmol

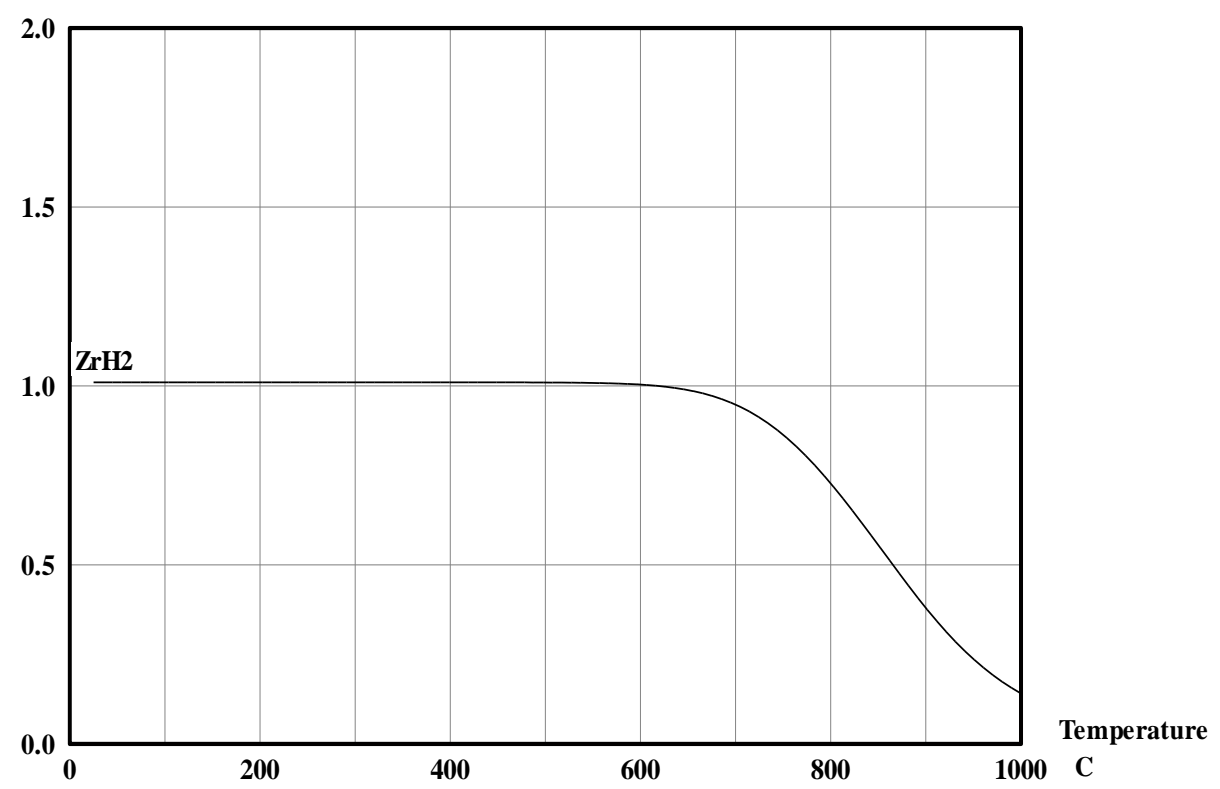

Figure 7: Equilibrium calculation for an absolute pressure of 0.5 bar.

Figure 8 shows the reaction for an absolute pressure of 0.1 bar. Here, the point for notable dehydriding has shifted to $\sim 550^{\circ} \mathrm{C}$ and the point of complete dehydriding is still over $1000^{\circ} \mathrm{C}$. Figure 9 shows the same calculation for 0.01 bar of pressure and Figure 10 shows the data for an absolute pressure of 0.001 bar. Although the point for notable dehydriding consistently decreases with pressure from $\sim 600^{\circ} \mathrm{C}$ at one bar to $\sim 450^{\circ} \mathrm{C}$ at 0.001 bar, the end point significantly moved toward the cooler region, from 
well over $1000^{\circ} \mathrm{C}$ to $\sim 800^{\circ} \mathrm{C}$. This indicates that a vacuum could sweep hydrogen from a reaction vessel and drive the dehydriding of zirconium hydride at temperatures as low as $450^{\circ} \mathrm{C}$ to $600^{\circ} \mathrm{C}$. The stronger the vacuum, the lower the temperature required for dehydriding and less exotic materials will need to be employed.

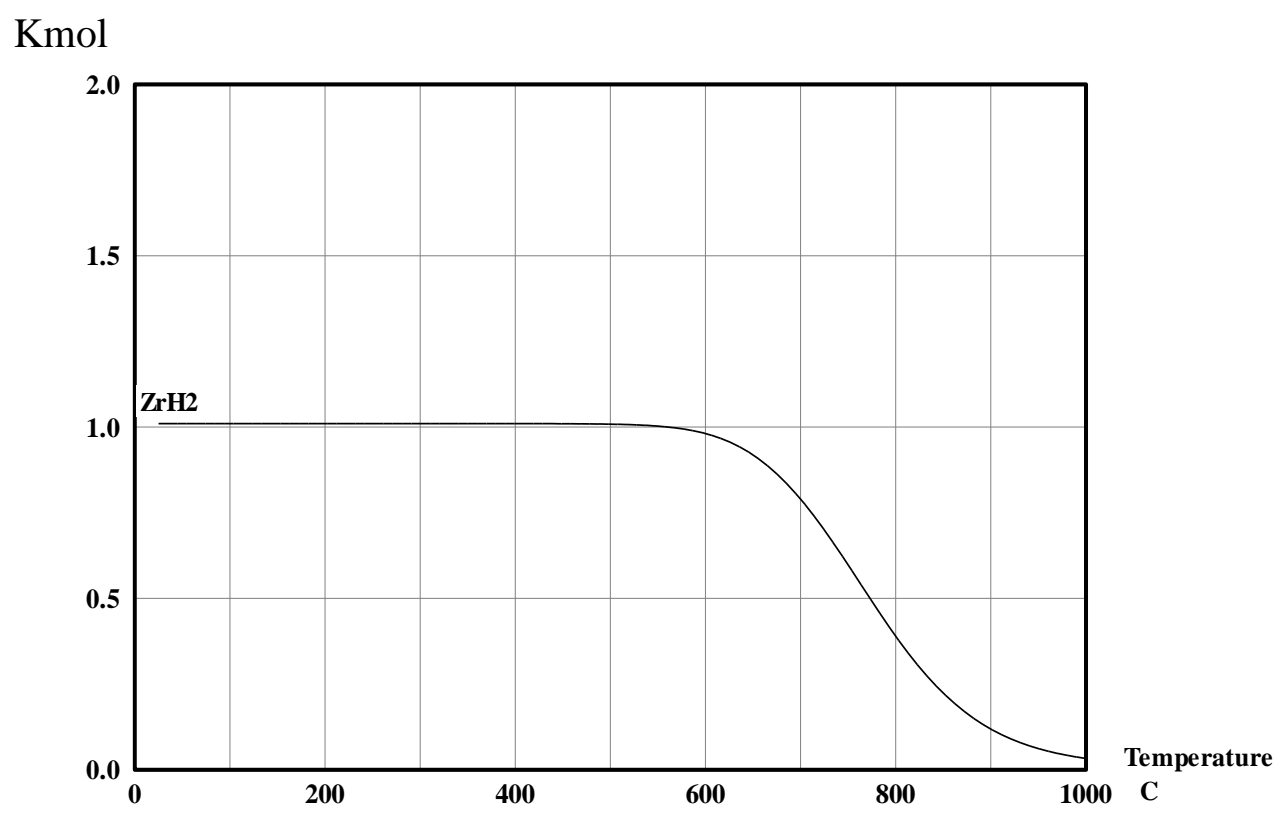

Figure 8: Equilibrium calculation for an absolute pressure of 0.1 bar. 


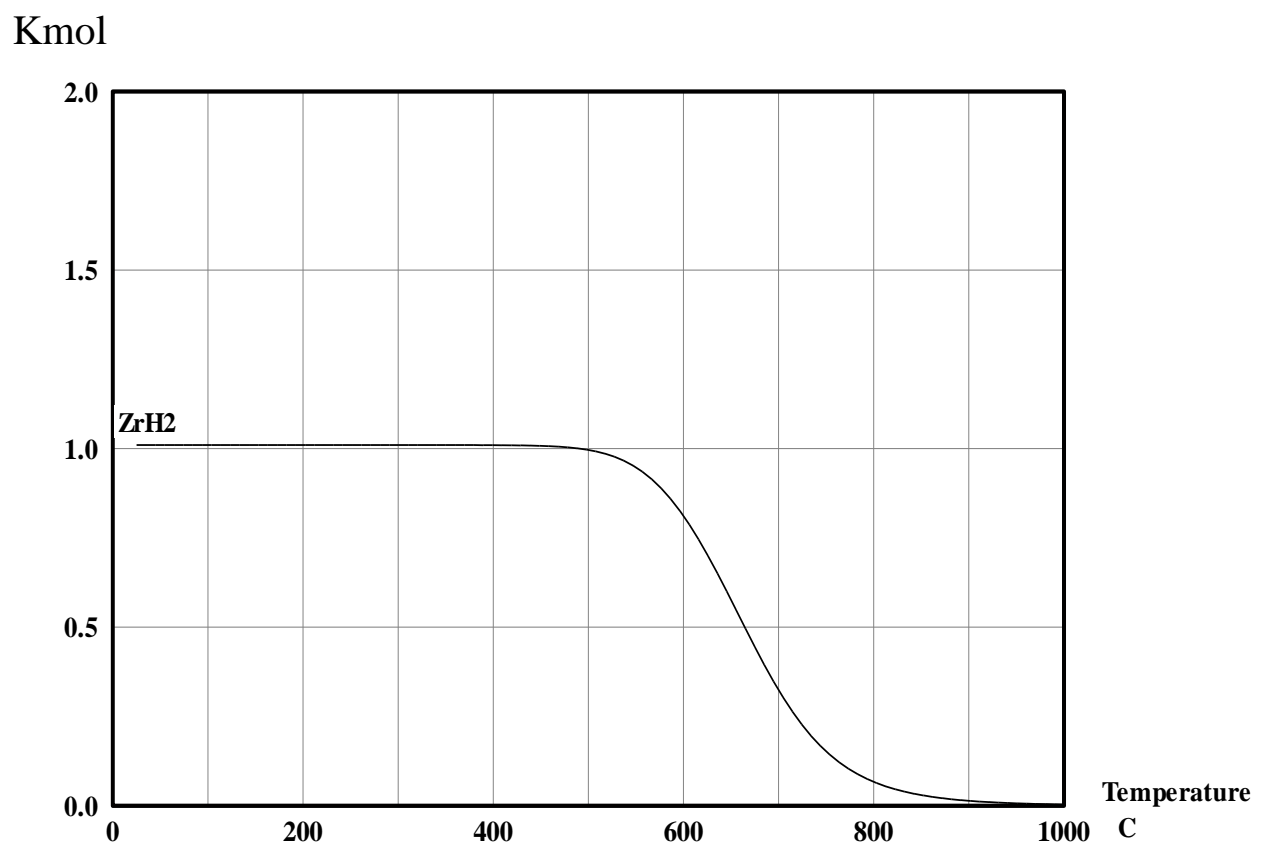

Figure 9: Equilibrium calculation for an absolute pressure of $0.01 \mathrm{bar}$.

Kmol

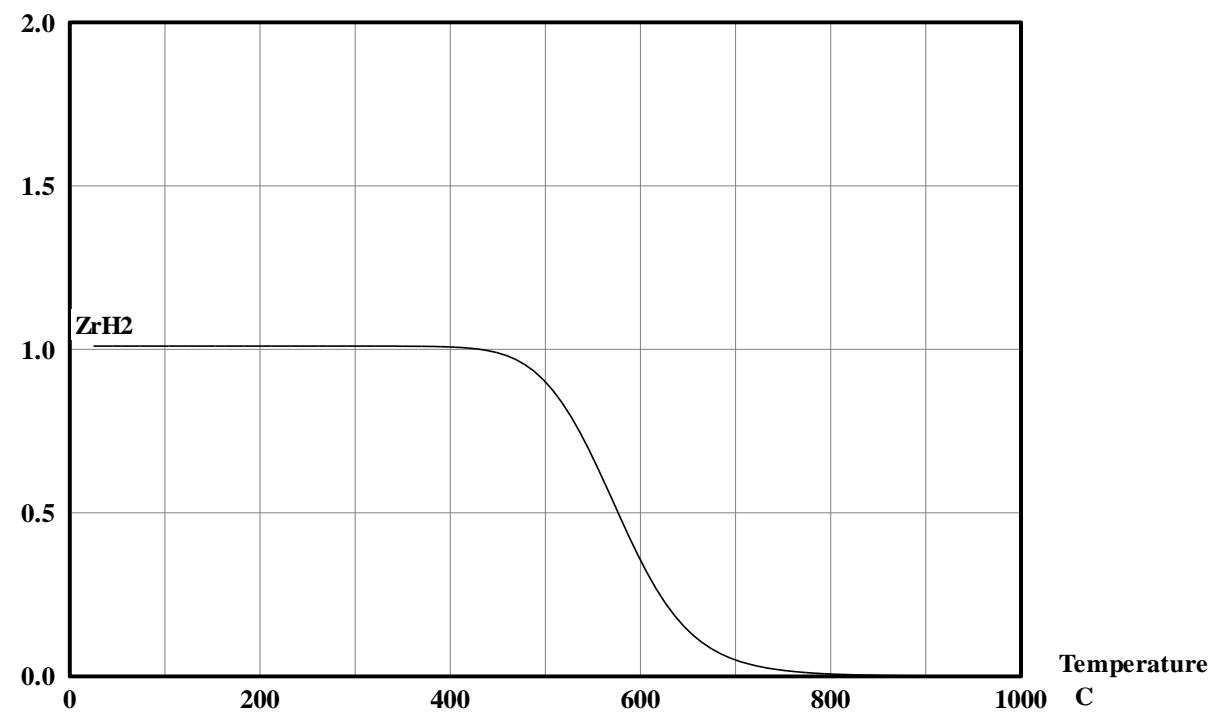

Figure 10: Equilibrium calculation for an absolute pressure of 0.001 bar. 


\subsection{MILLING METHODS}

This section reviews several common milling methods including hammer mills, stone mills, roller mills and ball mills. Ball mills use a set of larger, heavier milling balls to tumble around with the material to be ground and grind it to a fine powder. Figure 11 shows a graphical representation of a ball mill. Austin, et. al. studied breaking properties of various different materials, but most importantly, developed an analytical method of quantifying the breaking properties [42]. They later studied the kinetics of dry grinding and the presence of a "cushioning" effect as the particles become finer and finer [43]. A ball mill can become elaborate. Calka and Radlinski enhanced the impact of milling balls by controlling their paths with an external magnetic field [44].

Hammer mills pound the material into a powder by hitting it with a heavy object, i.e., hammering it. Applications range from huge hammering slabs of steel to grind gold bearing ore into a fine powder so that chemical extraction can separate the gold from the rock, to a small hammering device found in blacksmiths' shops to hammer hot iron into shape. 


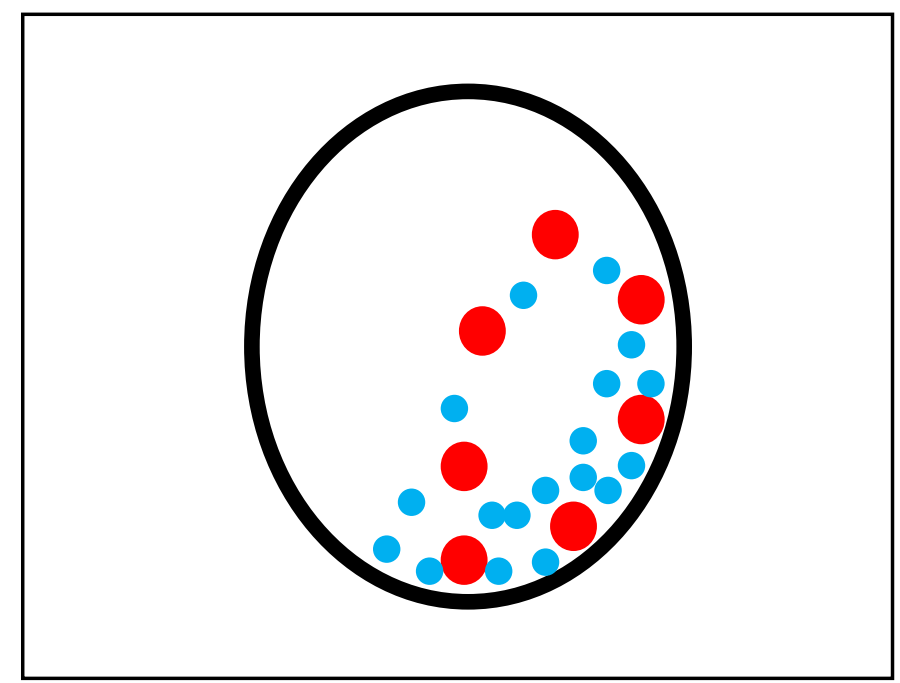

Figure 11: A graphical representation of a ball mill.

Figure 12 shows a depiction of a hammer mill. As the shaft spins, the harden steel plates rotate on a cam shaft and hammer the material against the sides of the mill, grinding it to a fine powder. These types of mills are very effective, albeit very heavy, large, expensive and loud. This brute force method of milling is not suitable for the application in this research due to the presence of high temperature ceramics that could not take the pounding from a hammering type device. Sudhagar, et. al. studied hammer mills and their effectiveness and efficiency on several types of agricultural material [45]. Although it was not their objective, they did show that hammer mills are very energy inefficient but very effective in their grinding ability. Austin created a simulation model of high speed hammer mills designed for fine grinding [46]. 


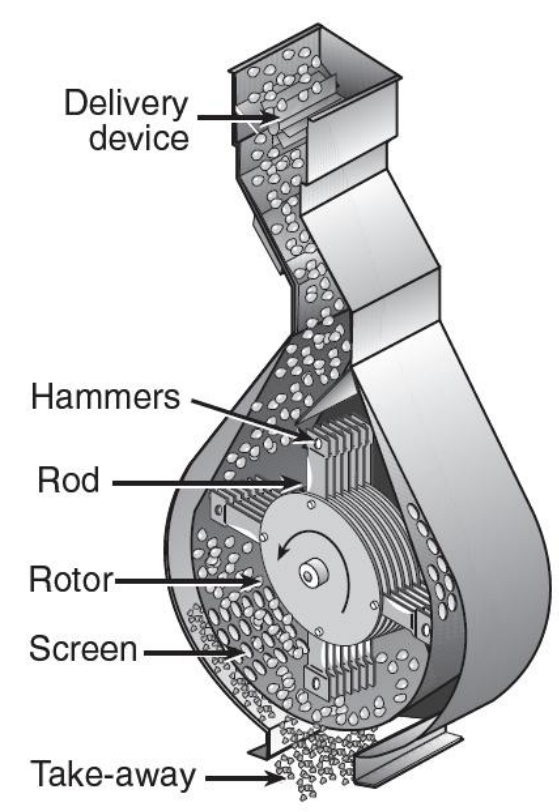

Figure 12: A representation of a hammer mill [47].

Stone mills are basically two round stones, one on top of the other; the bottom one stationary and the top one rotating. The design is such that the top rotating stone has a hole in the middle where the material to be ground is poured. As the material slides between the two stones toward the outer edge, it is ground to a fine powder. This type of mill has been used for centuries to ground material such as wheat and corn. The rotation was provided by such things as water wheels, windmills, animal power and even slaves. Bayram and Oner compared stone, disc and hammer mills for their effectiveness in grinder bulger (wheat variety) [48]. They concluded that stone mills were best suited for grinding bulger based on size distribution, surface texture and overall condition of the grinded bulger. Although this milling method is very effective, it is not applicable to grinding zirconium hydride in an "all in one" machine. 
Roller mills consist of a set of closely adjusted grooved cylinders in which the material falls between and is crushed. Figure 13 shows the inside mechanisms of a typical roller mill. These are very effective for such applications as grain mills. When corn is steam flaked for cattle feed, the kernel is steamed and then falls through a roller mill to make the flakes similar to the breakfast cereal, corn flakes. This makes a feed that tastes better and more nutrient rich for cattle. Schonert studied high compression roller mills and points out three advantages over other types of mills; they are more energy efficient than hammer mills, the wear and tear is less and they don't "over-grind" the material [49]. The energy efficiency advantage was challenged by Fang, et. al. [50]. Their research showed the energy needed to grind a specific amount of grain was about the same as that of a hammer mill. Again, a roller mill was not practical for this research.

The tumbler for this research project is patterned after the ball-mill type of milling operation. As the cylinders of zirconium become hydrided, they are tumbled in the ceramic (alumina) tumbler with zirconium oxide milling balls. Besides being extremely hard, zirconium oxide will not react with the material or decompose at the temperatures consistent with this experiment. In fact, zirconium oxide can be used in applications in which the temperature gets as high as $2400^{\circ} \mathrm{C}$ [51]. 


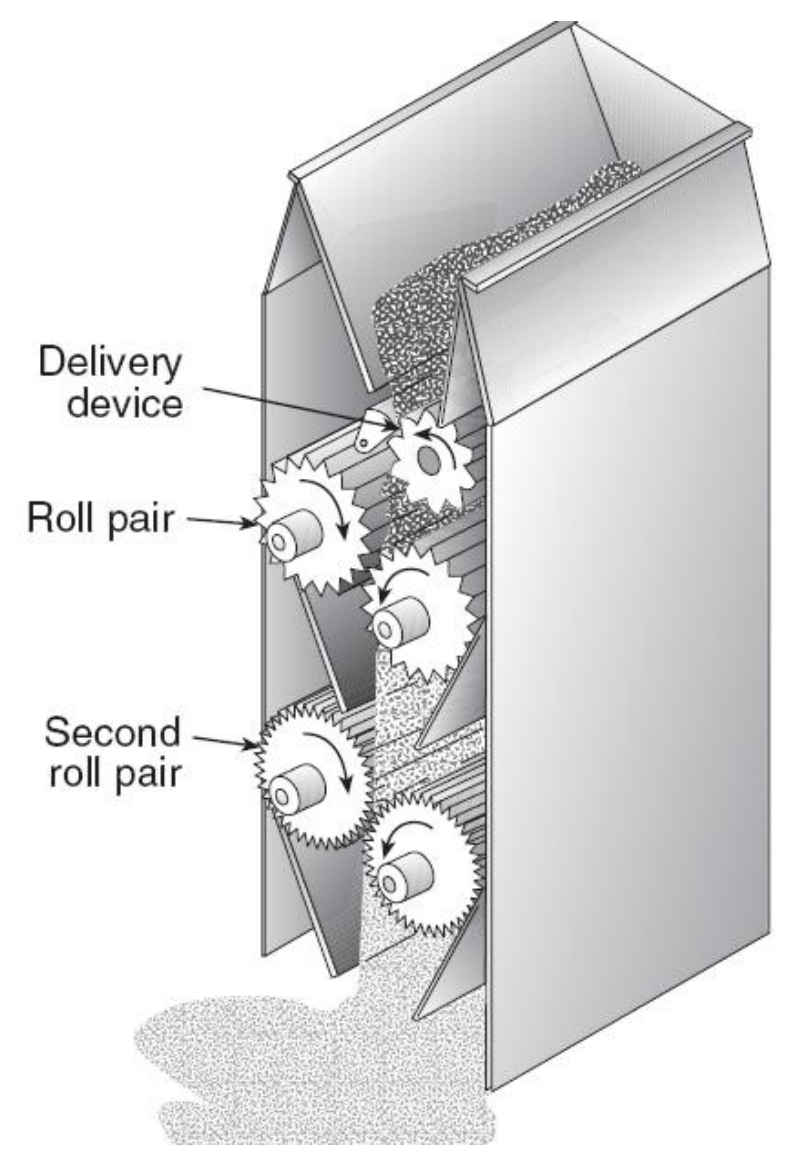

Figure 13: A roller mill showing the grooved cylinders to grind the material that falls between them [47]. 


\section{SYSTEM DESIGN REQUIREMENTS}

This section describes the engineering requirements established for the all-in-one hydride-milling-dehydride instrument. The section is divided into two sections outlining process requirements and functional requirements.

\subsection{PROCESS REQUIREMENTS}

1. The system must be capable of transforming Zircaloy metal pieces into metal powder.

This requirement is the basis for the research project. Being able to convert the spent fuel cladding hulls to a metal powder turns this waste stream into a product with an intrinsic value. The powder is necessary for the production of the cermet designed to encapsulate the transuranics removed from the spent fuel. With the transuranic elements in an oxide microspheres form, they can be combined with this powder in an extrusion press, forming a safe storage form or fuel rod, as previously mentioned.

2. The system must be able to achieve requirement $\# 1$ without intermediate material handling.

In order for the sample to go from Zircaloy tubes to zirconium metal powder, the atmosphere must be controlled to prevent contamination. During the elevated temperature stage associated with the hydride phase, the presence of air creates zirconium nitride and zirconium oxide instead of zirconium hydride. Zirconium nitride and zirconium oxide are very rigid and will not mill into a powder as readily as zirconium hydride. Therefore, extra care has to be taken in 
the creation and maintenance of the atmosphere surrounding the sample during all stages of this process. By eliminating intermediate handling, this hydride/milling/dehydride process can be controlled to eliminate possible contaminants. The optimal design would be one where Zircaloy tubes are inserted and zirconium metal powder emerges.

3. The system must be robust enough to withstand the milling procedure.

During the milling process, the tumbler will rotate with the sample and the milling balls tumbling inside. This creates small impacts that could start and propagate cracks on the inside of the tumbler. The ball mill design creates high impact stresses at the point where the milling ball comes in contact with the material and tumbler.

4. The system must be designed to allow safe removal of the final product, zirconium metal powder.

The zirconium metal powder is pyrophoric and therefore must be handled with care. The powder must be kept in an inert atmosphere. Therefore, the system must be designed to allow safe removal of the sample powder from the instrument in a small enough container to be placed in the access hatch of a glove box. Once in the glove box, the sample can be removed from the container and placed in vials for analysis.

5. The system must be designed to fall within the capabilities of the laboratory.

The laboratory electrical capacities have to be taken into consideration. The system was design for 220-volt, single phase (high voltage single phase). 
The existing laboratory breaker box had open breakers to accommodate this new service load. Also, the exhaust gas from the hydriding process was discharged from the laboratory with the help of an existing exhaust fume hood in the laboratory. Cooling of the hydraulic fluid was accomplished with an existing sink and water supply in the laboratory.

\subsection{FUNCTIONAL REQUIREMENTS}

1. The system must have a controlled inert atmosphere.

Extra care must be taken to prevent leaks of air into the inner chamber. As previously mentioned, exposing the Zircaloy tubes to nitrogen or oxygen at elevated temperatures creates zirconium nitride and zirconium oxide which makes milling into a powder impossible. Another reason to control this atmosphere is the danger associated with metal powders rapidly oxidizing to the extent of detonating. Murray, et. al, investigated the explosibility of metal powders and explored the power associated with metal and dust explosions [52].

2. The system must be capable of operating at temperatures approaching $1100^{\circ} \mathrm{C}$.

The design requirements will require the inner hydride/milling/dehydride chamber to withstand at least $1100^{\circ} \mathrm{C}\left(1000^{\circ} \mathrm{C}\right.$ plus a $10 \%$ margin $)$ and be robust enough at that high temperature not to shatter or crack. Aluminum oxide (Alumina $-\mathrm{Al}_{2} \mathrm{O}_{3}$ ) will meet these requirements rather well. Besides being robust, Alumina has a melting temperature of $2050^{\circ} \mathrm{C}$ [53]. This is twice the 
temperature required for the dehydride process. Alumina is also very robust for a ceramic, but still must be handled with care.

3. The system must be designed to mill the sample into a powder.

Zirconium hydride is extremely brittle and will fall apart under its own weight. Utilizing the ball mill design, zirconium oxide milling balls will be added to the tumbling chamber to aid in the milling of the powder. These milling balls are $1 / 4$ inch in diameter. The mechanism to rotate the tumbler has to operate in conditions of high heat and vacuum conditions. Since metals other than zirconium hydride, the selection of the materials used in the fabrication of the entire system has to be done carefully.

4. The system must be designed to pull a vacuum on the sample.

The requirement of vacuum conditions during the dehydriding phase presents extra challenges. All access ports, wire through feeds and other miscellaneous intrusions into the vacuum chamber must be air tight. Sealing becomes a challenge due to the high temperatures involved during the hydride and dehydride process. 


\section{SYSTEM DESIGN AND ASSEMBLY}

This section describes the initial design of the hydride-milling-dehydride (HMD) system. This original setup provided valuable insight into the operations of key components of the HMD system (e.g., the Oxygen getter, the tumbler control system, and the heating design) but it ultimately failed because of system leaked and there were geometry issues that prevented the Zircaloy charge from being heated to process temperatures. However, the HMD system was modified throughout the development experiments. The evolution of the system will be discussed in the next section along with the experimental results; in the end, a successful HMD system was developed and demonstrated. Most of the modifications were developed to overcome issues encountered during a specific experiment. Therefore, this section describes the starting point for the system and Section 5 describes the process of developing the final successful system. The final system design is the principal result of this research.

In this section, Section 4.1 describes the design of the primary system components, which include a description of the specialty gas supply system, the control equipment and the main process chamber. Sections 4.2 to 4.4 describe the hydraulic, pneumatic and electrical systems respectively, which were designed for the HMD machine.

\subsection{DESIGN OF PRIMARY SYSTEM COMPONENTS}

The initial design was based on the design requirements in Section 3, which included the capability of dehydriding zirconium hydride at temperatures up to 
$1000^{\circ} \mathrm{C}$. Therefore, the design and selection of materials for the machine had to take this high temperature into account.

The basic design concept utilizes a rotating, internally heated ball mill chamber where Zircaloy pieces may be hydrided, milled to produce zirconium hydride powder and then dehydrided under a vacuum at an elevated temperature. The HMD machine can be divided into three basic components; 1) the specialty gas system, 2) the control equipment, and 3) the vacuum chambers (and the associated process equipment within this chamber) (see Figure 14).

The specialty gas supply system is comprised of two gas cylinders, a titanium sponge nitrogen getter, a vacuum pump and the requisite tubes, valves and gauges to assemble the system as outlined schematically in Figure 14. The first gas cylinder contains high purity argon and the second cylinder contains a mixture of $95 \%$ argon and $5 \%$ hydrogen. The argon is used to purge the vessel at the startup of operations using an evacuation/argon backfill process. This is done several times to minimize oxygen and nitrogen levels within the chamber. 


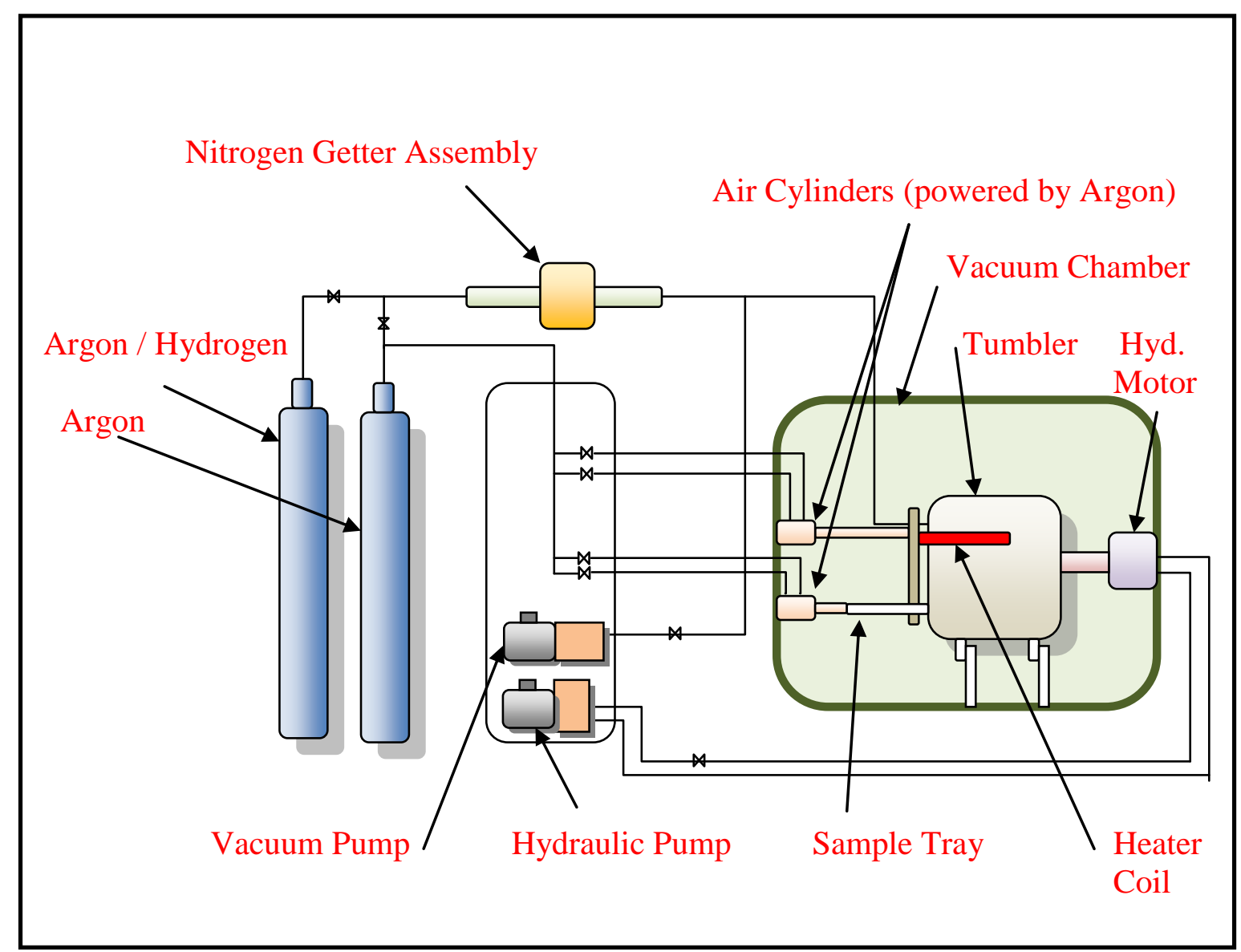

Figure 14: Overall system design.

In the previous research by Parkison [19], it was noted that commercial argon tanks contain enough nitrogen to prevent the hydride formation reaction from progressing. Therefore, a nitrogen getter was included in the gas delivery system. The getter consisted of an alumina tube with a six inch section packed with a titanium sponge. This section was inserted into a WATLOW ohmic heater to heat the titanium to $1050^{\circ} \mathrm{C}$ to $1100^{\circ} \mathrm{C}$ to remove nitrogen from the process gas. Figure 15 shows a photo of the 
nitrogen "getter" with a protective expanded metal cover, insulation and warning sign. The power supply used to control the WATLOW heater is shown on the right.

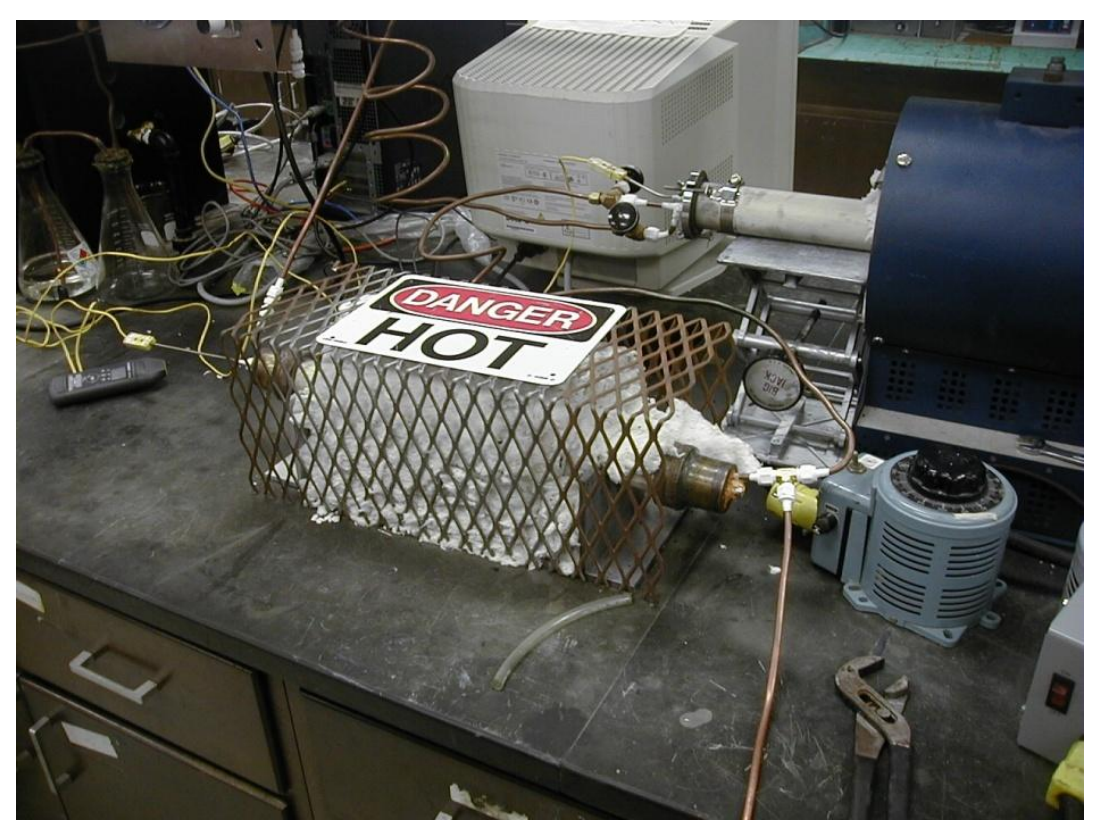

Figure 15: A nitrogen getter assembly to remove nitrogen from the process gas.

A control rack was designed and built that housed the hydraulic power supply, the vacuum pump, the heater controller, the motor starters with an accompaniment of electrical components, hydraulic controls, hoses and the pneumatic system. The controllers for the pneumatic cylinders and a control valve for the hydraulic motor were mounted on the front side to the right of the panel (see Figure 16) 


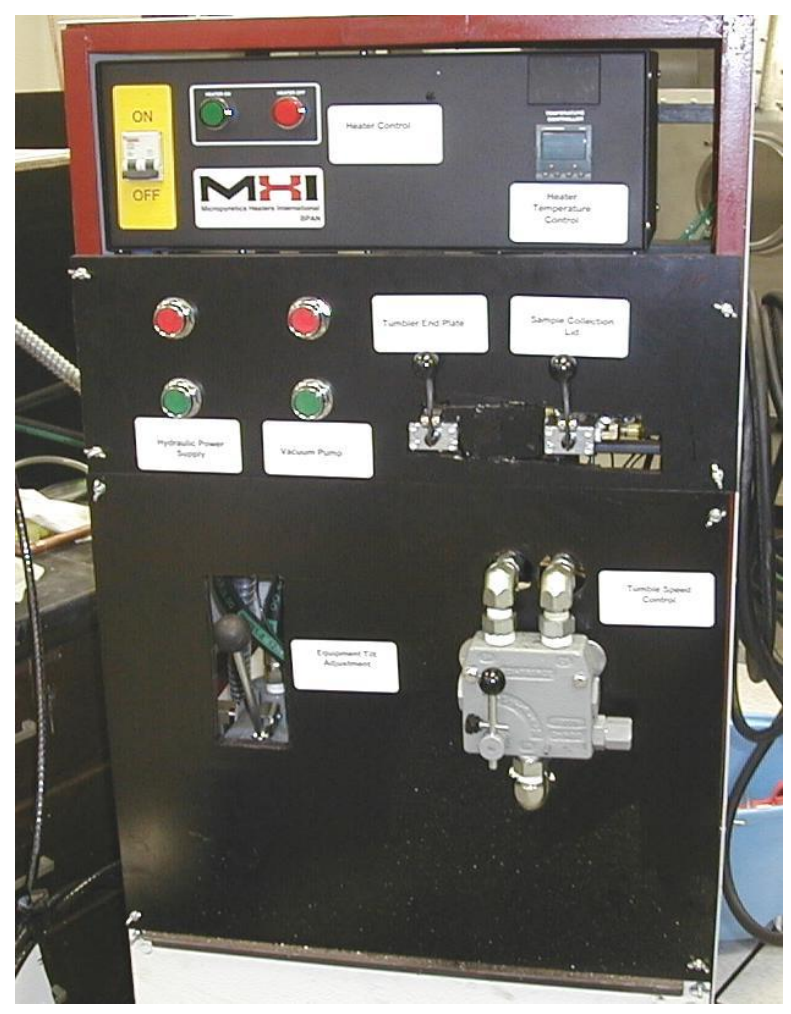

Figure 16: Photograph of the front panel of the control rack.

The back side of the control panel is shown in Figure 17 and Figure 18. Figure 17 shows the hydraulic power supply (foreground) and the vacuum pump. The hydraulic power supply was later moved to the top of the control panel to prevent hydraulic oil from leaking back to the reservoir. Figure 18 shows the physical location of the electrical wiring, motor starters, electronic controls, pneumatic hoses and hydraulic hoses that power the equipment. A more detailed description of each component in the control rack is provided in Sections 4.2 through 4.4 . 


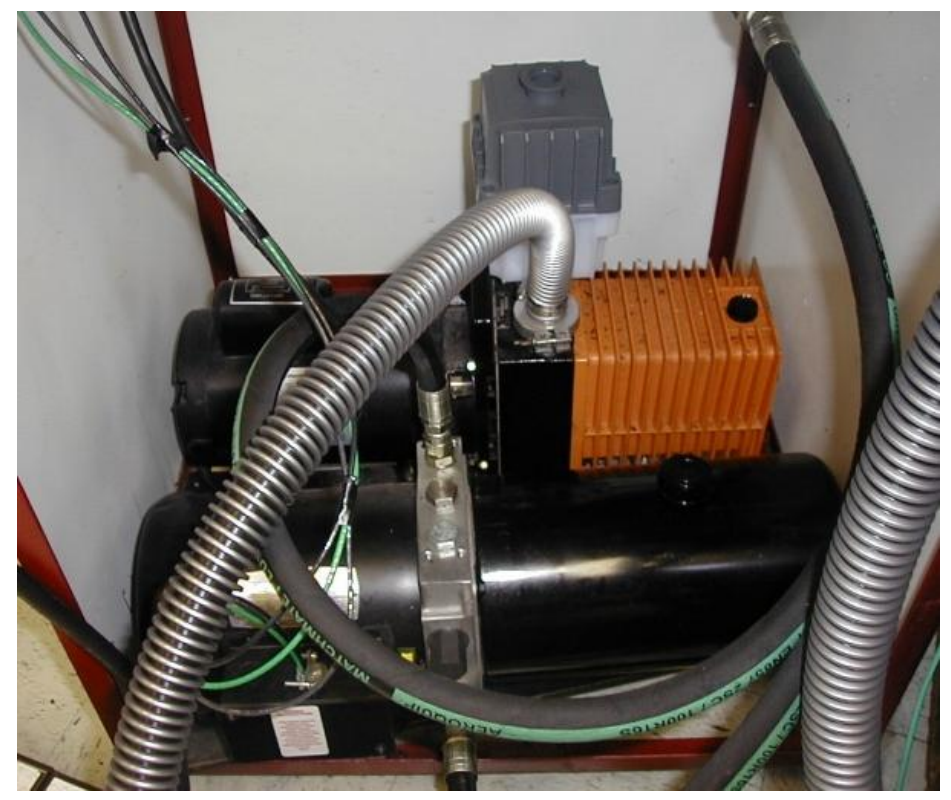

Figure 17: The backside of the control panel.

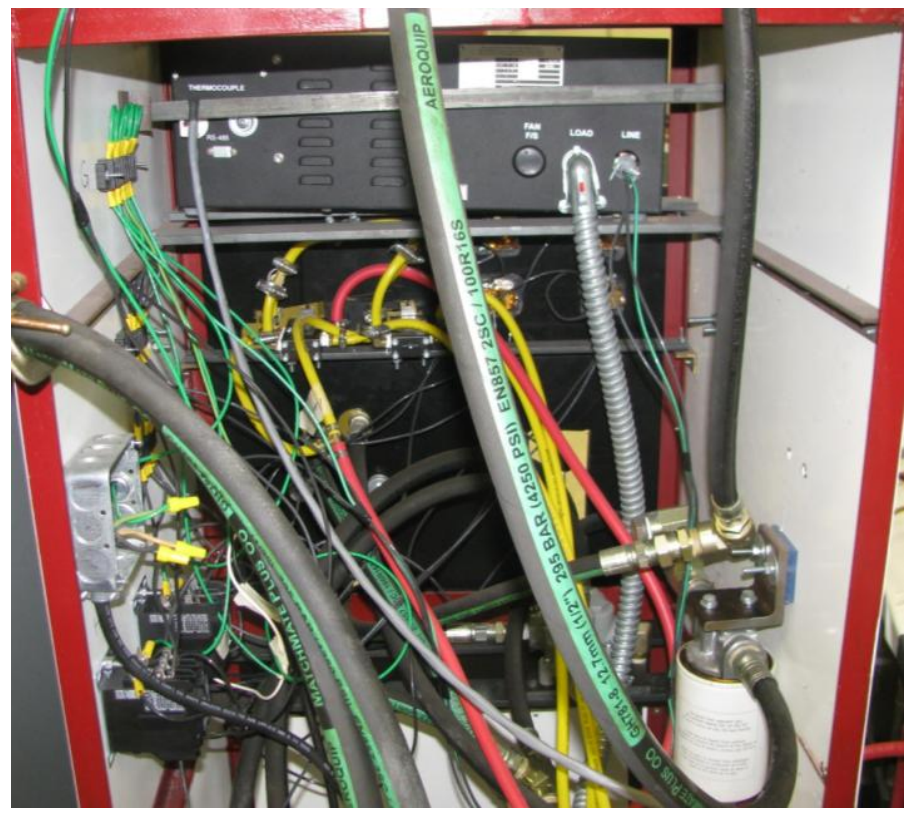

Figure 18: The backside of the control panel showing the electronics, hydraulics and pneumatics. 
The main section of this experimental apparatus is the vacuum chamber. Within this chamber lie the tumbler assembly (with the end plate assembly), hydraulic motor, sample collection system and the tumbler roller cradle system. Two main access ports allowed assembly, loading and unloading of the samples. Within this chamber, the atmosphere necessary for efficient hydriding and dehydriding can be maintained.

Since the intent was to incorporate the ball mill design to mill the zirconium hydride, the tumbling chamber was the center piece of the design. The initial design of the tumbler is shown in Figure 19. The intent was to bevel the inside edges to channel the powder back to the center of the chamber, preventing the power from spilling out of the end. Three tumbling bars were included to prevent the sample from simply sliding around the inside bottom of the chamber.

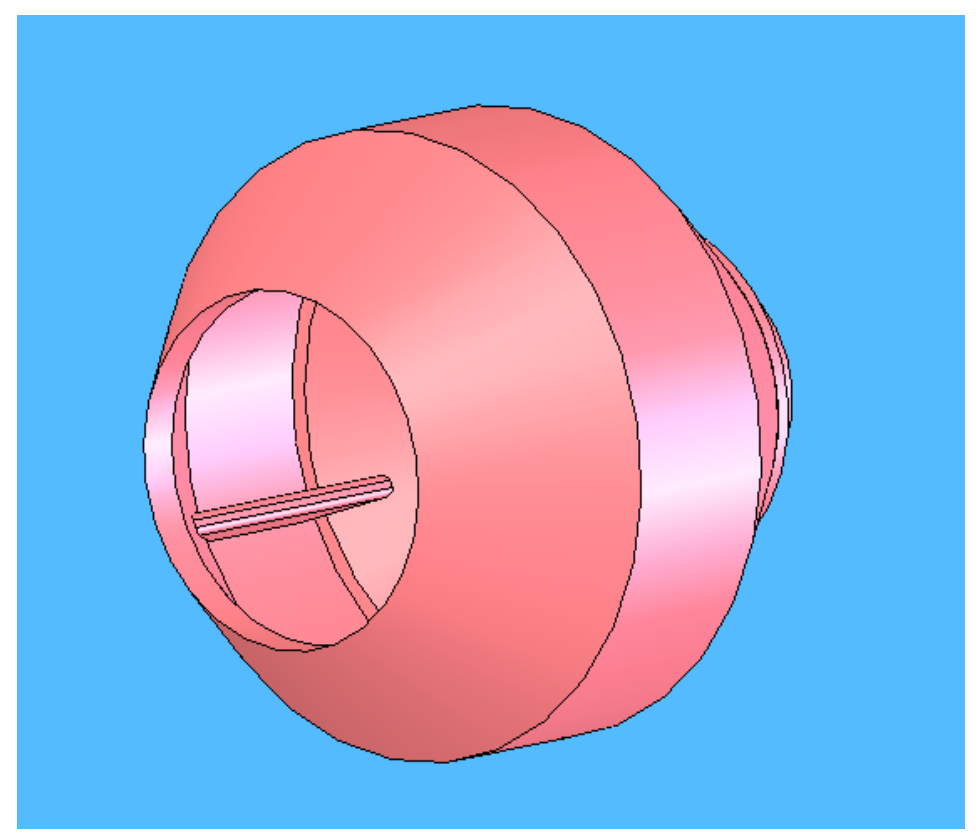

Figure 19: Preliminary design of the tumbler for zirconium powder formation. 
The open end was designed to accommodate a heater coil assembly comprising the heater coil, a sparge tube, sample tray, K-type thermocouple and end plate. This subassembly is shown in Figure 20. The sparge tube was originally designed to evenly distribute the incoming gas flow as well as protect the heater coil from shards of tumbling zirconium hydride. The sample collection plate was intended to slide into the chamber only during sample extraction. Figure 21 shows a model of a partial assembly of the tumbler, end plate assembly and a hydraulic motor (with the motor mounting weldment). The hydraulic motor was selected to turn the tumbler inside the sealed chamber. With this design, only hydraulic fluid would penetrate the vacuum chamber through sealed welded fittings.

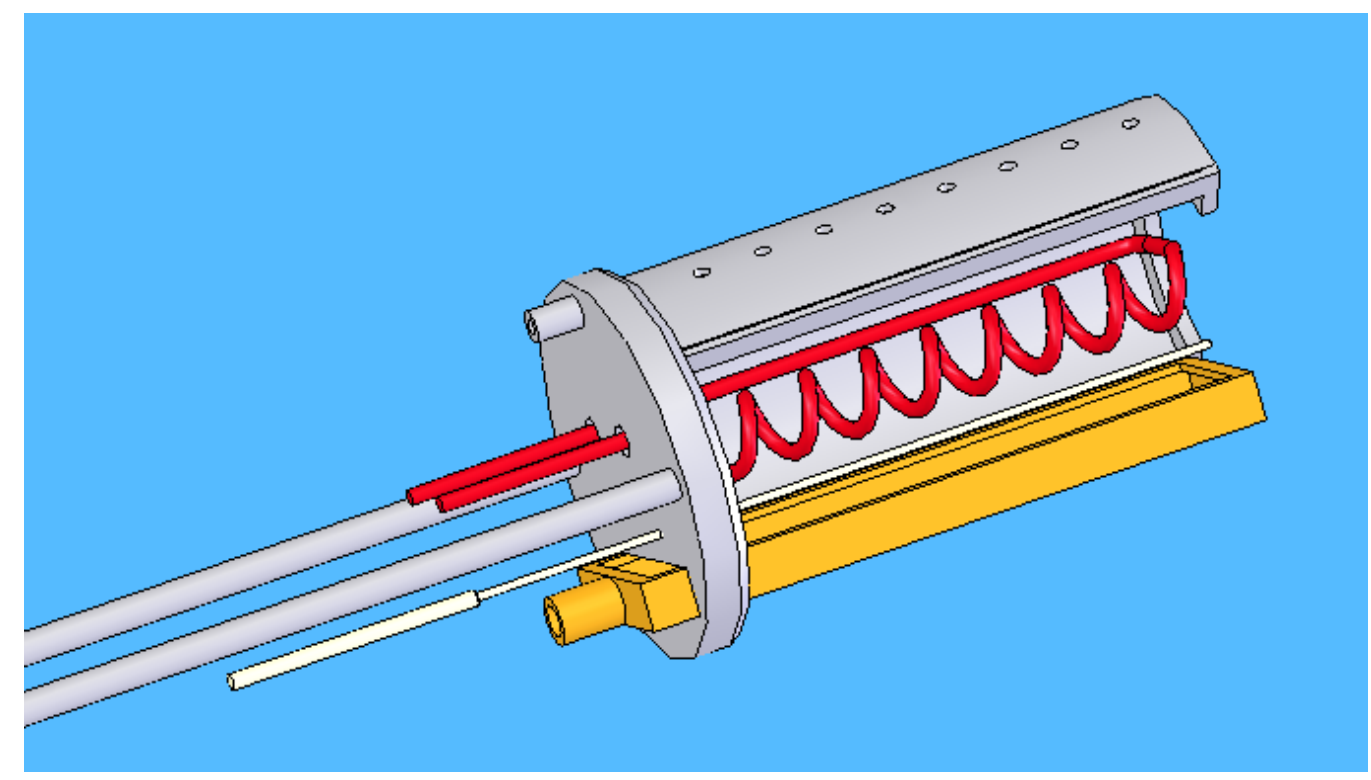

Figure 20: The moveable end cap showing the sparge tube, heating element, thermocouple and unloading tray. 


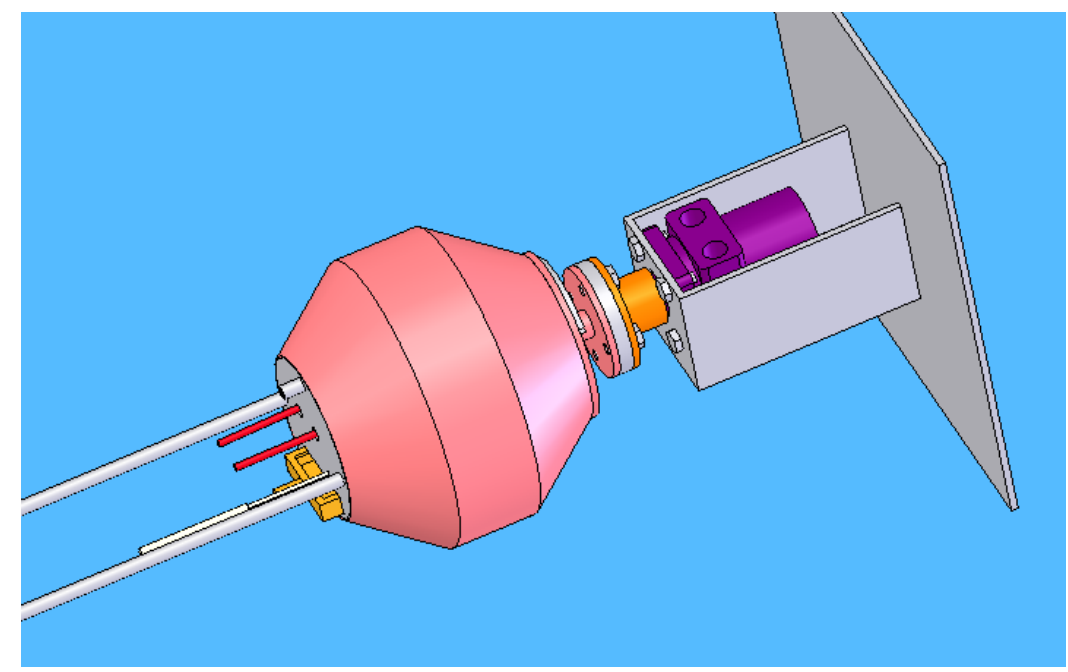

Figure 21: Partial assembly showing the hydraulic motor, couplings and end cap.

Due to the high processing temperature during dehydriding, it was decided that the tumbler should be manufactured from a ceramic and specifically alumina (aluminum oxide). Manufacturing a tumbler out of alumina in the shape from the initial design in Figure 19 proved to be very difficult and extremely expensive. With the evolution to a design that could be manufactured, the sample tray and in situ removal was eliminated from the original design A simpler tumbler was designed (Figure 22) where the sample would simply pour out of the end once the endplate moved away. This would be accomplished by enabling the entire vessel to tilt to pour out the sample into a cup. The entire vessel will be slightly tilted away from the endplate during hydriding, milling and dehydriding to keep the sample in the tumbling chamber. Once the sample poured into the cup, a pneumatic cylinder (powered by compressed argon) would close the lid on the cup. Figure 23 shows this lid system in both the open and closed configuration. The arrow points to the lid in both pictures. 

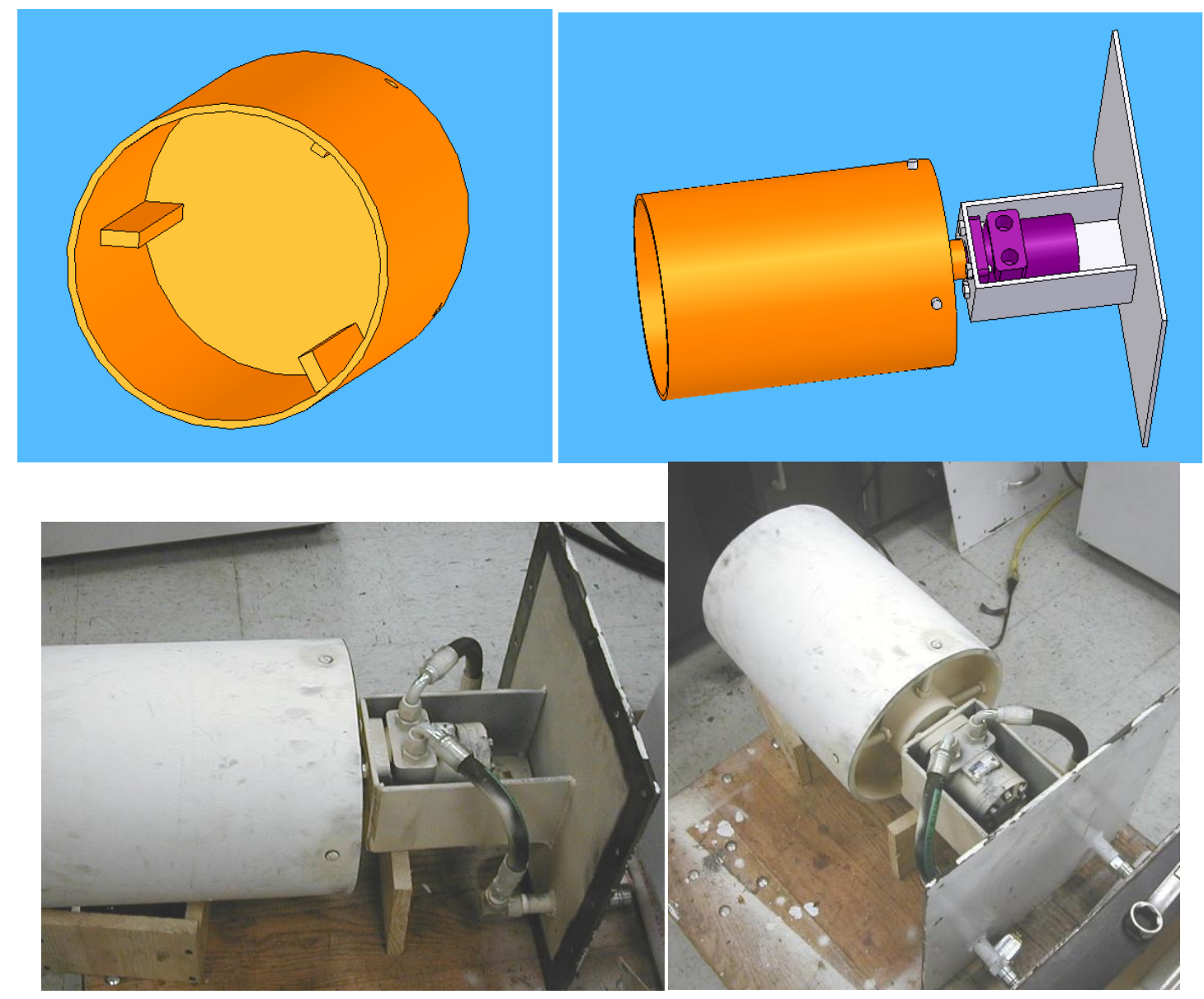

Figure 22: The revised tumbler design with the simpler sample collection technique.

This "pouring" of the sample required the entire chamber to tilt back and forth. An attempt was made to calculate the weight of the entire system and position the rotation axis where the least amount of force would be needed to rotate the system downward so the sample could pour from the tumbler into the cup. A contingency plan was to install a hydraulic cylinder powered by the same hydraulic power supply that operated the tumbler motor. This cylinder would be placed where it would lift the end 
where the hydraulic motor was situated to pour the sample into the cup. The control lever for this cylinder is positioned on the left side of the control panel (Figure 16).

Figure 24 shows the main assembly with the rocker support structure. As the assembly took shape, the weight calculation was accurate enough that the hydraulic cylinder was not needed. The entire system was balanced within a few pounds and could easily be tilted manually.

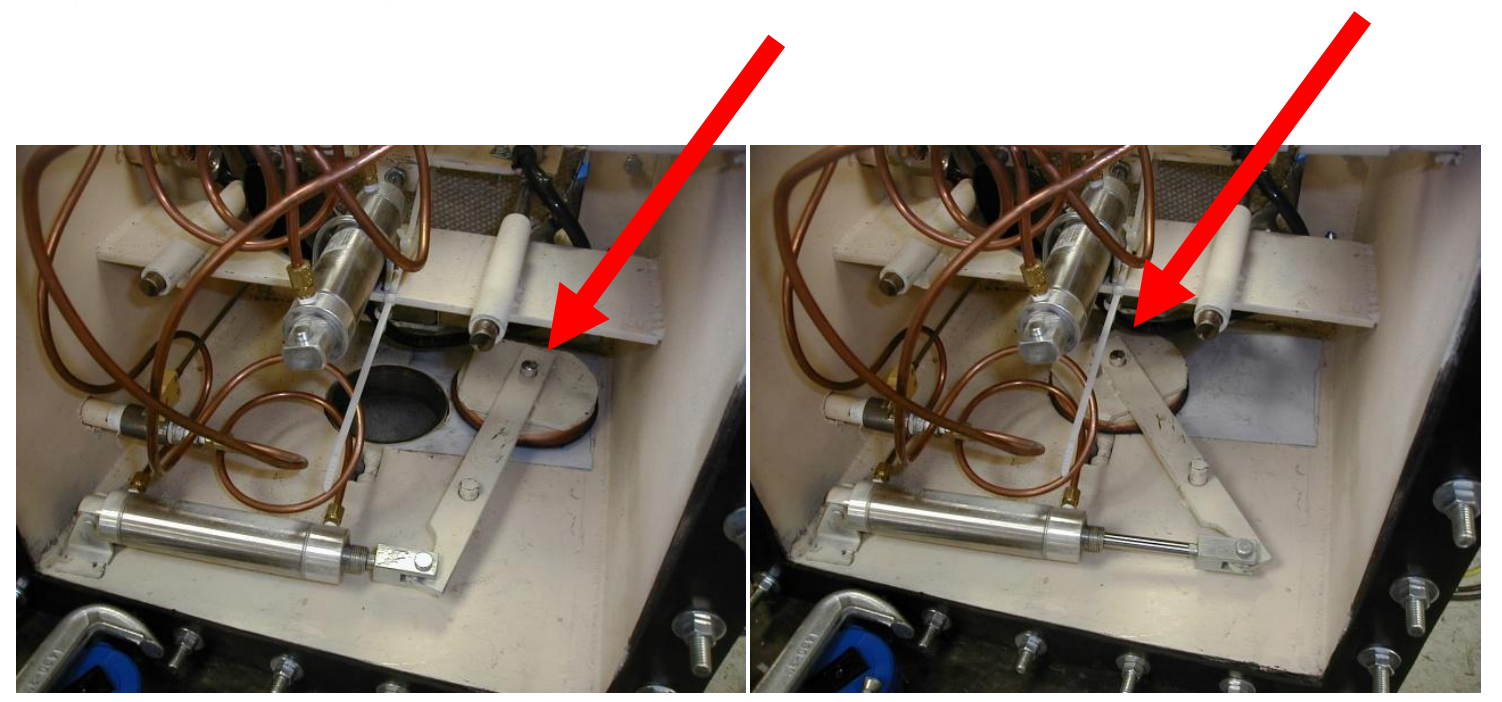

Figure 23: Sample collection cup and the system designed to apply the lid. 

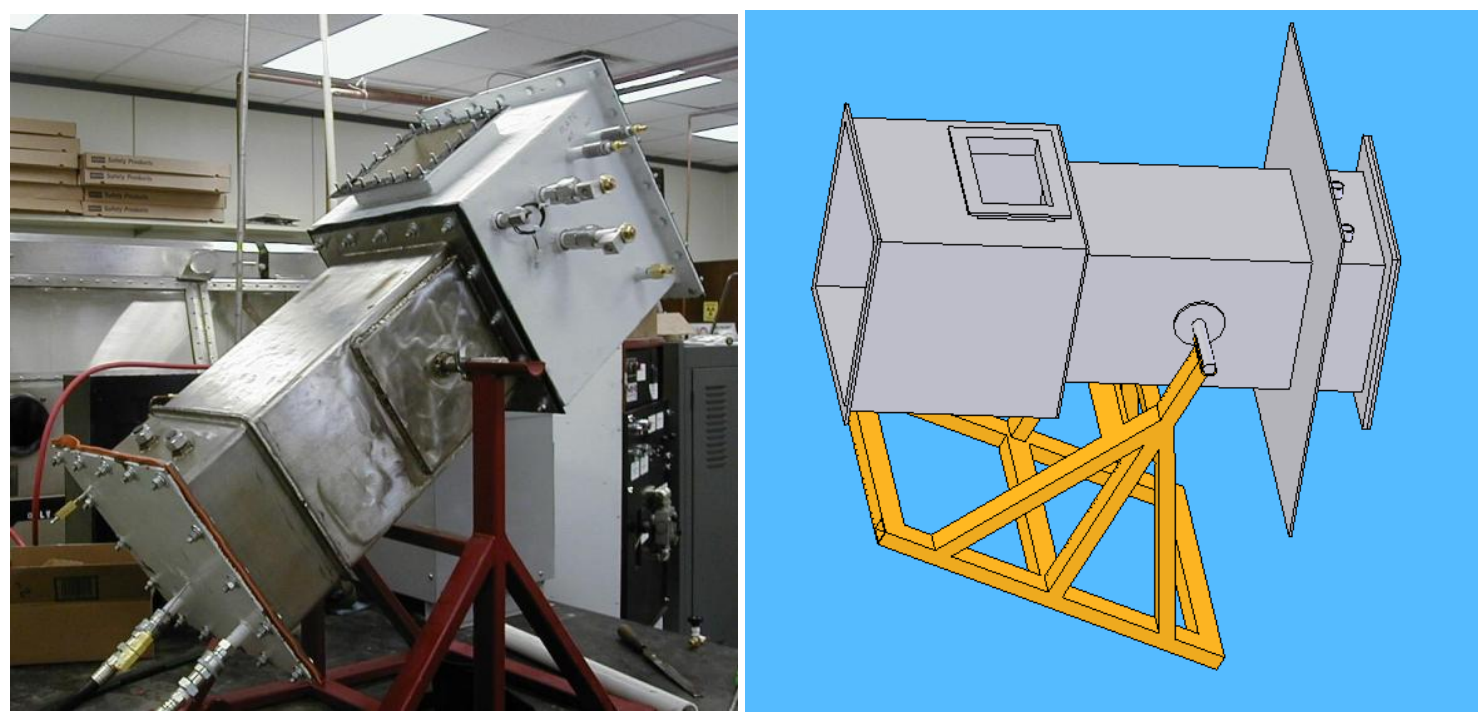

Figure 24: Main assembly with the rocker support system.

During assembly, as the tumbler slid into the main part of the chamber, it became apparent the ceramic tumbler was manufactured $3 / 8$ " too large on the diameter. Although there was a little leeway in the design, this manufacturing error consumed all the extra room. The tumbler cradle rollers were designed to be adjustable to the size to which the tumbler was actually built, but this manufacturing error required all the adjustment available from these wheel assemblies. Figure 25 shows the wheel assembly along with the Solid Works model from the original design. The original design called for one of these wheel assemblies to be mounted in each of the four corners of the tumbler housing. By bolting the wheel housing to the welded in place wheel block, the location of the wheel on the radius could be adjusted simply by adding washers under the wheel plate. The original design had 3/8" to $1 / 2$ " of difference between the OD of the tumbler and the inside distance from wheel to wheel on opposite corners of the tumbler housing. 

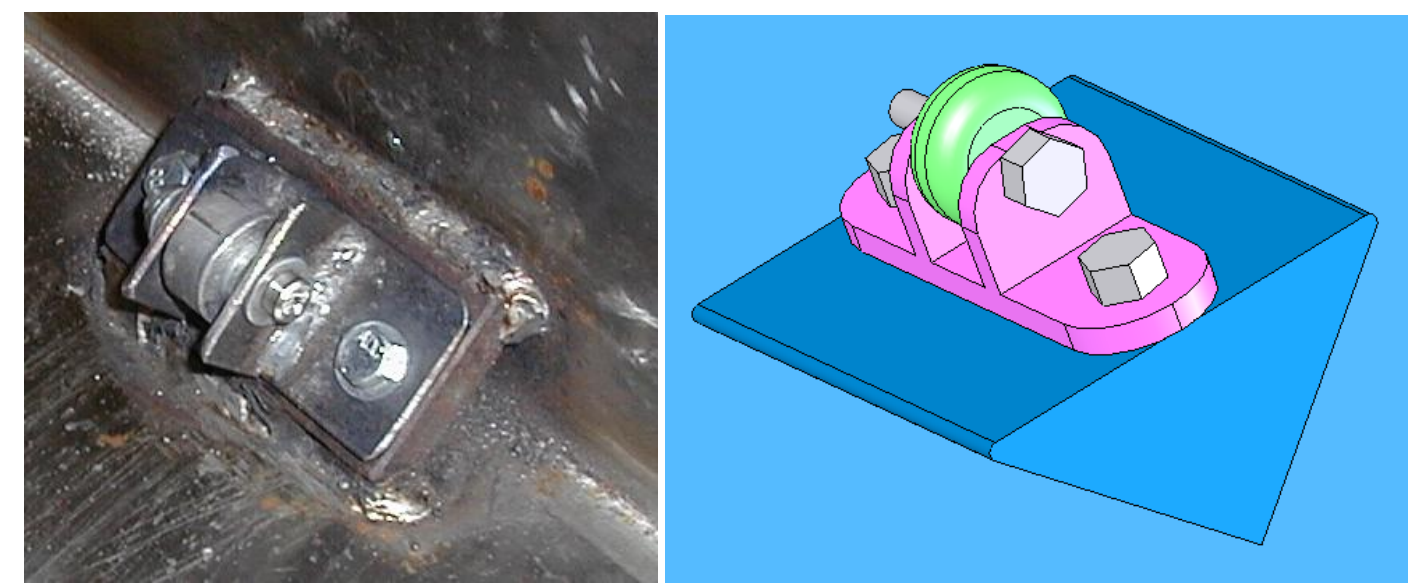

\section{Figure 25: Wheel assembly installed in the inside edge of the vessel along with its Solid Works model.}

The endplate that capped the tumbler consisted of two materials; Inconel metal and a ceramic insulating plate. These two materials were held together with a ceramic paste rated for high temperature service (but it turned out to be a major source of contamination, as described in Section 5). The endplate also held the heating element, thermocouple and gas feed tube. Figure 26 shows the original endplate design for the first experiment and as well as the revised model assembled after the original heater elements were broken. This configuration used a B-type thermocouple in an alumina tube shield to protect the thermocouple from the hydriding process. The sparge tube proved to be both too difficult to manufacture and not necessary for the operation of the equipment and therefore, was omitted from subsequent designs. 

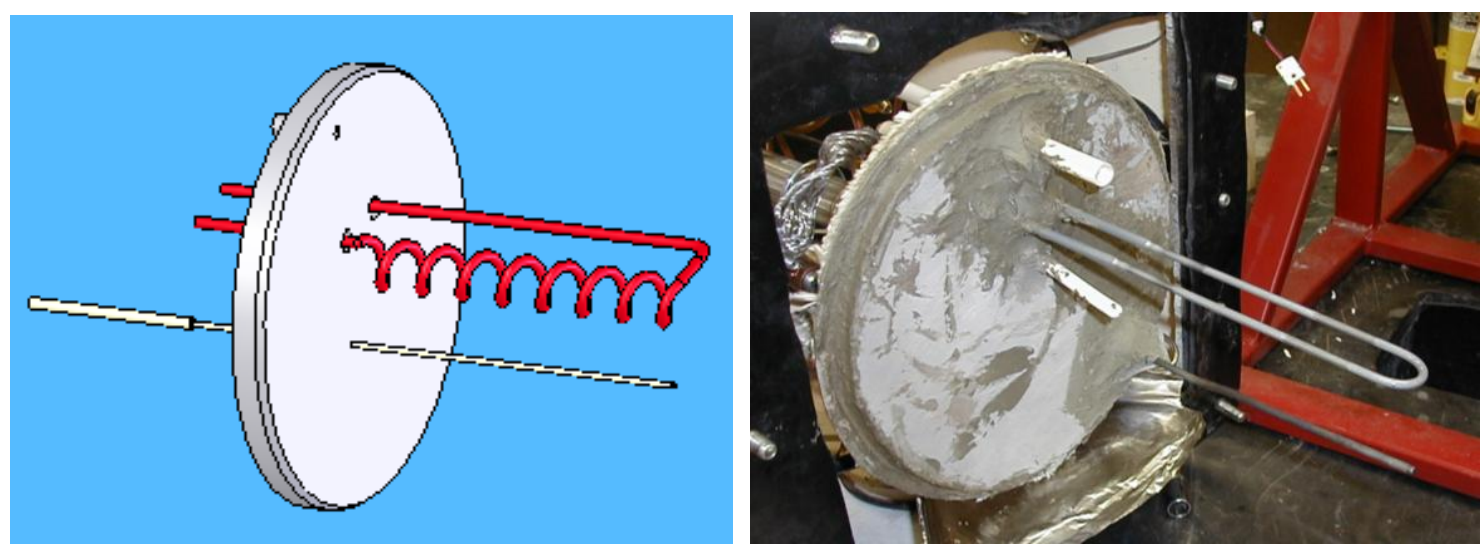

\section{Figure 26: The end plate showing the heating element, thermocouple (and shield) and gas feed tube.}

The end plate was configured to maintain the high temperatures inside the tumbler but the "pouring" of the sample required the partial removal of the end plate. Therefore, this plate was designed to slide in and out with a pneumatic cylinder powered by compressed argon gas, as previously stated. Figure 27 shows the two slides and the pneumatic cylinder system. The first picture shows the top view with the end plate to the left. The second picture is the end view looking at the back side of the endplate. The pneumatic cylinder, both slides and the copper tubing are clearly visible in this view. A U-bolt secures the pneumatic cylinder to the cross brace, locking it in place. 

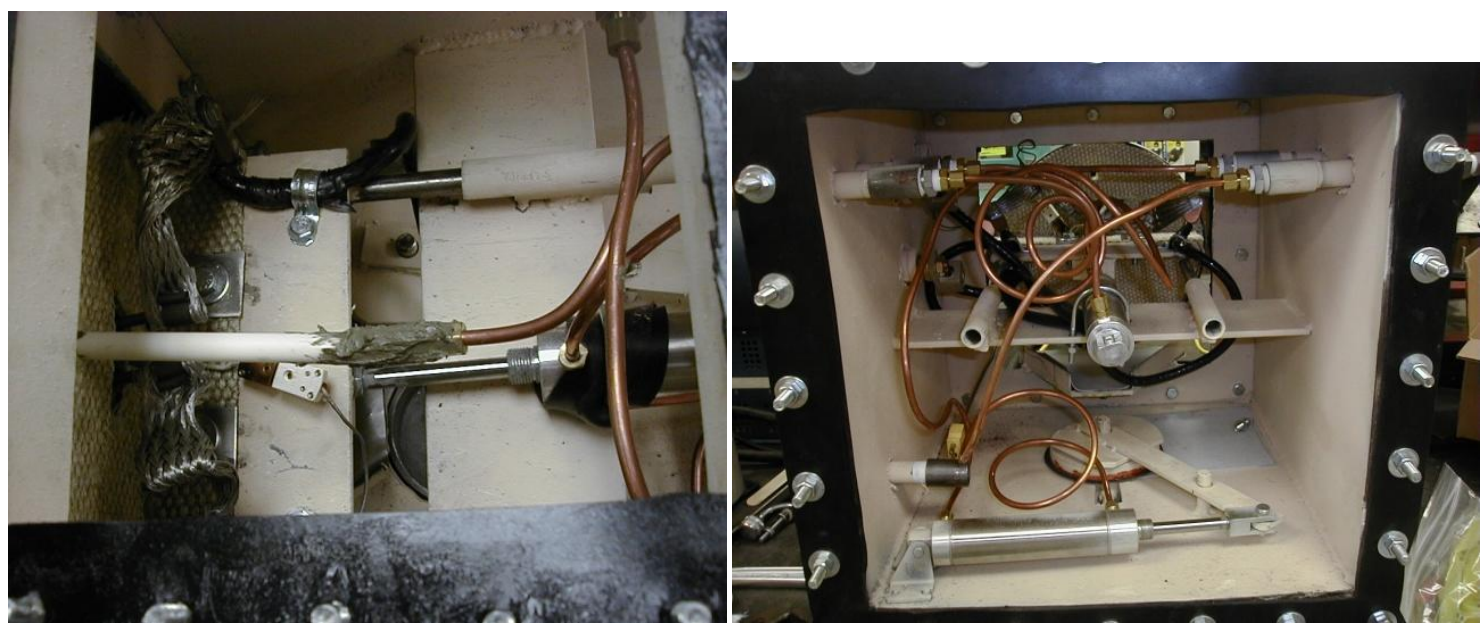

Figure 27: The pneumatic cylinder and the two slides shown from the top and end views.

\subsection{HYDRAULIC SYSTEM}

Appendix A shows the schematic diagram of the entire hydraulic system. The main purpose of the hydraulic system was to turn the tumbler. This was accomplished by a 1/3 horsepower hydraulic motor (CHAR-LYNN model 101-1009) attached to the tumbler by a hub and "spoke" network (See Figure 21). The fluid power was supplied by a hydraulic power supply (HALDEX BARNES model 1280553) consisting of a gear pump and an electric motor (Figure 28). This pump was capable of producing a 3000 psi flow. The flow initiated in the power supply travels through a control valve equipped with an overflow to protect the power supply (Figure 29). This valve controls the flow to the hydraulic motor and thus the speed. 


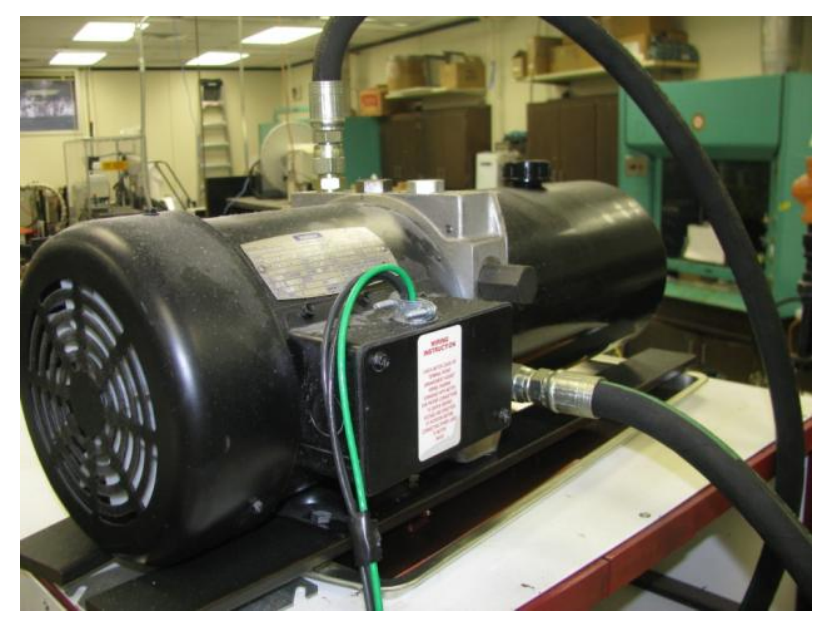

Figure 28: The hydraulic power supply which consists of a gear pump and an electric motor.

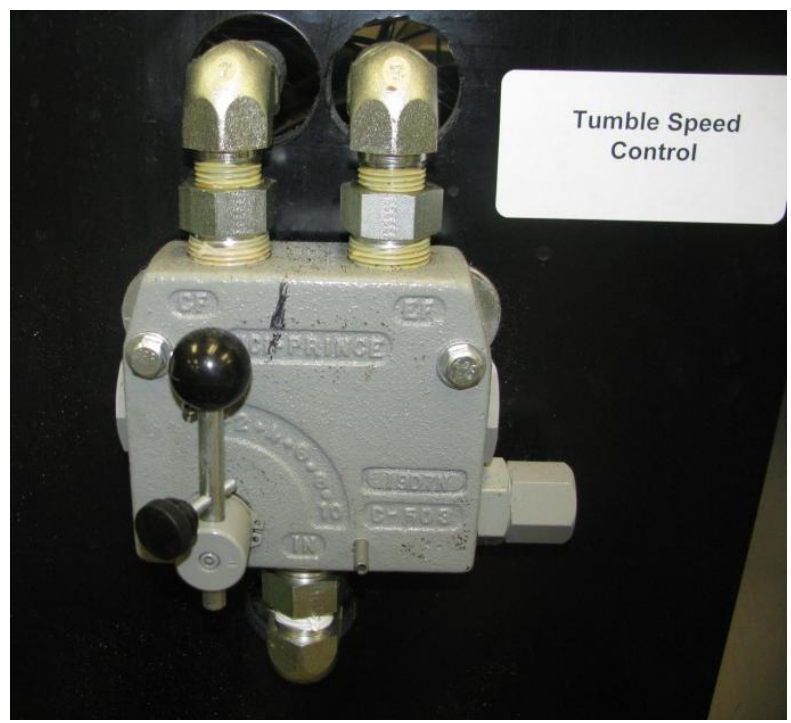

Figure 29: Tumbler speed control valve attached to the front of the control panel.

Exiting the control valve, the hydraulic fluid traveled through a set of quick disconnects and through two steel couplings welded to the access hatch housing the 
hydraulic motor. Figure 30 shows both quick disconnects (entering and exiting flow lines) as they were attached to the access hatch.

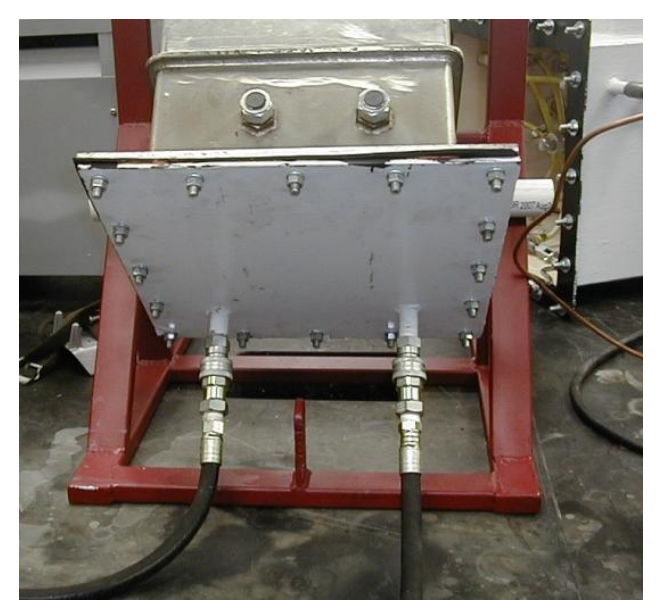

Figure 30: Hydraulic lines attached via quick disconnects to the seal welded couplings.

Once inside the vessel, the hydraulic lines fed the motor as seen in Figure 31. These lines were braided steel hoses with a nylon coating, with a pressure limit of 5000 psi. The nylon coating necessitated the insulation of the hoses and the motor. Figure 32 shows the insulation on these components.

Upon leaving the hydraulic motor under operating conditions, the hydraulic fluid may remove heat from the motor and, therefore, would need to be cooled. This was accomplished by flowing the fluid through a copper heat exchanger mounted in a sink. The sink was filled with water above the top line of the heat exchanger (see Figure 33). 


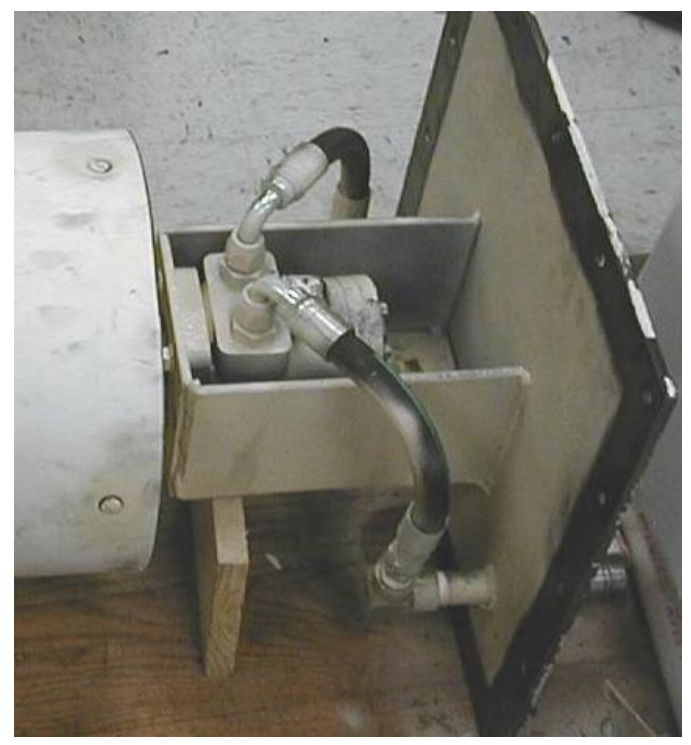

Figure 31: Hydraulic lines enter the access plate and connect to the hydraulic motor.

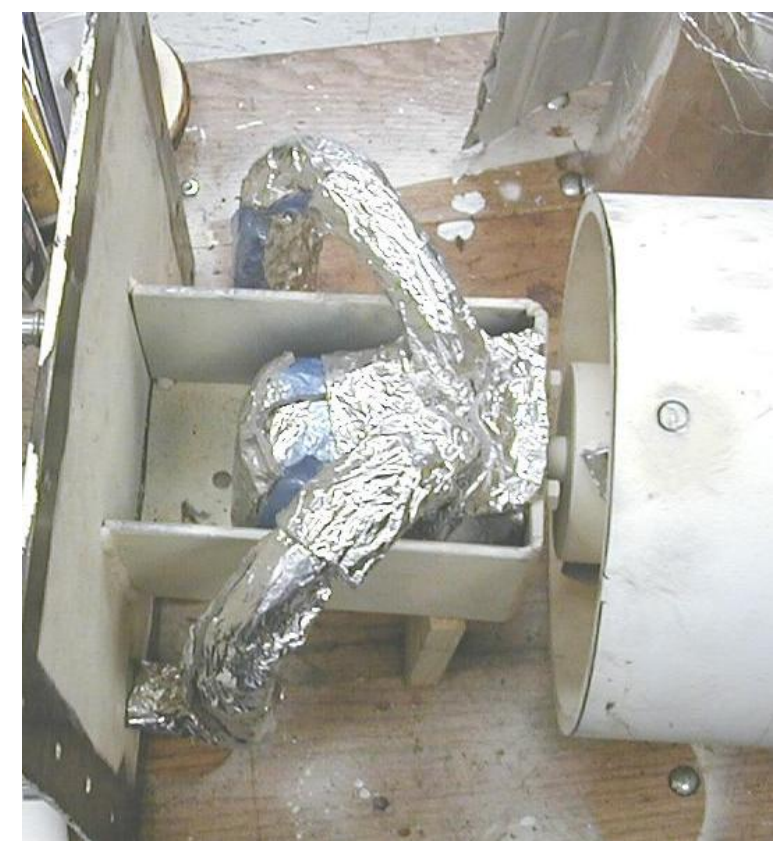

Figure 32: Insulation covering the hydraulic motor and the feed lines. 
It was eventually observed that this heat exchanger was not necessary, but it was built and installed as part of the original system.

Next, the hydraulic fluid flowed through an oil filter to clean the fluid before flowing into the oil reserve tank attached to the power supply. Figure 34 shows the oil filter and the mounting bracket attached to the inside of the control panel. Finally, the fluid flows back into the oil reserve tank mounted to the power supply and pump.

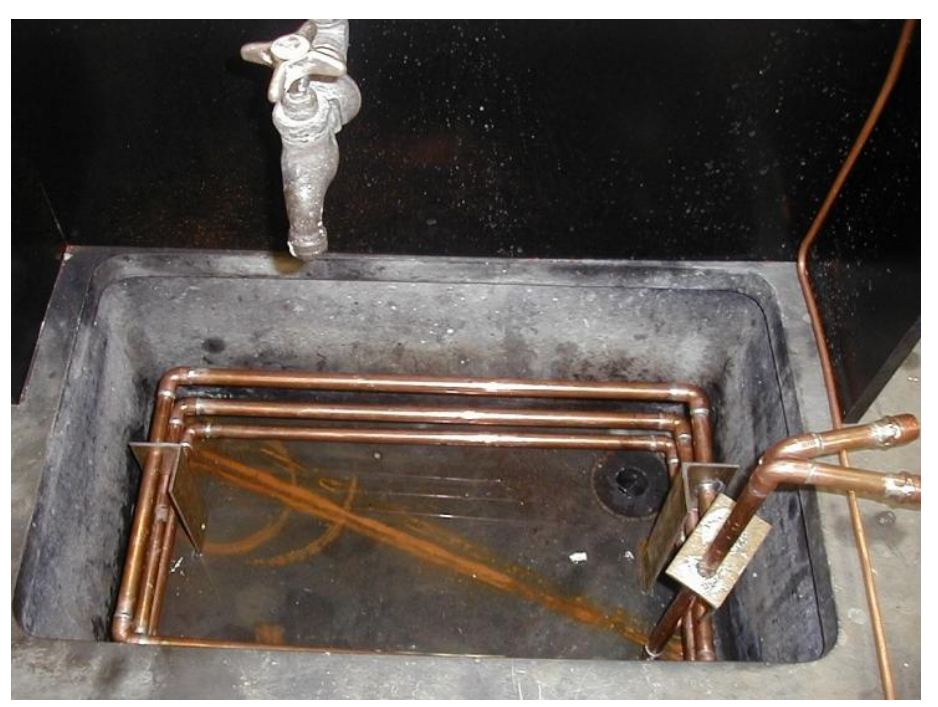

Figure 33: Heat exchanger to cool the hydraulic fluid once it has left the motor. 




Figure 34: Oil filter and mounting bracket inside the control panel.

\subsection{ELECTRICAL SYSTEM}

The electrical system has three main components; the electric motor control for the hydraulic power supply, the electric motor control for the vacuum pump and the control of the heater inside the tumbler. Appendix B, C and D show the electrical schematics for each of these systems.

The hydraulic power supply was powered with high-voltage single-phase current which consisted of three wires; two 120 volts lines and a neutral or ground line. The first step was to make sure the motor was wired internally for this type of current. Removing the cover plate revealed a wiring diagram for both high-voltage single-phase and low voltage single phase. Figure 35 shows the cover plate of the hydraulic power supply open with the wiring configurations for both high and low voltages. The vacuum pump 
motor was also wired for high-voltage single-phase. The heater controller was wired for high-voltage single-phase from the factory, so rewiring was not necessary.
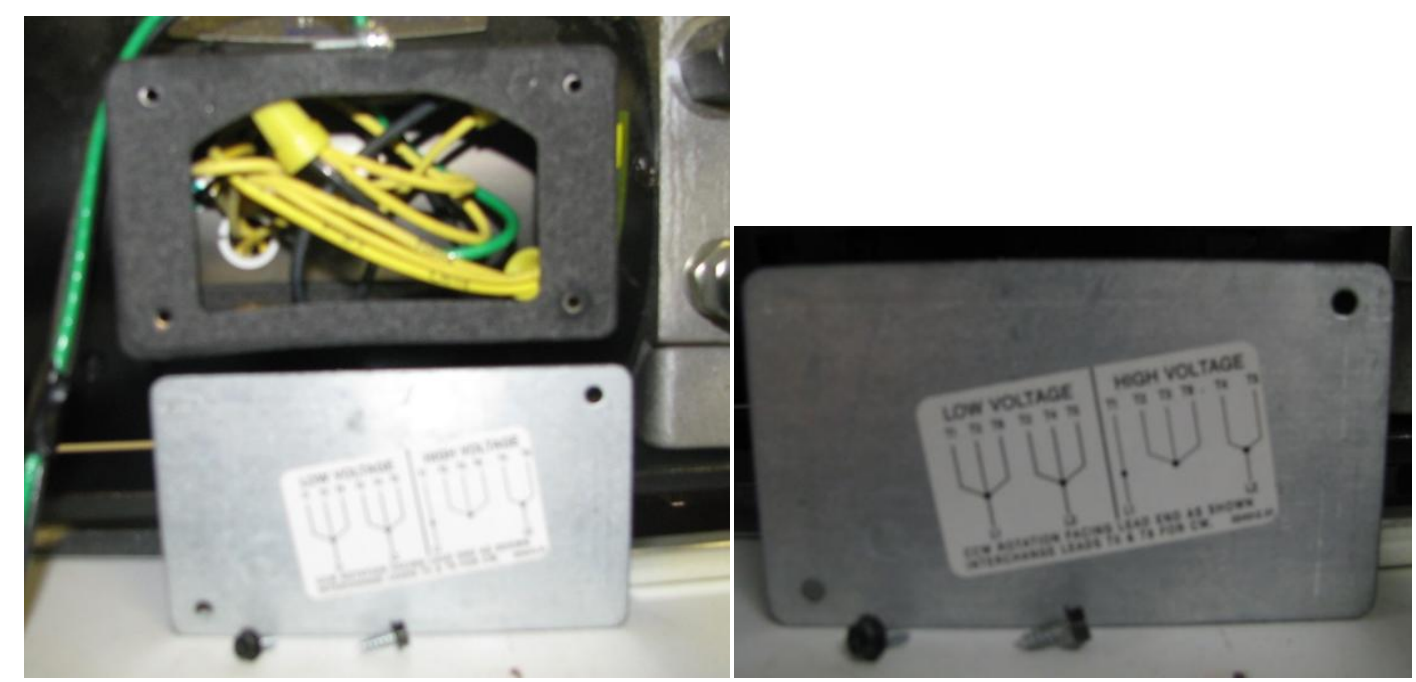

Figure 35: Wiring diagram for the hydraulic power supply motor.

The control panel was designed to have one power chord to distribute power to all the internal equipment housed in the control panel that required electricity. Figure 36 shows the power chord electrical box (cover plate not shown) where the power is brought into the control panel. From this electrical box, the three lines are connected to three separate distribution panels (Figure 37); neutral or ground (green wires) and the two power lines, L1 and L2 (black wires). 


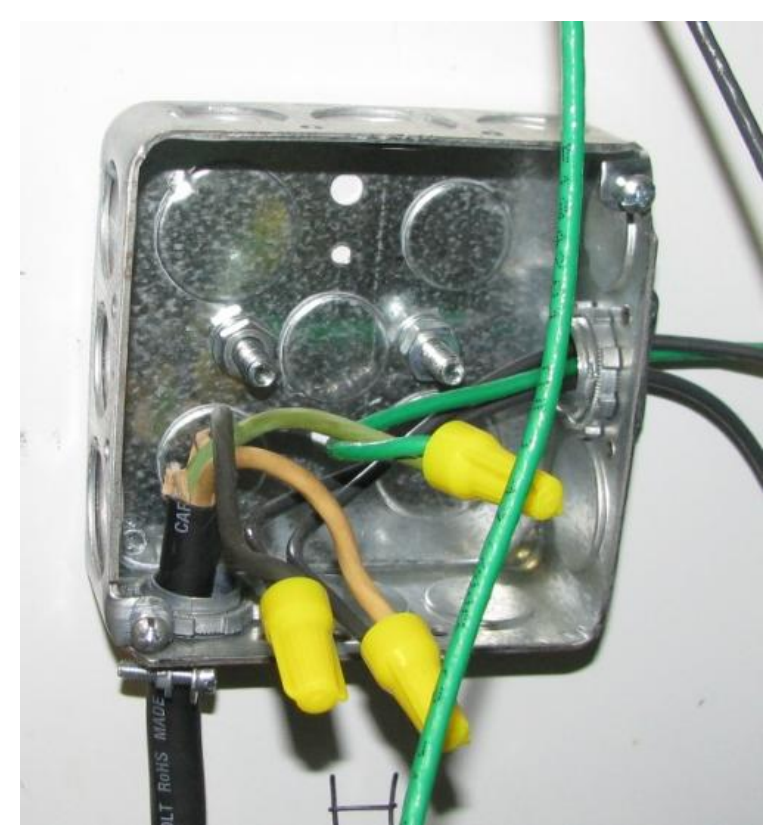

Figure 36: Electrical box mounted on the inside of the control panel.

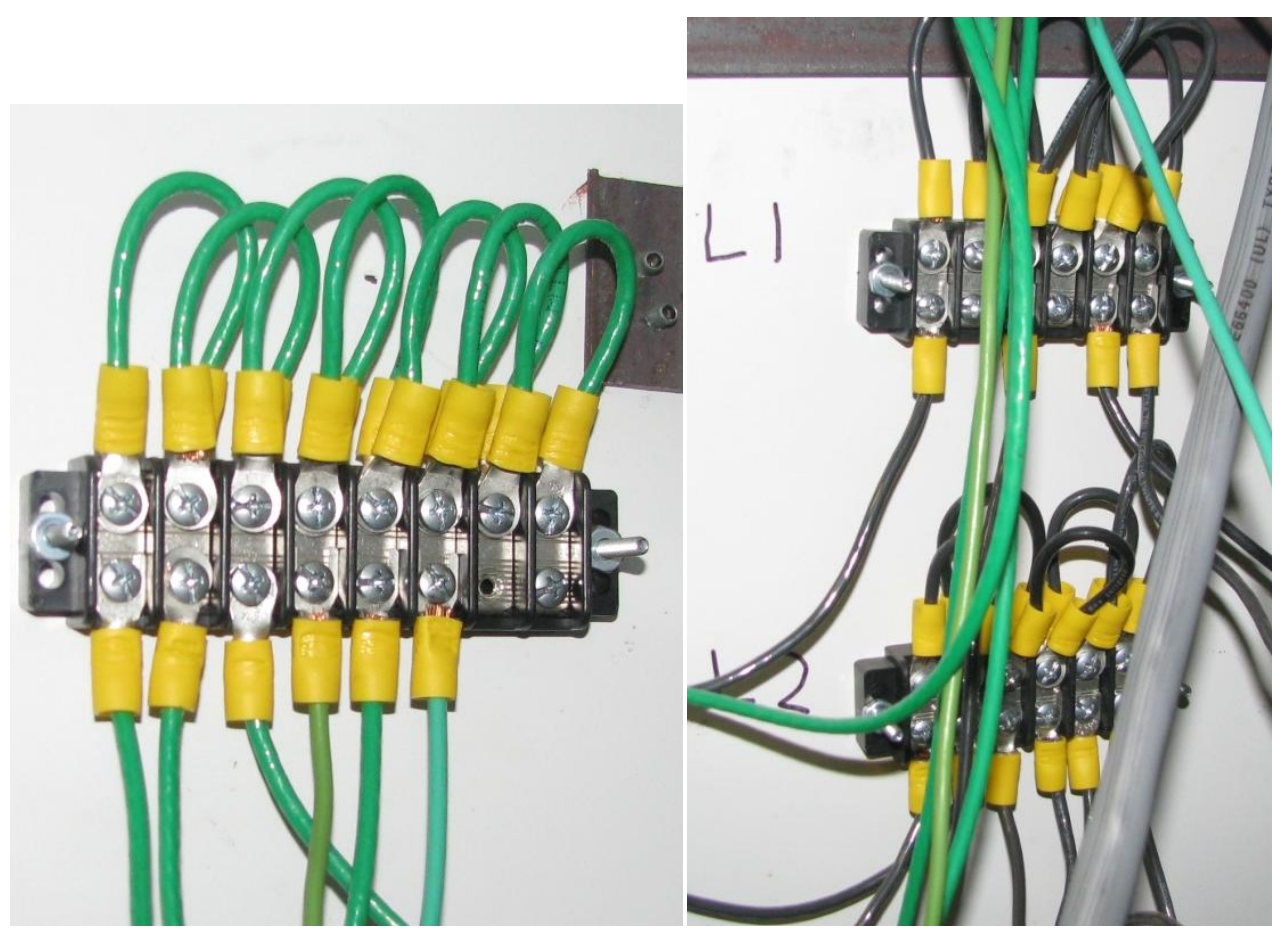

Figure 37: Electrical distribution panels showing the ground wires (left) and the two 120 bolt power lines, L1 and L2 (right). 
The vacuum pump and hydraulic power supplies were controlled with start and stop push buttons. Figure 38 shows both the back and front side of the start/stop buttons. The start button consisted of a normally open configuration. By pushing the start button, a circuit was connected and the coil in the motor starter was energized, thus locking the circuit such that the motor starts. The motor ran until the stop button was pushed. The stop button was a normally closed configuration and pushing it broke the circuit (see Appendix B and C).
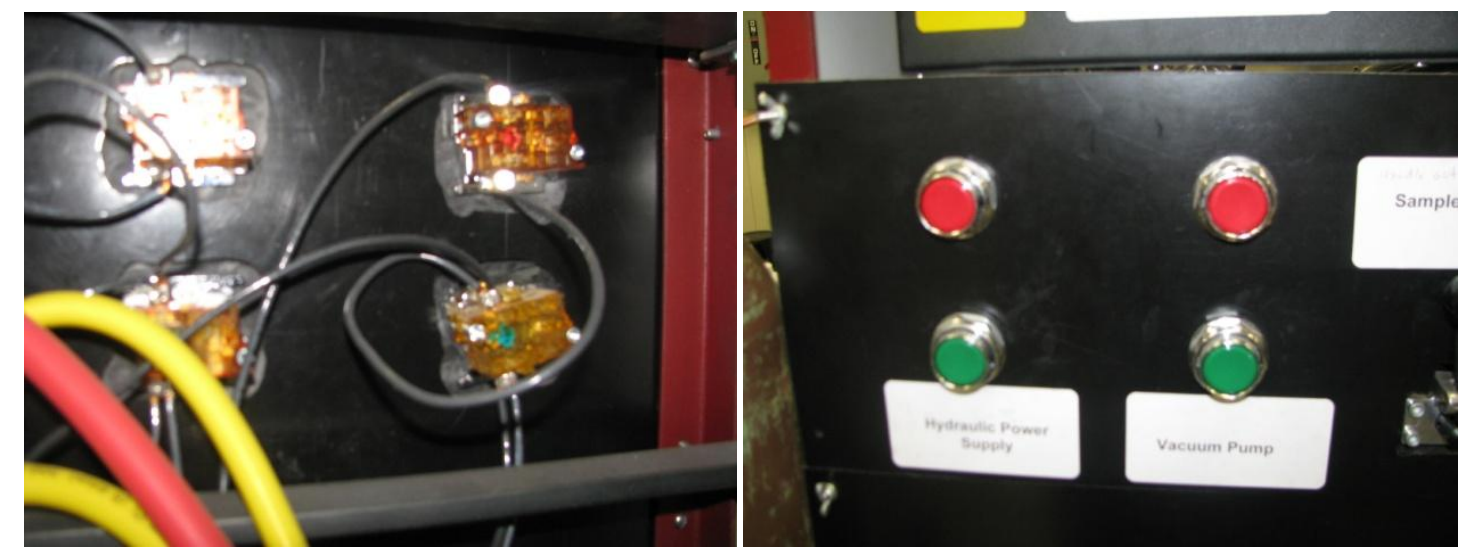

Figure 38: The push button controls for the hydraulic power supply and the vacuum pump.

Figure 39 shows the motor starter for the hydraulic power supply. The vacuum pump had the identical configuration. The bottom two wire connections were to the coil and were in a parallel configuration with the start button. As the start button was pushed, making contact allowed an electrical current to flow through the push button's internal circuit, the coil was energized and its magnetic field locked up the motor starter and energized the pump motor. 
The heater controls were internal to the heater controller unit and all that was necessary was to attach the two power lines and the ground wire and then connect the heater to the controller.. Appendix D shows the schematic for the heater wiring diagram.
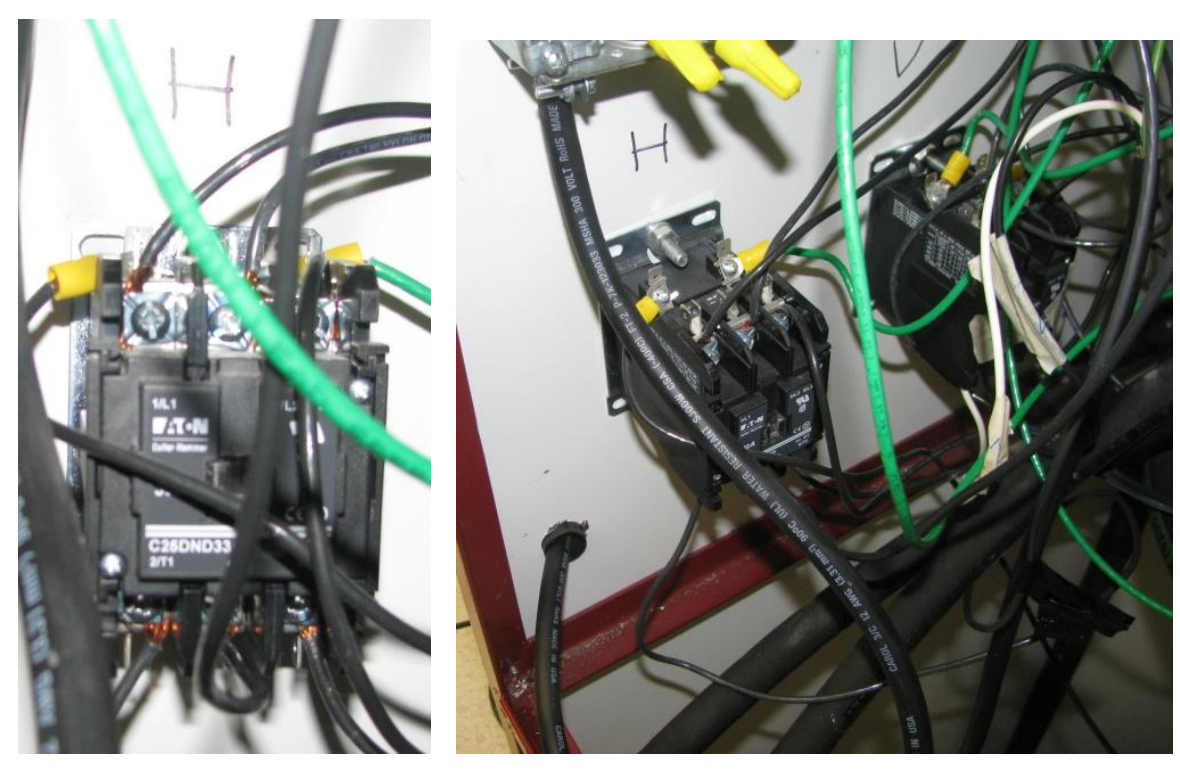

\section{Figure 39: Motor starter for the hydraulic power supply. The vacuum pump has the identical configuration.}

Figure 40 shows the front panel for the heater controller. The left side had a fused on/off switch. Flipping this switch energized the panel. Next to this switch were the on/off push buttons which actually turned on the power to the heater. A Type-B thermocouple came with the heater controller and was used to control the temperature inside the tumbler. The power controls with the temperature readout from this thermocouple are to the right side of the controller. The power controls allowed one to set the power on a percentage basis. Adjustment by the operator was based on the temperature inside the tumbler. 


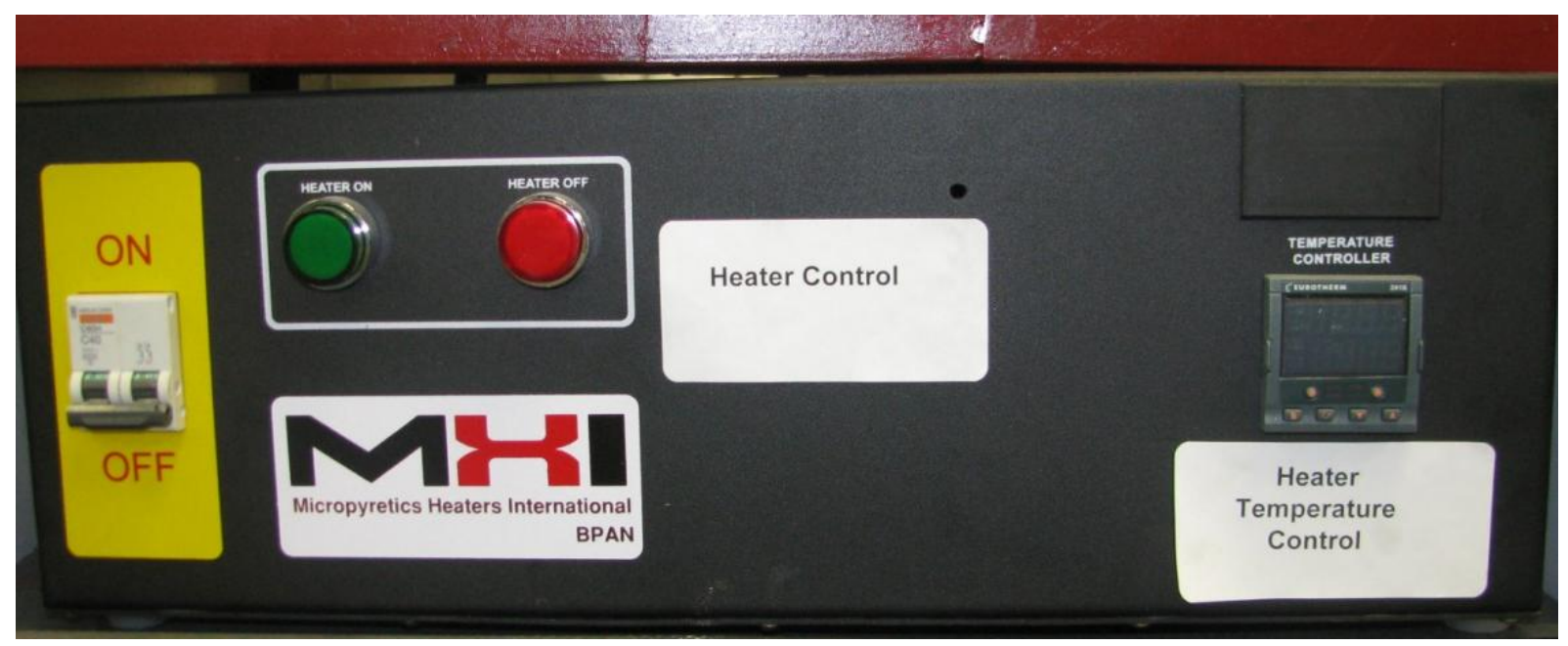

Figure 40: The front side of the control panel showing the heater controls.

The voltage leaving this controller was stepped down from 120 volts (max) to 40 volts by a transformer. This boosted the amperage to the heater. Figure 41 shows the transformer used in conjunction with this controller.

The electrical wires must penetrate the walls of the vacuum chamber in order to energize the heating coil inside the tumbler. To accomplish this, Conax-Buffalo fittings were used for both power leads and the thermocouple wires. These are shown installed on the secondary chamber in Figure 42. The second photo shows the sliding bracket that holds the end plate (end plate not shown) and the copper connections on the end of the large black wires that attached to the heater on the outside of the tumbler (and endplate). 


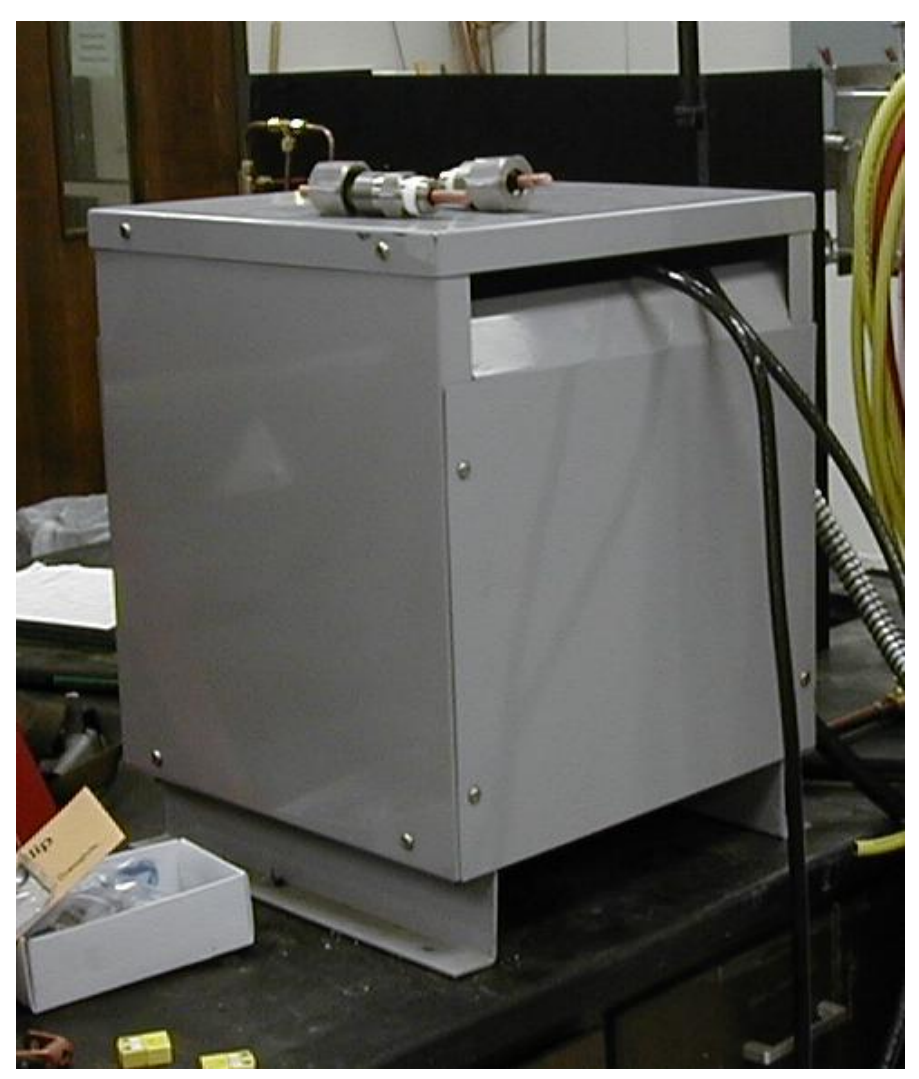

Figure 41: A transformer used to step down the voltage from 120 volts (max) to 40 volts.

The end plate bolted to the sliding bracket that allowed the plate to slide in place during operation and slide out during loading and unloading. The slide plate was controlled with the pneumatic cylinder powered by compressed argon (see next section on pneumatics). The heater coil was a molybdenum disilicide construction with a manufacture's maximum temperature rating of $1200^{\circ} \mathrm{C}$, which is above the required temperature for dehydriding. Figure 43 shows the end plate attached to the sliding plate. The electrical leads attached to the heating element via aluminum grounding cables shown in the figure. 

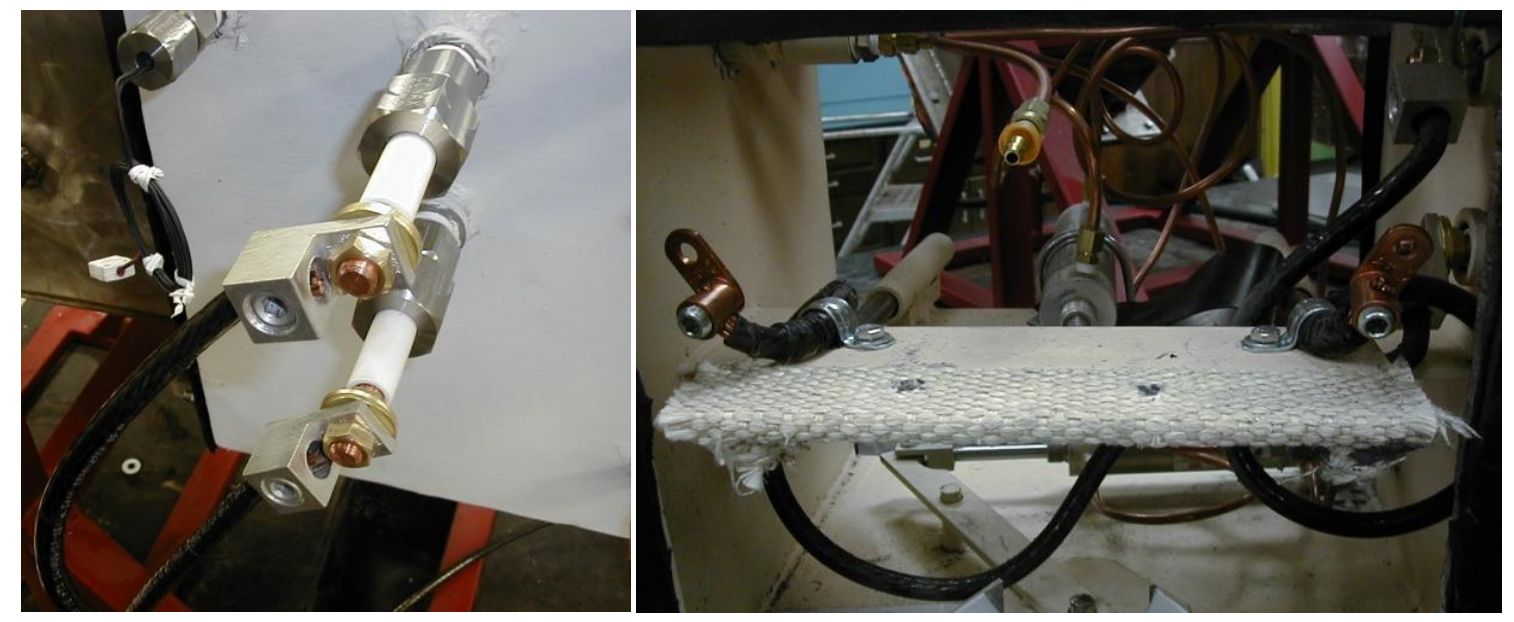

Figure 42: Conax-Buffalo fittings allowing current flow to penetrate the vacuum chamber.

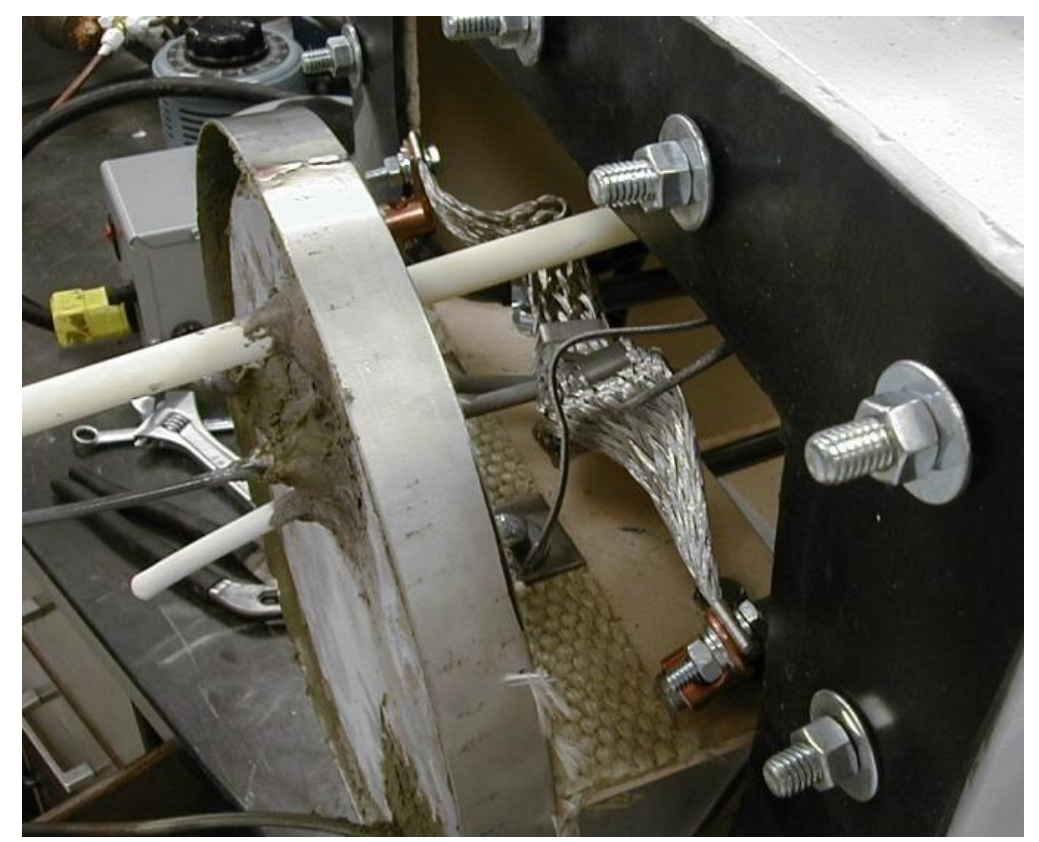

Figure 43: The end plate attached to the sliding plate prior to full assembly.

The original heating coil had a fragile spiral design that broke during assembly.

The replacement element is shown in Figure 44. This element was a simple loop design 
and was considerably lower in cost. The heater coil was held in place by the high temperature ceramic putty. This putty also attached the ceramic insulating plate to the Inconel end plate.

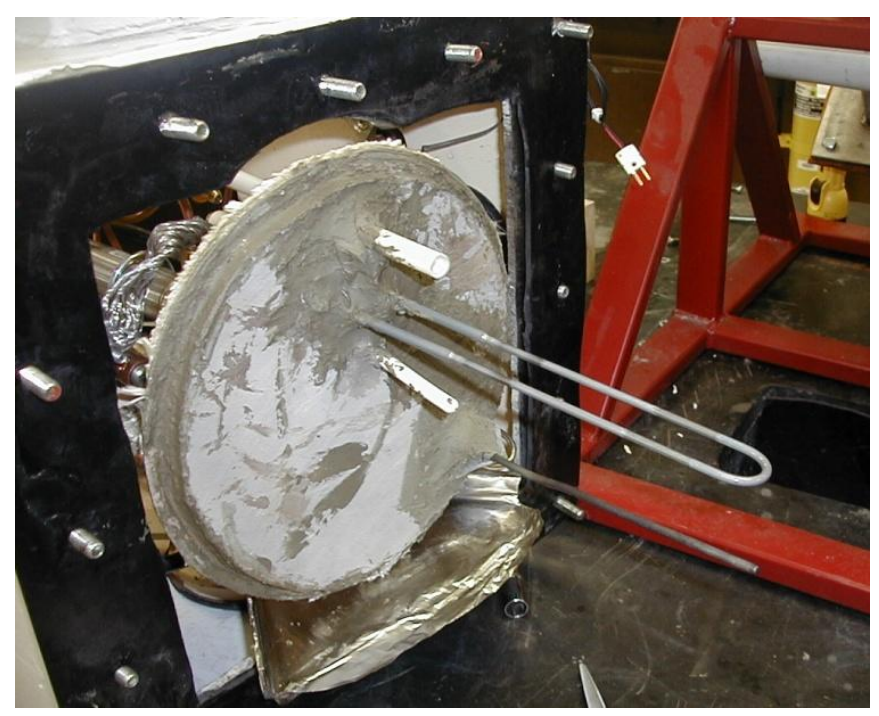

Figure 44: The molybdenum disilicide heating element attached to the end plate.

\subsection{PNEUMATIC SYSTEM}

The pneumatic system consisted of two systems; the end plate control system and the system to close the sample collection lid. Since both systems are internal to the vacuum chamber, argon was used to power both gas cylinders. The reasoning behind this was in the event of a leak, argon would be introduced into the processing chambers instead of air. The presence of air in the processing chamber would either create zirconium nitride or depending on when the leak occurred, could rapidly oxidize the 
zirconium power causing a fire (zirconium oxide). Appendix F shows the schematic for the pneumatic system.

Control levers on the front of the control panel operated the gas cylinders for these two systems. Figure 45 shows both the front and back of these pneumatic control valves.
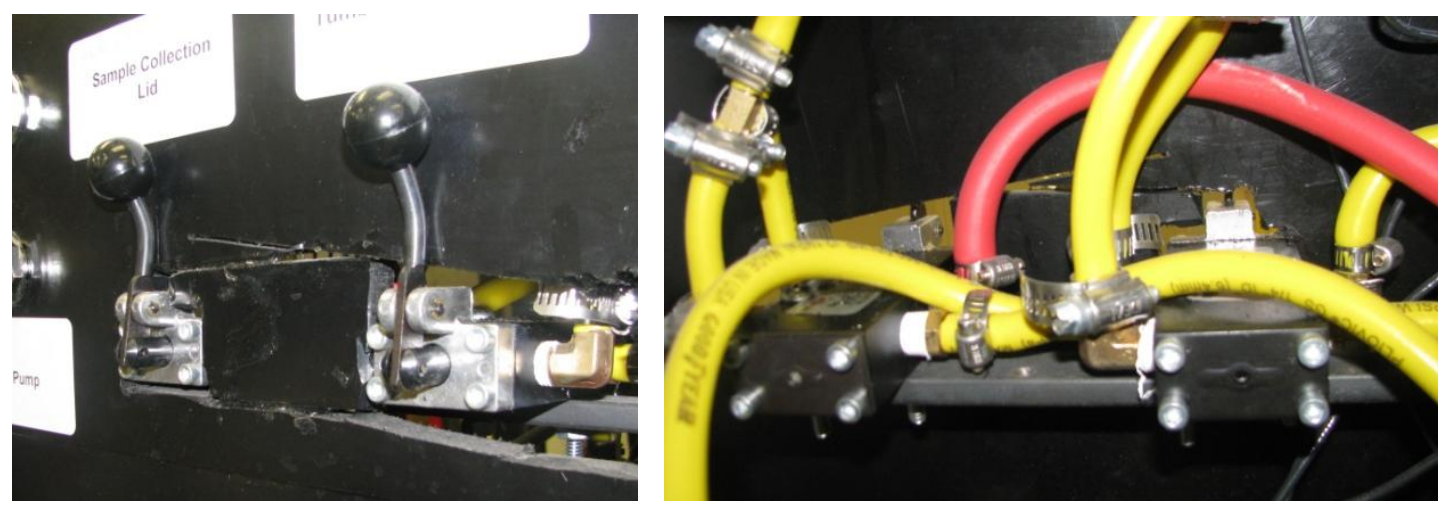

Figure 45: Pneumatic control valves to actuate the end plate and the sample collection lid.

Inside the vessel, the pneumatic pressure lines were copper tubing instead of the yellow rubber hoses due to the elevated temperatures within the chamber during the hydriding and the dehydriding processes. Rubber hoses on the outside gave more flexibility during the unloading process which required the vessel to tilt. 


\section{PROCESS DEMONSTRATION}

This section is divided in three parts; Section 5.1 describes the methods used to prepare the system for operation, Section 5.2 describes the 22 process development tests and the immediate test results; this section also contains descriptions of system modifications made after each test which documents the evolution of the system from concept to final working machine..

Section 5.3 describes the characterization tests performed on the final powders described from the final two successful runs.

\subsection{SYSTEM PREPARATION AND ASSEMBLY TESTS}

Prior to the actual hydride/mill/dehydride experiments, a simple test was conducted of the heating system. The ceramic tumbler was placed vertically on a set of fire bricks with the end plate resting on top of the open end. The molybdenum disilicide heating element was inserted into the tumbler's open end and connected to the heater controller and turned on. A K-type thermocouple was inserted into the tumbler void to monitor the interior temperature. The power was slowly increased to $100 \%$ as the temperature inside the tumbler rose to $750^{\circ} \mathrm{C}$ and then leveled off. The outside of the alumina tumbler grew too hot to touch. It became apparent that the system had reached a maximum temperature and that the heat loss to the surrounding air was greater than the design requirements called for. Since the design requirements called for a higher temperature for dehydriding, the tumbler was insulated to retard heat transfer to the 
environment. Details of the insulation are described along with experiment \#1 in Section 5.2 .

The preparations leading up to each experiment were the same. The first step was to cut the 14 foot long Zircaloy-4 tubes obtained from Argonne National Laboratory into smaller pieces; from 1/4 inch to 1 inch long. Figure 46 shows the diamond bladed saw used to cut these tubes to size.

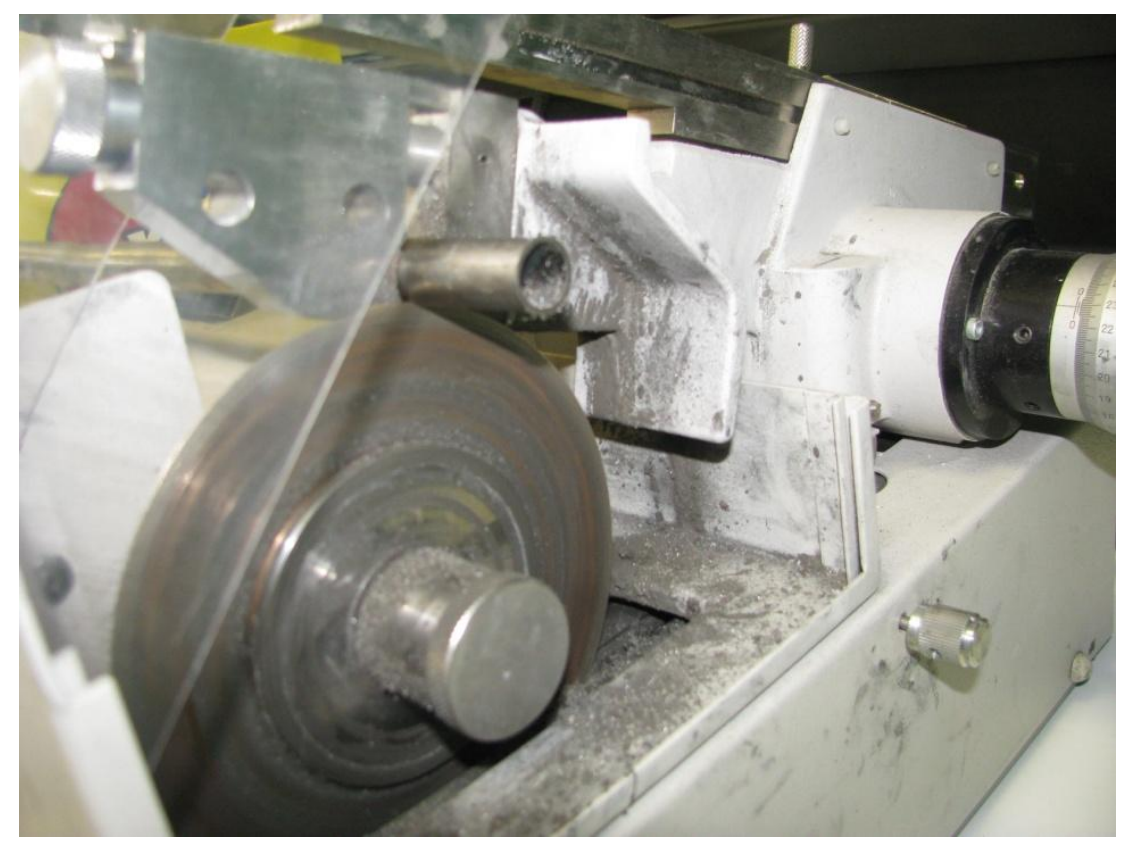

Figure 46: Zircaloy tubes being cut to size with a diamond bladed saw.

Once the tubes were sectioned, they were cleaned to remove contaminants with an alcohol/water solution in the ultrasonic cleaner shown in Figure 47. This method removed dirt, grease and cutting residue from the tube sections. 


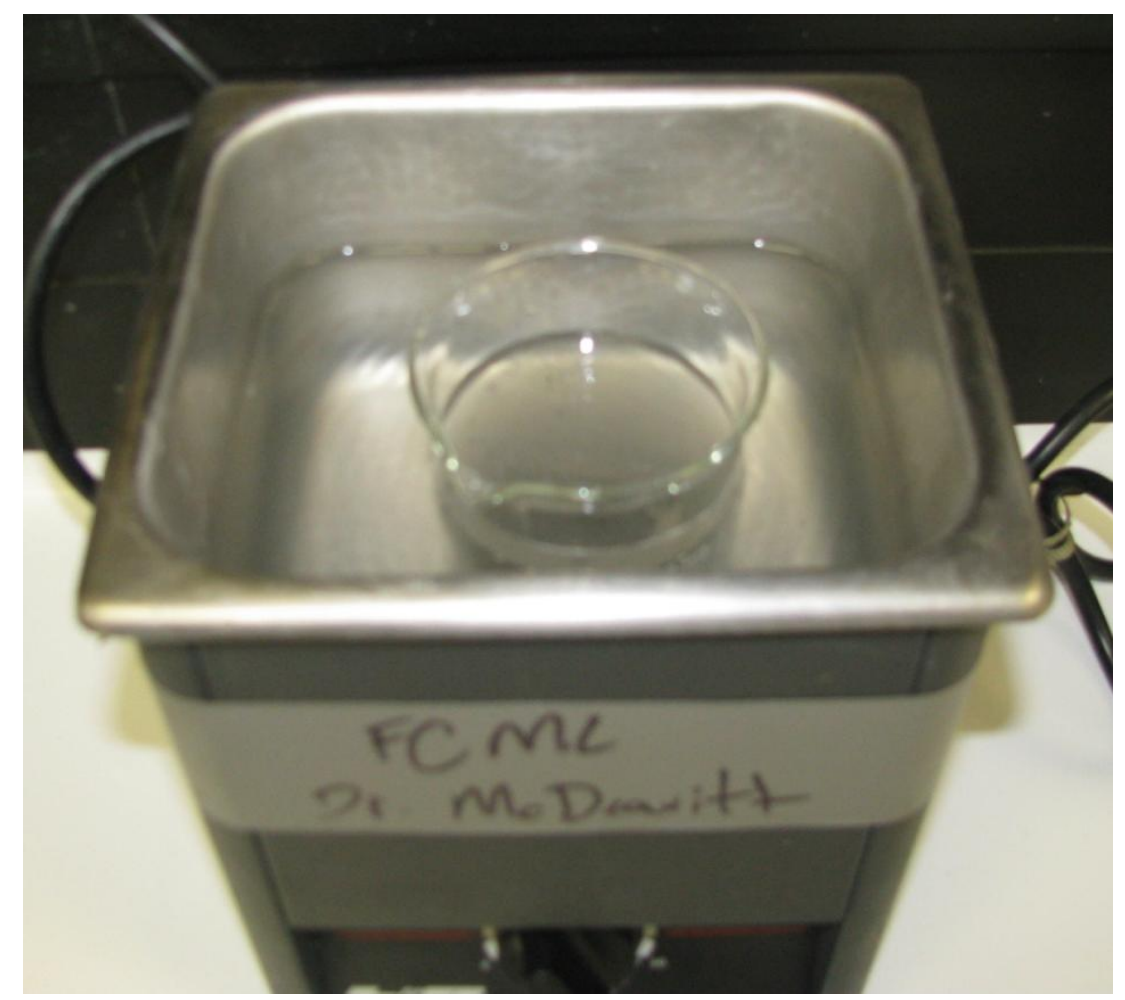

Figure 47: Vibrating cleaning system to prep the samples prior to testing.

The samples were then rinsed with water, dried and weighed with a high precision scale (Figure 48). These values were recorded to compare with the post-test measurements.

At this point, the clean sectioned tubes were placed into the tumbling chamber along with several ( $1 / 4$ inch diameter) zirconium oxide milling balls. These milling balls will not react with the samples at the process temperatures. Figure 49 shows the samples and milling balls loaded in the tumbler prior to testing in an early HMD system tumbler. 


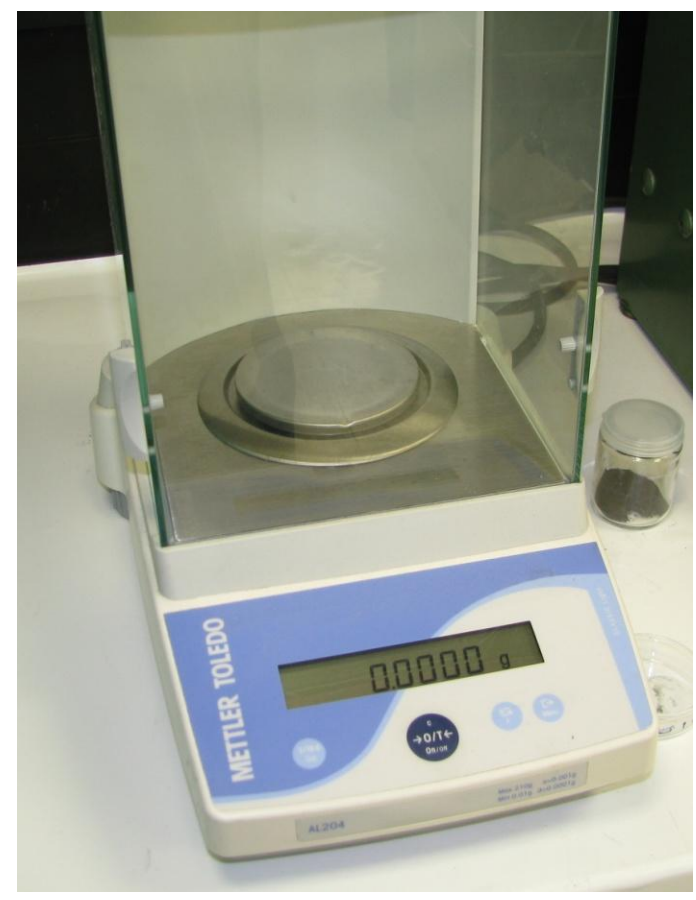

Figure 48: Weighing the samples prior to testing.

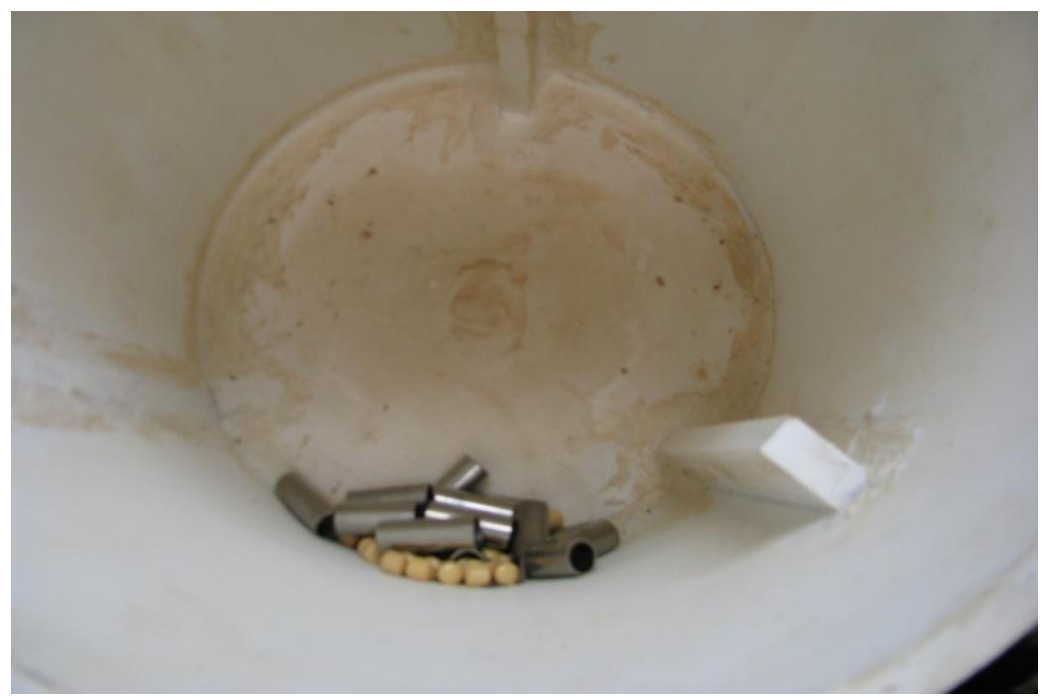

Figure 49: Samples prior to processing. 


\subsection{PROCESS DEVELOPMENT}

This section describes in detail each of the 22 experiments and the design changes associated with each test. A complete documentation of each sample condition at the conclusion of each experiment will be provided.

\subsubsection{EXPERIMENT \#1}

The summary of experiment \#1 is provided in Table 4. Prior to the start of the experiment.00000, the tumbler was insulated. Due to the manufacturing error mentioned in Section 4, the thickness of the insulation had to be less than $1 / 2$ inch on the diameter or 1/4 inch thick. The insulation was a calcium aluminum silicate ceramic fiber with an adhesive backing (McMaster-Carr no. 4057K7). This insulation gave a thermal conductivity of $0.82\left(\mathrm{Btu}-\mathrm{in} / \mathrm{hr}-\mathrm{ft}^{2}\right)$ at $800^{\circ} \mathrm{F}\left(427^{\circ} \mathrm{C}\right)$. Although the insulation has an adhesive backing, the adhesive did not adhere to the alumina tumbler sufficiently. Therefore, a high temperature ceramic putty (McMaster-Carr no. 7482A31) was used to fix the insulation in place.

Table 4: Summary of experiment \#1

\begin{tabular}{|c|c|c|}
\hline Experiment \#1 & 8-Jul-08 & \\
\hline & Temperature $\left({ }^{\circ} \mathrm{C}\right)$ & Time (hrs) \\
\hline Hydride & 421 & 0.33 \\
\hline Milling & N/A & 0 \\
\hline Dehydride & N/A & 0 \\
\hline Mass Change & \multicolumn{2}{|c|}{0} \\
\hline Comments & Tripped Breaker after 50 min. \\
\hline
\end{tabular}


Figure 50 shows the tumbler prior to insertion into the vessel. A thin stainless steel metal ring was installed at the point where the rollers contacted the tumbler to prevent the rollers from damaging the tumbler and insulation.
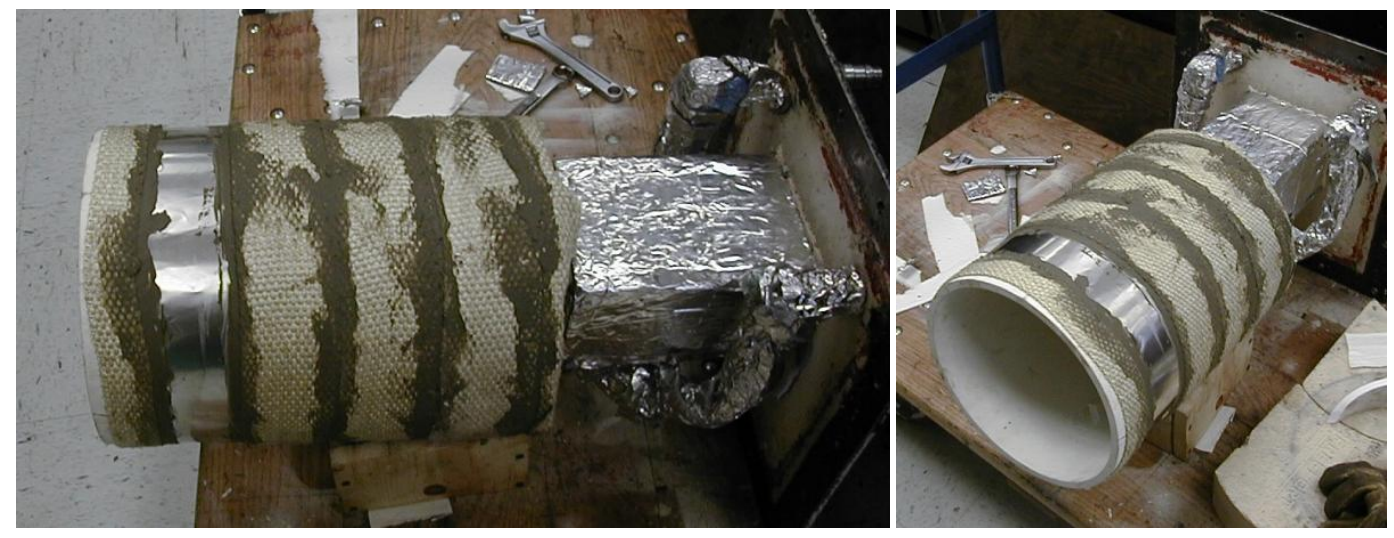

Figure 50: Insulation on the tumbler to inhibit heat loss from the chamber.

Once the system was assembled and the Zircaloy tube sections were loaded, the system was purged with an evacuation - argon fill process twice to eliminate the oxygen and nitrogen from the test chamber. With argon flowing through the system, the heating element was energized and the power was slowly increased. After 30 minutes, the power was at $60 \%$ and the inside thermocouple read $324^{\circ} \mathrm{C}$. At this point the gas flow was switched from argon to the hydrogen-argon mixture, initiating the hydriding process. The heater power was increased to $70 \%$. At this point (40 minutes into the experiment), the main electrical breaker at the wall tripped. The heater was not able to restart after the breaker was reenergized. 
Upon inspection, the molybdenum disilicide heating element was damaged at the point where it crossed through the end plate. It was not evident at the time what caused this short circuit (see Section 5.2.8). Another molybdenum disilicide element was acquired and installed in the same manner for the next experiment. Extra care was taken to ensure the coil was not damaged during assembly.

\subsubsection{EXPERIMENT \#2}

The summary of experiment \#2 is provided in Table 5. As in the first experiment, the temperature climbed until the inside of the vessel approached the hydriding temperature. The specialty gas was switched from pure argon to the argon / hydrogen mixture at about $340^{\circ} \mathrm{C}$. Almost immediately, the heater failed and the temperature dropped. It became apparent that the heating element had broken again.

Table 5: A summary of experiment \#2.

\begin{tabular}{|c|c|c|}
\hline Experiment \#2 & 7-Aug-08 & \\
\hline & Temperature $\left({ }^{\circ} \mathrm{C}\right)$ & Time (hrs) \\
\hline Hydride & 341 & 0.17 \\
\hline Milling & N/A & 0 \\
\hline Dehydride & N/A & 0 \\
\hline Mass Change & \multicolumn{2}{|c|}{0} \\
\hline Comments & \multicolumn{2}{|c|}{ Heating element failure } \\
\hline
\end{tabular}

The heating element power was at $100 \%$ when the element broke in experiment \#2 while the temperature was considerably below the temperature targeted for efficient hydriding, or $500^{\circ} \mathrm{C}$. Therefore, it was obvious that a different heating method had to be 
devised. The combination of insufficient heating and extreme brittleness of the molybdenum disilicide type heating coils proved very inadequate for this process.

Alternative heating elements were revisited and it was decided to install an AeroRod (model \#BXX-12-B-24-4-T, Addison, Illinois) flexible heating element based on vendor recommendations. These coils have an Inconel sheath, which is very corrosion resistance. Since these elements are flexible, they can be shaped to best fit this process. Figure 51 shows the endplate with these elements installed. The gray ceramic putty secured the elements to the end plate. These elements were shaped in such a manner to concentrate the heat flux on the sample in the bottom of the tumbling chamber.
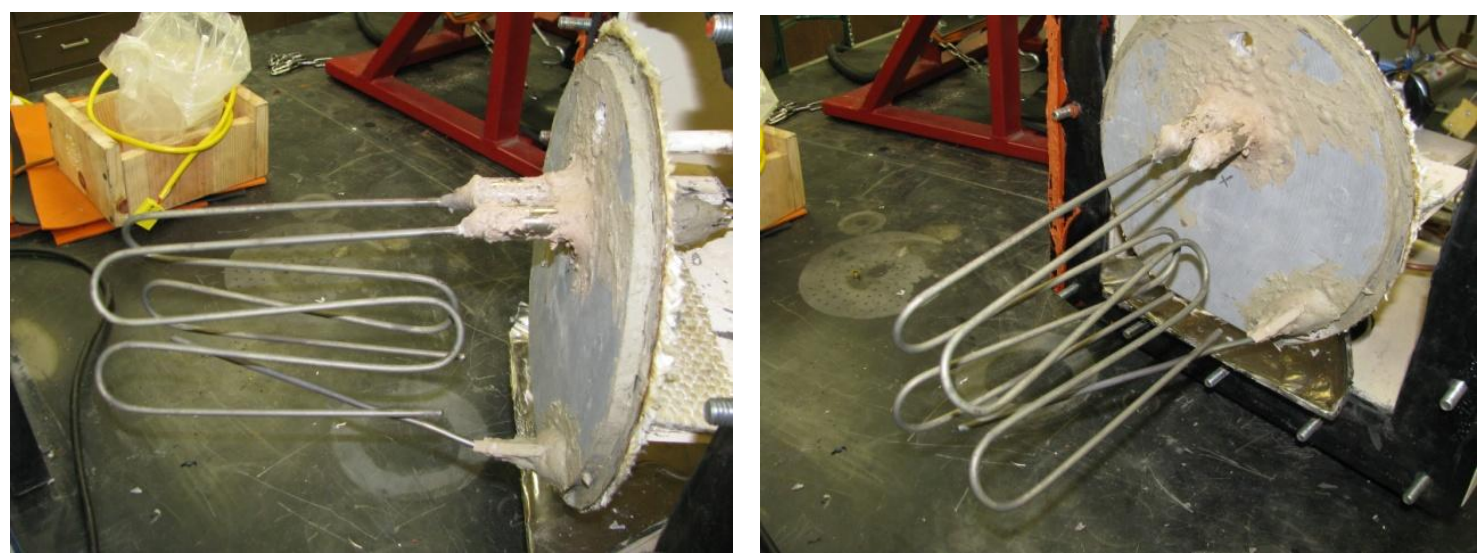

Figure 51: AeroRod heating elements shaped to enhance the heat flux on the sample.

\subsubsection{EXPERIMENT \#3}

The summary of experiment \#3 is provided in Table 6. This heating system initially appeared to work considerably better. At $65 \%$ power, the internal thermocouple 
read $412^{\circ} \mathrm{C}$. At this point, the argon / hydrogen flow was started. The internal temperature rose to $506^{\circ} \mathrm{C}$ at which point the power was turned down slightly in an attempt to control the sample temperature.

Table 6: A summary of experiment \#3.

\begin{tabular}{|c|c|c|}
\hline Experiment \#3 & 8-Dec-08 & \\
\hline & Temperature $\left({ }^{\circ} \mathrm{C}\right)$ & Time (hrs) \\
\hline Hydride & 506 & $1+$ \\
\hline Milling & N/A & 0 \\
\hline Dehydride & N/A & 0 \\
\hline Mass Change & \multicolumn{2}{|c|}{0} \\
\hline Comments & Tripped Breaker after 70 min. \\
\hline
\end{tabular}

After one hour and ten minutes, the breaker tripped and the heating element failed and the heating system would not restart. At that point, it was decided to attempt to tumble the contents in case the material might have completely hydrided. While the tumbler worked well before the experiment, it failed to turn at the elevated temperature. The system was allowed to cool before examining the internal components.

As in the previous two experiments, the heating element had failed. The element was rated to $1200^{\circ} \mathrm{C}$ but failed at approximately $500^{\circ} \mathrm{C}$. Examining the element showed no signs of external damage but a continuity check showed a break in the internal circuit of the element.

The source of the tumbling failure was readily apparent upon disassembly. Figure 52 shows the ceramic putty failed to keep the insulation attached to the outside of the 
tumbler. The insulation wadded up against the inside of the chamber wall and prevented the tumbler from rotating.
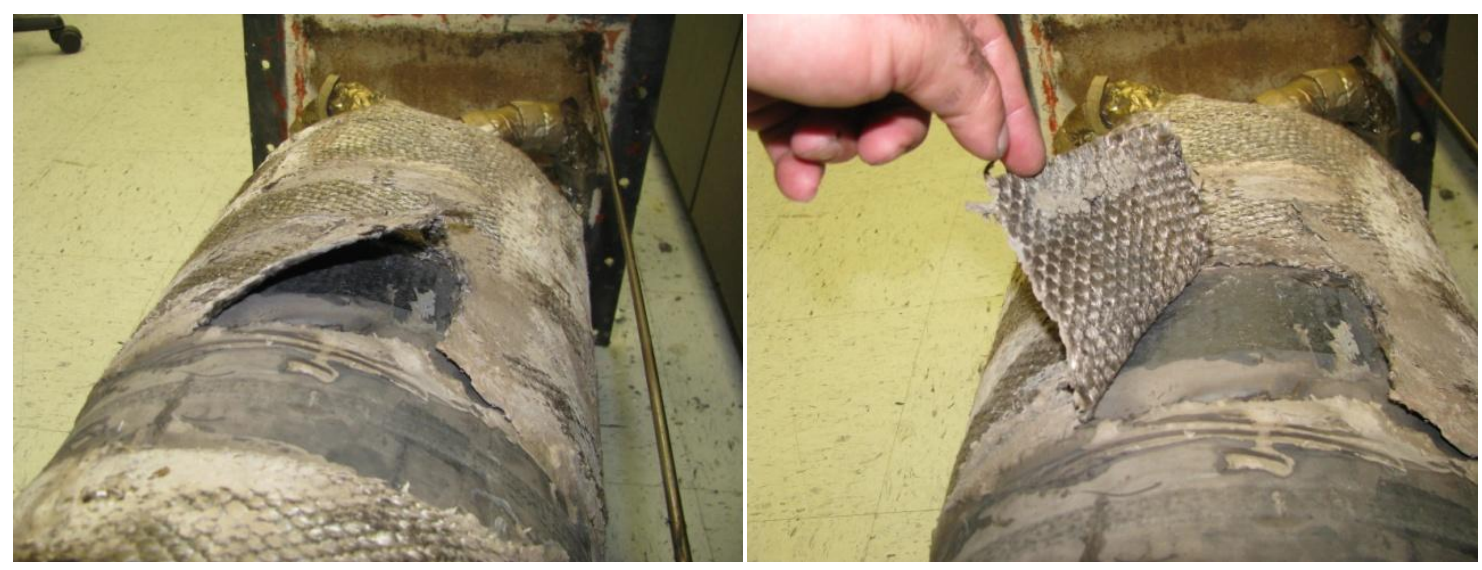

Figure 52: Insulation adhesion failure.

The insulation was repaired with additional adhesive and a liberal use of the ceramic putty. Revisiting the heating element options led to the selection of silicon carbide heating elements. Two silicon carbide elements were installed in the end plate for the next experiment. These elements have a six inch unheated length as manufactured by the vendor. Therefore, two ceramic (alumina) offset tubes were used to maximize the heating length without touching the opposite end of the tumbler. Figure 53 shows the end plate with these silicon carbide elements installed. The bottom picture shows successful independent testing of these heating elements (notice the red glow). 

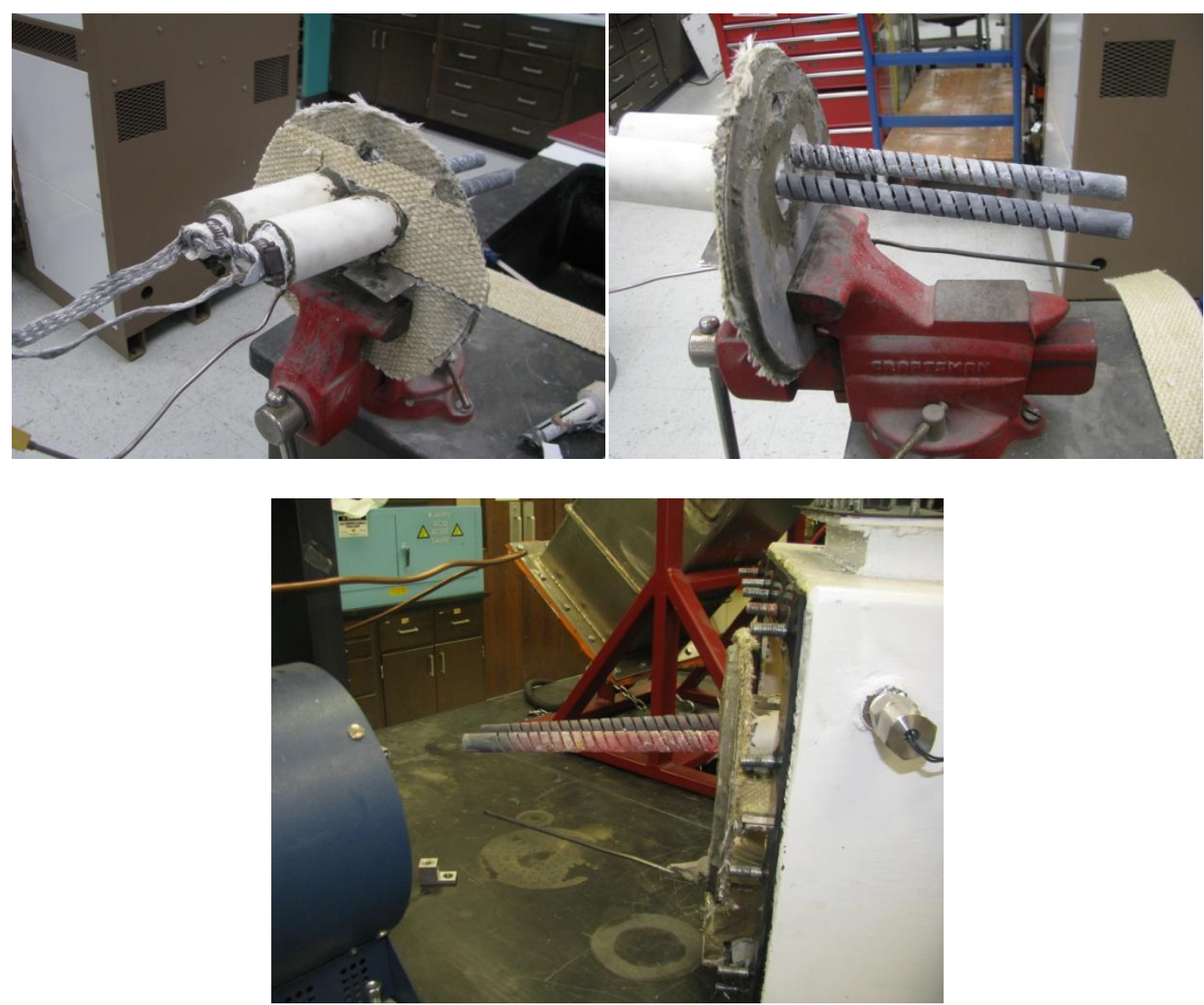

Figure 53: The end plate with the silicon carbide heating elements installed.

\subsubsection{EXPERIMENT \#4}

The summary of experiment \#4 is provided in Table 7. The silicon carbide elements appeared to solve the heating problem. The interior of the tumbling chamber heated rather quickly to $412^{\circ} \mathrm{C}$ at $55 \%$ power. At this point, something happened to trip the breaker on the heater control unit. The breaker was reset, but unlike previous experiments, the coils continued to provide heat. Once up to temperature, the power was dialed back to $60 \%$ to hold the interior temperature between $480^{\circ} \mathrm{C}$ and $485^{\circ} \mathrm{C}$. 
Table 7: A summary of experiment \#4.

\begin{tabular}{|c|c|c|}
\hline Experiment \#4 & 2-Mar-09 & Time (hrs) \\
\hline & Temperature $\left({ }^{\circ} \mathrm{C}\right)$ & 5 \\
\hline Hydride & 485 & inconsistent \\
\hline Milling & N/A & 0 \\
\hline Dehydride & N/A & \multicolumn{2}{|c|}{$0.36 \%$} \\
\hline Mass Change & \multicolumn{2}{|c|}{} \\
\hline Comments & Tumbler inconistant-problem detected \\
\hline
\end{tabular}

The Zircaloy charge was exposed to the $95 \%$ argon and $5 \%$ hydrogen gas for five hours at temperatures between $412^{\circ} \mathrm{C}$ and $494^{\circ} \mathrm{C}$. There was a slight dip in temperature when the breaker tripped, but this was just for a few minutes and the heat came back on line.

After the 5 hours of attempting to hydride, the heating element was turned off and an attempt was made to mill the sample. The tumbler rotation was not smooth. It would rotate for a revolution or two and stop. Reversing the external hydraulic lines reversed the direction of the motor rotation and the tumbler would spin a few revolutions and stop again. This process was repeated several times in an attempt to mill hydrided material as much as the system would allow in this condition.

Figure 54 shows the sample condition upon removal from the chamber. The smashed tube on the right is untreated Zircaloy while the smashed tube on the left has been hydrided. By smashing the tube flat it is revealed that more cracking is prevalent than the untreated tube. This cracking shows evidence that there was a slight hydriding 
or at least embrittlement of the Zircaloy tubes. The color change from silver to a brownish-black is also indicative of hydriding.

Upon inspection, it was apparent that one of the two silicon carbide heating elements had developed a short circuit and was destroyed. Since the remaining two heating elements were wired in parallel, the other elements performed well after the first was damaged. The pattern of element shorting was consistent with each type of element installed.

Problems with tumbling could again be traced back to the insulation not staying in place. Since the clearance between the inside of the chamber and the OD of the tumbler was so small, any section of insulation that loosens during the heating process associated with hydriding, binds against the chamber wall and prevents rotation of the tumbler.

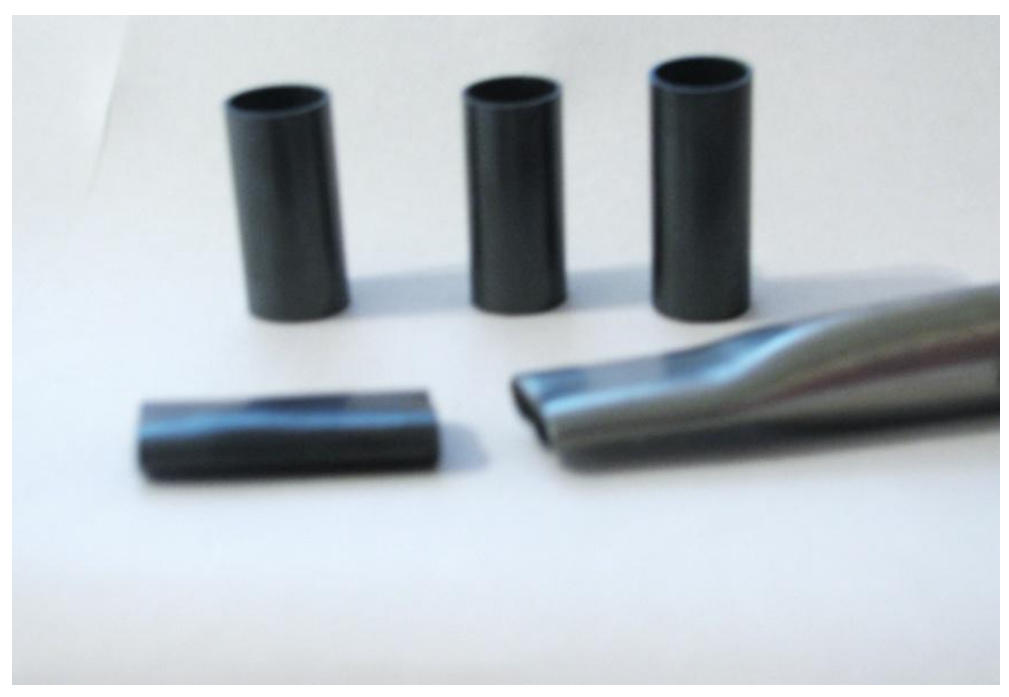

Figure 54: Samples from experiment \#4 shows slight embrittlement. 
Changes to the system in preparation for the next experiment included securing two new heaters to the end plate and reapplying all insulation on the tumbler. The unheated portion of the heating elements was insulated to help prevent heat loss. Figure 55 shows a top view of the insulation wrapped around the alumina holding tubes.

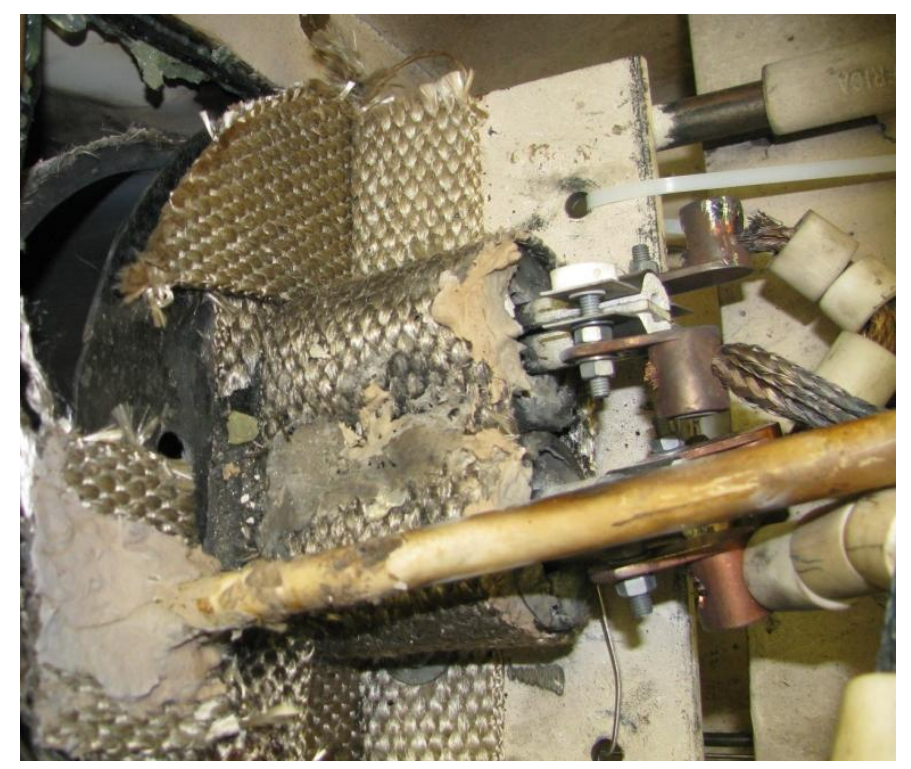

Figure 55: Insulating the unheated length of the heating elements.

\subsubsection{EXPERIMENT \#5}

The summary of experiment $\# 5$ is provided in Table 8 . Experiment $\# 5$ ended shortly after it began. The heating elements shorted 90 minutes into the process. Upon shorting, the elements shattered. This made the investigation into the cause difficult. No real change to the design was attempted due to the unknown cause of the system failure. It was suspected that securing both end of the unheated length in the holding tubes prevented thermal expansion of the elements and/or alumina tubes. Therefore, for the 
next experiment, only the end closest to the electrical connection was secured. The end closest to the sample was simply laid in a ceramic cradle, allowing it to float. The system was reassembled and loaded with more Zircaloy sample tubes.

Table 8: A summary of experiment \#5.

\begin{tabular}{|c|c|c|}
\hline Experiment \#5 & 20-Mar-09 & Time (hrs) \\
\hline & Temperature $\left({ }^{\circ} \mathrm{C}\right)$ & 1.5 \\
\hline Hydride & 493 & 0 \\
\hline Milling & N/A & 0 \\
\hline Dehydride & N/A & \multicolumn{2}{|c|}{$0.00 \%$} \\
\hline Mass Change & Tripped Breaker after 90 minutes \\
\hline Comments & \multicolumn{2}{|c|}{}
\end{tabular}

\subsubsection{EXPERIMENT \#6}

The summary of experiment \#6 is provided in Table 9. The heating elements worked very well throughout this experiment. The internal thermocouple varied from $436^{\circ} \mathrm{C}$ to $485^{\circ} \mathrm{C}$ throughout the hydride process but consistently maintained temperatures within two of degrees of $477^{\circ} \mathrm{C}$. This condition was maintained for 12 hours. The sample was tumbled for two to three minutes, which would be sufficient to determine if the sample hydrided correctly. It was still apparent that the insulation was retarding the tumbler; preventing it from smoothly rotating. 
Table 9: A summary of experiment \#6.

\begin{tabular}{|c|c|c|}
\hline Experiment \#6 & 14-Apr-09 & \\
\hline & Temperature $\left({ }^{\circ} \mathrm{C}\right)$ & Time (hrs) \\
\hline Hydride & 477 & 12 \\
\hline Milling & N/A & 0.16 \\
\hline Dehydride & N/A & 0 \\
\hline Mass Change & \multicolumn{2}{|c|}{0} \\
\hline Comments & Heating elements worked well \\
\hline
\end{tabular}

Figure 56 shows the samples upon extracting from the chamber. The gold tint is indicative of zirconium nitride. This was evidence that the nitrogen getter had to be rebuilt. Once the titanium holding screen was removed, it was evident that the gas supply system had developed a leak and air was introduced into the system. Figure 57 shows this screen and the titanium nitride produced during this experiment (gold color).

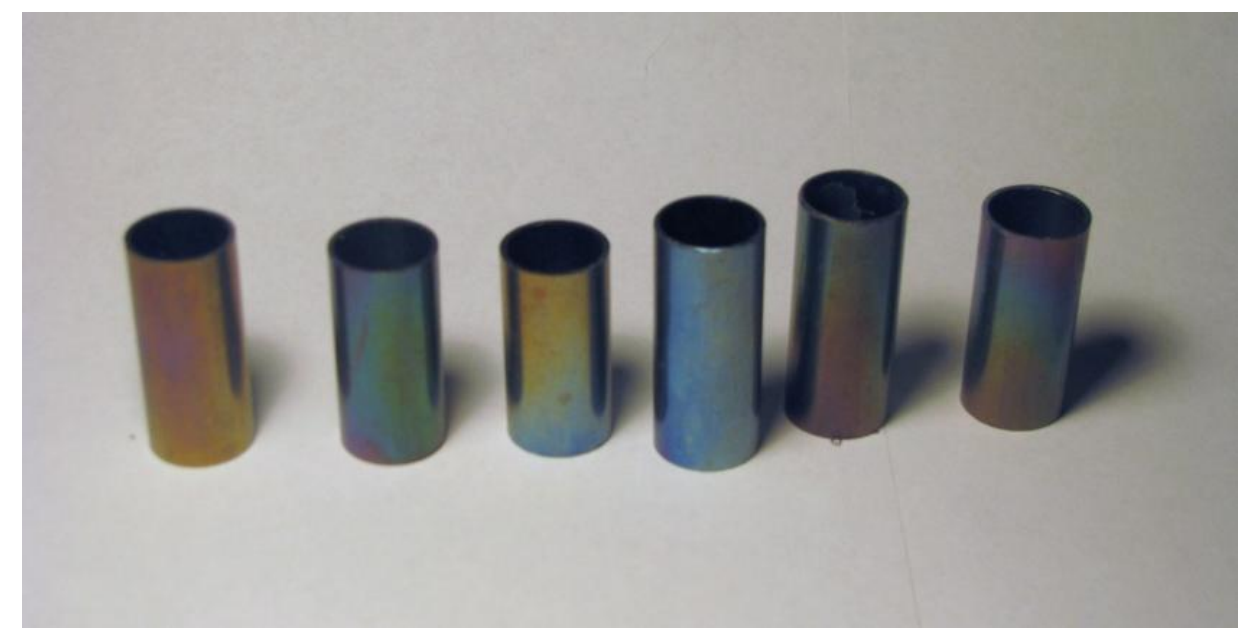

Figure 56: Samples from experiment \#6 show a gold tint which is indicative of zirconium nitride. 


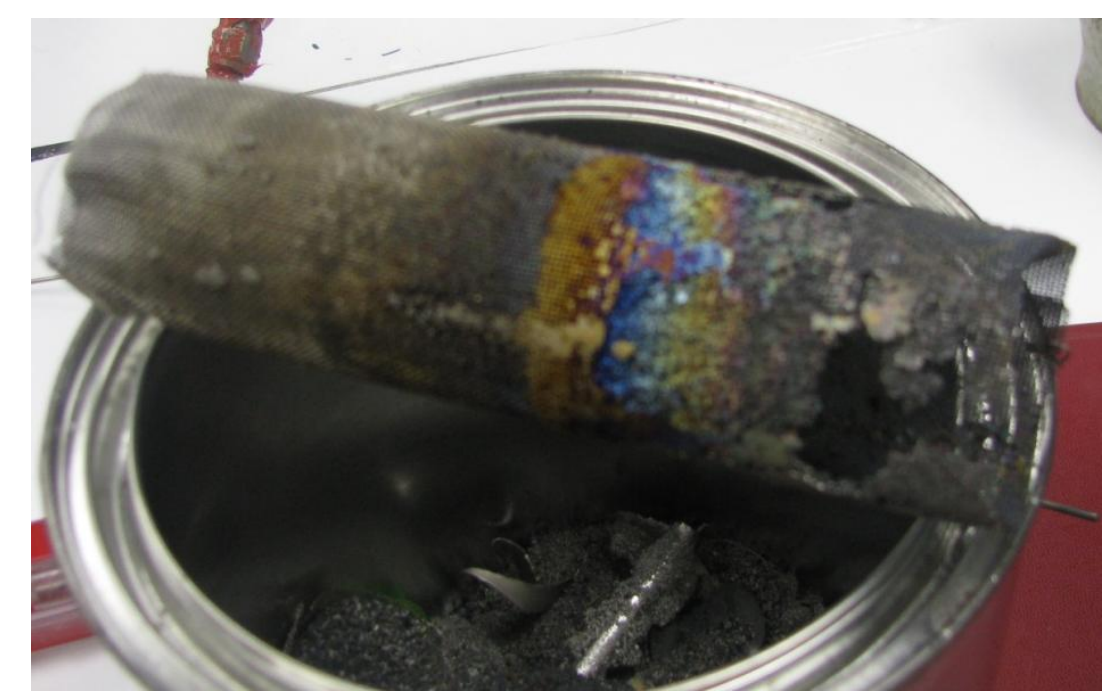

Figure 57: The screen holding the titanium powder after nitrogen contamination.

\subsubsection{EXPERIMENT \#7}

The summary of experiment \#7 is provided in Table 10. The heater did not function properly from the start. Heating to the hydriding temperature $\left(500+{ }^{\circ} \mathrm{C}\right)$ took 95\% power. Hydriding progressed for 14 hours and 10 minutes. Once again, the tumbling was intermittent. The insulation did not bind up against the wall, but it was observed that the tolerance between the insulation and the housing was too small. The hydraulic motor could not overcome the resistance between the insulation and housing. 
Table 10: A summary of experiment \#7.

\begin{tabular}{|c|c|c|}
\hline Experiment \#7 & 2-May-09 & \\
\hline & Temperature $\left({ }^{\circ} \mathrm{C}\right)$ & Time (hrs) \\
\hline Hydride & 510 & 14 \\
\hline Milling & N/A & Intermittent \\
\hline Dehydride & N/A & 0 \\
\hline Mass Change & \multicolumn{2}{|c|}{0} \\
\hline Comments & Tumbler rotated intermittently \\
\hline
\end{tabular}

Post-test examination of the sample showed that partial hydriding seemed to have occurred. Figure 58 shows the samples from this experiment. The sample piece in the middle was flattened with a hammer after removal from the system. It is evident that some hydrogen embrittlement of the Zircaloy tubes occurred.

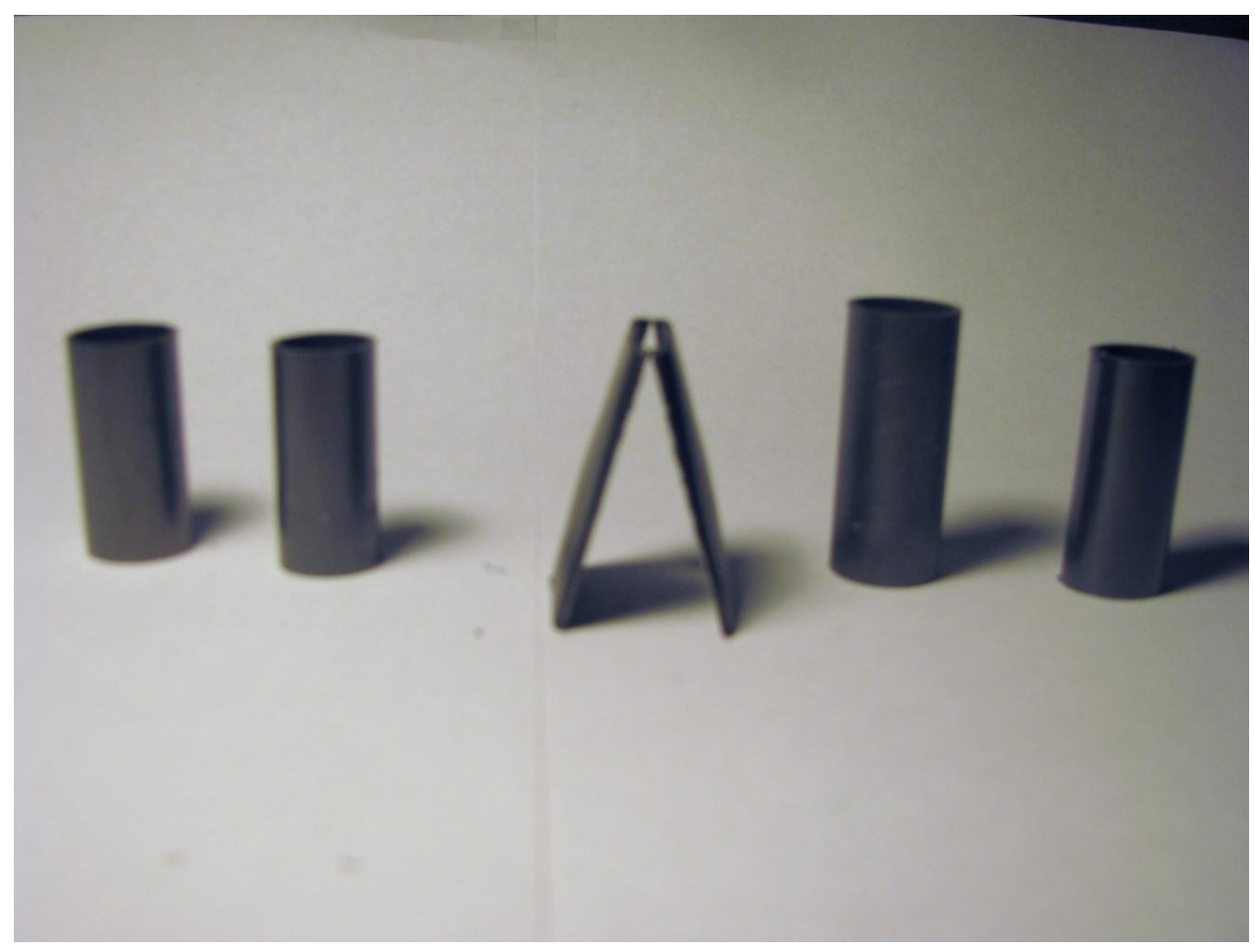

Figure 58: Samples from experiment \#7 showing partial hydriding. 
For the next experiment, two fundamental changes were implemented. First, the insulation was removed from the tumbler and instead, the external housing was insulated. Second, it was known that the partial hydriding at temperatures near $500^{\circ} \mathrm{C}$ for $12+$ hours was inconsistent with Parkison's research noted in Section 2. For the conditions the HMD system was attempting to produce, the Zircaloy charge should have been fully hydride after $\sim 4$ hours. It was postulated that the location of the thermocouple was not providing an accurate measurement of the sample temperature. Figure 53 shows that the thermocouple was located near the heating elements and not the sample. Therefore, it was possible that the temperature of the sample was somewhat cooler than the thermocouple reading. Noting that this was a possibility, the next experiment was conducted at temperatures approaching $600^{\circ} \mathrm{C}$. Inserting additional thermocouples would require additional welded access ports in the vacuum chamber and additional ConaxBuffalo fittings to allow the electronic signal from the thermocouple to be read outside the chamber.

\subsubsection{EXPERIMENT \#8}

The summary of experiment \#8 is provided in Table 11. Early in the experiment, a problem arose. As the temperature increased to $619^{\circ} \mathrm{C}, 75$ minutes into the experiment, a loud pop was heard inside the vessel. Not knowing exactly what occurred, it was decided to continue. Throughout the process, the breaker tripped twelve times but the system restarted each time. It was very evident that there was a serious problem. 
Table 11: A summary of experiment \#8.

\begin{tabular}{|c|c|c|}
\hline Experiment \#8 & 20-May-09 & \\
\hline & Temperature $\left({ }^{\circ} \mathrm{C}\right)$ & Time (hrs) \\
\hline Hydride & $509-619$ & 10 \\
\hline Milling & N/A & 0 \\
\hline Dehydride & N/A & 0 \\
\hline Mass Change & \multicolumn{2}{|c|}{0} \\
\hline Comments & Beaker problems and loud noise \\
\hline
\end{tabular}

After ten hours hydriding at temperatures ranging from $509^{\circ} \mathrm{C}$ to $619^{\circ} \mathrm{C}$, an attempt at tumbling revealed a problem. The system would not tumble at all. Disassembling the machine revealed that the loud "pop" was the ceramic tumbler cracking. Figure 59 shows the tumbler in its broken state. It was clear that the ceramic tumbler underwent a thermal shock during the heating process.

It was at this point that the original design (as described in Section 4) was discarded. Some factors contributing to this decision include:

1. The repeated element failure had been traced to the ceramic putty used to install the elements, it appeared to become electrically conductive at elevated temperatures;

2. There were multiple sources of "dusting" and suspected contamination within the process vessel that were associated with some of the system components;

3. The cost of another ceramic tumbler was prohibitive and the fragility of the tumbler made revising this design unlikely to succeed; and

4. The effectiveness of heating from within the process vessel was now determined to be quiet poor. 
Therefore, it was concluded the problems with contamination, heating and tumbling would best be overcome through a complete redesign.

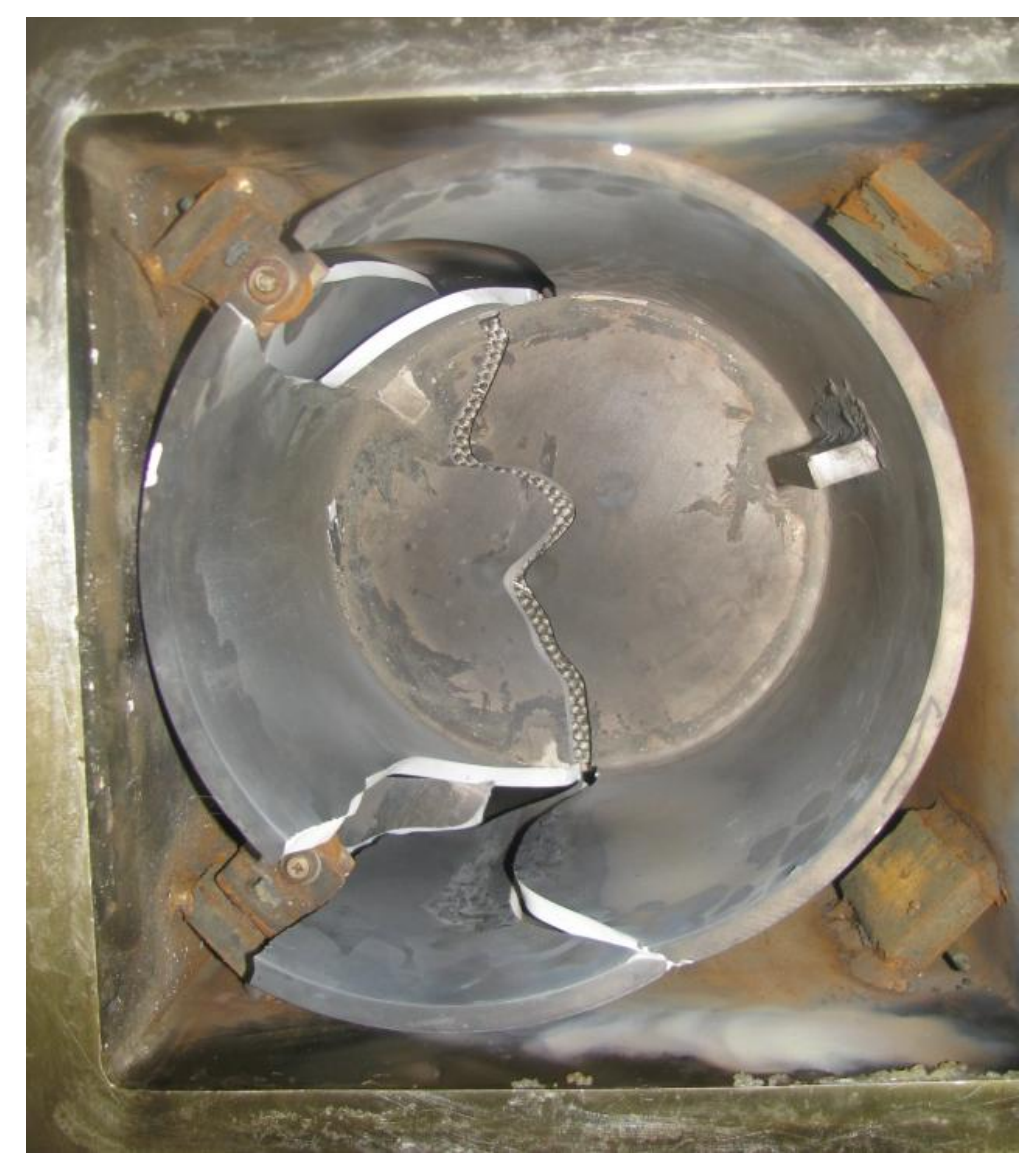

Figure 59: The tumbler broken due to a thermal shock during experiment \#8.

In the interim period, while the system was being redesigned, zirconium hydride powder was purchased and a sample was submitted for Thermogravimetric Analysis (TGA). The TGA system (Netzsch, Model No, STA-LUXX) was used to simulate a dehydriding test under vacuum conditions. Figure 60 shows the results of this test as a plot of sample mass vs. temperature. The decrease in mass at temperatures between 
$620^{\circ} \mathrm{C}$ and $720^{\circ} \mathrm{C}$ indicates that the zirconium hydride decomposition reaction may be accomplished at these temperatures. Therefore, the design requirement for the HMD system for dehydriding was dropped from $1000^{\circ} \mathrm{C}$ to $700^{\circ} \mathrm{C}$.

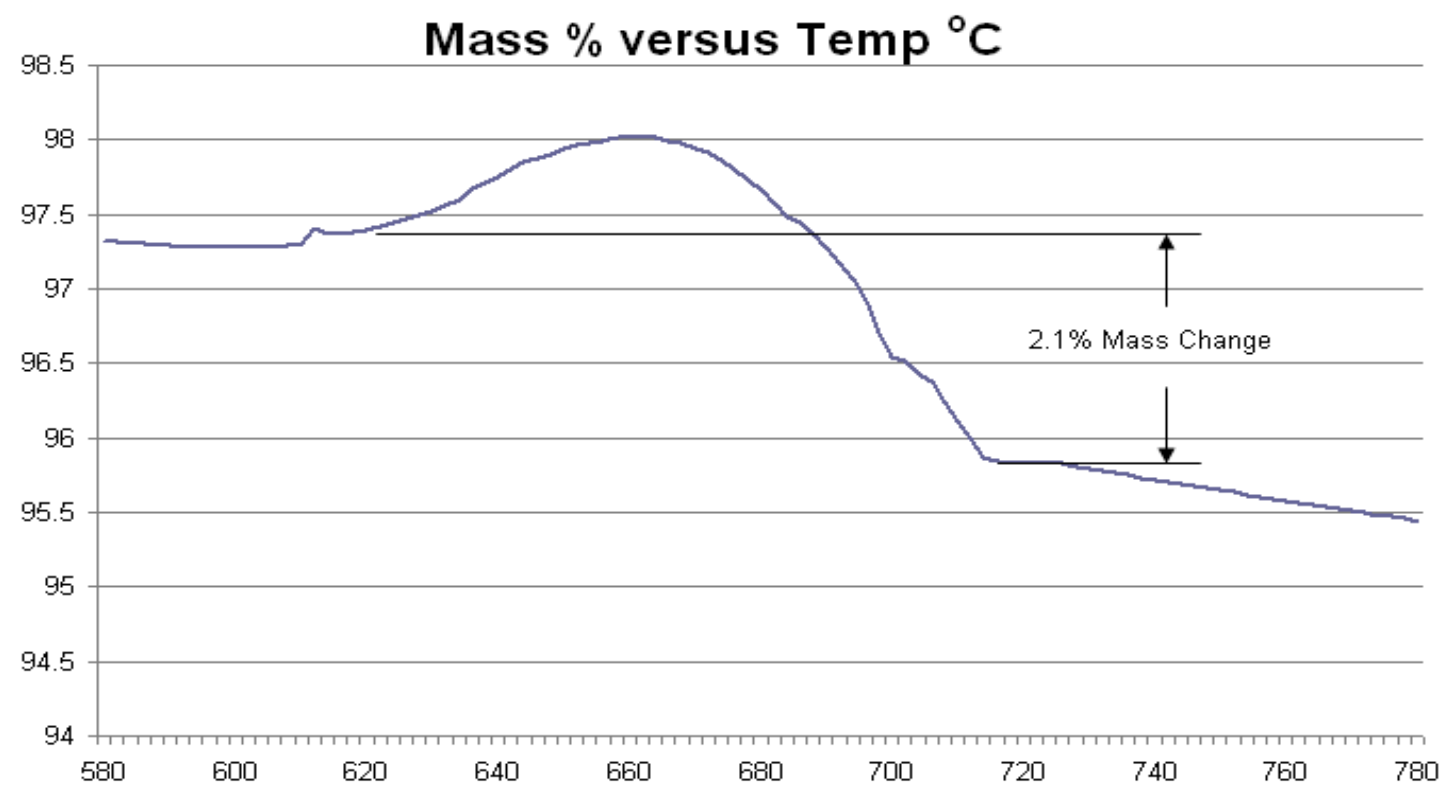

Figure 60: Results of dehydriding $\mathrm{ZrH}_{2}$ using a Thermogravometric Analyzer.

The $2.1 \%$ mass decrease is consistent with zirconium hydride transforming to pure zirconium. From the molecular weights, it is evident that,

$$
\begin{aligned}
& \mathrm{ZrH}_{2}=91.22+2 \times(1.008)=93.236 \mathrm{amu} \\
& \mathrm{ZrH}_{2} / \mathrm{Zr}=93.236 / 91.22=1.0221 \text { or } 2.21 \% \text { mass change }
\end{aligned}
$$

Therefore, the TGA data are consistent with analytical calculations.

The significance of this finding was that the tumbler did not have to be constructed of special materials. Stainless steels (300 series) have working temperatures 
close to $700^{\circ} \mathrm{C}$. A new tumbling chamber designed for use with an external heater was made using a stainless steel pipe sealed at one end and a $150 \mathrm{lbs}$ flange at the other. Figure 61 shows the new tumbling chamber weldment. A 1-1/2" hex head stainless steel nut was welded to the sealed end to engage the hydraulic motor. A mating bolt was welded to the hub mounted on the motor shaft.

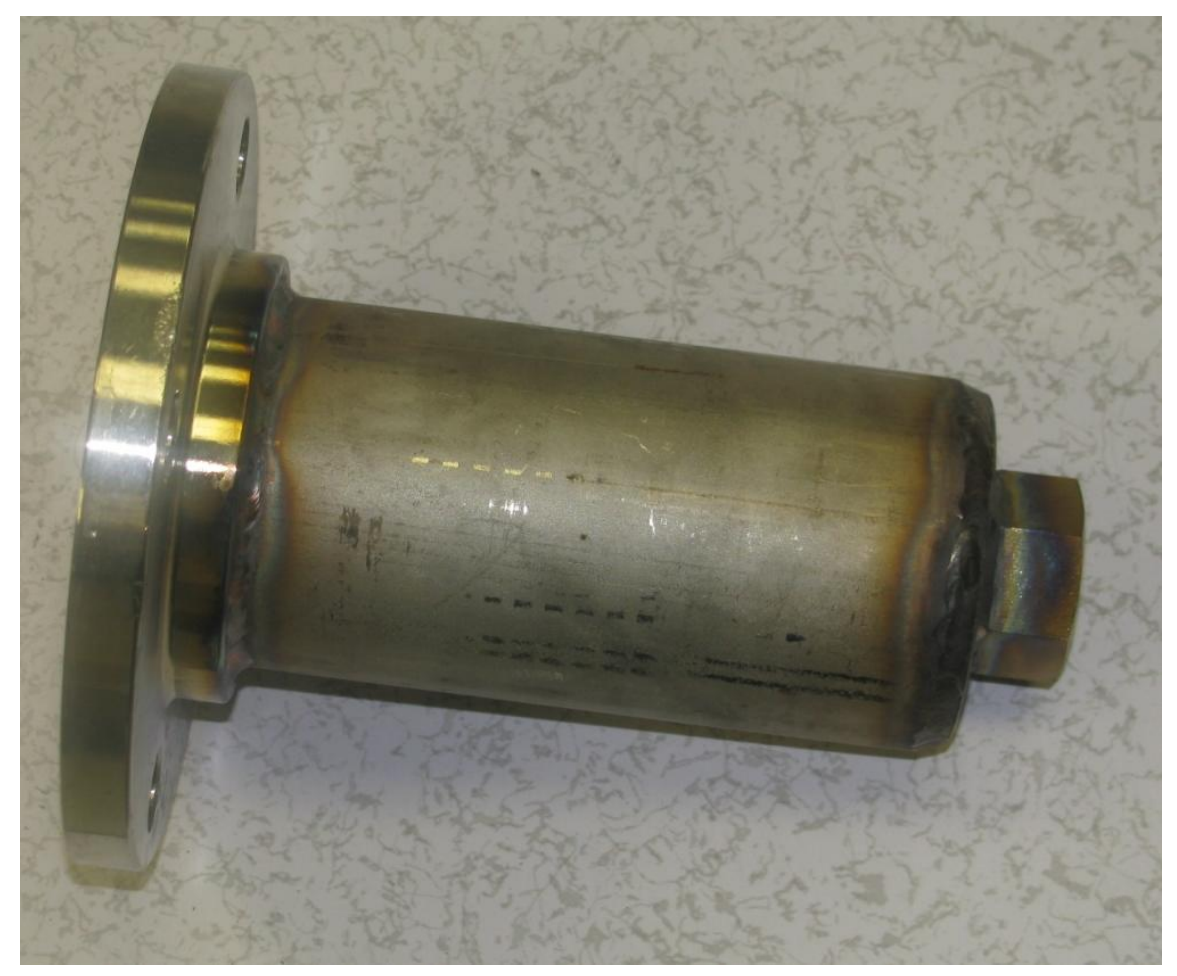

Figure 61: The new tumbling chamber made from a stainless steel pipe.

To protect the tumbling chamber and the Zircaloy charge from contamination during each successive experiment, a stainless steel sleeve was inserted into the chamber. Figure 62 shows this sleeve prior to mounting inside the chamber with the samples loaded inside. A small hole was drilled in the bottom of this sleeve to insert a small 
stainless steel bolt. This bolt facilitated stirring during tumbling and prevented the sample from simply sliding around the bottom of the sleeve during the tumbling process.

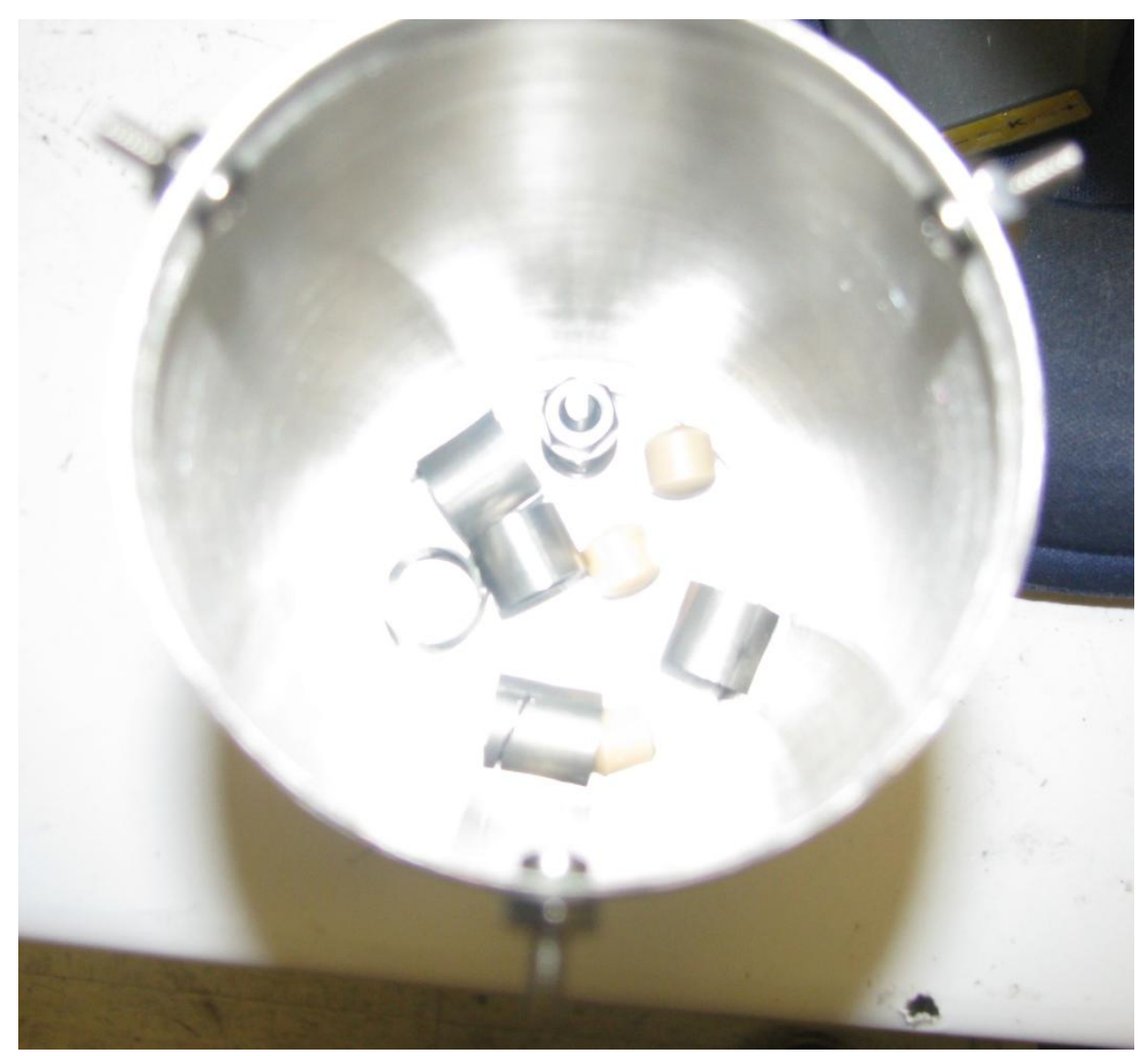

\section{Figure 62: The stainless steel sleeve to protect the tumbling chamber from contamination.}

An attempt was made to isolate the hydraulic motor from the heat generated during the hydriding and dehydriding process. Figure 63 shows the mating bolt attached to the hydraulic motor hub with the protective insulation. The first picture shows the hub that was attached to the hydraulic motor shaft as well as the insulation around the motor. 
The second picture illustrates the white ceramic fiber board cut to size and fitted to create a heat barrier for the hydraulic motor.
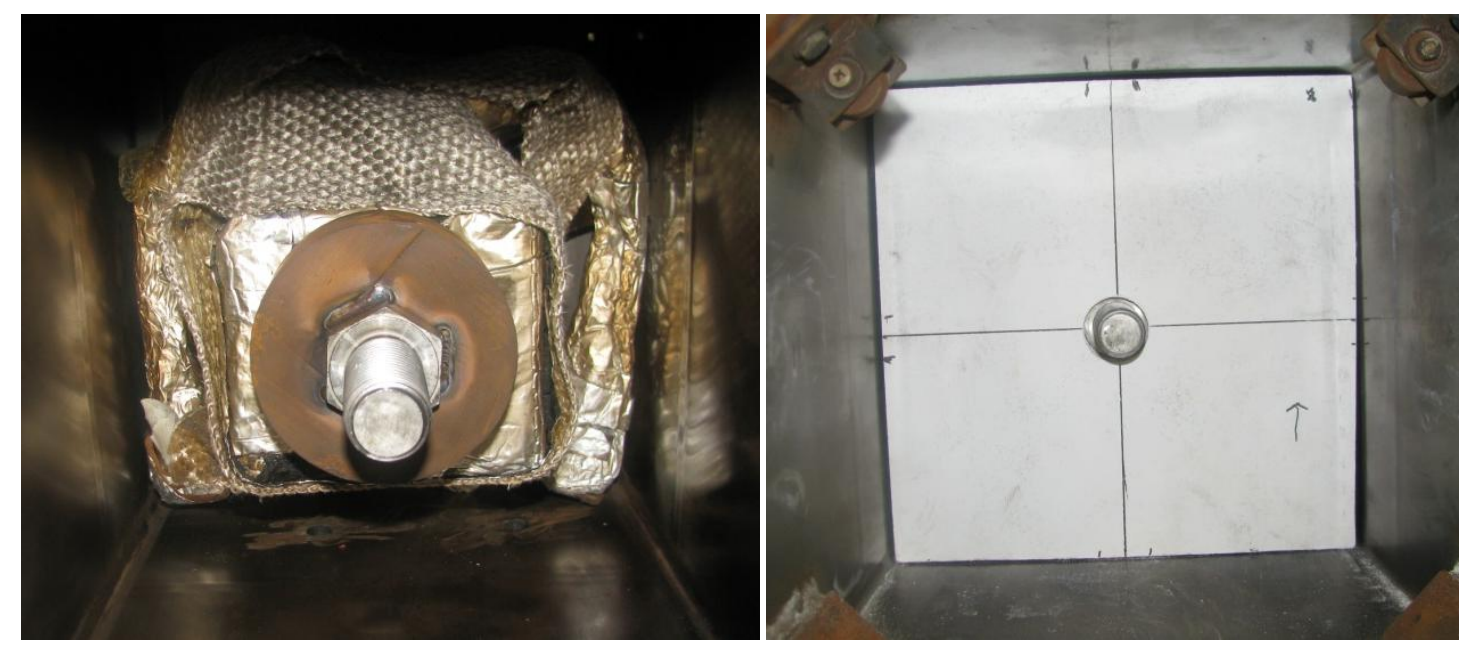

\section{Figure 63: Insulation around the 1-1/2" stainless steel bolt welded to the hub that is} attached to the hydraulic motor.

The heating system was redesigned to heat from the outside instead of the inside as was the case in the previous design. Figure 64 shows the WATLOW heater installed in the vessel with a ceramic cradle and a silica type insulation packed around the heater. This heater is rated by the manufacturer to $1000^{\circ} \mathrm{C}$.

A temperature controller was purchased from the same vender as the heater. Therefore, it was specifically designed to control this type of heating element. A K-type thermocouple mounted inside the sample chamber controlled the power to the heater. Once the desired process temperature was set, the controller continuously adjusted the heater amperage to maintain this temperature. Figure 65 shows this controller. The 
on/off switch was on the right while the temperature set point controller and actual temperature readout was on the left.
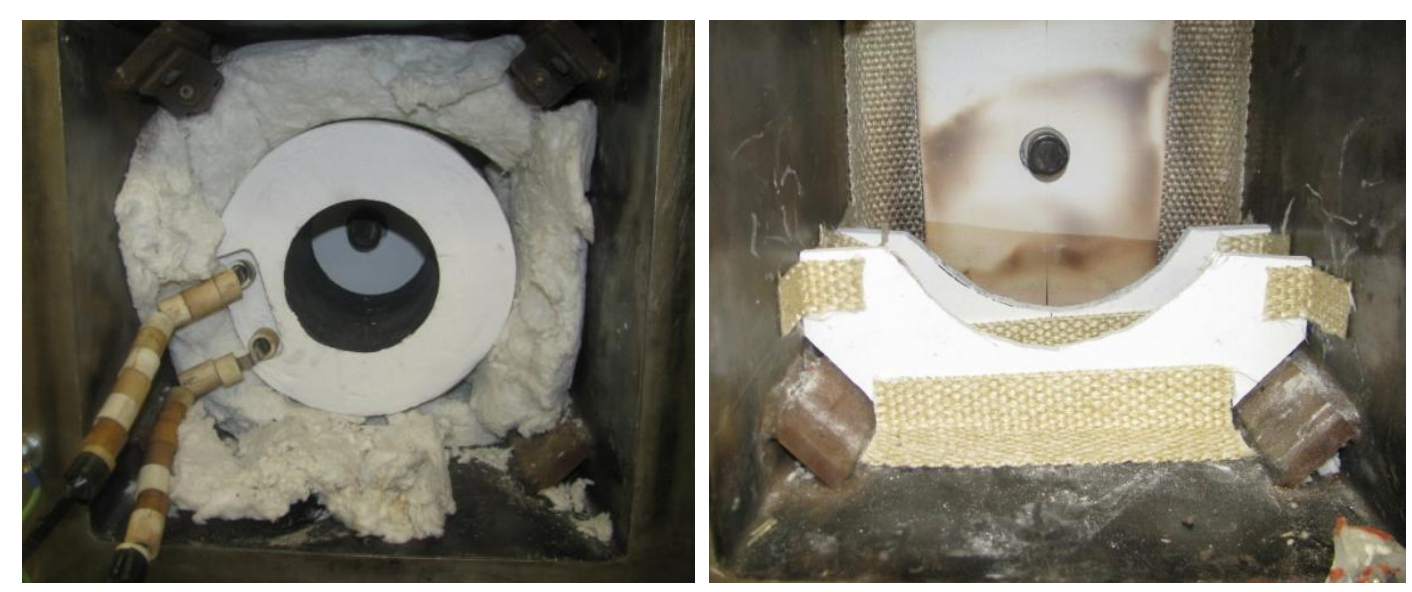

Figure 64: The WATLOW heater installed and surrounded by insulation.

A roto-coupling (Rotary Systems, Ramsey, MN, part no. 012-N-21212-BTS) was installed on the blind flange that mated with the welded flange on the chamber. This type of coupling allowed gas flow in and out during rotation. The design of the coupling was such that the thermocouple port, along the central axis, rotated with the tumbler. This prohibited heating while tumbling. The thermocouple lead had to be disconnected during tumbling to prevent twisting the wire. Figure 66 shows the roto-coupling attached to the blind flange with a ceramic spacer. The spacer was installed to isolate the roto-coupling from the hot process chamber to protect the internal seals, bearings and bearing grease. The thermocouple was held in place with a resin rated for vacuum installations called torr seal (Varian, Palo Alto, CA, model \#9530001). 


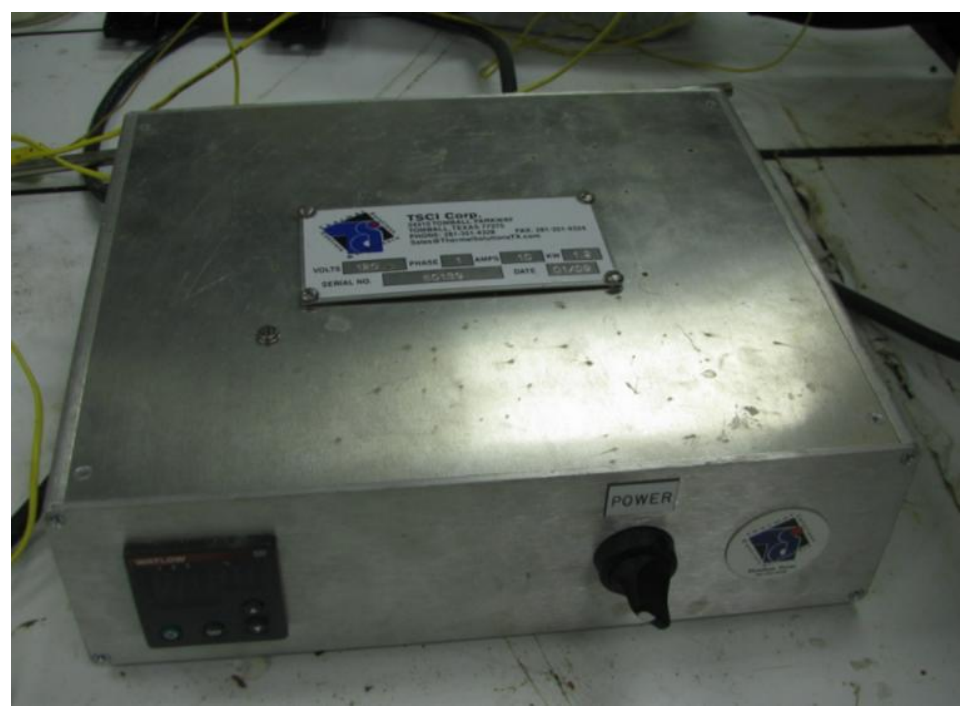

Figure 65: The controller for the WATLOW heating element.

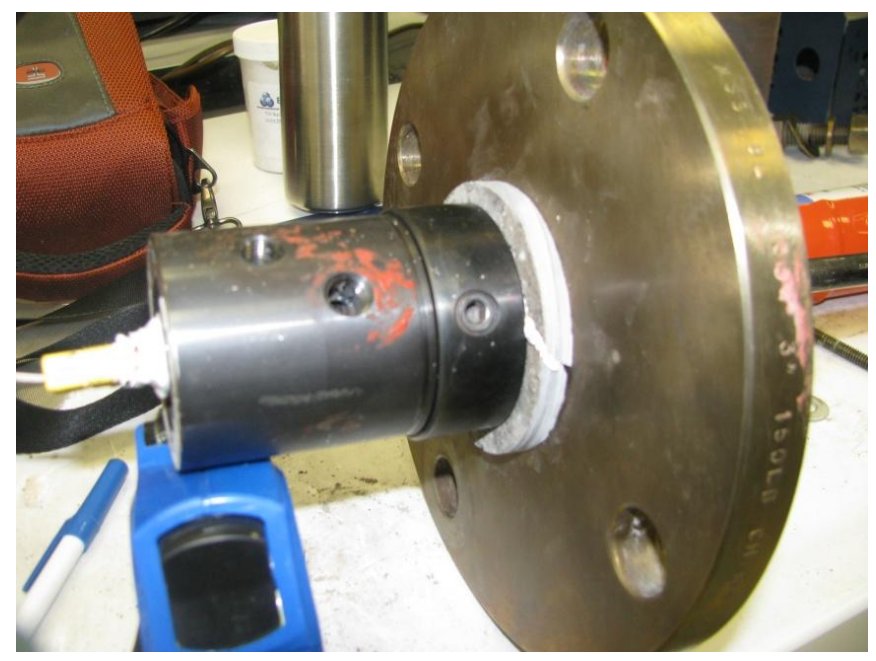

Figure 66: The blind flange with the roto-coupling installed with a ceramic spacer.

One significant challenge was finding a seal that would seal against a vacuum at $\geq 500^{\circ} \mathrm{C}$. The first seal (Graphite gasket with a stainless steel insert - McMaster Carr no. $94095 \mathrm{~K} 88$ ) used was originally rated at $900^{\circ} \mathrm{C}$ by the vendor. Later it was determined the vendor's rating was mistakenly reported. The actual rating was $900^{\circ} \mathrm{F}$. The seal 
composition was a combination of stainless steel and graphite. Figure 67 shows this seal installed on the blind flange.

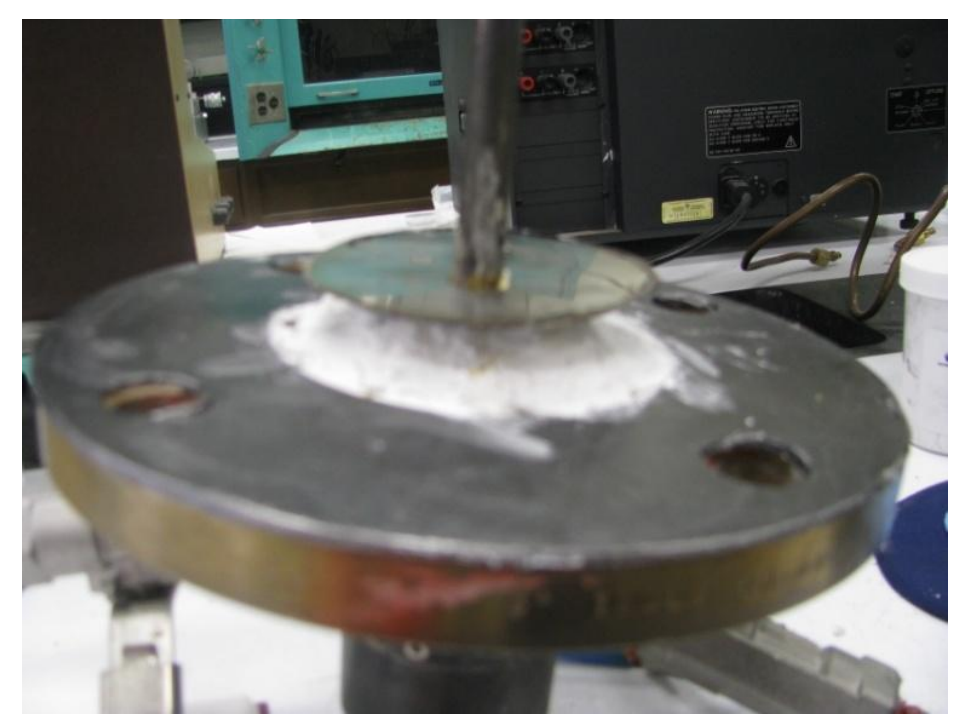

Figure 67: Seal type used to seal between the two mating flanges.

Once the redesign was complete, the revised HMD system was assembled as shown in Figure 68. The metal bracket in the picture is in place to hold the end of the roto-coupling and support the outer end of the tumbling chamber. Silica insulation was packed around the chamber to prevent heat loss.

Another improvement to the design was installing an oxygen trap (Alltech, Guelph, Ontario, Canada, BIG oxygen trap) upstream of the nitrogen trap (titanium sponge) on the specialty gas line. Other researchers in the Fuel Cycle and Materials Laboratory were having problems with small amounts of oxygen in their specialty gas. 
Oxygen present in this experiment forms zirconium oxide instead of zirconium hydride.

Figure 69 shows the oxygen trap mounted to the side of the control panel.

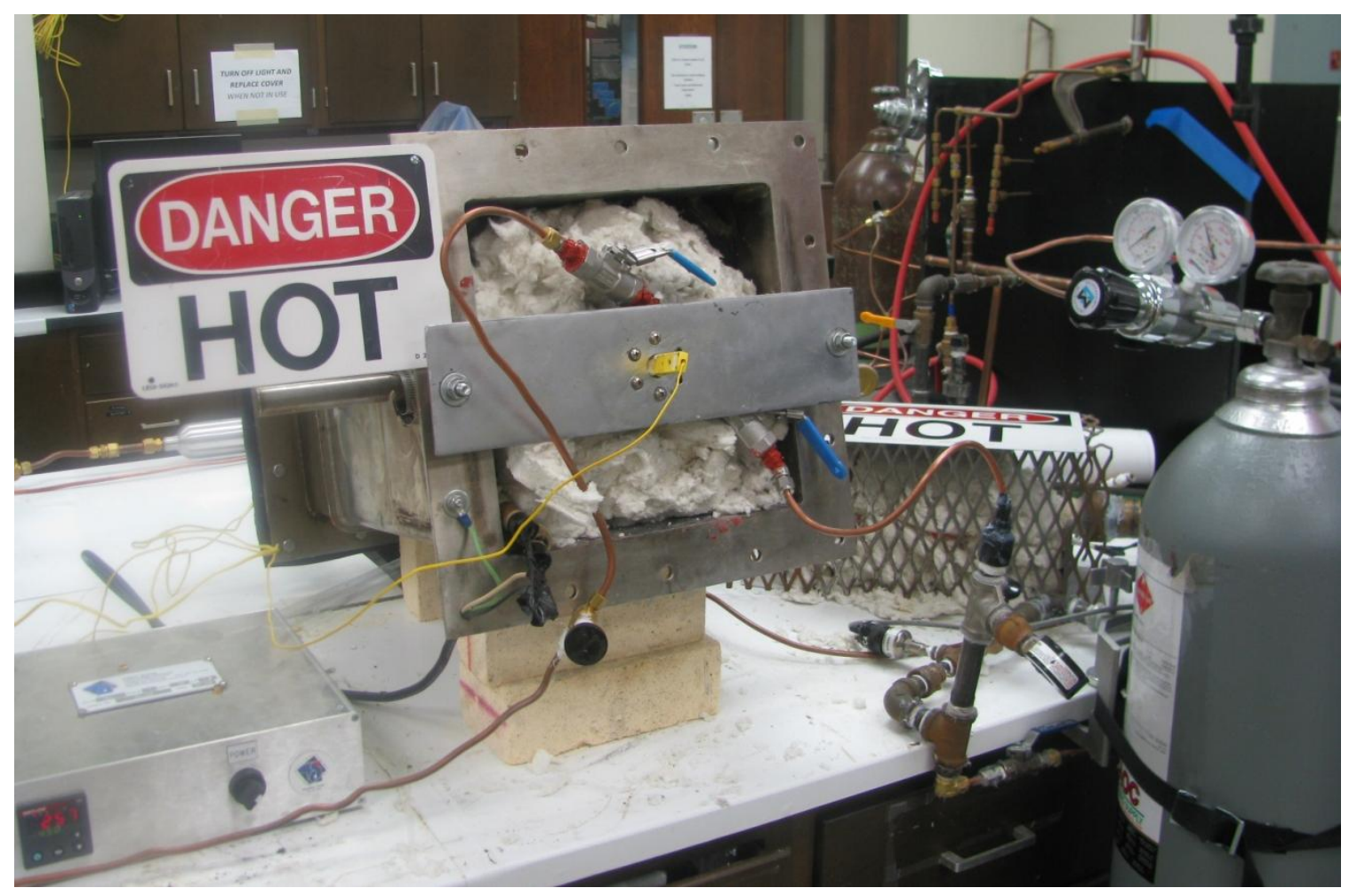

Figure 68: The assembly of the rebuilt HMD machine. 


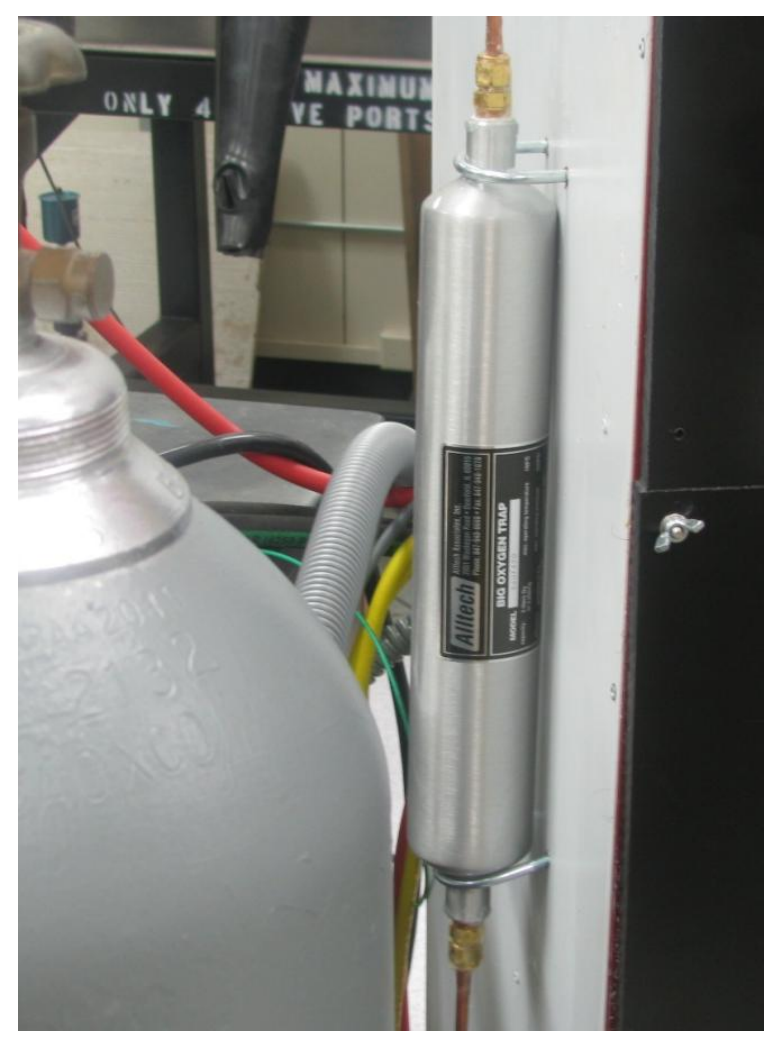

Figure 69: An oxygen trap mounted to the side of the control panel to filter oxygen from the specialty gas stream.

\subsubsection{EXPERIMENT \#9}

The summary of experiment \#9 is provided in Table 12. The target for this experiment was to hydride at $550^{\circ} \mathrm{C}$ for eight hours and milling for one hour. The experiment progressed satisfactory until the dehydriding process. The heater failed to heat after the tumbling process. Therefore, the experiment was stopped. 
Table 12: A summary of experiment \#9.

\begin{tabular}{|c|c|c|}
\hline Experiment \#9 & 25-Aug-09 & \\
\hline & Temperature $\left({ }^{\circ} \mathrm{C}\right)$ & Time (hrs) \\
\hline Hydride & 540 & 9 \\
\hline Milling & N/A & 1 \\
\hline Dehydride & 700 & 0.16 \\
\hline Mass Change & \multicolumn{2}{|c|}{0} \\
\hline Comments & \multicolumn{2}{|c|}{ Heater malfunction } \\
\hline
\end{tabular}

The heater was exchanged with the vendor for a new heater. Examination of the sample showed partial hydriding of the tubes. The sample was brittle enough to shatter when struck by a hammer, but it was not as brittle as is characteristic of fully hydrided zirconium hydride described in Section 2, Figure 2. Figure 70 shows the samples upon removal from the tumbler. Although the samples appear to have a gold tint indicative of zirconium nitride, the samples actually had a blackish-brown film. A cotton swab was inserted inside the gas inlet and a residue was found inside. It appeared that the grease from the roto-coupling was volatilized during the test and coated the samples, preventing hydriding.

After discussing this with the roto-coupling vendor, it was decided to seal the center hole (thermocouple port) and the bolt holes with a fractal paste that the vendor recommended (See Figure 71). A thorough cleaning was conducted and the ceramic paste was installed on the inside of the blind flange. Figure 72 shows the inside of this plate with the white ceramic paste installed. 


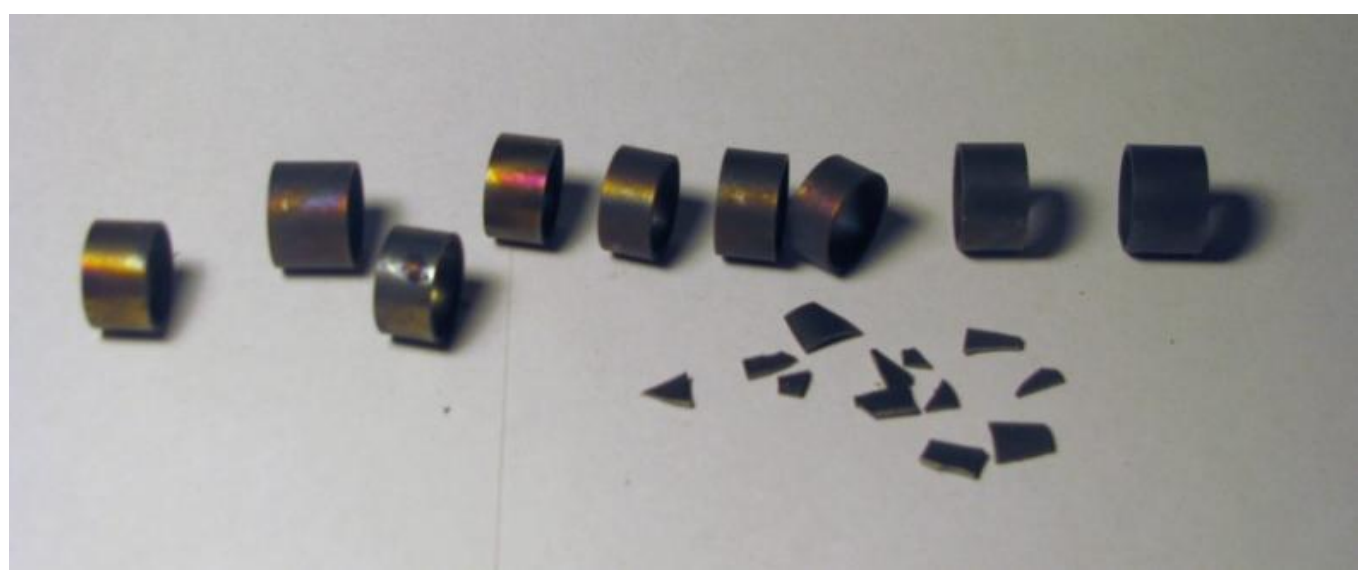

Figure 70: Samples from experiment \#9 shows partial hydriding.

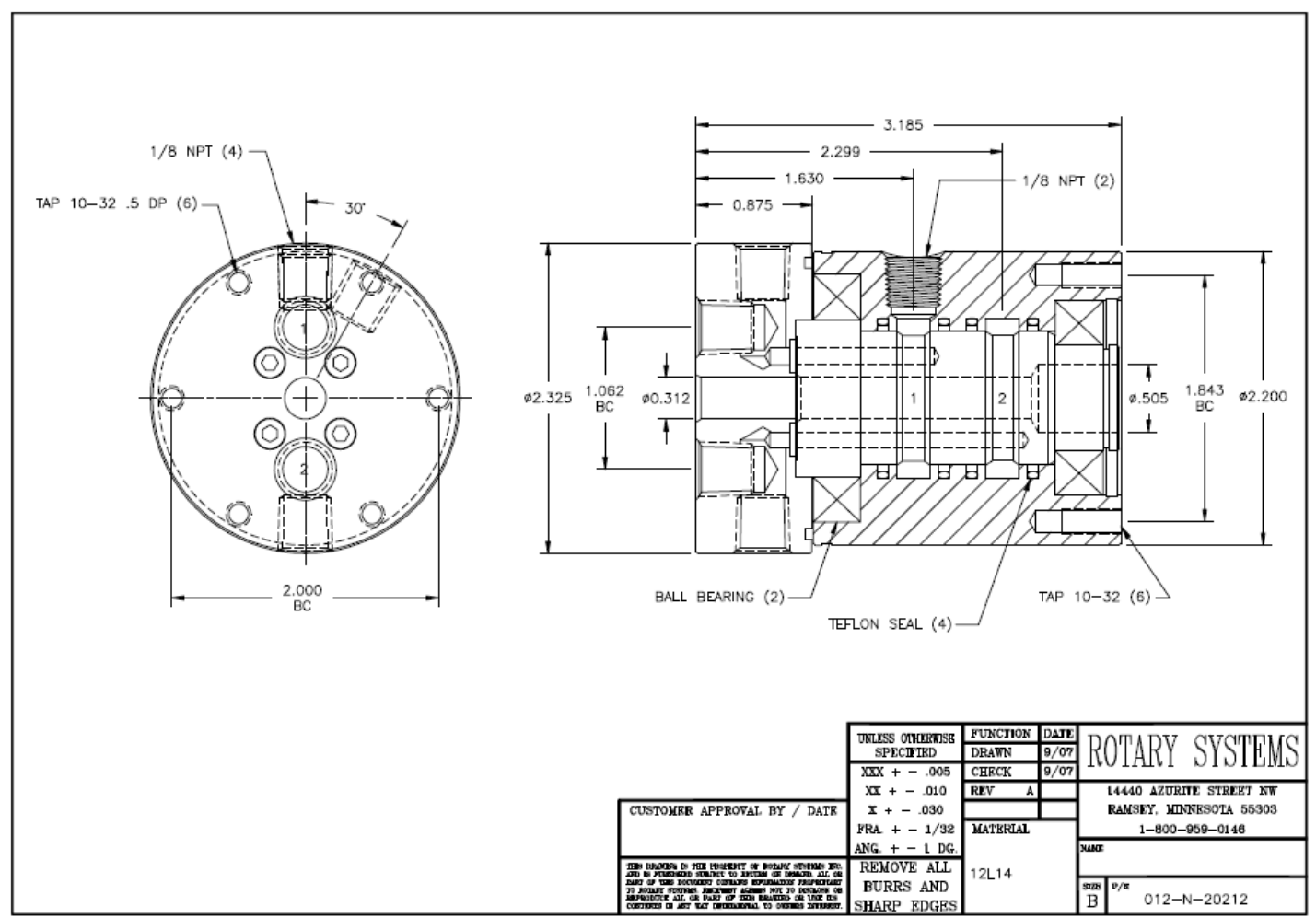

Figure 71: An assembly drawing of the roto-coupling. 


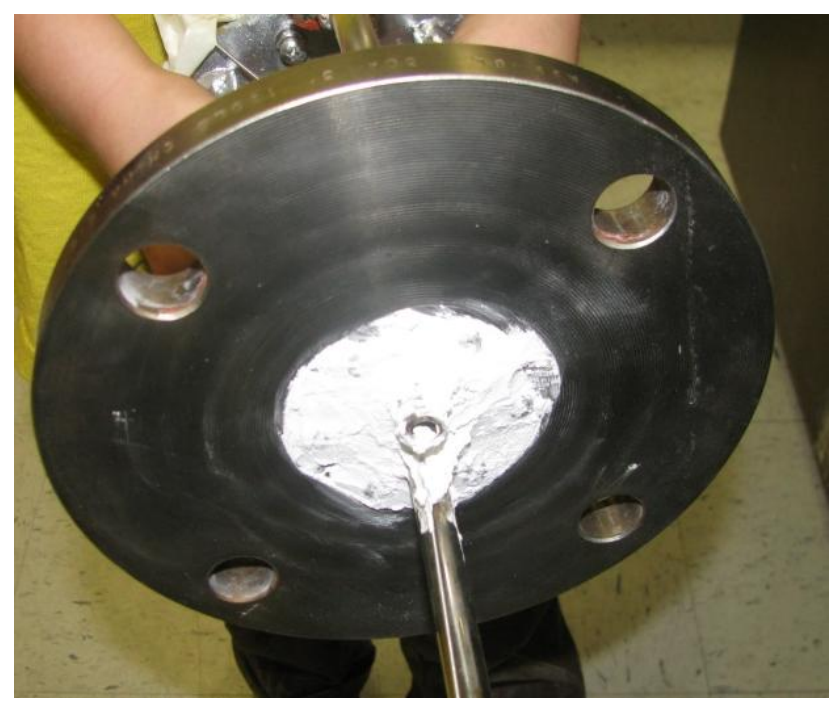

Figure 72: Ceramic putty applied to seal the inside from contamination caused by the roto-coupling.

The same seal was used between the two flanges for this next experiment. The final change for experiment \#10 was to bend the thermocouple measuring the inside temperature so that it lightly touched the edge of the sleeve. This gave a more accurate temperature reading of the sample without interfering with the tumbling process.

\subsubsection{EXPERIMENT \#10}

The summary of experiment \#10 is provided in Table 13. For this experiment, it was decided to hydride at $450^{\circ} \mathrm{C}$ for four hours, milling for one hour, hydride at $450^{\circ} \mathrm{C}$ for four more hours, milling for one more hour before attempting to dehydride. 
Table 13: A summary of experiment \#10.

\begin{tabular}{|c|c|c|}
\hline Experiment \#10 & 3-Sep-09 & \\
\hline & Temperature $\left({ }^{\circ} \mathrm{C}\right)$ & Time (hrs) \\
\hline Hydride & 450 & $4 / 4$ \\
\hline Milling & N/A & $1 / 1$ \\
\hline Dehydride & 715 & 0.16 \\
\hline Mass Change & \multicolumn{2}{|c|}{0} \\
\hline Comments & Sample coated with black residue. \\
\hline
\end{tabular}

During the dehydride process, the controller set point reached a maximum at $816^{\circ} \mathrm{C}$. After heating the process to only $632^{\circ} \mathrm{C}$, the controller was switched to a Variactype controller (see Figure 73). This controller succeeded in heating the sample to a maximum temperature of $713^{\circ} \mathrm{C}$. At this point, a vacuum was pulled on the sample chamber for a short period of time to facilitate dehydriding, if possible.

The sample once again did not pulverize. Figure 74 shows the post-test charge from experiment \#10. The samples did not hydride completely but showed some embrittlement due to a slight hydriding. A moderate blow with a hammer shattered the samples. The samples were covered with a black "soot" coating that appeared to prevent the complete hydrogen embrittlement process. 


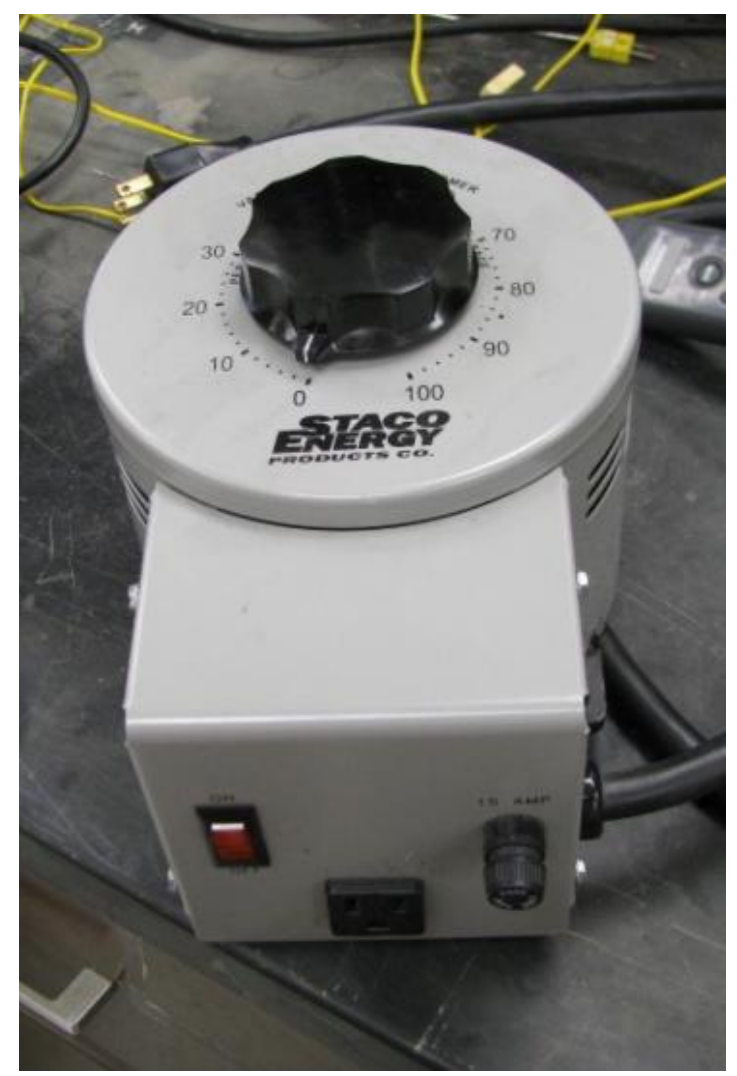

Figure 73: A variac-type controller temporarily used to control the WATLOW heating element.

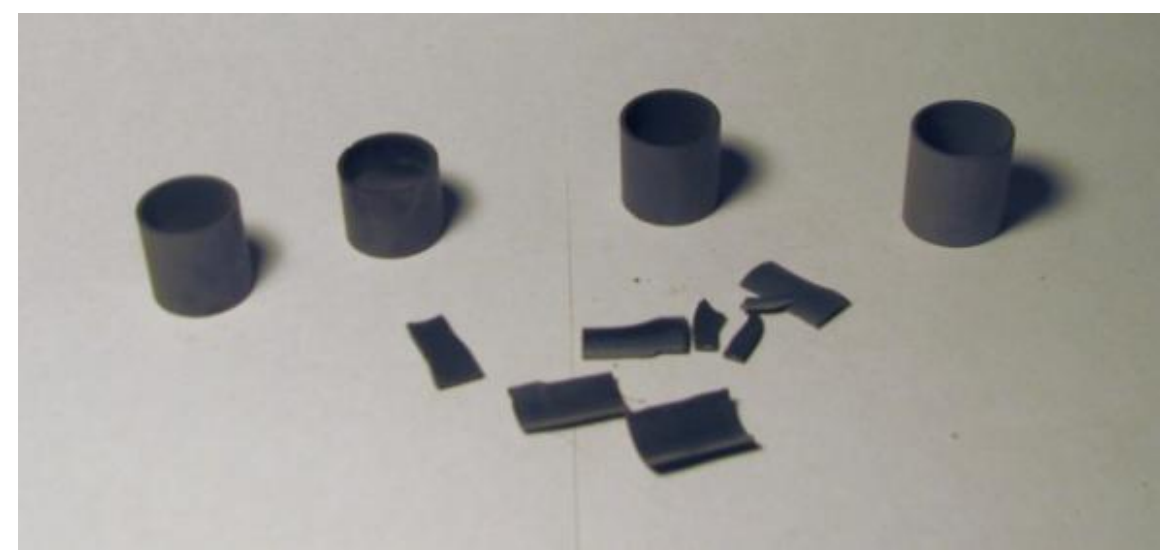

Figure 74: Samples from experiment \#10 showing slight hydriding and a dark "soot" coating. 
As before, the sample contamination appeared to be originating in the rotocoupling. Inspection of the ceramic paste on experiment \#10 showed cracking and the appearance of an oily residue leaking by in the center of the roto-coupling. Therefore, the only modification to experiment \#11 was a thicker and more complete application of this paste. Figure 75 shows the application of this ceramic paste.
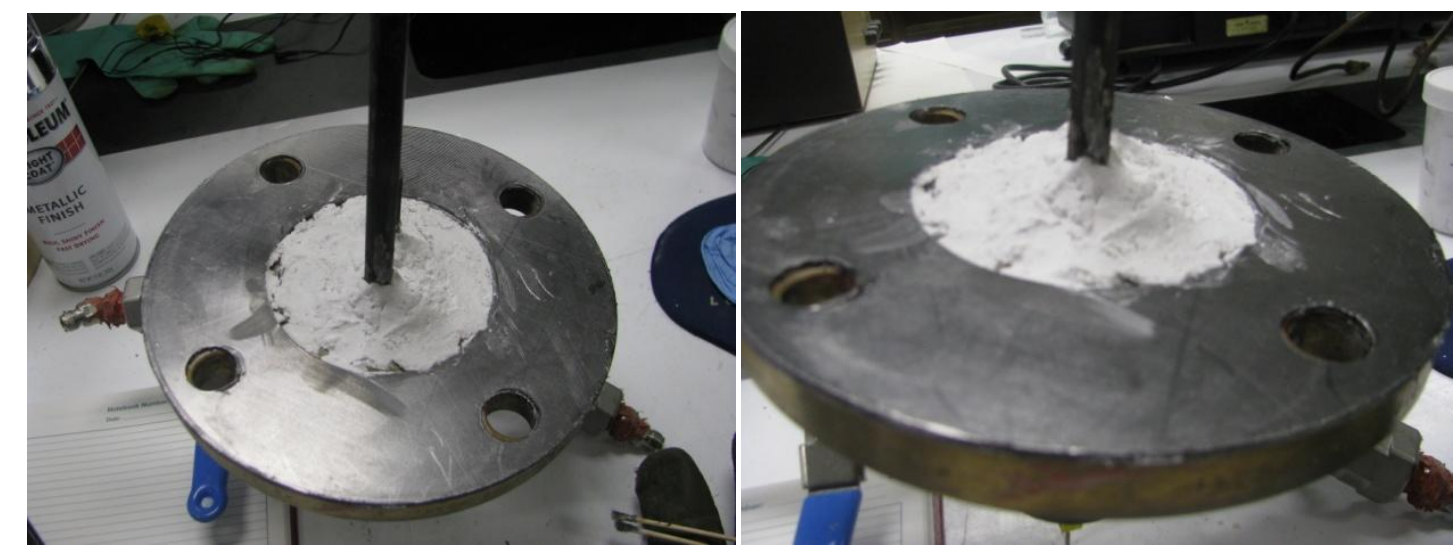

Figure 75: Ceramic paste applied to prevent oil residue from contaminating samples.

\subsubsection{EXPERIMENT \#11}

The summary of experiment \#11 is provided in Table 14. The goal of this experiment was to hydride at $430^{\circ} \mathrm{C}$ for eight hours and then mill overnight. During the milling process, a specialty gas line vibrated loose, exposing the sample to air. The sample showed very little hydriding. Figure 76 shows the samples from this experiment. Although some embrittlement was evident, it was not sufficient to mill into a powder. 
Table 14: A summary of experiment \#11.

\begin{tabular}{|c|c|c|}
\hline Experiment \#11 & 23-Sep-09 & \\
\hline & Temperature $\left({ }^{\circ} \mathrm{C}\right)$ & Time (hrs) \\
\hline Hydride & 430 & 8 \\
\hline Milling & N/A & 12 \\
\hline Dehydride & N/A & 0 \\
\hline Mass Change & \multicolumn{2}{|c|}{0} \\
\hline Comments & Gas line vibrated loose. \\
\hline
\end{tabular}

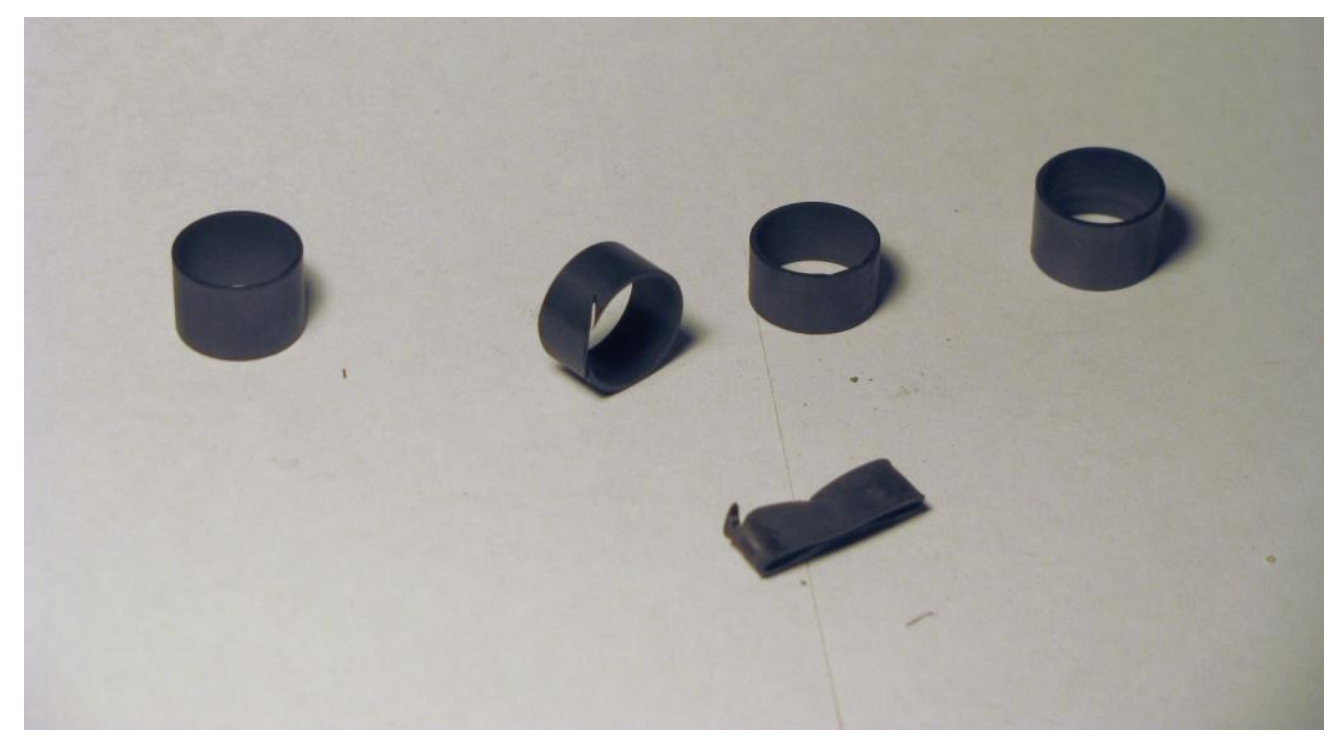

Figure 76: Samples from experiment \#11.

\subsubsection{EXPERIMENT \#12}

The summary of experiment \#12 is provided in Table 15 . Due to the potential problems with the heater, it was decided not to attempt the dehydride process until successful hydriding and milling was accomplished. Once the problems with hydriding and milling were solved, Subsequent experiments would be heated to the elevated temperatures necessary for dehydriding. 
Table 15: A summary of experiment \#12.

\begin{tabular}{|c|c|c|}
\hline Experiment \#12 & 9-Oct-09 & \\
\hline & Temperature $\left({ }^{\circ} \mathrm{C}\right)$ & Time (hrs) \\
\hline Hydride & 507 & 8 \\
\hline Milling & N/A & 0.5 \\
\hline Dehydride & N/A & 0 \\
\hline Mass Change & \multicolumn{2}{|c|}{0} \\
\hline Comments & Sample coated with black film \\
\hline
\end{tabular}

The preliminary goal of this experiment was to hydride at $515^{\circ} \mathrm{C}$ for eight hours and mill overnight. The only modification for experiment \#12 was to install a stainless steel plate in an attempt to "collect" the "soot" that seemed to be coming off the rotocoupling. Figure 77 shows this plate prior to the test.

This plate did not solve the problem for the sample had the same appearance.

Figure 78 shows the sample from experiment \#12. The black "soot" appeared to be present with this sample also, albeit not as thick. This sample was easily broken with a hammer but was still not fully hydrided. 


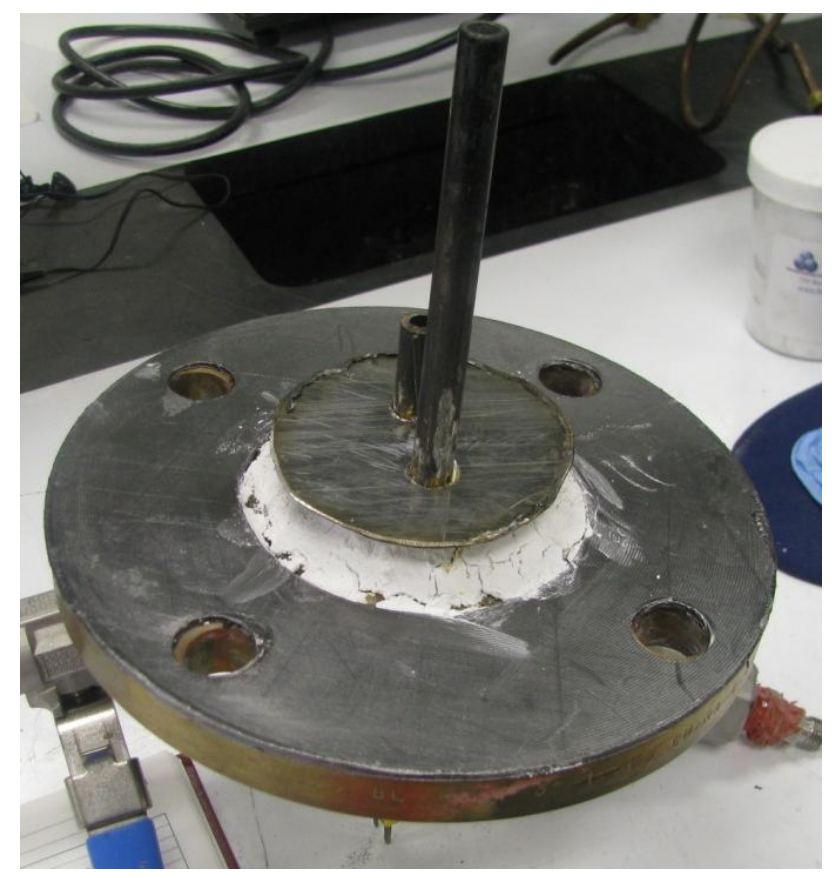

Figure 77: Installation of a small stainless steel plate to retard the flow of contaminants into the sample chamber.

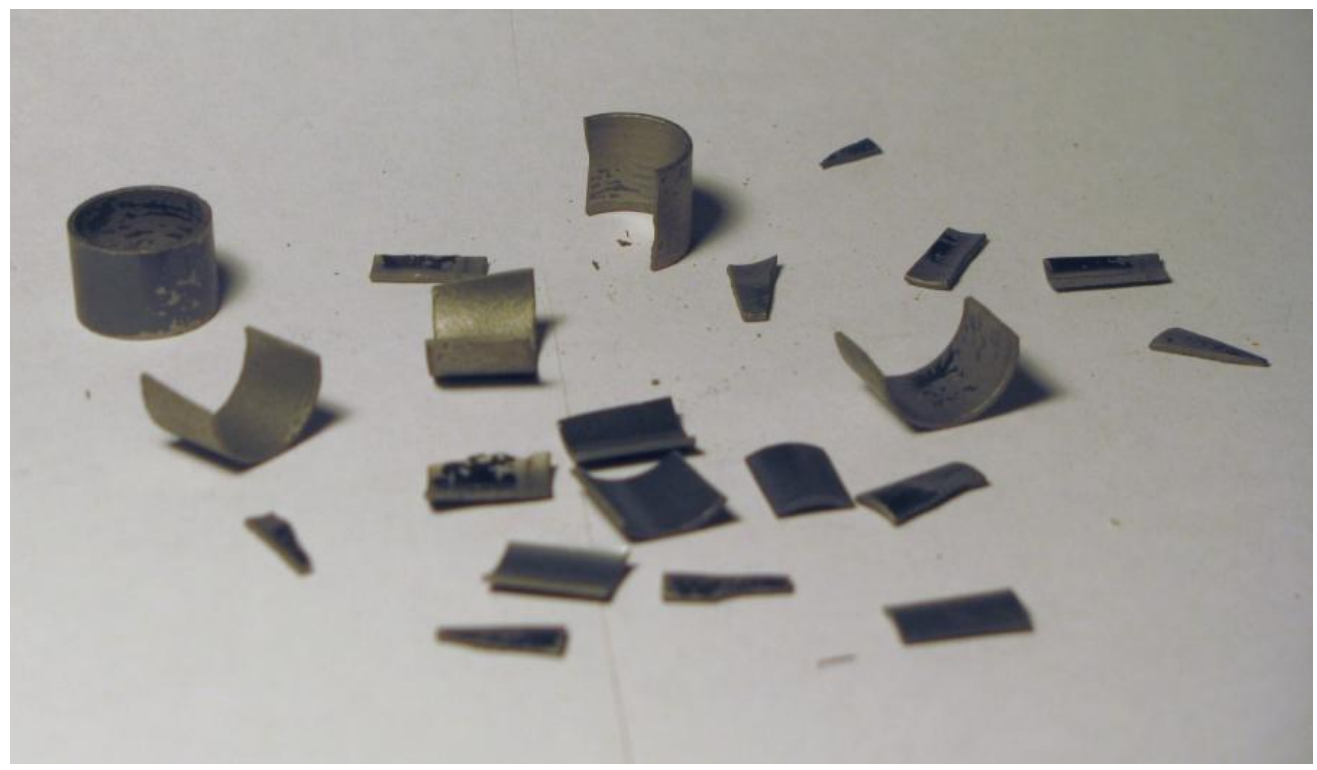

Figure 78: Sample from experiment \#12. 
One important observation was the seal was significantly damaged. Upon further inspection, it was observed that it was coated with an "oily" residue. This was the graphite separating from the stainless steel backing ring. Figure 79 shows the seal residue on the blind flange following this experiment. This graphite seemed consistent with the residue coating the samples.

A search for a new type of seal led to the Flexitallic type gaskets. The vendor information showed good sealing capabilities up to $900^{\circ} \mathrm{C}$ and no off gassing potential. Figure 80 shows the gasket installed on the tumbler flange prior to the next experiment.

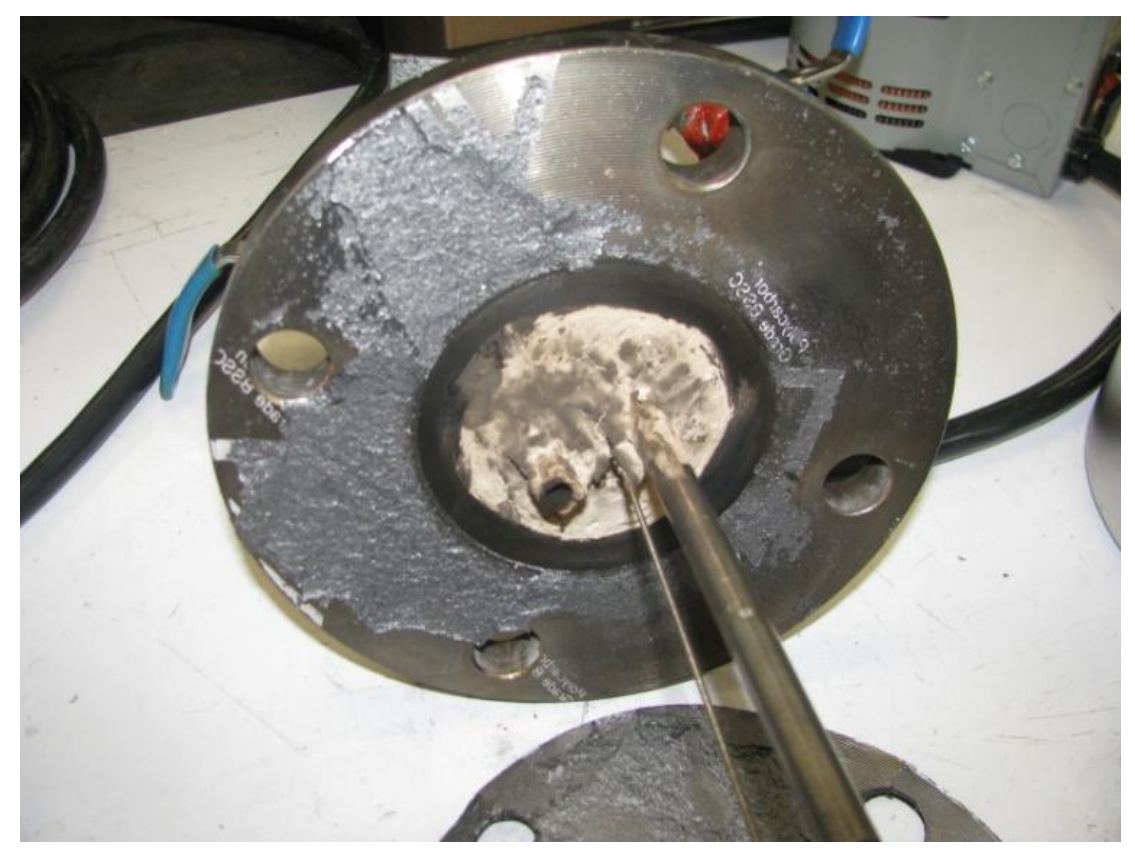

Figure 79: Graphite residue remaining on the blind flange following experiment \# 12. 


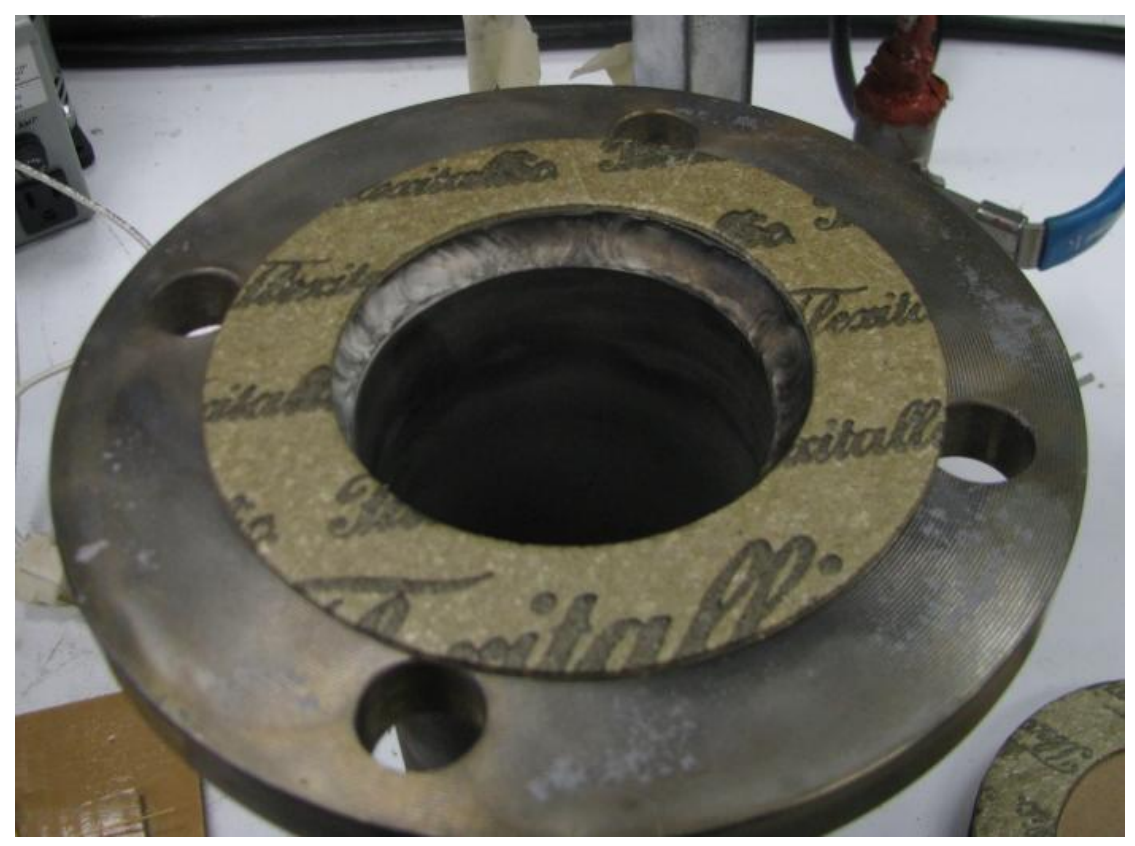

Figure 80: Flexitallic gasket mounted on the tumbler flange.

\subsubsection{EXPERIMENT \#13}

The summary of experiment \#13 is provided in Table 16. The target temperature for hydriding in this experiment was $535^{\circ} \mathrm{C}$ for eight hours and milling overnight. This experiment progressed satisfactory until a two hours into milling. The bearings of the roto-coupling seized. Upon retrieving the charge, it was observed that the charge did not fully hydride. Figure 81 shows the sample upon removal from the vessel.

This sample was nearly identical to previous samples. The "soot" layer appeared to prevent total hydriding. The sample was easily shattered with a hammer. Since the bearings of the roto-coupling locked up during milling, new bearings were installed. It was obvious that the roto-coupling was exceeding its operation temperature. The 
solution was to move the roto-coupling away from the blind flange. An offset structure was constructed to move the coupling away from the heat.

Table 16: A summary of experiment \#13.

\begin{tabular}{|c|c|c|}
\hline Experiment \#13 & 28-Oct-09 & \\
\hline & Temperature $\left({ }^{\circ} \mathrm{C}\right)$ & Time $(\mathrm{hrs})$ \\
\hline Hydride & 528 & 8 \\
\hline Milling & N/A & 2 \\
\hline Dehydride & N/A & 0 \\
\hline Mass Change & \multicolumn{2}{|c|}{0} \\
\hline Comments & Bearing seized on roto-coupling \\
\hline
\end{tabular}

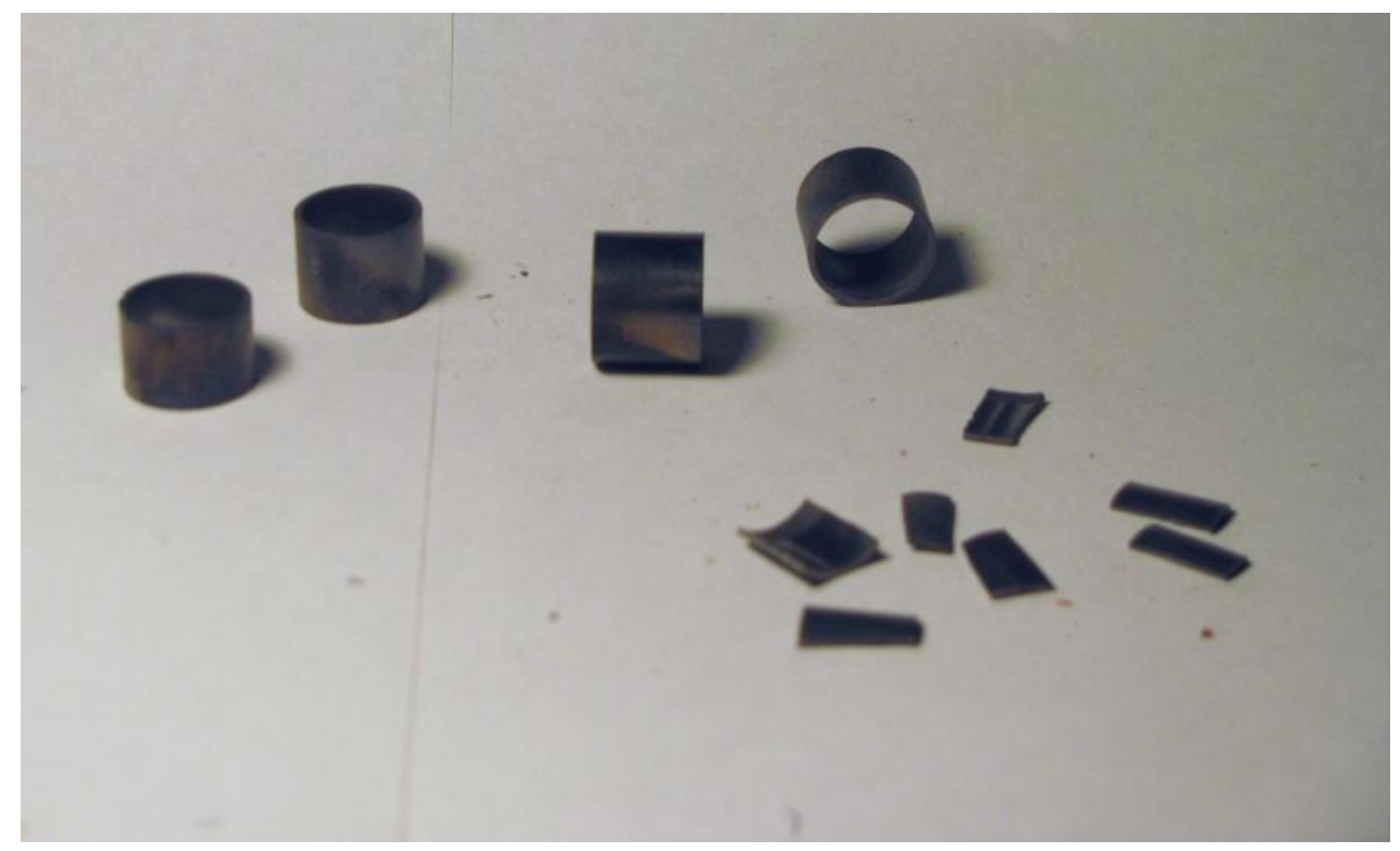

Figure 81: Samples from experiment \#13. 
To accomplish this, the gas feed lines were permanently welded into the blind flange. Figure 82 shows this structure installed on the blind flange. At this point, the roto-coupling role was simply a support bearing for the vessel. A metal brace was bolted to the outer vessel and the roto-coupling to give support to the outer end of the tumbling vessel. Two shut off valves were installed on the gas-flow lines to enable the flow to be shut off and the lines disconnected, permitting the vessel to rotate. The thermocouple was once again installed with torr seal to give access to the sample. Figure 83 shows the thermocouple shape as it was once again bent to touch the edge of the sample collection cup. This gave a more accurate indication of the actual sample temperature.

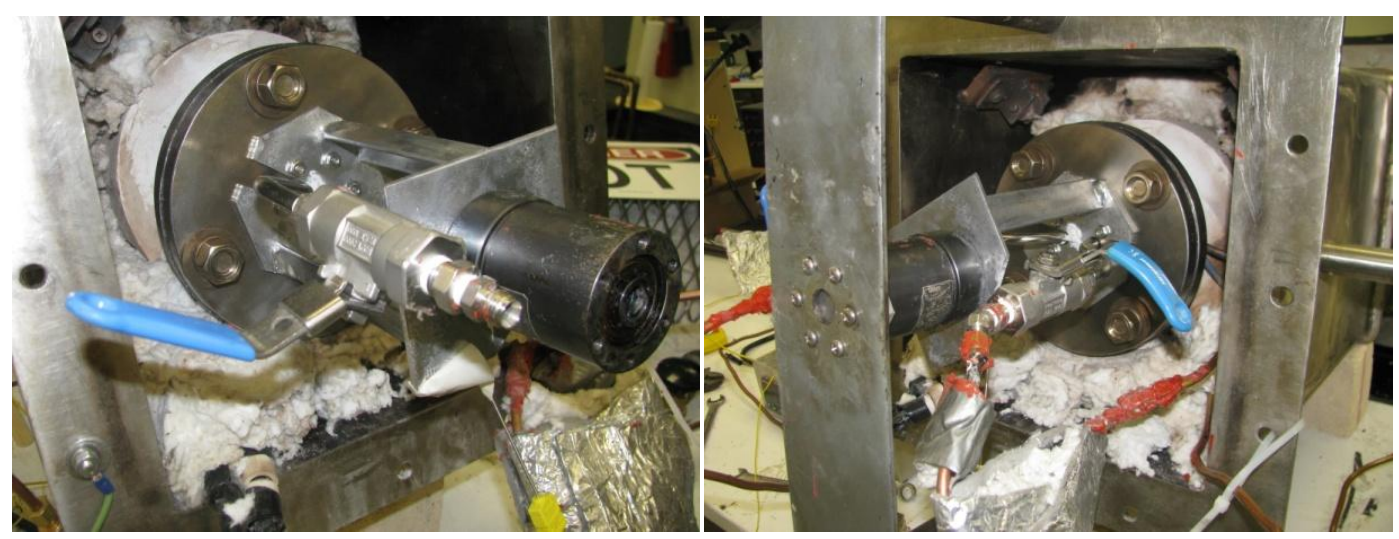

Figure 82: The offset structure installed on the blind flange. 


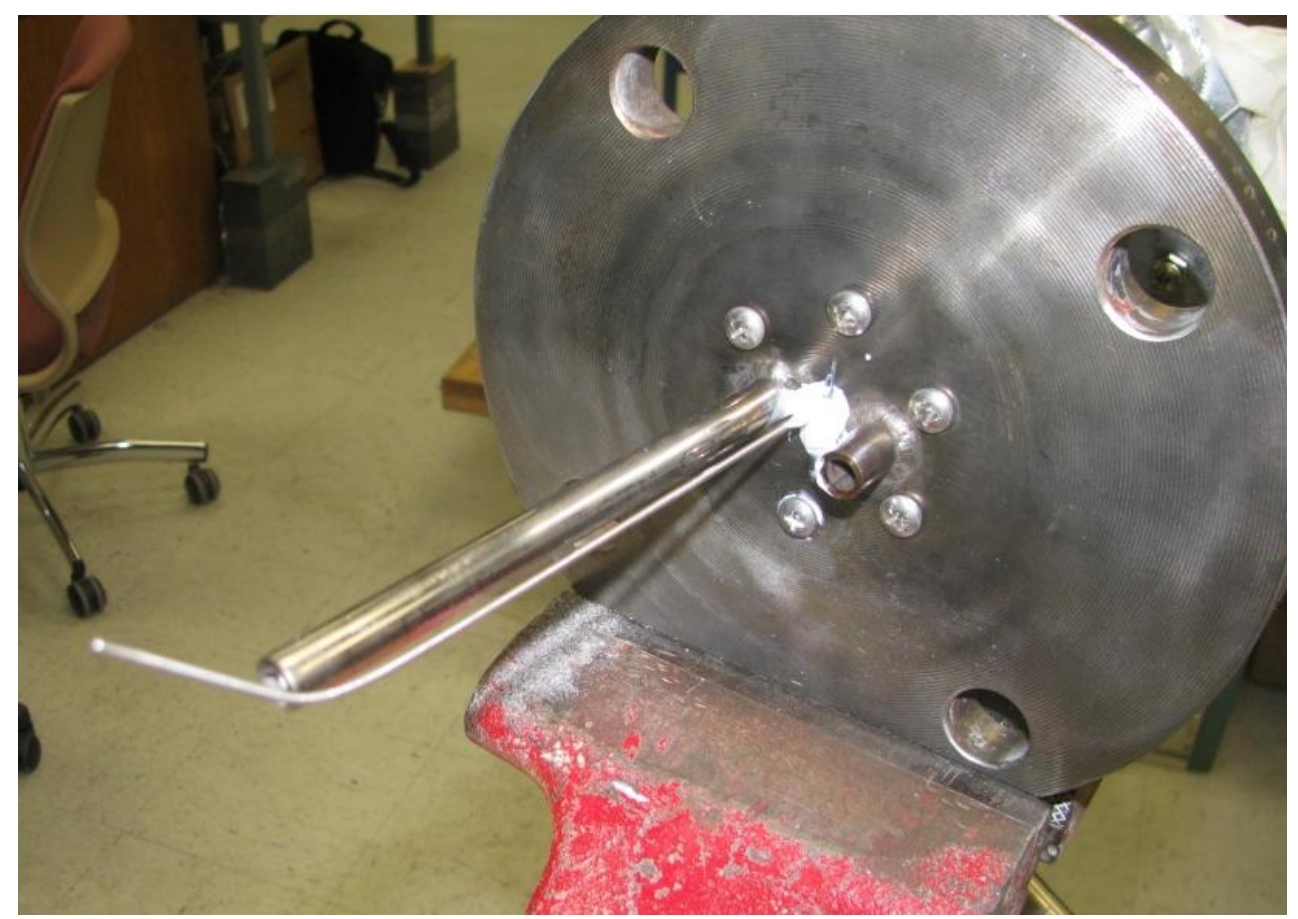

Figure 83: The thermocouple bent to lightly touch the sample cup edge.

\subsubsection{EXPERIMENT \#14}

The summary of experiment \#14 is provided in Table 17. The preliminary goals for the experiment were to hydride at $500^{\circ} \mathrm{C}$ overnight $(12+$ hours $)$ and mill for two hours. The experiment progressed without incident, but the sample showed the same results (Figure 84). This experiment eliminated the grease in the roto-coupling bearings as the source of the contamination. Focus then turned to the seals as the source.

For the next experiment, a new Flexitallic seal was installed. The previous seal appeared to be coated with the same "soot" that was causing sample problems. It was not clear whether the seal was the problem or the victim of the "soot" problem. The vessel was bead-blasted and cleaned thoroughly prior to experiment \#15. 
Table 17: A summary of experiment \#14.

\begin{tabular}{|c|c|c|}
\hline Experiment \#14 & 3-Nov-09 & \\
\hline & Temperature $\left({ }^{\circ} \mathrm{C}\right)$ & Time $(\mathrm{hrs})$ \\
\hline Hydride & 493 & 18.5 \\
\hline Milling & N/A & 2 \\
\hline Dehydride & N/A & 0 \\
\hline Mass Change & \multicolumn{2}{|c|}{0} \\
\hline Comments & Sample coated with black film. \\
\hline
\end{tabular}

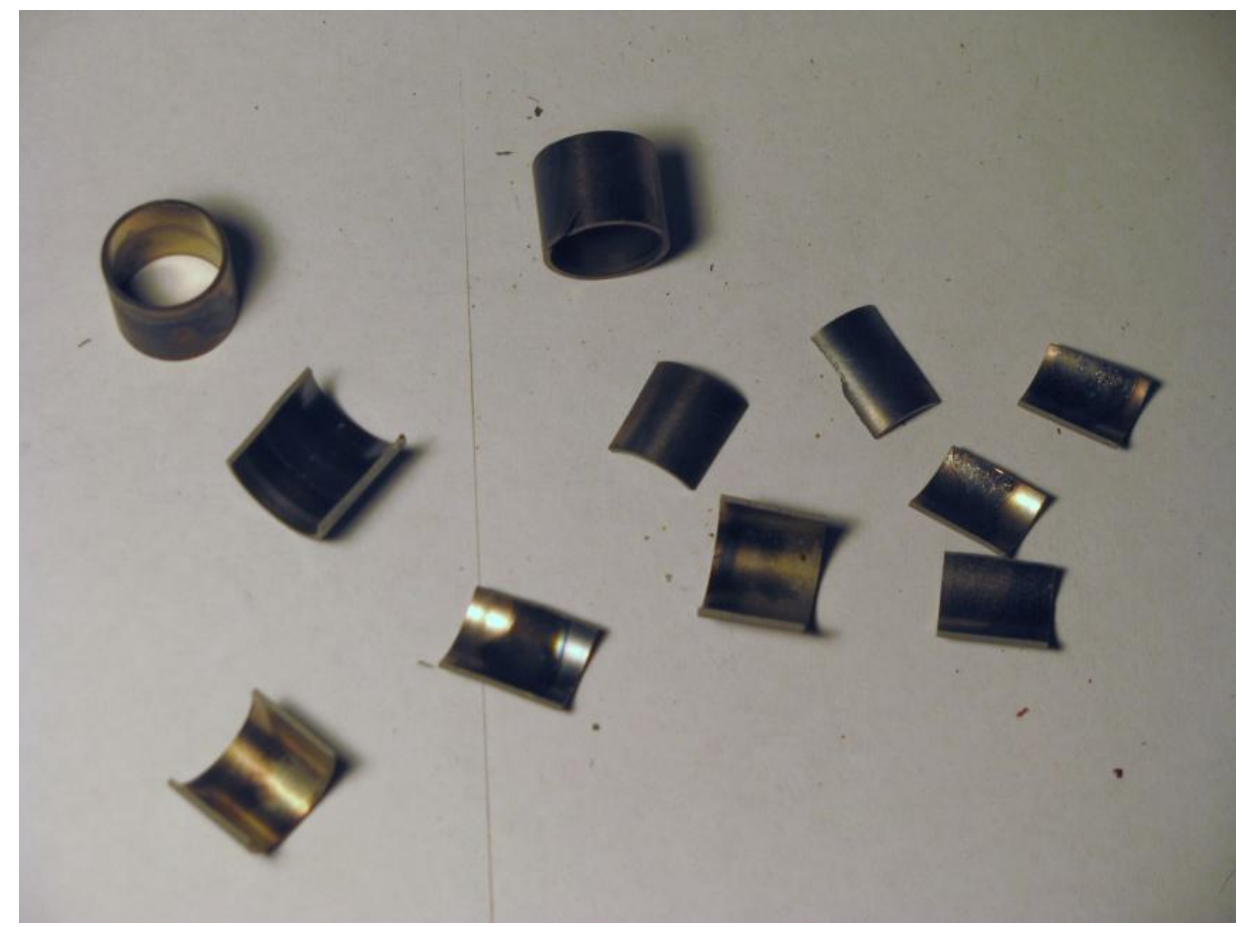

Figure 84: Samples from experiment \#14.

\subsubsection{EXPERIMENT \#15}

The summary of experiment \#15 is provided in Table 18. The goals of this experiment were to hydride at $500^{\circ} \mathrm{C}$ for 24 hours and mill for two hours. The experiment 
progressed satisfactory with no perceived problems. The sample however was nearly identical to the previous samples. Figure 85 shows the samples from this run.

Table 18: A summary of experiment \#15.

\begin{tabular}{|c|c|c|}
\hline Experiment \#15 & 17-Nov-09 & \\
\hline & Temperature $\left({ }^{\circ} \mathrm{C}\right)$ & Time (hrs) \\
\hline Hydride & 501 & 24 \\
\hline Milling & N/A & 2 \\
\hline Dehydride & N/A & 0 \\
\hline Mass Change & \multicolumn{2}{|c|}{0} \\
\hline Comments & Sample coated with black film \\
\hline
\end{tabular}

In some respects, the experiment showed even less progress. These samples would not shatter and were coated with a thick "soot" layer. The seal seemed to fall apart with a sticky surface finish and coat the entire inside of the vessel with the "soot" (see Figure 86). It appeared obvious that a new type of seal was needed.

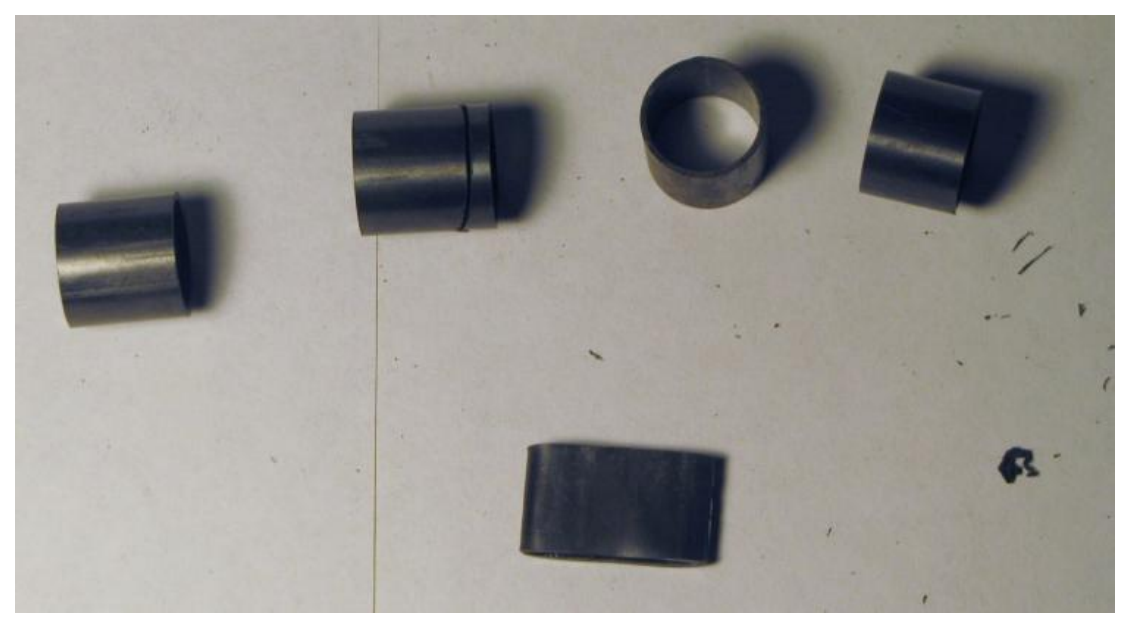

Figure 85: The sample from experiment \#15. 


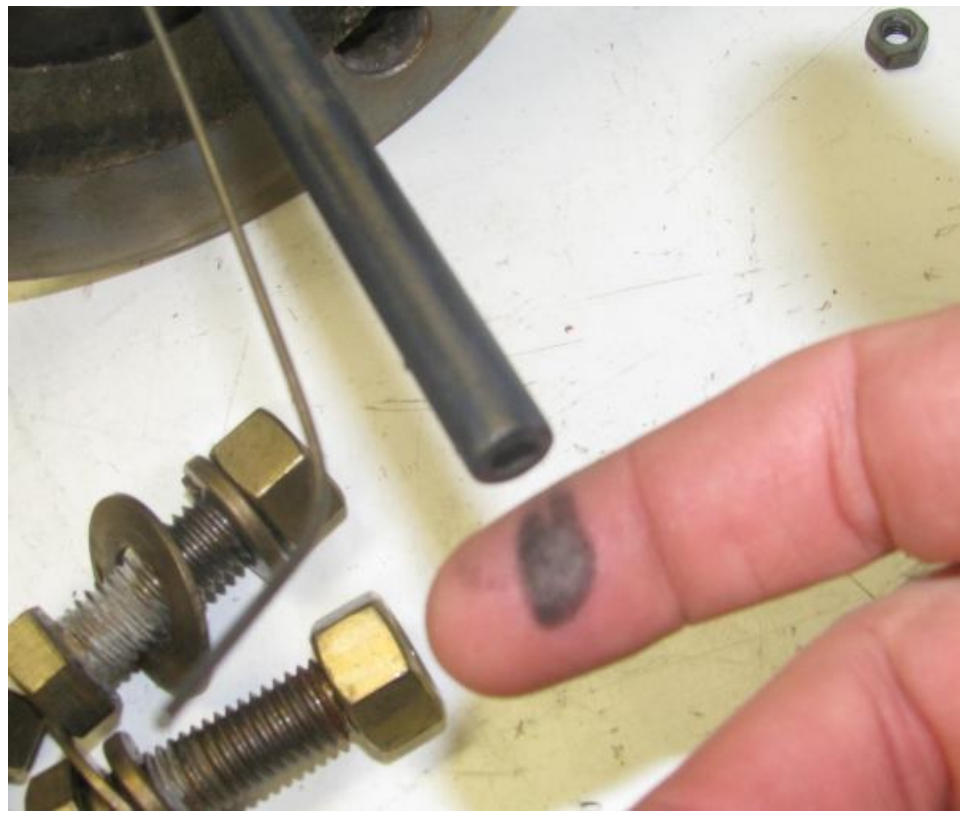

Figure 86: A black residue coating the interior of the sample chamber.

Revisiting options for vacuum seals, one type of seal seemed to be completely free of contaminants. For high pressure vacuum applications, copper seals work very well. However, these seals anneal at $450^{\circ} \mathrm{C}$ and are not recommended beyond that temperature. For this reason, copper seals were originally dismissed for this application. Revisiting the issue, it was decided that under a static situation, it might not significantly affect the sealing capability if the copper seal annealed. Therefore, experiment \#16 used a copper seal between the two flanges of the vessel. 


\subsubsection{EXPERIMENT \#16}

The summary of experiment \#16 is provided in Table 19. The goals of this experiment were to hydride at $500^{\circ} \mathrm{C}$ for 24 hours and mill for two hours. However, the valve controlling the argon / hydrogen flow kept closing and shutting off the flow. The details concerning the overnight time period are not known. The valve was completely closed the next morning. The hydriding did progress for about 6 hours that were directly observed.

Table 19: A summary of experiment \#16.

\begin{tabular}{|c|c|c|}
\hline Experiment \#16 & 27-Nov-09 & \\
\hline & Temperature $\left({ }^{\circ} \mathrm{C}\right)$ & Time (hrs) \\
\hline Hydride & 507 & 24 \\
\hline Milling & N/A & 2 \\
\hline Dehydride & N/A & 0 \\
\hline Mass Change & \multicolumn{2}{|c|}{0} \\
\hline Comments & \multicolumn{2}{|c|}{ Faulty valve } \\
\hline
\end{tabular}

The sample had the same black coating and did not fully hydride (see Figure 87). Since the seal was apparently not the source, the next possible source of this contamination was the torr seal around the thermocouple.

For the next experiment, the seal point around the thermocouple was moved away from the heat with the help of a stainless steel tube. This tube was welded into the blind flange and extended eight inches from the heat into the clean air of the laboratory. The thermocouple was inserted in this tube and torr seal was applied to the outer most 
end. By extending this joint, the heat would be considerably less intense and within the operating temperature of the torr seal.

The valve that caused the gas flow problems was adjusted. The packing nut was tightened to prevent the valve from closing by itself. It was also taped to hold its open location.

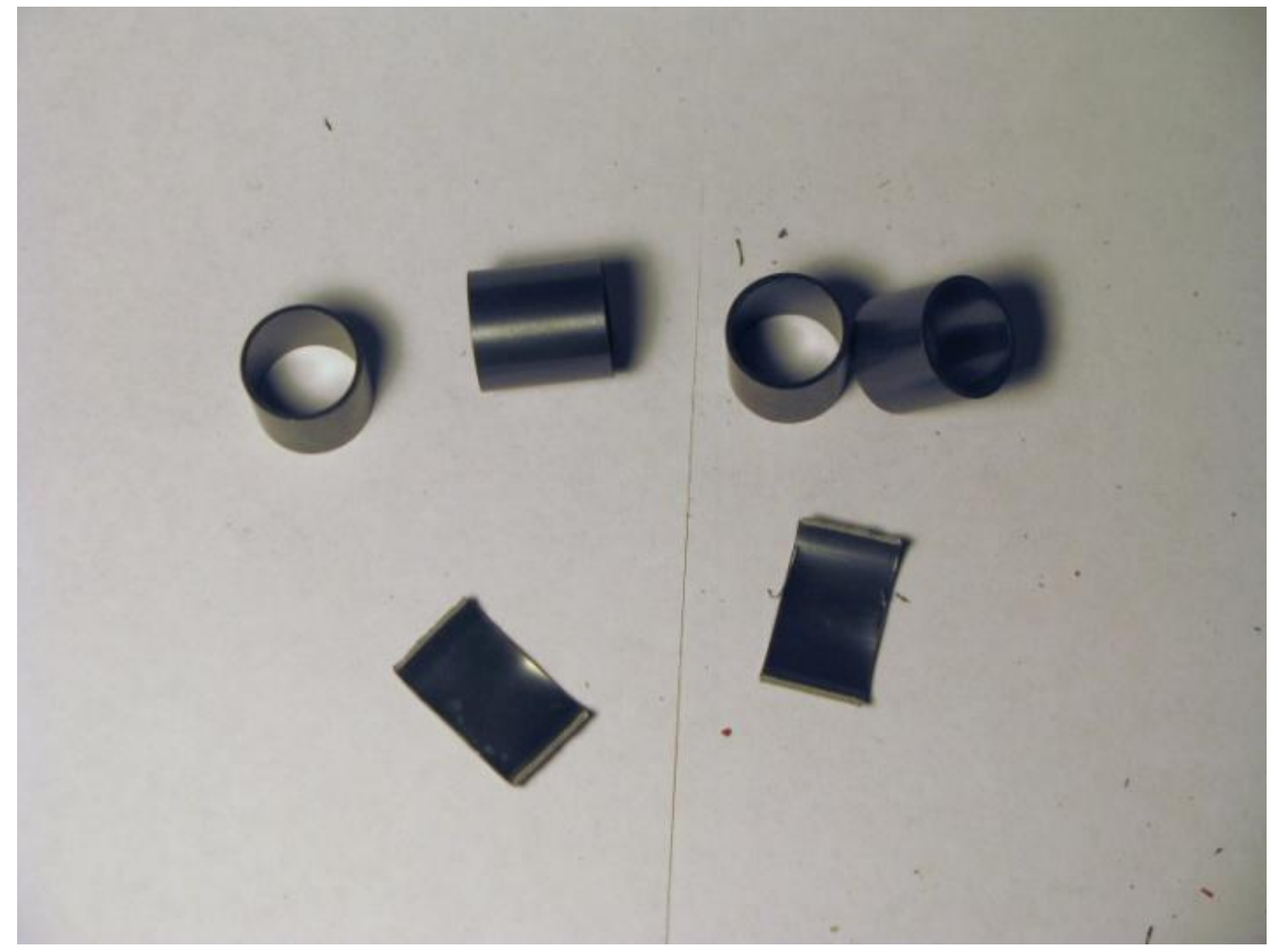

Figure 87: The sample from experiment \#16.

\subsubsection{EXPERIMENT \#17}

The summary of experiment \#17 is provided in Table 20. The preliminary goals of this experiment were to hydride at $500^{\circ} \mathrm{C}$ for 24 hours and mill for two hours. The 
valve continued to malfunction and the experiment was aborted after 5-1/2 hours of confirmed hydriding. Figure 88 shows the samples from this experiment.

Table 20: A summary of experiment \#17.

\begin{tabular}{|c|c|c|}
\hline Experiment \#17 & 7-Dec-09 & \\
\hline & Temperature $\left({ }^{\circ} \mathrm{C}\right)$ & Time (hrs) \\
\hline Hydride & 505 & 5.5 \\
\hline Milling & N/A & 0 \\
\hline Dehydride & N/A & 0 \\
\hline Mass Change & \multicolumn{2}{|c|}{0} \\
\hline Comments & \multicolumn{2}{|c|}{ Valve problems } \\
\hline
\end{tabular}

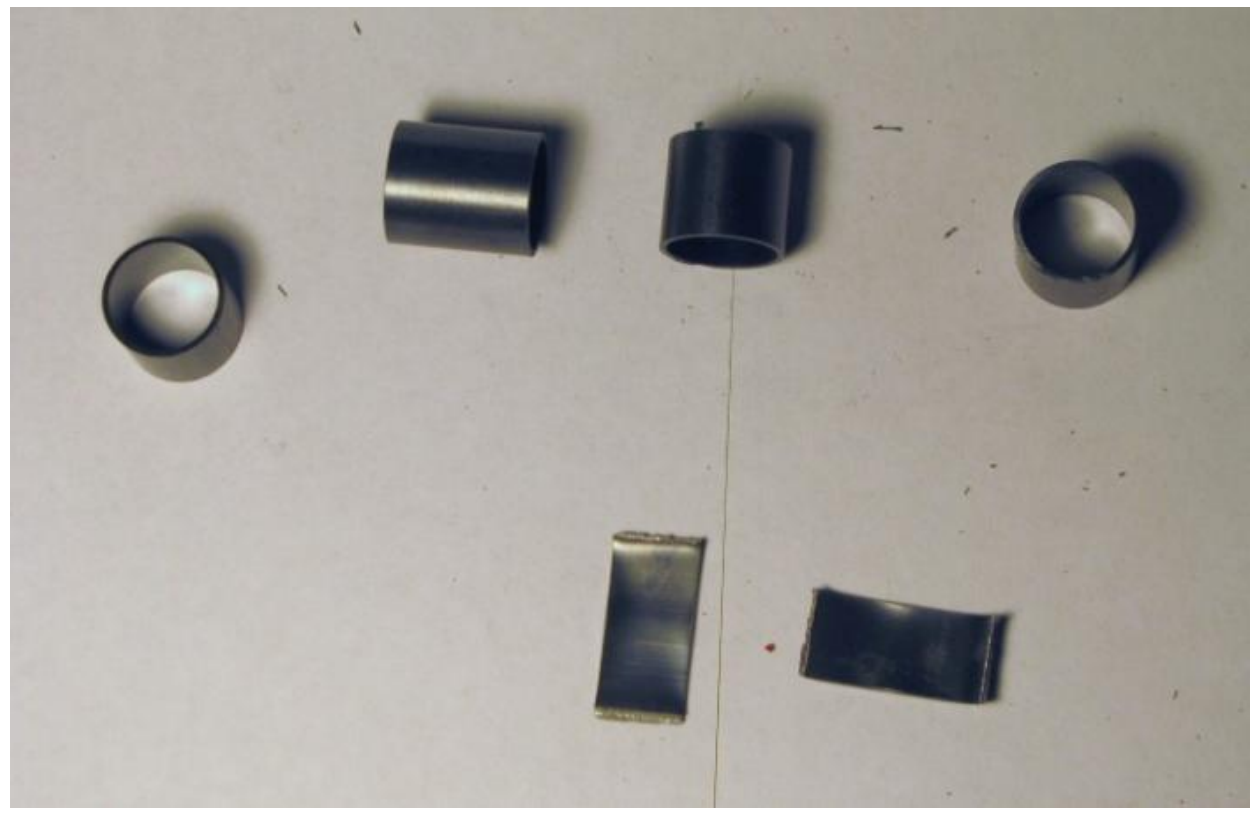

Figure 88: The samples from experiment \#17. 
Modifications to the system for experiment \#18 were to obtain a new copper seal and to replace the troublesome valve. The packing on the new valve was tightened once it was installed.

\subsubsection{EXPERIMENT \#18}

The summary of experiment \#18 is provided in Table 21 . The preliminary goals for this experiment were to hydride at $500^{\circ} \mathrm{C}$ for 24 hours and mill for one hour. This experiment progressed in a satisfactory manner. The new valve worked well and held its setting overnight.

Table 21: A summary of experiment \#18.

\begin{tabular}{|c|c|c|}
\hline Experiment \#18 & 12-Dec-09 & \\
\hline & Temperature $\left({ }^{\circ} \mathrm{C}\right)$ & Time (hrs) \\
\hline Hydride & 505 & 24 \\
\hline Milling & N/A & 0.16 \\
\hline Dehydride & N/A & 0 \\
\hline Mass Change & \multicolumn{2}{|c|}{0} \\
\hline Comments & Zirconum Hydride Powder \\
\hline
\end{tabular}

Milling time was cut short to 30 minutes due to the encouraging sound emanating from inside the tumbler. Previous milling operations had a distinct "clanging" sound while the materials in the mill sounded more like sand pouring. Upon viewing the sample, it was found that the sample had hydrided sufficiently and was milled into a powder. The powder was a brownish-black color and was "sticky" due to the electrostatic forces between the powder and the sample cup. The sample was washed 
from the sample cup with water. Figure 89 shows the sample removed from the water bath. This sample color is consistent with the results from Parkison's research [19].

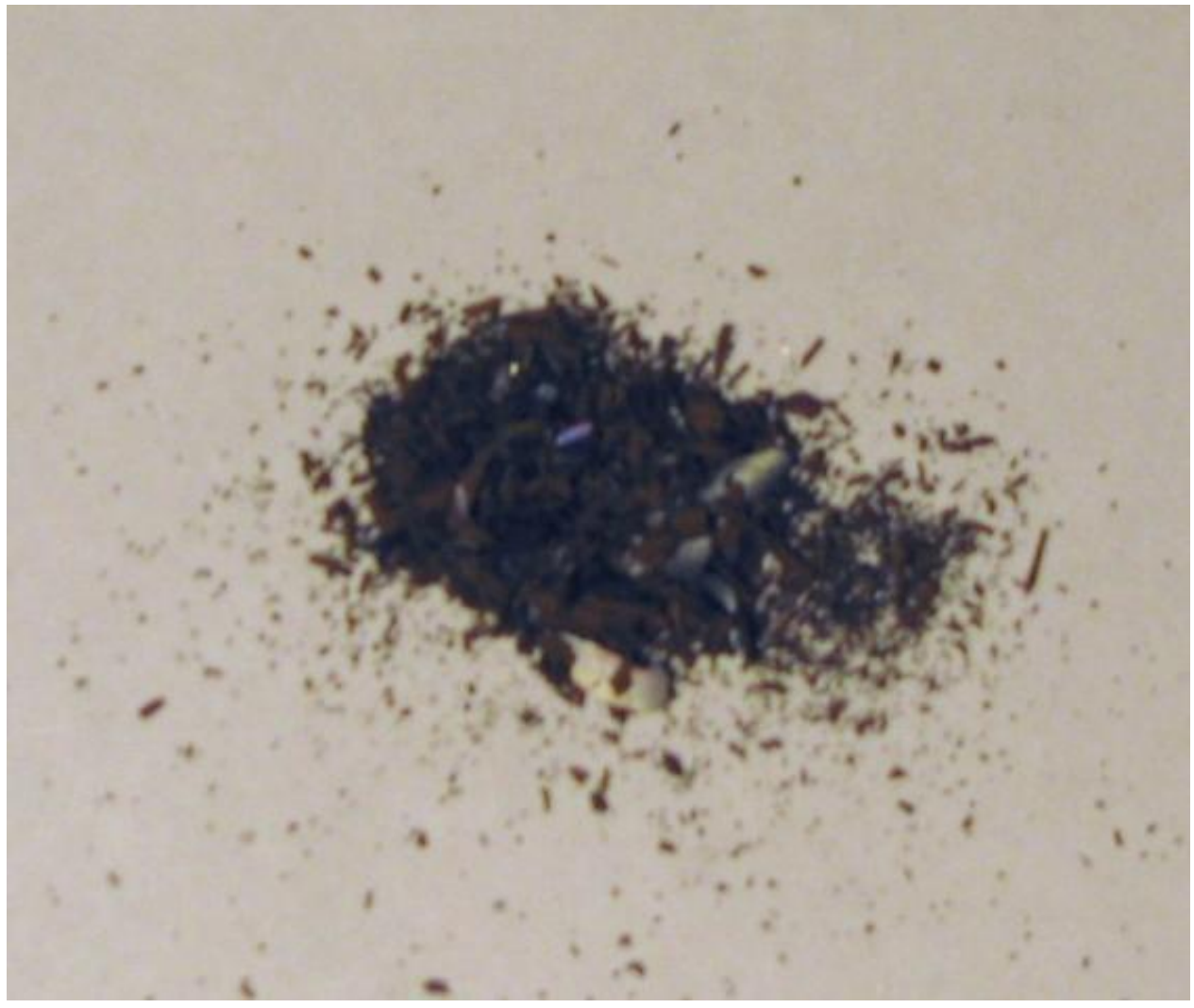

Figure 89: The sample powder from experiment \#18.

The only modification for experiment \#19 was to secure a new copper seal. The copper seal annealed, but continued to seal throughout the entire experiment. Also, now that successful hydriding has been achieved, an attempt to dehydride will be pursued. 


\subsubsection{EXPERIMENT \#19}

The summary of experiment \#19 is provided in Table 22. The preliminary goals for this experiment were basically the same as for experiment \#18, namely, hydride for 24 hours at $500^{\circ} \mathrm{C}$ and mill for two hours before attempting to dehydride. The experiment progressed satisfactory and the sample was milled for only 45 minutes, again based on the sound.

Table 22: A summary of experiment \#19.

\begin{tabular}{|c|c|c|}
\hline Experiment \#19 & 17-Dec-09 & Time (hrs) \\
\hline & Temperature $\left({ }^{\circ} \mathrm{C}\right)$ & 24 \\
\hline Hydride & 504 & 0.75 \\
\hline Milling & N/A & 0.25 \\
\hline Dehydride & 803 & \multicolumn{2}{|c|}{$-2.6 \% *$} \\
\hline Mass Change & \multicolumn{2}{|c|}{ Silver coarse powder } \\
\hline Comments & \multicolumn{2}{|c|}{} \\
\hline
\end{tabular}

* Electrostatic forces prevented the recovery of all the powder.

The dehydriding strategy was to heat the sample as hot as the heater would go and then quickly pull a vacuum on the vessel. Although the vacuum needed to be applied rather quickly to prevent the sample from cooling, the vacuum had to be controlled to prevent sucking the powder into the vacuum system. The heater was able to heat the sample to $803^{\circ} \mathrm{C}$ and the vacuum system was able to pull a vacuum to 0.00026 bars.

After a cool down period, the vessel was removed and placed in an argon-filled glove box (See Figure 90). In the glove box, the blind flange was removed and the sample extracted. Figure 91 shows the sample from this experiment. The shiny silver 
powder is a sign of zirconium metal. Zirconium oxide is a yellowish color, while zirconium nitride is a gold color and zirconium hydride is a brownish-black color. Sample analysis will be presented in the next section.

To confirm the repeatability of this process, another experiment was necessary. For the next experiment, the equipment was cleaned and reassembled. Due to the presence of larger pieces, a longer milling time was scheduled.

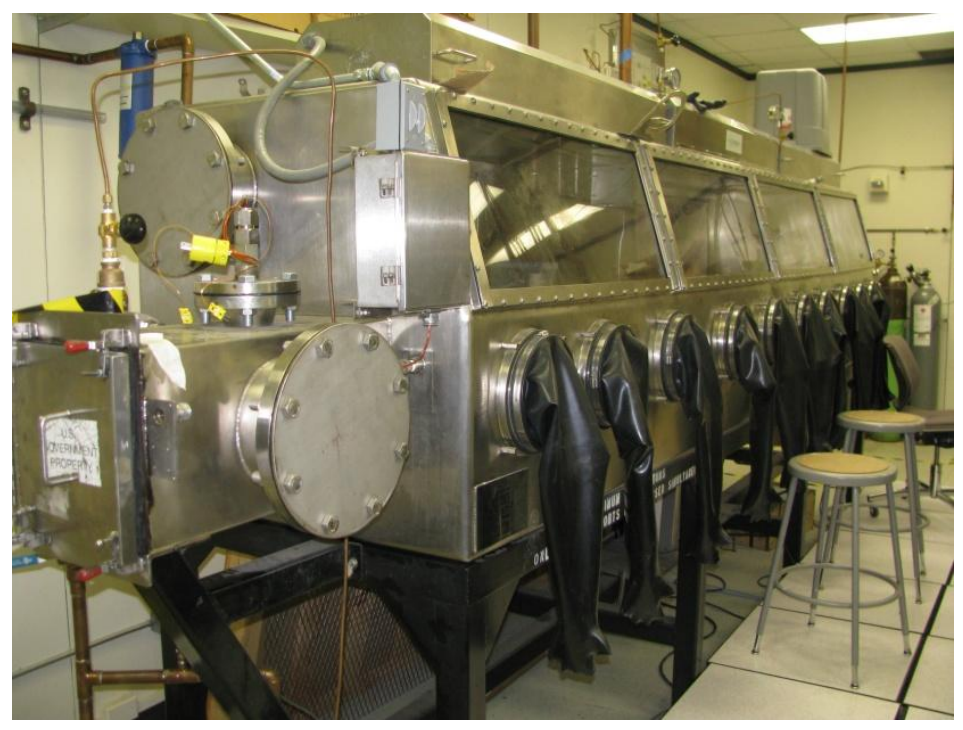

Figure 90: The argon filled glove box installed in the Fuel Cycle and Materials Laboratory. 


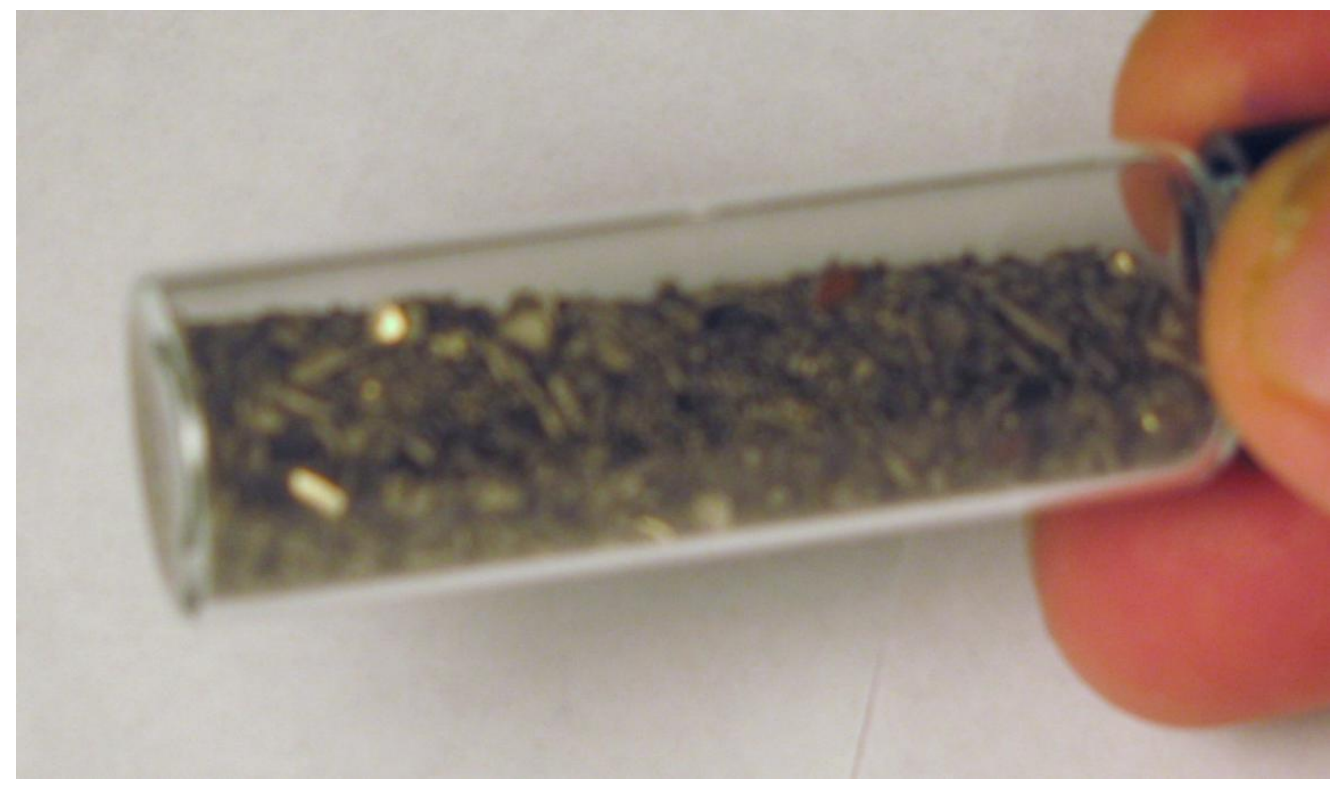

Figure 91: The sample from experiment \#19 incased in an argon filled vial.

\subsubsection{EXPERIMENT \#20}

The summary of experiment \#20 is provided in Table 23. The goals of this experiment were exactly the same as the previous experiment except for the longer milling time.

Table 23: A summary of experiment \#20.

\begin{tabular}{|c|c|c|}
\hline Experiment \#20 & 21-Dec-09 & \\
\hline & Temperature $\left({ }^{\circ} \mathrm{C}\right)$ & Time (hrs) \\
\hline Hydride & 503 & $?$ \\
\hline Milling & N/A & 0 \\
\hline Dehydride & N/A & 0 \\
\hline Mass Change & \multicolumn{2}{|c|}{0} \\
\hline Comments & Tripped Breaker overnight \\
\hline
\end{tabular}


During the overnight hours, a system breaker tripped, the heater for the nitrogen getter was turned off and the charge was ruined. Figure 92 shows the gold tint indicative of zirconium nitride.

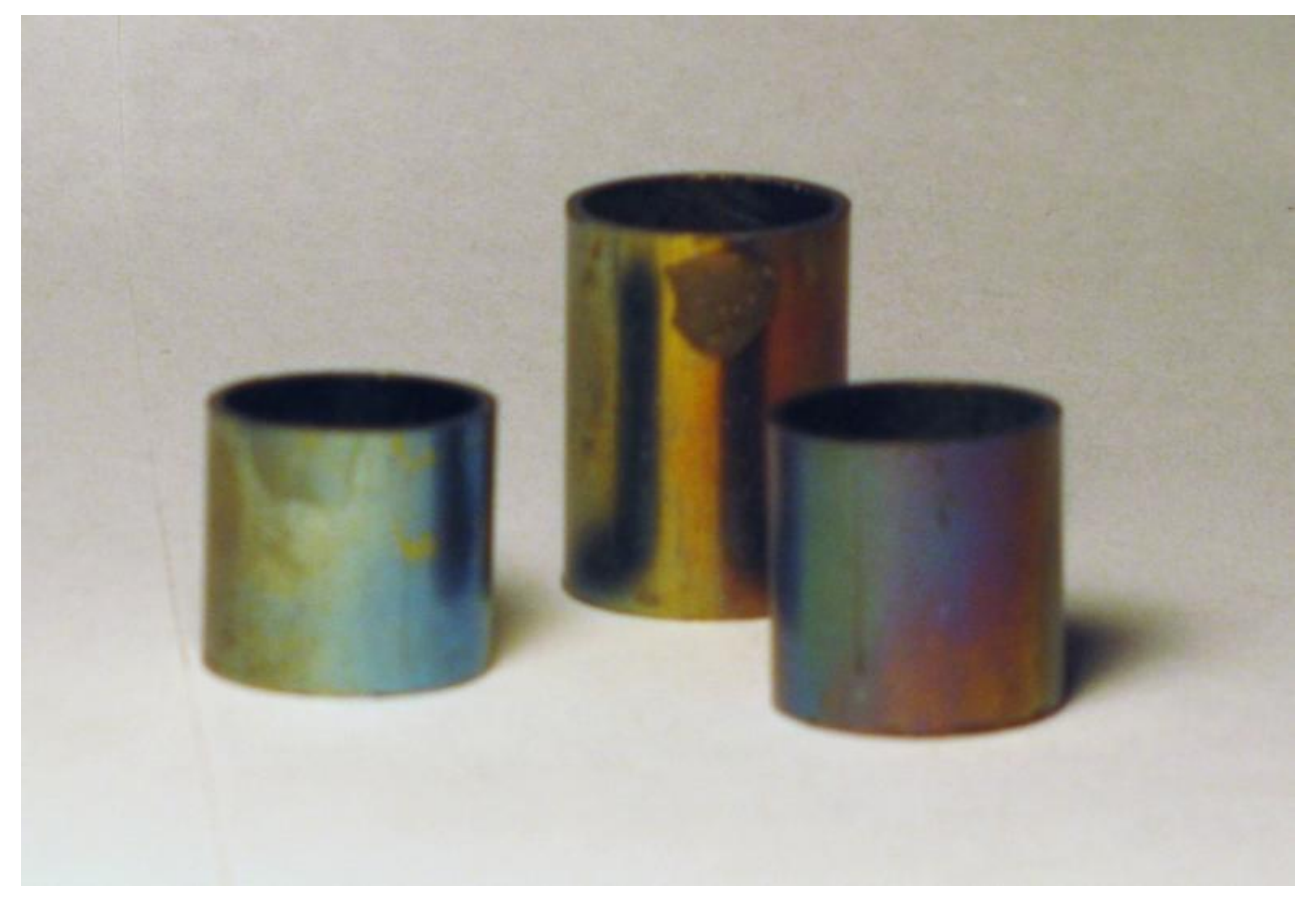

Figure 92: Samples from experiment \#20 showing clearly the formation of zirconium nitride.

For the next experiment, the nitrogen getter was rebuilt. After disassembling the titanium holding screen, it was apparent the titanium was acceptable for use in additional experiments but it was still replaced. The next experiment followed the same procedure and goals as was laid out in experiment \#20. 


\subsubsection{EXPERIMENT \#21}

The summary of experiment \#21 is provided in Table 24. This experiment failed early on. The vacuum pump failed to initially evacuate the chamber. Upon inspection, the pump internal bearings had seized. The pump was rebuilt and reinstalled on the system.

Table 24: A summary of experiment \#21.

\begin{tabular}{|c|c|c|}
\hline Experiment \#21 & 7-Jan-10 & \\
\hline & Temperature $\left({ }^{\circ} \mathrm{C}\right)$ & Time $(\mathrm{hrs})$ \\
\hline Hydride & N/A & 0 \\
\hline Milling & N/A & 0 \\
\hline Dehydride & N/A & 0 \\
\hline Mass Change & \multicolumn{2}{|c|}{0} \\
\hline Comments & \multicolumn{2}{|c|}{ Vacuum pump failure } \\
\hline
\end{tabular}

\subsubsection{EXPERIMENT \#22}

The summary of experiment \#22 is provided in Table 25. Again, the same goals and procedures of experiment \#19 were used with the exception of a longer milling time; 24 hours. This experiment went well. Upon removal of the sample in the glove box, it was discovered that the sample had completely pulverized into a fine powder. Figure 93 shows this sample in an argon filled vial. 
Table 25: A summary of experiment \#22.

\begin{tabular}{|c|c|c|}
\hline Experiment \#22 & 26-Jan-10 & Time (hrs) \\
\hline & Temperature $\left({ }^{\circ} \mathrm{C}\right)$ & 16 \\
\hline Hydride & 504 & 12 \\
\hline Milling & N/A & 0.16 \\
\hline Dehydride & 804 & \multicolumn{2}{|c|}{$-22 \% *$} \\
\hline Mass Change & \multicolumn{2}{|c|}{ Silvery fine powder } \\
\hline Comments & \multicolumn{2}{|c|}{} \\
\hline
\end{tabular}

*Electrostatic forces prevented the recovery of all of the powder.

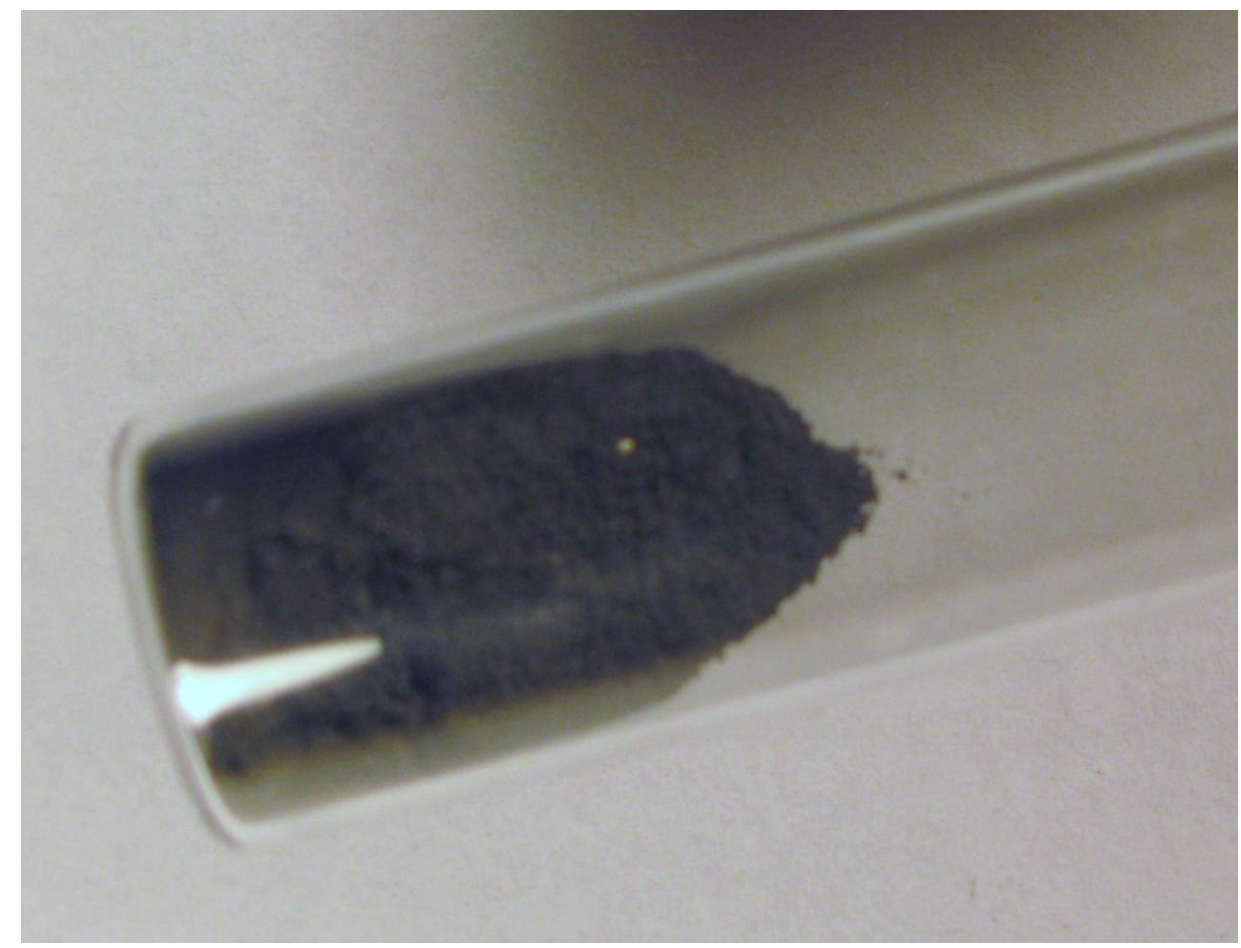

Figure 93: Samples from experiment \#22 showing the fine silver powder in an argon filled vial.

Although the picture appears to be a black powder, it was in fact a dull silver powder. Analysis of this sample and the sample from experiment \#19 will be discussed in the next section. 


\subsection{CHARACTERIZATION OF THE POWDER}

Samples from experiments \#19 and \#22 were characterized using three methods.

The first was x-ray diffraction to determine and confirm the chemical composition of the samples. The second was to quantify the milling process by classifying the powder samples based on size. A set of sieves and a shaker assembly were used with both samples. Finally, a set of detailed micrographs were taken of each sample with a digital camera.

The x-ray diffraction analysis was performed by Dr. Joseph Reibenspies of the Chemistry Department at Texas A\&M University. The samples were placed in the hermetically sealed sample holder of a two circle goniometer, enclosed in a radiation safety enclosure. The $\mathrm{x}$-ray source was a $2.2 \mathrm{~kW} \mathrm{Cu} \mathrm{x}$-ray tube, maintained at an operating current of $40 \mathrm{kV}$ and $40 \mathrm{~mA}$. The x-ray optics were the standard BraggBrentano para-focusing mode with the x-ray diverging from a DS (divergence limiting slit) slit $(1 \mathrm{~mm})$ at the tube to strike the sample and then converging at a position sensitive x-ray detector (Lynx-Eye, Bruker-AXS). The two-circle $250 \mathrm{~mm}$ diameter goniometer was computer controlled with independent stepper motors and optical encoders for the $\theta$ and $2 \theta$ circles with the smallest angular step size of $0.0001^{\circ} 2 \theta$. The software for data collection and evaluation was Windows based. Data collection is accomplished by an automated COMMANDER program by employing a DQL file. Data was analyzed by the program EVA [54].

Figure 94 shows the x-ray diffraction data for the sample from experiment \#19. The data indicate the presences of zirconium hydride $\left(\mathrm{ZrH}_{1.66}\right)$, zirconium oxide $\left(\mathrm{Zr}_{3} \mathrm{O}\right)$, 
zirconium hydride $\left(\mathrm{ZrH}_{2}\right)$ and zirconium hydride $(\mathrm{ZrH})$. This type of analysis does not show the relative concentrations of the constituents, but only their presence. Since zirconium oxide is present, it is a fair assumption that zirconium metal powder existed right after the experiment and was later oxidized due to leakage in the vials containing the samples. (Note: although the legend on Figure 94 says this is example \#3, it is actually the powder from experiment \#19.) This was an artifact of the chemistry laboratory labeling system.

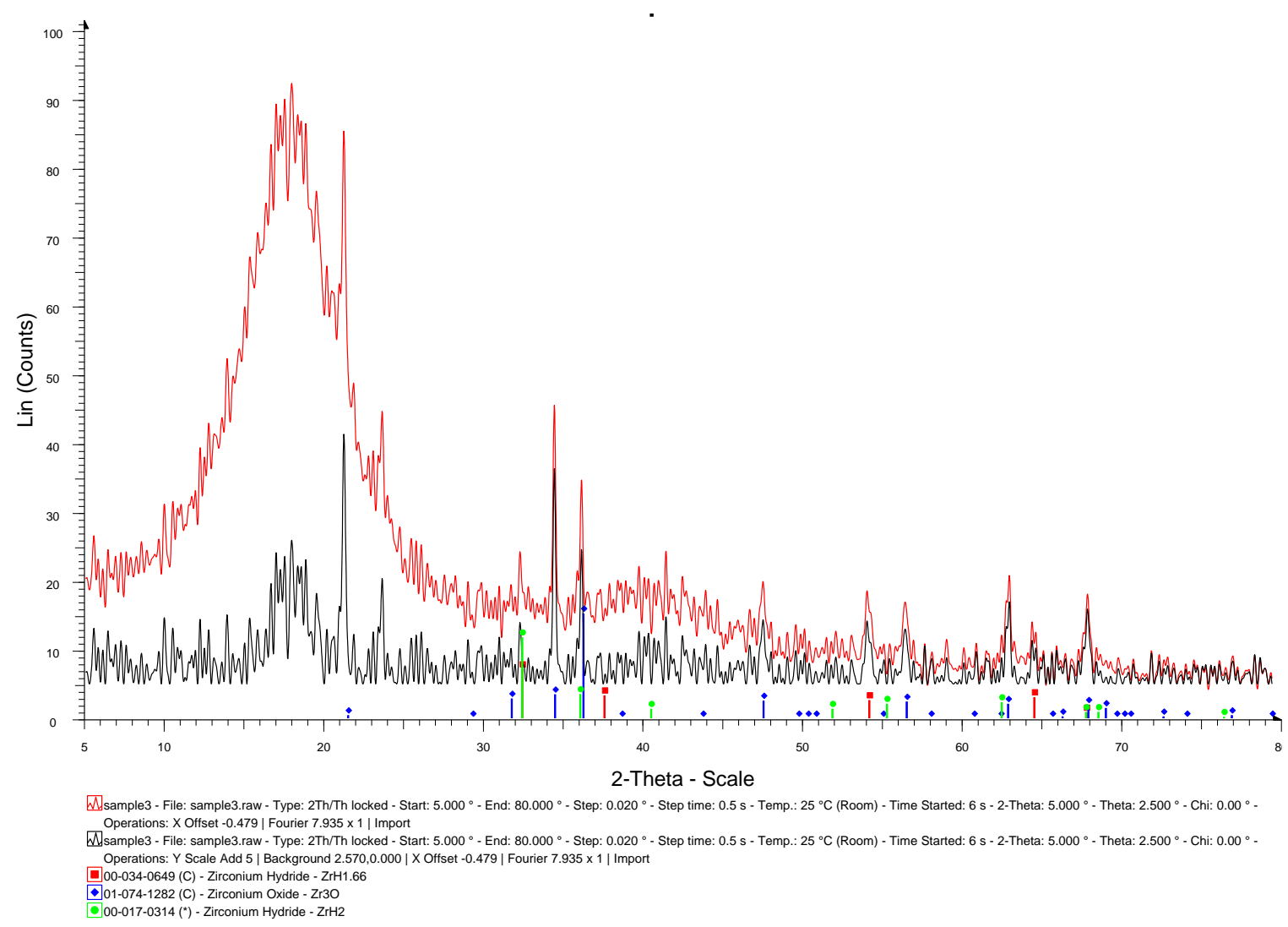

Figure 94: XRD analysis on the powder sample from experiment \#19. 
Figure 95 shows the x-ray diffraction data for the sample from experiment \#22. Like experiment \#19, the data show the sample consisted of zirconium hydride $\left(\mathrm{ZrH}_{1.66}\right)$, zirconium oxide $\left(\mathrm{Zr}_{3} \mathrm{O}\right)$, zirconium hydride $\left(\mathrm{ZrH}_{2}\right)$ and zirconium hydride $(\mathrm{ZrH})$. The same analysis was applied to the data from experiment \#22, namely; the presence of zirconium oxide indicates zirconium metal was produced from the experiment and later oxidized in the containment vial due to air leakage.

The XRD analysis data confirmed the process of generating zirconium metal powder with this experimental process, hydride, mill, and dehydride. However, the presence of zirconium hydride implies that the dehydride process should be studied further to improve the dehydriding efficiency. This XRD analysis data did not quantify the amount of each constituents but only their presence, so the efficiency of the hydriding is unknown. A visual indicator is that zirconium hydride is brownish black in color. Zirconium metal is shiny silver and zirconium oxide is a pale yellow. Both samples were originally silver in color. This indicates that the dehydriding process took place and that zirconium metal dominated the samples. It should be noted that the presence of zirconium oxide in the samples could be small shards of the milling balls left behind after the milling process. This is a remote possibility due to the hardness of zirconium oxide $\left(1300 \mathrm{~kg} / \mathrm{mm}^{2}\right)[55]$. 


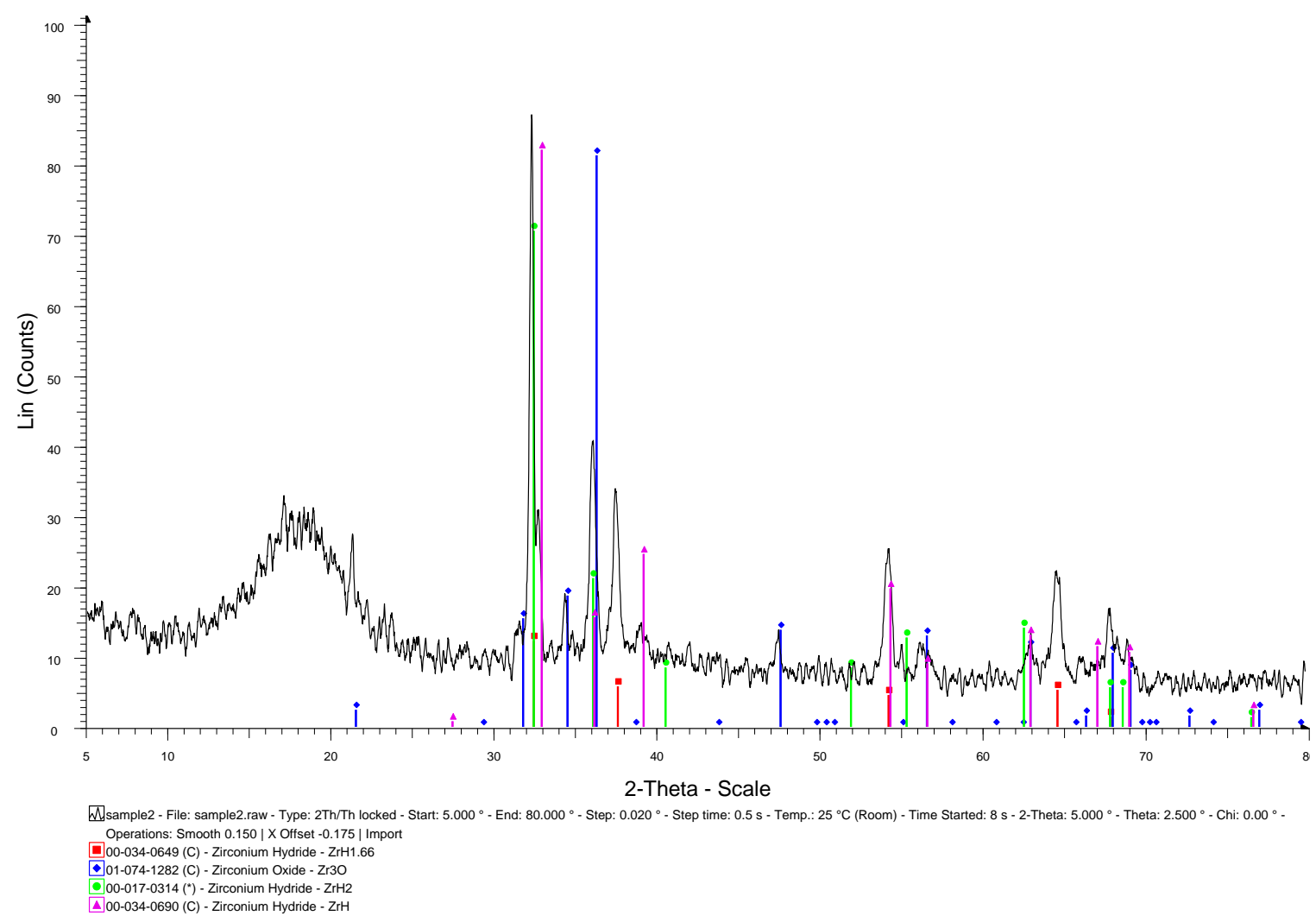

Figure 95: XRD analysis from the sample generated in experiment \#22.

Figure 94 and Figure 95 look different due to the amplitudes of the peaks but upon further inspection, the peaks are located at the same 2-theta location, therefore revealing the same relative crystalline structures.

Both samples were classified for size. The first sample (experiment \#19) was milled for 45 minutes. The second sample (experiment \#22) was milled overnight (24 hours). The samples were weighed and then placed in a shaker assembly with a sequence of wire mesh sieves. Figure 96 shows the shaker assembly with the sieves used to classify the samples. 
The sieves were assembled in the shaker with the largest opening at the top and the smallest on the bottom. The final segment is a cup. Theses sieves were weighed (see Figure 48) prior to use. The sample was poured into the top sieve and the shaker was turned on for three minutes. Upon removal, the sieves were reweighed. Subtracting the two weights gives the weight of sample that fell through the sieve directly above but failed to fall through the openings in that particular sieve. The data from both samples are plotted on Figure 97.

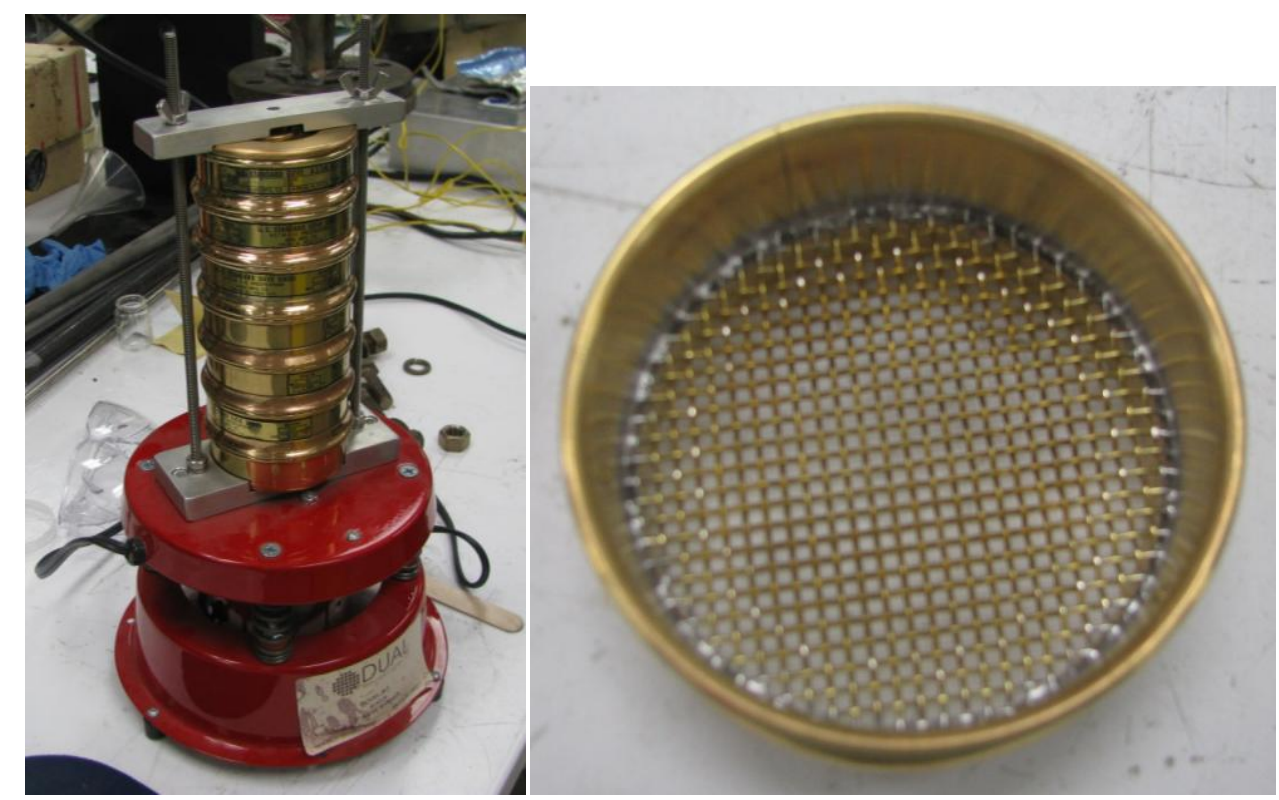

Figure 96: Sieves and shaker used to classify the two powder samples.

Although the particle size of both samples has a maximum distribution at about the same sample size, the first sample (experiment \#19) displayed significant larger 
particle sizes than did the second sample. The longer milling time obviously produced smaller particles.

The samples were examined using a digital microscope (Model HIROX). The software allowed for the insertion of a scale. Figure 98 shows four pictures of the sample powder from experiment $\# 19$. In the upper right hand corner of each picture, a $50 \mu \mathrm{m}$ scale shows the relative sizes of the particles.

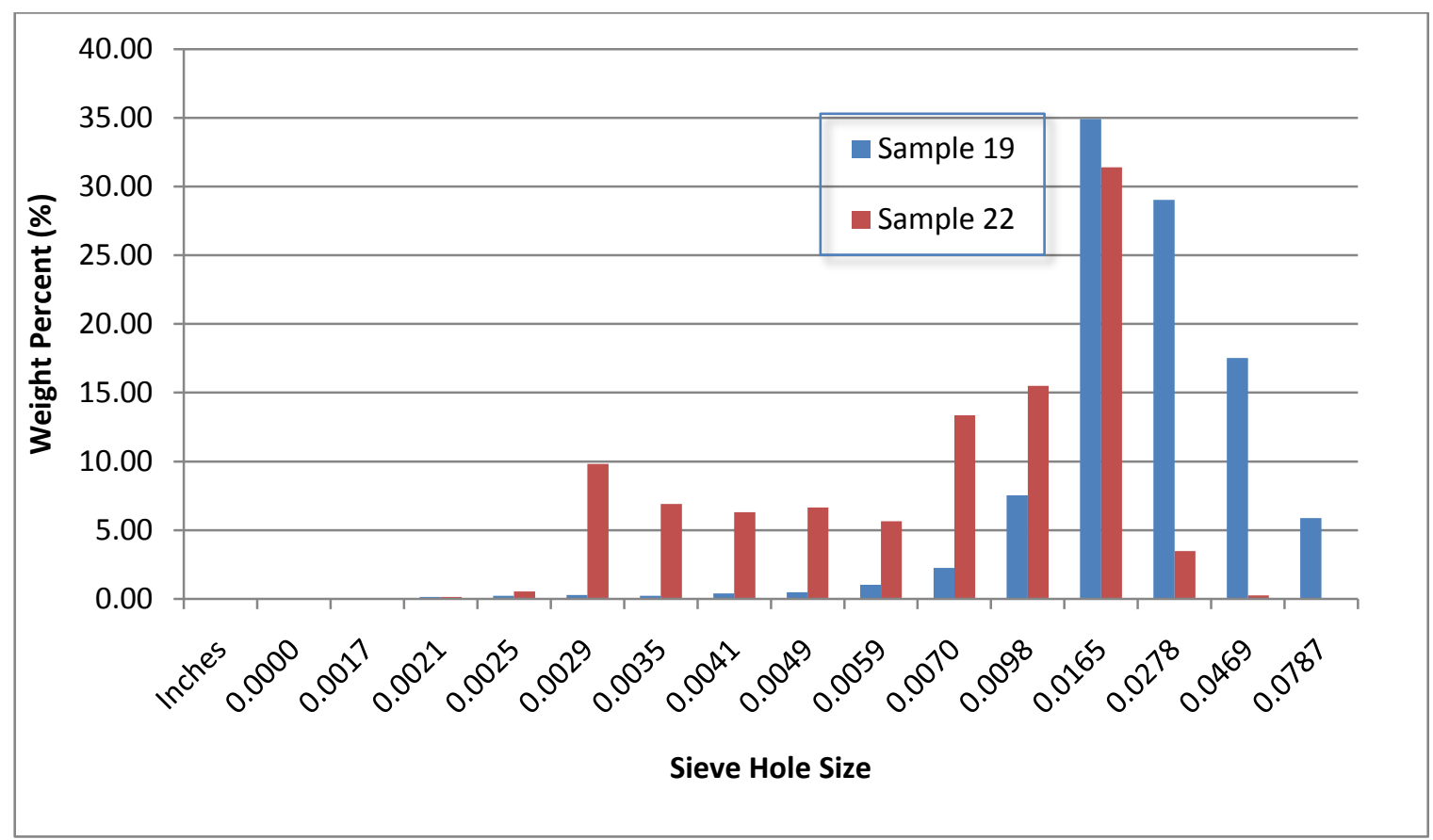

Figure 97: Size characterization of both powder samples.

Microscopic photographs for the powder from experiment \#22 are shown in Figure 99. The same scale was use to get a visual size comparison to the samples in experiment \#19. The extra milling time proved to decrease the average particle size 
while increasing the consistency of the particle size. Although some larger pieces still existed, they are few. To achieve a more consistent powder, the milling time should be optimized.

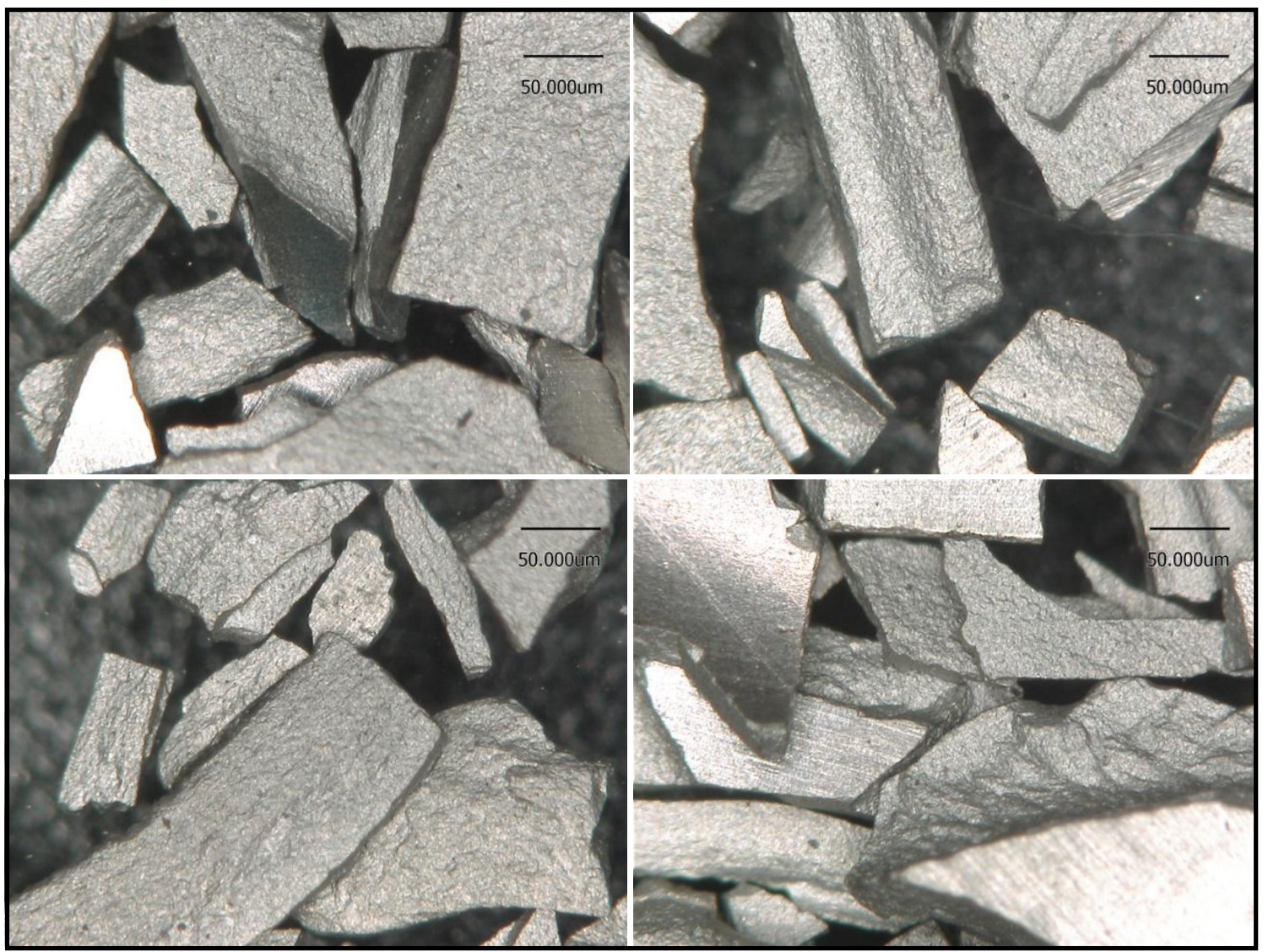

Figure 98: Microscopic photographs of the powder from experiment \#19. 


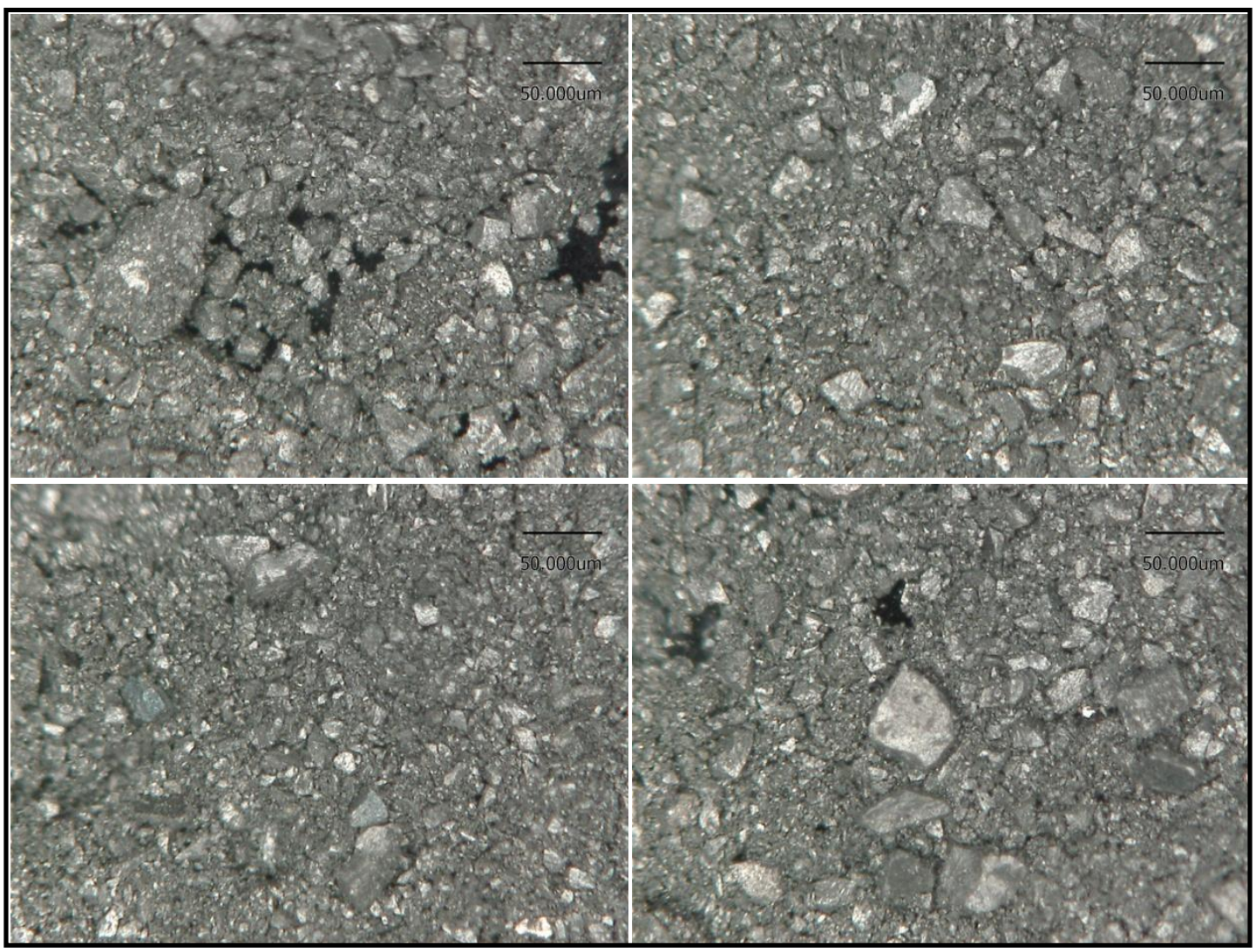

Figure 99: Microscopic photographs of the powder from experiment \#22. 


\section{DISCUSSION OF RESULTS}

The importance of atmospheric control necessary to facilitate the hydride and dehydride processes is key to the success of these two processes. Several experiments were ruined due to the presence of a small amount of nitrogen. Several others failed due to contamination by the seals, bearing grease, torr seal or the ceramic putty. Another aspect of atmospheric control is the process temperature. Knowing the temperature of the Zircaloy charges is paramount to the success of the process. The temperature of the heating elements or gas flow inside the chamber may not be at the same temperature as the charge. Altering the shape of the thermocouple to touch the side of the chamber increased the accuracy of measuring the charge temperature,

This research project highlights the importance of bench top prototyping. Designing this bench top model was considerably less expensive than a production model could cost. Lessons learned with this model can be incorporated into a production model to help facilitate the UREX program.

\subsection{SIGNIFICANCE OF RESULTS}

This research accomplished two objectives. The first was to verify the conditions necessary for dehydriding zirconium hydride. Specifically, this research demonstrated that the dehydriding temperature drastically decreases under vacuum conditions. The dehydride temperature dropped from around $1,000^{\circ} \mathrm{C}$ at atmospheric pressure to about $720^{\circ} \mathrm{C}$ at a 0.001 bar vacuum. This is significant due to material considerations. At 
$1,000^{\circ} \mathrm{C}$, material selections are quite limited. By dropping to $720^{\circ} \mathrm{C}$, a less expensive stainless steel becomes acceptable.

The second objective was to design, build and operate a piece of specialized equipment to take zirconium spent nuclear fuel casing hulls and create a pure zirconium metal powder. This was accomplished by first hydriding the metal at elevated temperatures with an argon / hydrogen gas mixture. Once zirconium hydride was created, the brittleness of the material was taken advantage of and the material was milled to a fine powder. This zirconium hydride power was heated in a vacuum to eliminate the hydrogen; leaving a pure zirconium metal powder.

This powder is very useful in several ways. One is it can be placed in an extrusion press with the TRU microspheres resulting in a stable storage form or a fuel rod for an advanced reactor. By placing this fuel rod back in a reactor, the TRU can be burned, reducing the need for long-term storage. By demonstrating that the Zircaloy hulls can be powderized in a simple, inexpensive machine, this process is one step closer to becoming reality.

Another useful aspect is the reduction of material slated to be stored in waste repositories. The metal extracted from this process is a nuclear grade zirconium; having an intrinsic value. The high cost of extracting hafnium from zirconium ore gives this power a value beyond being placed underground in a waste repository.

The machine value goes beyond zirconium processing. Another researcher in the Fuel Cycle and Materials Laboratory is currently using the machine to make uranium powder with the same hydride / mill / dehydride method. The heat necessary to process 
uranium is on the order of $200^{\circ} \mathrm{C}$ to $300^{\circ} \mathrm{C}$ but the process is similar. At these temperatures, the copper seal will not anneal and could be reused, if it is not contaminated in the process. Similarly, this process and machine could be used with other metal hydrides to create metal powders. 


\section{SUMMARY AND RECOMMENDATIONS}

\subsection{RECOMMENDATIONS FOR FUTURE WORK}

The two milling times were 45 minutes and overnight. A future project should be to establish the optimum milling time. The 45 -minute mill time left some larger pieces (1/16" diameter) while the overnight mill time resulted in a fine powder. At this point, the optimum mill time is uncertain. It is clear that 45 minutes is not long enough and overnight appears to be sufficient. Another perspective is that since only a small portion of the total Zircaloy cladding available is needed to encase the TRU, the sample can be sifted and the large pieces discarded.

The zirconium hydride dehydriding process was only lightly covered in this research. A thorough study of the relationship between pressures and temperatures could be conducted with the Thermogravometric Analyzer (TGA). During the TGA analysis in this research, a pressure gauge failure prevented the actual vacuum pressure from being accurately known during the dehydriding process. Further work with this equipment could easily determine the relationship between pressure and temperature in the dehydriding process. With a severe vacuum, the dehydriding temperature might be considerably lower than the $720^{\circ} \mathrm{C}$ that was observed.

The process could be expanded to other metals. As previously stated, uranium powder is already being produced with the machine by another researcher in the Fuel Cycle and Materials Laboratory. Any metal that becomes brittle when hydrided could be processed into a fine powder with this system. 


\subsection{RECOMMENDED DESIGN IMPROVEMENTS}

After the initial system failure, many modifications were instituted to improve the rebuilt machine. One of the big lessons that was learned was to heat from the outside in. This eliminated several problems including broken heater coils and contamination potential from the heating elements.

A cooling system should be added to the hydraulic motor. The heat from the process traveled along the motor shaft and destroyed the seals on the first hydraulic motor. Some existing holes were opened on the main housing to allow convection currents to cool the motor and that seemed to prevent damage to the seals. A better method should be devised.

The tumbling chamber used standard 150\# welded flanges with a 150\# blind flange. The seal between these two flanges was a continuing problem. The copper seal seemed to work satisfactorily but it was not a perfect solution. A machined threaded connection might be a better method. By specifying a tight thread, a seal might not be necessary. It would also be easier to disassemble in the glove box. The current method used four $5 / 8$ " bolts to secure the two flanges. To compress the copper (making it seal into the flange grooves), these bolts had to be very tight. After heating, cooling, heating and cooling, they became extremely tight and they were very difficult to loosen in the glove box. Holding the vessel upright and using two 15/16" end wrenches with your hands inside the gloves was dangerous. The vessel would easily fall and potentially 
damage other experiments or the glove box itself. By exerting a great force on the end wrenches, one could also easily tear one of the gloves.

A better insulating method should also be incorporated. The current method used a silica-type insulation simply packed around the heater and tumbling vessel. This allowed quite a bit of the heat to escape. By using a better insulating system, the temperature could be increased with less energy.

A better flow control valve for the hydraulic motor would improve the milling process. With the current valve, a $36 \mathrm{rpm}$ tumbling speed was as low as possible. This seemed to be sufficient, but a slower speed could conceivably mill the sample into a powder quicker than the overnight. 


\section{REFERENCES}

[1] A.R. Totemeier and S.M. McDeavitt, Powdered Metallurgical Fabrication of Zirconium Matrix Cermet Nuclear Fuels, Journal of Materials Science, 44(20) 5494-5500 (2009).

[2] Recycling Spent Nuclear Fuel, Department of Energy: Office of Nuclear Energy, http://www.ne.doe.gov/pdfFiles/factSheets/RecyclingSpentNuclearFuel.pdf, March 2008, (Retrieved date: January 11, 2009).

[3] CEA, Radioactive Waste Management Research, Radiotoxicity of Spent Fuel, 2002

http://www.cea.fr/var/cea/storage/static/gb/library/Clefs46/pagesg/clefs46_16.htl, (Retrieved date: January 12, 2009).

[4] R.G. Bennett, NAE National Meeting Symposium in honor of Foreign Secretary Harold K. Forsen, (2003), Washington, DC.

[5] C.G. Whipple, Can Nuclear Waste be Stored Safely at Yucca Mountain?, Scientific American Magazine, June 1996, $72-79$.

[6] End of the Line for Yucca Mountain, World Nuclear News, http://www.worldnuclear-news.org/WR_End_of_the_line_for_Yucca_Mountain_0403101.html, March 2010. (Retrieved date: May 17, 2010).

[7] Yucca Mountain Terminated, World Nuclear News, http://www.world-nuclearnews.org/newsarticle.aspx?id=25183, May, 2009. (Retrieved date: January 15, 2009).

[8] R. Metcalf, J. Ragusa and R. Bean, Safeguards Envelope: The First Steps, $8^{\text {th }}$ International Conference on Facility Operations - Safeguards Interface, Portland, OR (2008).

[9] W.S. Charlton, R.F. LeBouf, C. Gariazzo, D.G. Ford, C. Beard, S. Landsherger and M. Whitaker, Proliferation Resistance Methodology for Nuclear Fuel Cycles, Journal of Nuclear Technology, 157 (2007) 143-156

[10] L.M. Bollinger, S.P. Harris, C.T. Hibdon and C.O. Muehllause, Neutron Absorption and Scattering by Hafnium, Physics Review, 92 (1953) 1527-1531.

[11] G.F. Vandergrift, Transformation of UREX Effluents to Solid Oxides by Concentration, Denitration and Calcinations, http://www.ipd.anl.gov/anlpubs/2000/12/38162.pdf, Technical Report, United States Department of Energy, Argonne National Lab, (2000). (Retrieved date: May 17, 2010) 
[12] G.F. Vandergrift, M.C. Regalbuto, S. Aase, A. Bakel, T.J. Battisti, (et.al), Designing and Demonstration of the UREX+ Process Using Spent Nuclear Fuel, Advances for Future Nuclear Fuel Cycles International Conference, Nimes France, (2004).

[13] K. Czerwinski, A. Wright, J. Warburton, C. Gong, P. Weck and G. Vandergrift, Evaluation of Fundamental Radionuclide Extraction Data for UREX, University of Nevada-Las Vegas, http://aaa.nevada.edu/proposal/trp40_1.pdf, (2008), (Retrieved date: May 5, 2010).

[14] S.M. McDeavitt, A. Parkison, A.R. Totemeier, J.J. Wagener, and R.D. Kelley, A Zirconium Matrix Cermet for Storage and Transmutation of Transuranic Isotopes Separated from Spent Nuclear Fuel, $136^{\text {th }}$ Annual Meeting of the Minerals, Metals and Materials Society Conference, (2007). Orlando, Florida

[15] D.T. Kraemer, Establishing Methods for Recycling Spent Zircaloy Cladding Using a Hydride-Dehydride Processing Route, Master's Thesis, Purdue University, August 2005.

[16] S.M. McDeavitt, A. Parkison, A.R. Totemeier and J.J. Wagener, J.J, Fabrication of Cermet Nuclear Fuels Designed for the Transmutation of Transuranic Isotopes, Materials Science Forum, 561-565 (2007) 1735-1736.

[17] SolidWorks, Education Addition 2008 SP 4.0, Dassault Systèmes SolidWorks Corporation, 2008. Concord, Massachusetts.

[18] S.M. McDeavitt, D.T. Kraemer, A. Parkison, A.R. Totemeier and J.J. Wagener, Zirconium Matrix Cermet Storage Form and Transmutation Fuel for Transuranics, Proc. of American Nuclear Society Winter Meeting, Washington, DC, Nov 13-17,2005, ANS Transactions 93-743(2005).

[19] A. Parkison, Hydride Production in Zircaloy-4 as a Function of Time and Temperature, Texas A\&M University, College Station, Texas, May 2008.

[20] Private communication - from A.J. Parkison and S.M. McDeavitt, Hydride Formation Process Development for the Powder Metallurgical Recycle of Zircaloy Submitted to Metallurgical and Materials Transactions A (2010).

[21] Private communication - from S.M. McDeavitt and A.J. Parkison, Hydride Formation Process Development for the Powder Metallurgical Recycle of Zircaloy Submitted to Metallurgical and Materials Transactions A (2010). 
[22] K. Konashi, Development Study of Fast Reactor Core with Hydride Neutron Absorber, Advance Nuclear Energy Materials, Proc. of the ICAPP2006, Reno, NV, 2006.

[23] G.L. Miller, Metallurgy of the Rarer Metals-2 Zirconium, $2^{\text {nd }}$ Edition, Academic Press Inc, Publishers, New York, 1955.

[24] D. Olander, and A. Motta, Light Water Reactor Materials, Nuclear. Engineering \& Technology, 37 (2005), Chapter 5.

[25] S. Yamanaka, K. Yoshioka, M. Uno, M. Katsura, H. Anada, T. Matsuda and S. Kobayashi, Thermal and Mechanical Properties of Zirconium Hydride, Journal of Alloys and Compounds, 293-295 (1999) 23-29.

[26] S.M. McDeavitt, Hot Isostatic Pressing of U-10Zr Alloy Nuclear Fuel by Coupled Grain Boundary Diffusion and Power Law Creep. Ph.D. Dissertation, Purdue University, West Lafayette, IN. (1992).

[27] S.M. McDeavitt, Lecture notes NUEN 265: Materials Science for Nuclear Energy Applications, 2009. http://nuclear.tamu.edu/academics/course_det/index.php?course=NUEN265, (Retrieved date: March 15, 2008).

[28] Zircaloy Embitterment due to Hydrogen Absorption, University of California at Berkeley, http://iron.nuc.berkeley.edu/ bdwirth/Public/NE104B/documents/Expt_M1.pdf, (Retrieved date: January 17, 2009).

[29] S.R. Ovshinsky, M.A. Fetcenko, J. Ross, A Nickel Metal Hydride Battery for Electric Vehicles, Science, 260 (1993) 176-181.

[30] J. Chen, N. Kuriyama, H.T. Takeshita, H. Tanaka, T. Sakai and M. Haruta, Hydrogen Storage Alloys with PuNi3-Type Structures as Metal Hydride Electrodes, Electrochem, Solid-State Lett., 3 (2000) 249-252.

[31] J.J. Reilly and R.H. Wiswall Jr., Formation and Properties of Iron Titanium Hydride, Inorganic Chemistry, 13 (1974) 218-222.

[32] Weapons of Mass Destruction, Global Security Organization, http://www.globalsecurity.org/wmd/systems/w48.htm, (Retrieved date: July 6, 2008).

[33] F. Schuth, B. Bogdanovic and M. Felderhoff, Light Metal Hydrides and Complex Hydrides for Hydrogen Storage, The Royal Society of Chemistry (2004) 22492258 
[34] S.V. Alapati, J.K. Johnson and D.S. Sholl, Predicting Reaction Equilibria for Destabilized Metal Hydride Decomposition Reaction for Reversible Hydrogen Storage, Journal of Physical Chemistry C, 111 (2007) 1584-1591.

[35] T. Flanagan and W.A. Oates, Some Aspects of Equilibrium and Non-Equilibrium Phenomena in Intermetallic Compound and Alloy Hydrides. Journal of Less Common Metals, 100, (1984) 299-305.

[36] S. Qian, and D.O. Northwood, Elastic and Plastic Accommodation Effects on Hysteresis during Hydride Formation and Decomposition, International Journal of Hydrogen Energy, 15 (1990) 649-654.

[37] R. Balasubramaniam, Hysteresis in Metal-Hydrogen Systems, Journal of Alloys and Compounds, 253-254, (1997) 203-206.

[38] B.R. Simonovic, S. Mentus, R. Dimitrijevic and M.V. Suxic, Multiple Hydriding / Dehydriding of $\mathrm{Zr}_{1.02} \mathrm{Ni}_{0.98}$ Alloy, International Journal of Hydrogen Energy, 24 (1999) 449-454.

[39] M.H. Chang, S. Cho, E.S. Lee, M.Y. Ahn, D.H. Kim, J.J. Jang, H. Chung, M. Shim, K.M. Song, D. Kim and H. Yoshida, Parameter Estimation for the Kinetics of Dehydriding Reactions Between Zirconium-Cobalt and Hydrogen, Fusion Science and Technology, 54 (2008) 31-34.

[40] M.J. Moran and H.N. Shapiro, Fundamentals of Engineering Thermodynamics, $2^{\text {nd }}$ Ed, John Wiley \& Sons, New York, (1992), Chapter 11.

[41] Outokumpu HSC Chemistry for Windows, Version XX, Outokumpu Research Oy, FIN-28101 PORI, Finland, 2002.

[42] I.G. Austin, P. Bragga and M. Celik, Breakage Properties of Some Materials in a Laboratory Ball Mill, Powder Technology, 28 (1981) 235-243.

[43] I.G. Austin, and P. Bragga, An Analysis of Fine Dry Grinding in Ball Mills, Powder Technology, 28 (1981) 83-90.

[44] A. Calka and A.P. Radlinski, Universal High Performance Ball-milling Device and its Application for Mechanical Alloying, Materials Science and Engineering, 134 (1991) 1350-1353.

[45] M. Sudhagar, L. Tabil and S. Sokhansanj, Grinding Performance and Physical Properties of Wheat and Barley Straws, Corn Stover and Switchgrass, Biomass and Bioenergy, 27 (2004) 239-252. 
[46] L. Austin, A Preliminary Simulation Model for Fine Grinding in High Speed Hammer Mills, Powder Technology, 143-144 (2004) 240-252.

[47] K. Koch, Hammer and Roller Mills, Feed Manufacturing, MF-2048, Kansas State University Agricultural Experiment Station and Cooperative Extension Service, May 2002. Manhattan, Kansas.

[48] M. Bayram and M.D. Oner, Stone, Disc and Hammer Milling of Bulgur, Journal of Cereal Science, 41 (2005) 291-296.

[49] K. Schonert, A First Survey of Grinding with High-Compression Roller Mills, International Journal of Mineral Processing, 22, (1988) 401-412.

[50] Q. Fang, I. Boloni, E. Haque and C.K. Spillman, Comparison of Energy Efficiency Between a Roller Mill and a Hammer Mill, Applied Engineering in Agriculture, 13, (1997) 631-635.

[51] Accuratus Company web site, http://Accuratus.com/zirc.html, (Retrieved date: July 12, 2008).

[52] M. Jacobson, A.R. Cooper, and J. Nagy, Explosibility of Metal Powders, Bureaus of Mines, (1964). Washington, D.C.

[53] M. Anderson, and A. Oden, A New All-Ceramic Crown: A Dense-Sintered, High Purity Alumina Coping With Porcelain, Acta Odontologica Scandinavica, 51 (1993) 59-64.

[54] J.H. Reibenspies, X-Ray Diffraction Analysis, Chemistry Department, Texas A\&M University, April, 2010. College Station, Texas.

[55] Accuratus Corporation website, http://www.accuratus.com/zirc.html, Retrieved date: June 10, 2010). 


\section{APPENDIX A}

\section{HYDRAULIC SYSTEM SCHEMATIC}

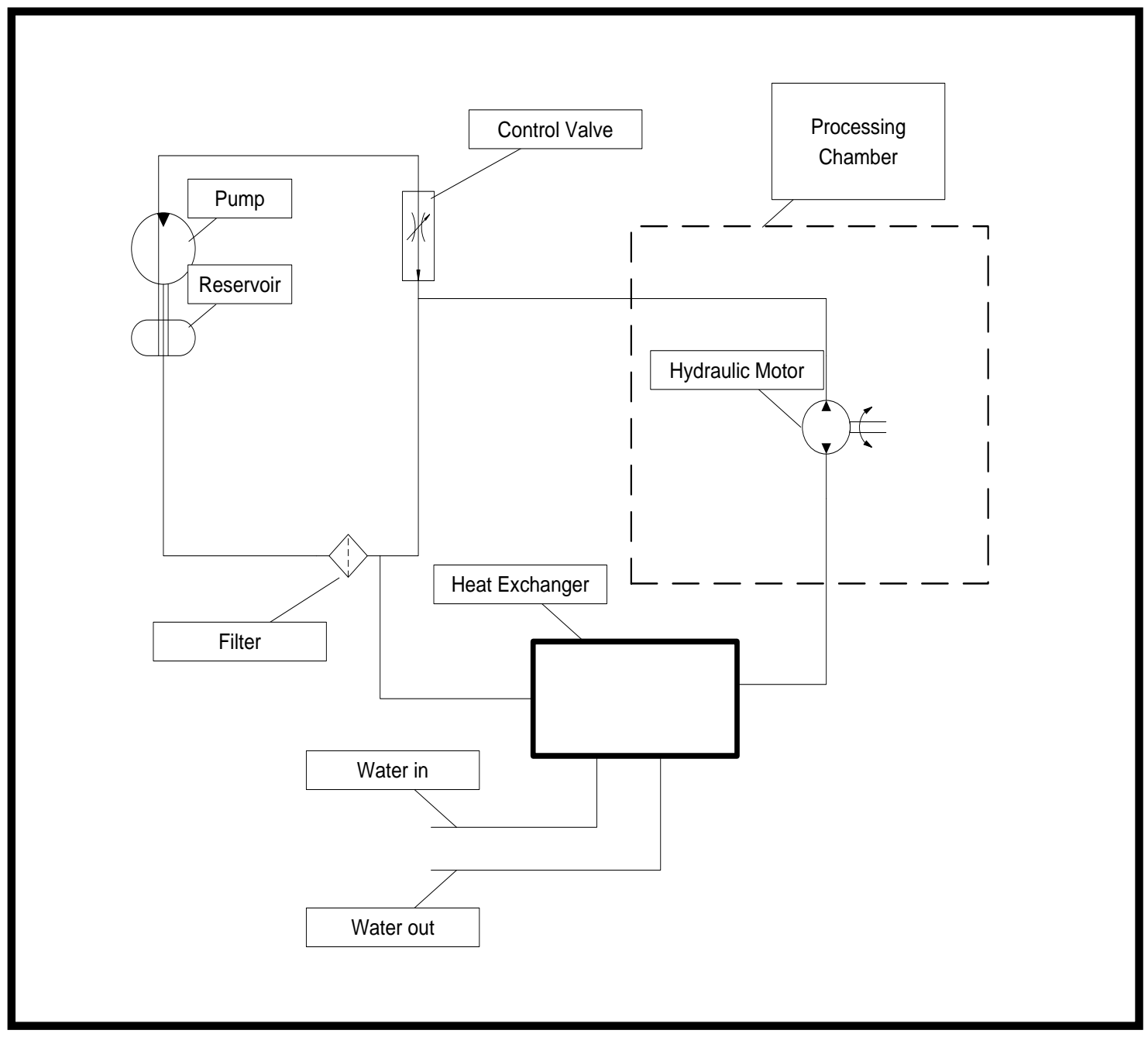




\section{APPENDIX B}

ELECTRICAL SYSTEM SCHEMATIC FOR THE HYDRAULIC POWER SUPPLY

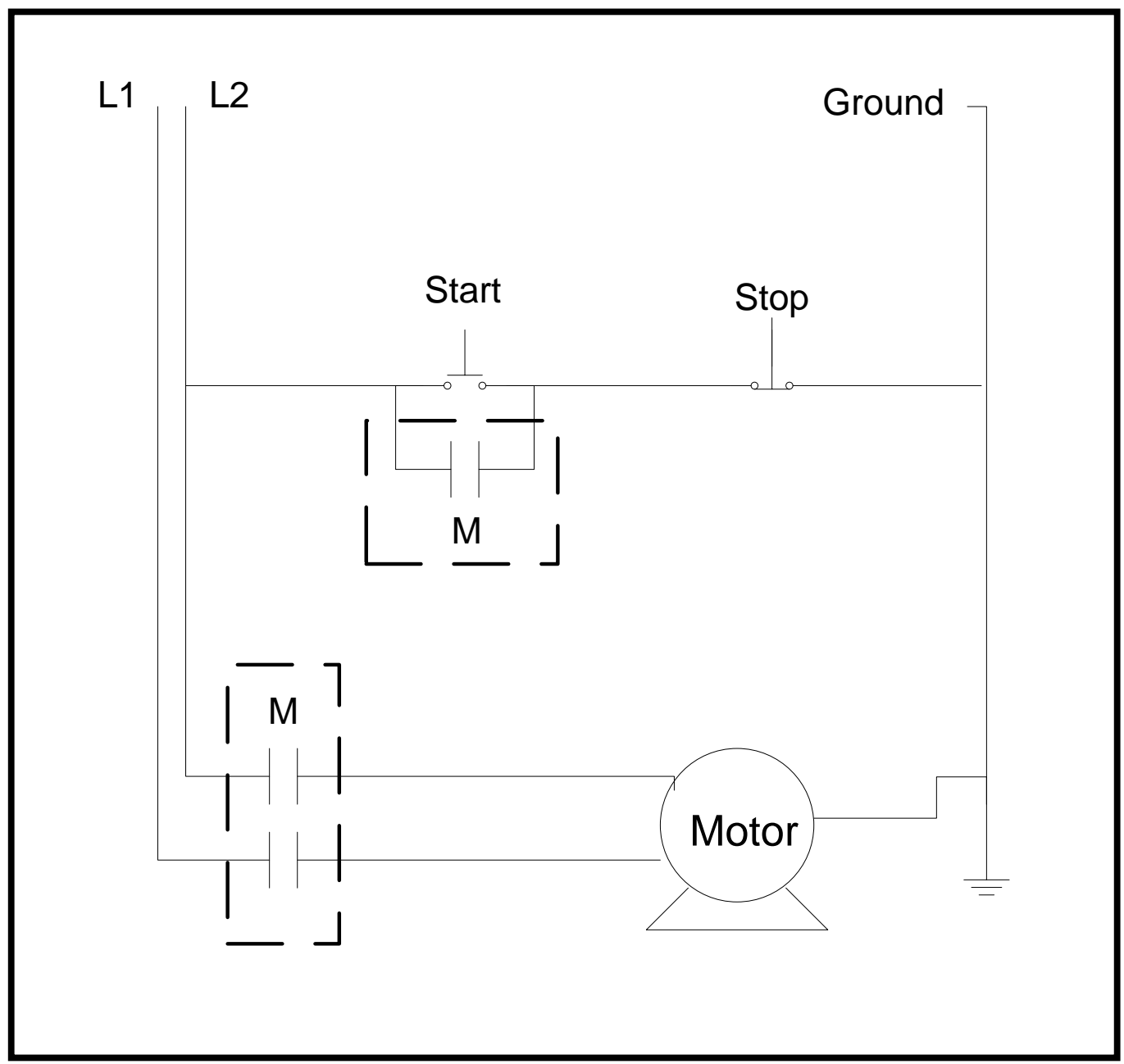


APPENDIX C

ELECTRICAL SYSTEM SCHEMATIC FOR THE VACUUM SYSTEM

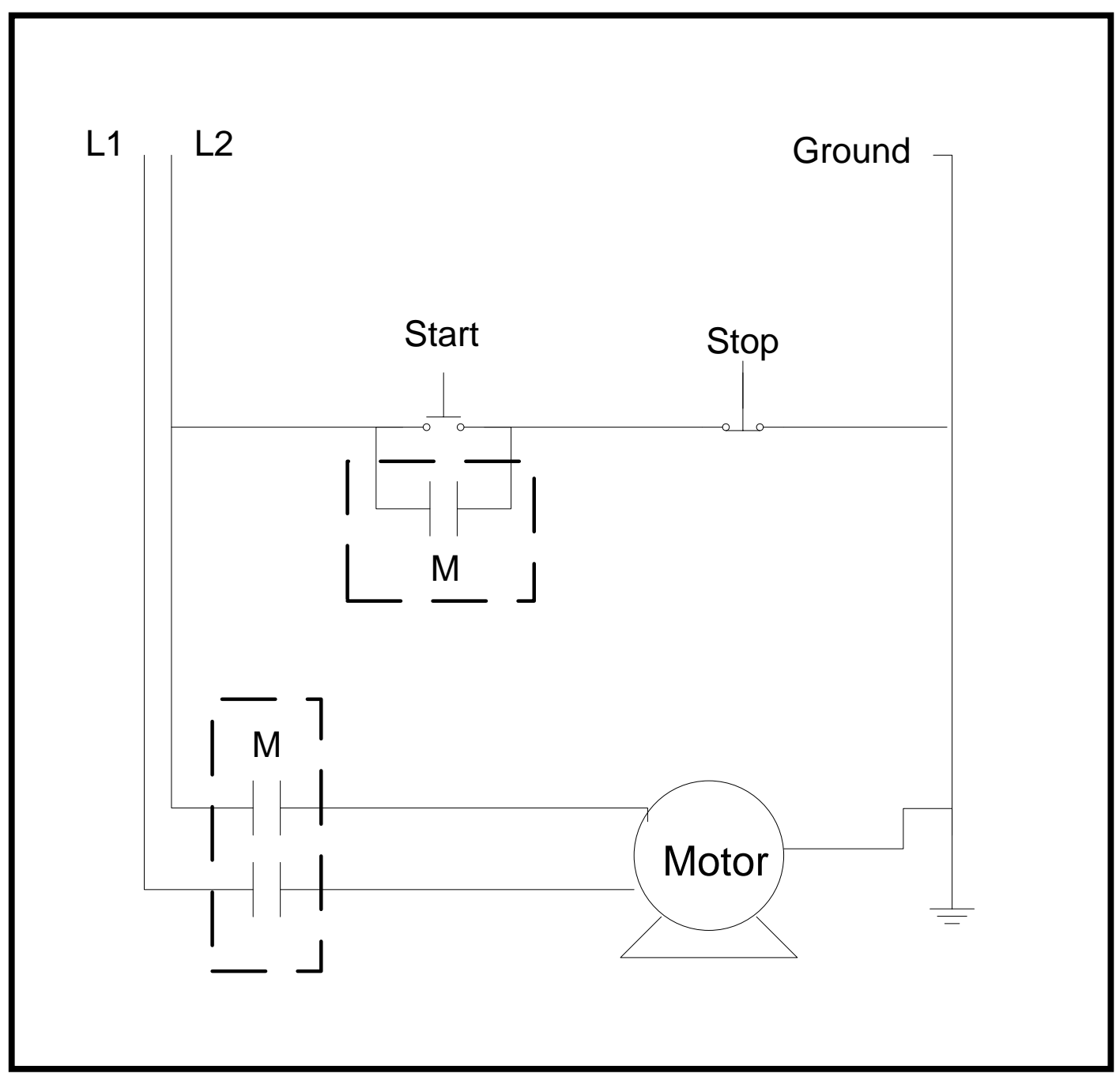




\section{APPENDIX D}

\section{ELECTRICAL SYSTEM SCHEMATIC FOR THE HEATER}

\section{SYSTEM}

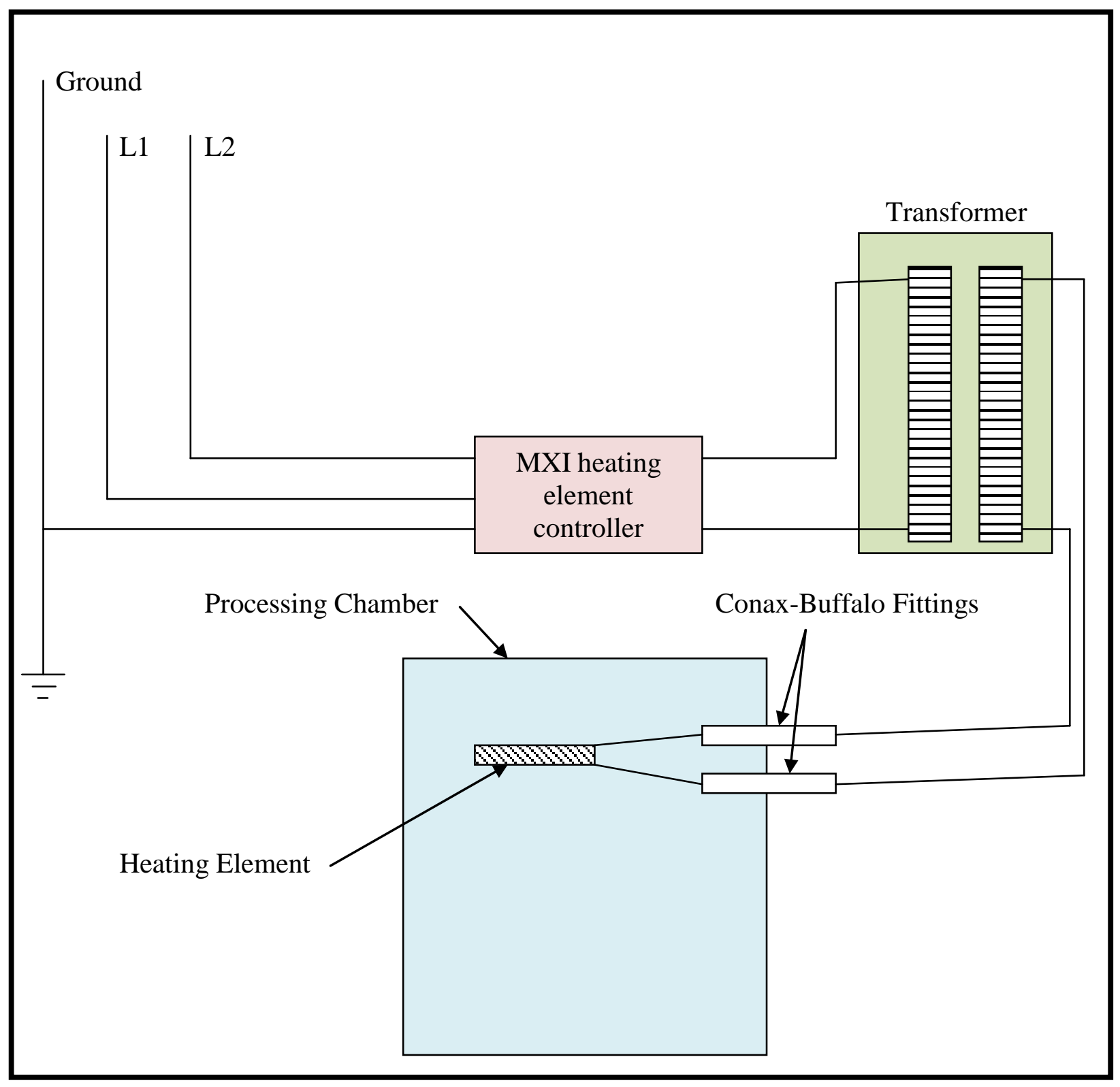




\section{APPENDIX E}

\section{ELECTRICAL SYSTEM SCHEMATIC FOR THE HEATER}

SYSTEM AFTER REBUILD

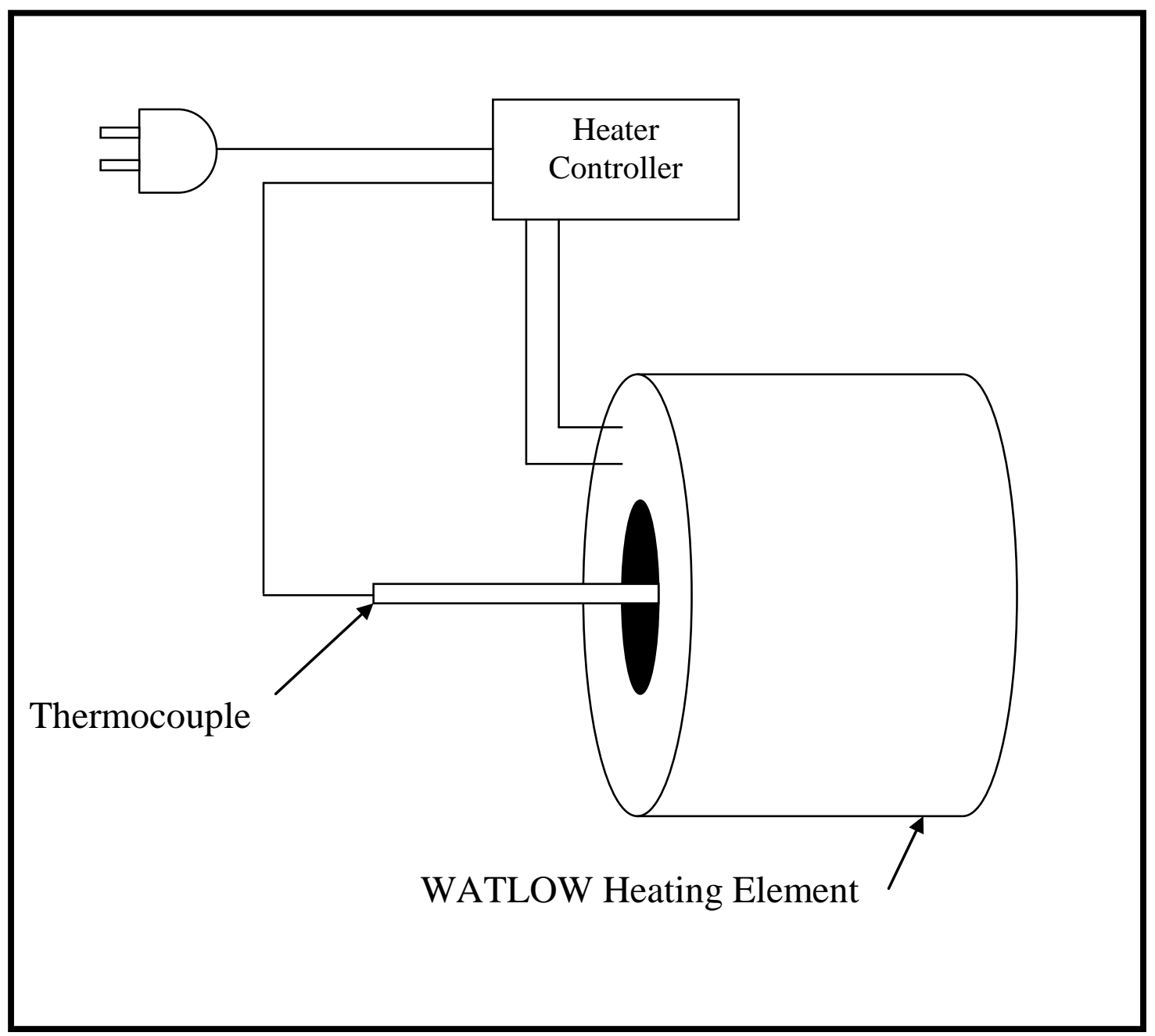




\section{APPENDIX F}

\section{PNEUMATICS SYSTEM SCHEMATIC}

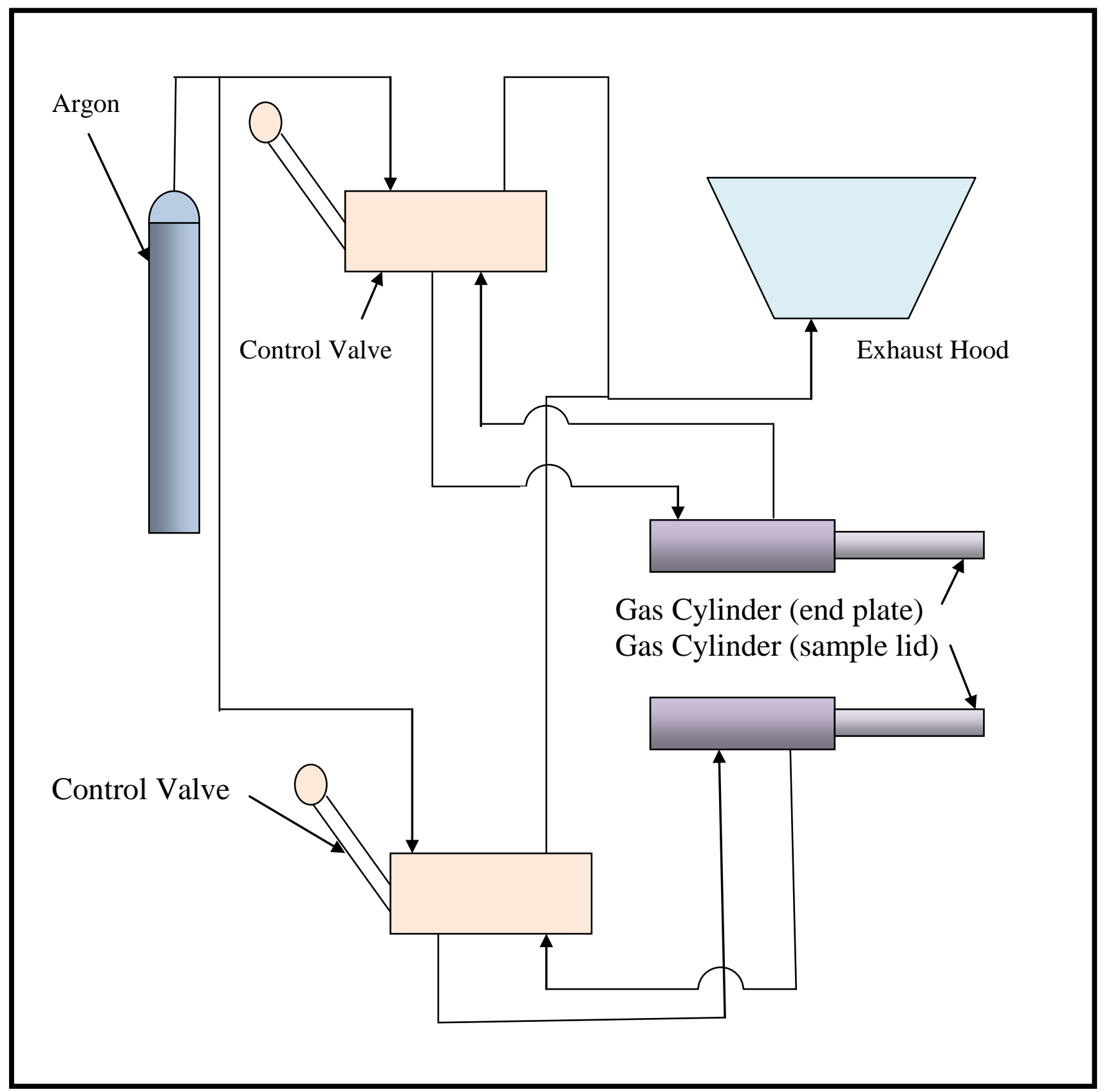




\section{VITA}

Name:

Address:

Email Address

Education
Randy Dean Kelley

Texas A\&M University

Department of Nuclear Engineering

3133 TAMU

College Station, Texas 77843-3133

rdkelley111@gmail.com

B.S. Nuclear Engineering, Texas A\&M University, College Station, Texas

M.S. Mechanical Engineering, Kansas State University, Manhattan, Kansas

M.B.A., West Texas A\&M University, Canyon, Texas

M.E. Mechanical Engineering, Texas A\&M University, College Station, Texas 